\title{
A Better Past Through Technology: World War II Warplanes as Cultural Heritage
}

Kent Allen Wayland

Knoxville, Tennessee

B.A., Vanderbilt University, 1992

M.A., University of Virginia, 2000

A Dissertation Presented to the Graduate

Faculty of the University of Virginia in Candidacy

for the Degree of Doctor of Philosophy

Department of Anthropology

University of Virginia

May, 2006

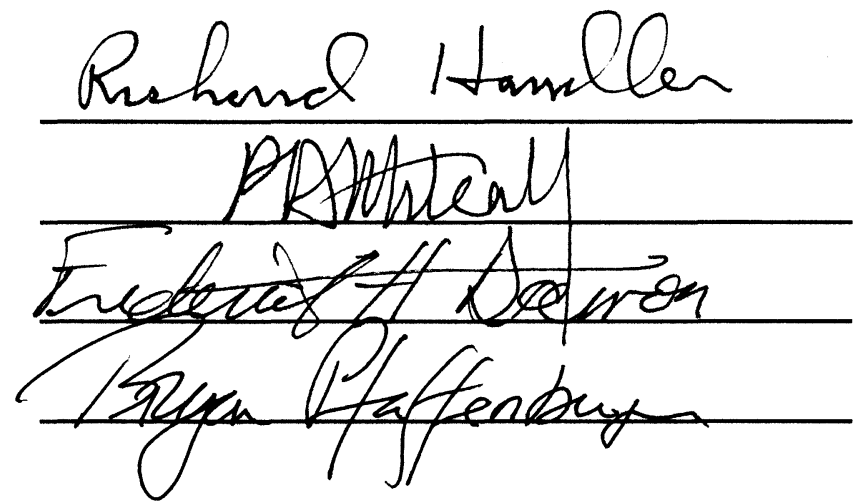


(C) Copyright by

Kent Allen Wayland

All Rights Reserved

May 2006 


\begin{abstract}
The restoration of World War II warplanes offers the chance to explore technology and history as cultural constructs in American culture. Beginning in the 1960's, several different groups began to collect these planes, called "warbirds," and to fly them at airshows and public commemorations as a form of cultural heritage. This investigation merges actor network theory from the field of science \& technology studies with anthropological work on cultural invention to examine how these warbird afficionados use their airplanes to invent a usable past. The past they invoke allows them not only to attract veterans who share their emotional stories of the war, but also to imagine the United States during the "Good War" as an ideal, militarized nation which should serve as a model for the present. This cultural invention occurs both at airshows, where the warbirds perform for the public, and in restoration and maintenance hangars, where both professionals and volunteers engage in craft labor. Both the sublime experience of the planes' operation and the obsolete skills required for their maintenance evoke a better, simpler past for these afficionados. Such interactions with the aircraft foster an Industrial Romanticism which manages to embrace the discourse of technological progress as necessary while at the same time preserving a wistful sense that the passing of these piston-engined aircraft meant the loss of their own ability to understand and work on machines. This labor, then, provides for a performance of masculine competence which now escapes them in their daily life.
\end{abstract}




\section{Table of Contents}

Acknowledgments $\ldots \ldots \ldots \ldots \ldots \ldots \ldots \ldots \ldots \ldots \ldots \ldots$. . . . . . . .

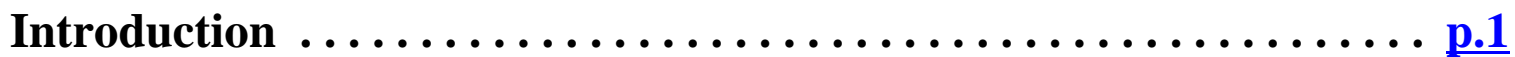

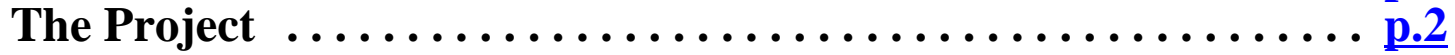

The Anthropology of Technology ..................

Technology in "American Culture" ..................11

Outline of Chapters $\ldots \ldots \ldots \ldots \ldots \ldots \ldots \ldots \ldots \ldots \ldots \ldots \ldots \ldots \ldots \ldots .13$

Chapter One: The Warbird Movement $\ldots \ldots \ldots \ldots \ldots \ldots \ldots \ldots$ p.15

Wartime Production and Postwar Disposition .......... p.15

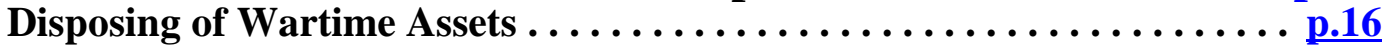

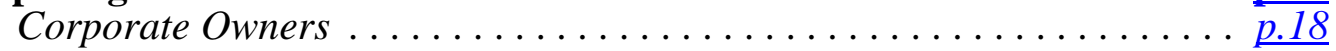

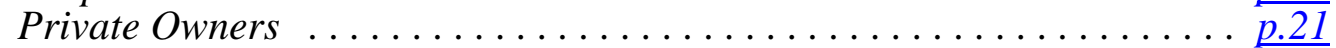

How "Warbirds" Came About .................. p.23

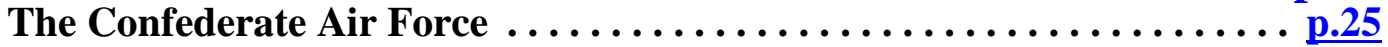

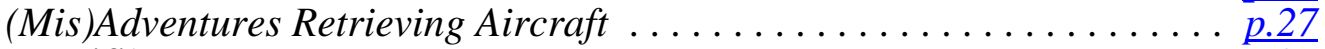

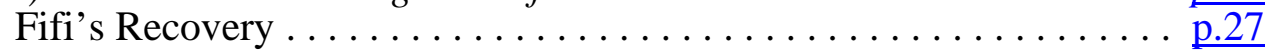

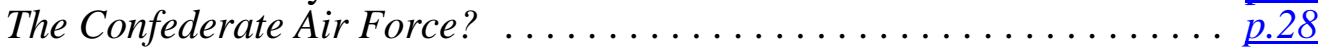

Changing the Name ................... . . . . . . . .

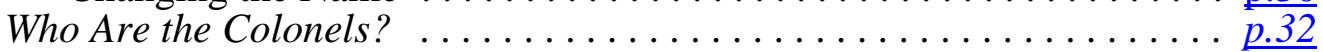

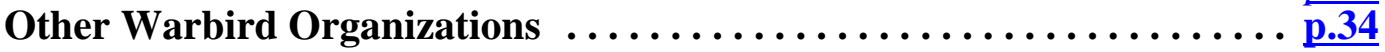

Volunteer-Based Warbird Museums ................ p.36

Private Owners and Wealthy Collectors $\ldots \ldots \ldots \ldots \ldots \ldots \ldots \ldots \ldots . . .38$

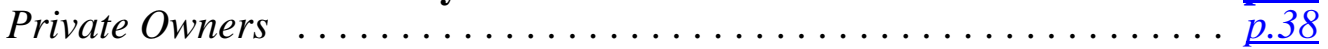

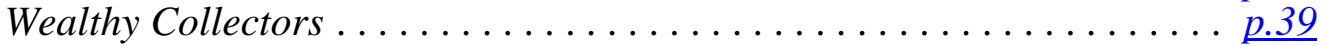

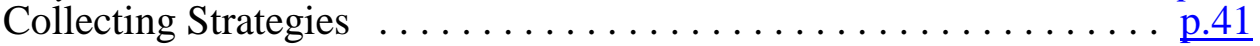

Professional Restoration Shops $\ldots \ldots \ldots \ldots \ldots \ldots \ldots \ldots \ldots \ldots \ldots . . \ldots \ldots$.43

Wreckage and Parts ......................... . . . . .

The Mechanics and Others in the Shop ................ $\ldots \ldots$

The Hangar ..............................

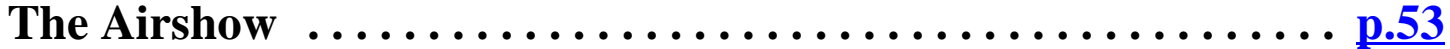

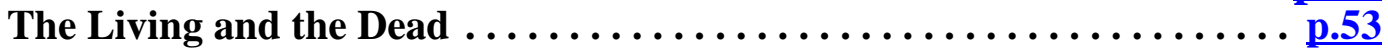

Constituting the Warbird Movement .................

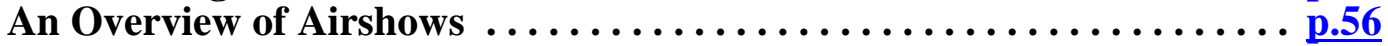

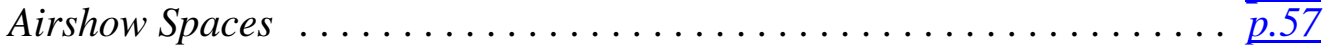

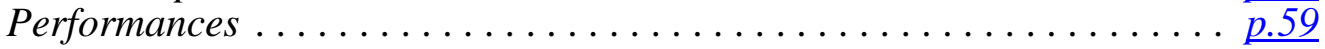

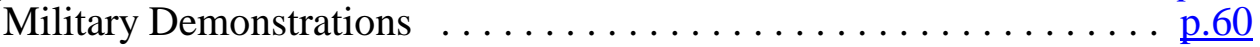

Warbirds and Reenactments ................. . .61

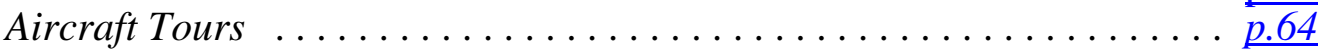

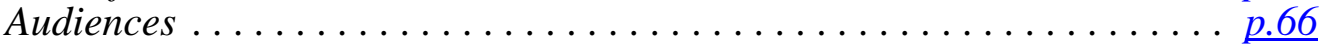

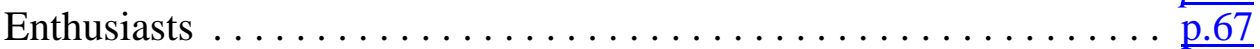

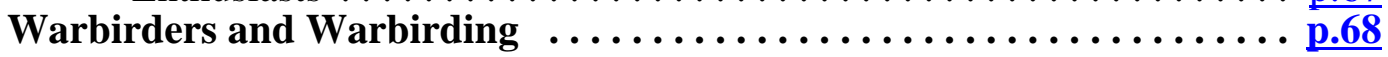


Chapter Two: The Historicity of the Airplanes $\ldots \ldots \ldots \ldots \ldots$ p.70 Inventing the Enduring Object ................. p.72

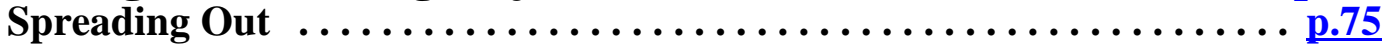

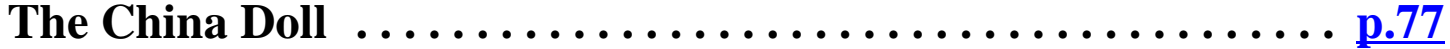

The Meaning of China Doll ....................... p.79

The Hangar: Restoring and maintaining the Aircraft $\ldots \ldots \ldots \ldots \ldots$ p.80

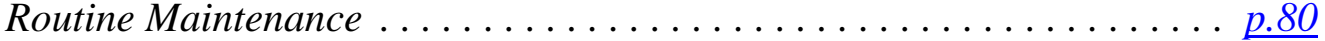

The Case of the Tail-Wheel Lock ............... p.83

Reconstituting Lost Skills . . . . . . . . . . . . . . p.89

Restoration Work ......................... p.91

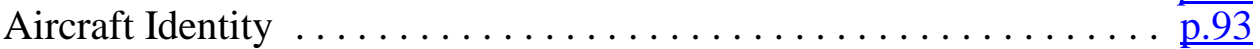

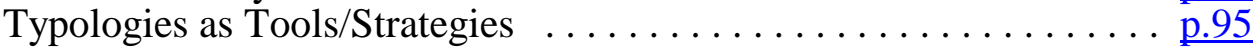

Warbird Ontologies ...................... p.99

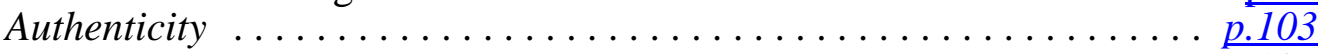

Traces ................

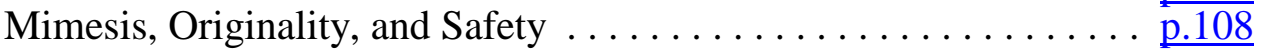

Authenticity as Invention . . . . . . . . . . . . . . p.110

Historicizing the Doll at the Airshow ...................111

An Historic Appearance . . . . . . . . . . . . . . . . . . . . p.112

The Experiential Contrast with Current Aircraft . . . . . . . . . . p.115

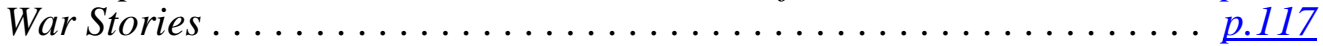

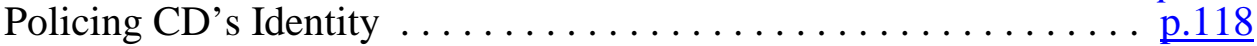

The Ambiguity of Historical Reference . . . . . . . . . . . . p.122

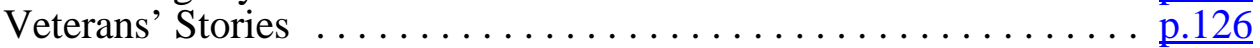

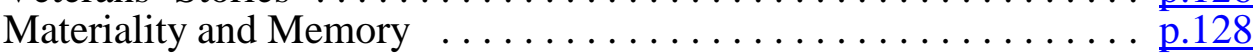

Beyond the CAF .....................130

Authenticity as Competition .....................130

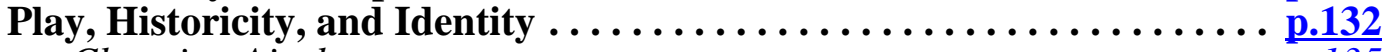

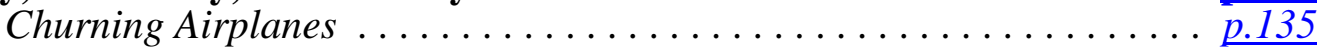

Conclusion $\ldots \ldots \ldots \ldots \ldots \ldots \ldots \ldots \ldots \ldots \ldots \ldots \ldots \ldots \ldots \ldots \ldots \ldots$ 
Chapter Three: History, Nationalism and Militarism ........ p.139

The Ideal Nation ..........................139

The Good War and the Ideal Nation ................... p.140

Shifting the Frame: From Personal to National . . . . . . . . . . p. p.141

The Positive Vision ............................ p.142

The Negative Vision ...........................143

Strength Against External Threats . . . . . . . . . . . . . p. p.144

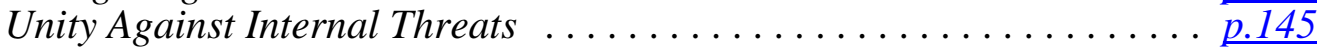

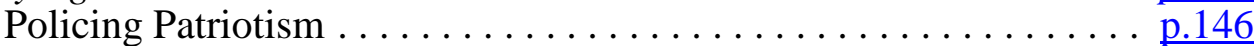

What about "Freedom?" . . . . . . . . . . . . . . . . . . . . p.147

Pearl Harbor as a Necessary Catastrophe ............... p.148

Performing History, Producing a Usable Past .......... p.149

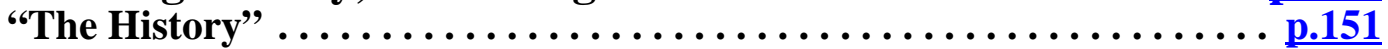

Just the Facts versus Being a Good Patriot . . . . . . . . . . . . . p.153

Performing the Ideal Nation . ....................

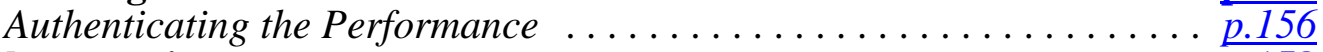

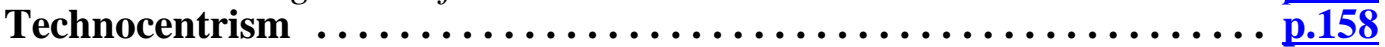

"The History" of Machines . . . . . . . . . . . . . . . . . p.160

Americans and Their Machines . .................. $\ldots \ldots 2$

When Technological Enthusiasm Outstrips "The History"

Machines as America . . . . . . . . . . . . . . . . . . . . . . p.166

The Strength of the Nation . . . . . . . . . . . . . . p.167

Machines as Agents ...................... p.169

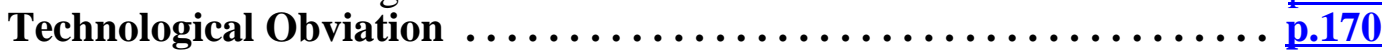

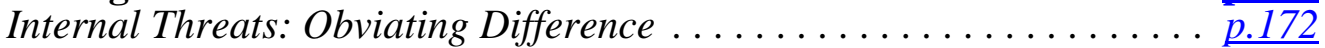

The Obviation of Violence ..................... . p.174

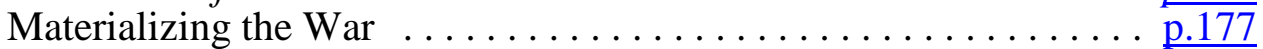

The Technological Sublime . . . . . . . . . . . . . . . . . . . . p.179

The Usable Past $\ldots \ldots \ldots \ldots \ldots \ldots \ldots \ldots \ldots \ldots \ldots \ldots \ldots \ldots . \ldots \ldots$. $18 \ldots$

The Lesson of Pearl Harbor . . . . . . . . . . . . . . . . p.182

Militarization of History/"History" as Militarization . . . . . . . . . p.183

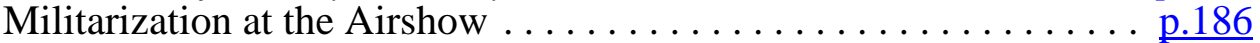

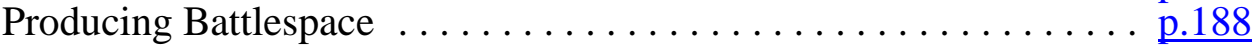

9/11 Was a Failed Pearl Harbor ................ p.189

Conclusion ............................. p.193 
Chapter Four: Industrial Romanticism $\ldots \ldots \ldots \ldots \ldots \ldots \ldots \ldots$ p.194

Progress and Romanticism $\ldots \ldots \ldots \ldots \ldots \ldots \ldots \ldots \ldots \ldots . \ldots \ldots$ p.195

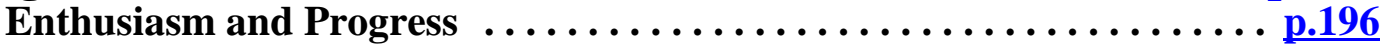

Plenty of Progress ............................... p.197

Displaying Progress: The Heritage Flight . . . . . . . . . . . . p. p.198

Rejecting Critiques of Technology $\ldots \ldots \ldots \ldots \ldots \ldots \ldots \ldots \ldots \ldots \ldots .201$

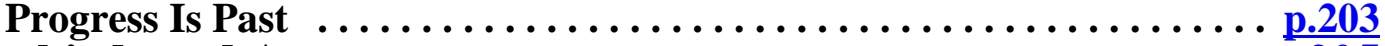

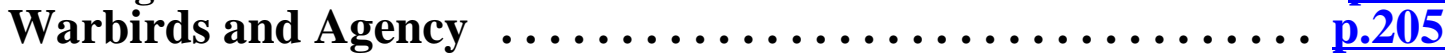

Warbirds Require Hard, Skilled Work ................... p.205

Before the Remove-and-Replace World ....................206

Computers, Real Engineers and the Love of Machines ........... p.208

Simplicity .................................

Warbirds Involve Unalienated Labor .................. p.210

Wartime Labor of Love ........................... p.211

Today's Labor of Love: Craft (Re)Production ................. p.213

Having a Relationship: Mutuality $\ldots \ldots \ldots \ldots \ldots \ldots \ldots \ldots \ldots \ldots . .2 .217$

Personality .....................................219

The IR Aesthetic $\ldots \ldots \ldots \ldots \ldots \ldots \ldots \ldots \ldots \ldots \ldots \ldots \ldots .220$

The Sensuality of Warbirds $\ldots \ldots \ldots \ldots \ldots \ldots \ldots \ldots \ldots \ldots \ldots \ldots .222$

Visuality ...................................222

Sound, Tactility \& Smell .............................

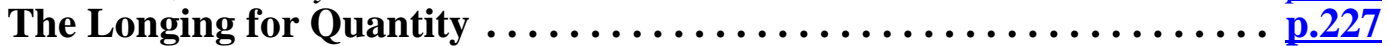

Technological Sublime as Aesthetic $\ldots \ldots \ldots \ldots \ldots \ldots \ldots \ldots \ldots \ldots$ p.228

The Ghost Squadron $\ldots \ldots \ldots \ldots \ldots \ldots \ldots \ldots \ldots \ldots \ldots$ p.230 
Chapter Five: Inventing Warbirder Masculinity ......... p.233

Gender, Technology and the Military $\ldots \ldots \ldots \ldots \ldots \ldots \ldots$ p.233

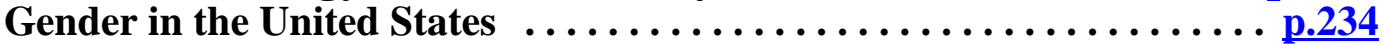

Masculinity and Technology .......................235

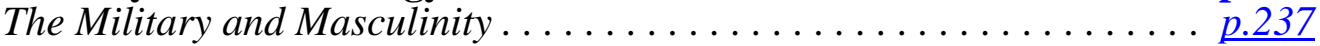

Locating Myself in Gender Categories $\ldots \ldots \ldots \ldots \ldots \ldots \ldots \ldots \ldots .238$

Gender and Technology in Warbirding $\ldots \ldots \ldots \ldots \ldots \ldots \ldots .2 .239$

A Masculine Domain ........................... . 240

Warbirds as an Agency of Masculinity $\ldots \ldots \ldots \ldots \ldots \ldots \ldots \ldots .242$

Machine Competence ........................ p.243

The MIG Arrives . . . . . . . . . . . . . . . . . . . p. p.245

Remove-and-Replace versus The Satisfaction of Improvisation . . . p. p.247

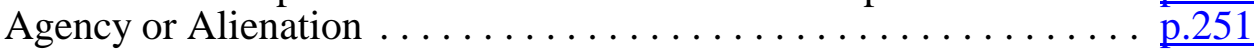

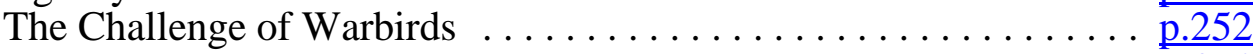

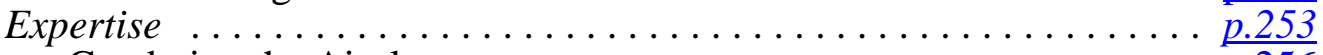

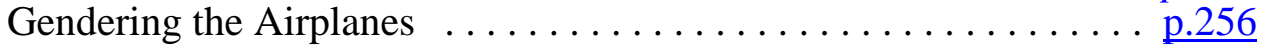

The Good Warbirder: Further Masculine Qualities . . . . . . . . . . . . p.259

Autonomy and Self-Confidence . . . . . . . . . . . . . p.259

Counter-Discourses: Safety and Ego . . . . . . . . . . . . . . p.260

Power and the Technological Sublime ............... p.263

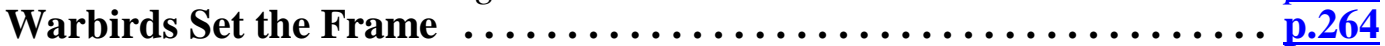

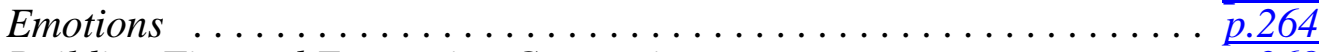

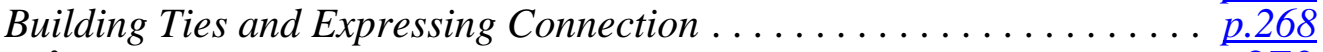

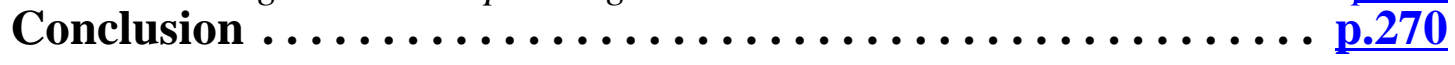

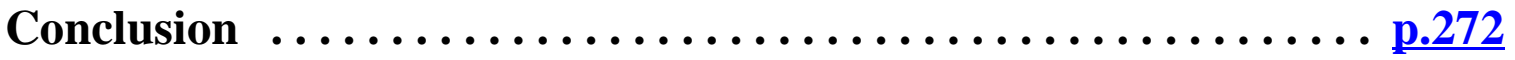

Works Cited $\ldots \ldots \ldots \ldots \ldots \ldots \ldots \ldots \ldots \ldots \ldots \ldots \ldots \ldots \ldots \ldots \ldots \ldots \ldots$ 


\section{Acknowledgments}

Throughout my academic career I have depended upon the support of informants, colleagues, friends and family. I first owe thanks to the men and women I met while conducting my research. The members of the Commemorative Air Force were engaging, friendly and patient with me as I asked odd questions and applied limited mechanical aptitude to working on airplanes. The owners of the restoration shop where I spent several

months were equally supportive, if bemused by my interest, and the mechanics at the shop kindly tolerated my awkward presence in their workspace. They contributed to this work significantly, not only by allowing me to observe their daily work, but also by reflecting on those activities.

I found that the warbird world was a friendly one. I made friends everywhere I went and genuinely enjoyed the company of most people I met in the warbird world, a fact which makes the strong critique I adopt in this dissertation all the more difficult for me personally. The politics of the warbird movement, especially its role in fostering and celebrating militarism, require a strong critique, I believe. As a "native" to whom the pleasure of daily interaction with the aircraft was accessible, I feel a special responsibility to offer such a critique. Speaking out is, for me, a matter of personal and intellectual honesty. I hope, however, that my friends in the warbird world find that my account also demonstrates the genuine enjoyment and humanistic connection that the airplane work gives them. The connection between generations that warbird activities foster has to be seen as positive, as does the role that warbird work gives to retirees seeking to find a sense of purpose in their daily lives. While I criticize the political effects of their work, then, I greatly sympathize with its personal meaningfulness, and I appreciate the great pleasure they gain from working on and flying these airplanes.

No substantial work can happen without loved ones and mentors, and I have been a great beneficiary of both. I thank Claudia Chang at Sweet Briar College for demonstrating 
the daily pleasure of teaching and talking anthropology. The late Christopher Crocker pushed me to dig deeper than the "myth of the war experience" to understand better the experience of those who went through World War II. Fred Damon showed me the delight that comes from reflecting on the broad cultural and social movements that anthropology can chart, and Peter Metcalf offered guidance at important transition points and encouraged me to get beyond the obvious critiques that could be made of the warbird world. Bryan Pfaffenberger enthusiastically introduced me to the field of Science \& Technology Studies, all the while proselytizing for anthropology's role in that field and encouraging me to take a place within it as well. Finally, Richard Handler has served as the best sounding board, critic, supporter, and intellectual interlocutor possible. He helped me through all of those moments when I lost my way amidst all of the rich material, and his encouragement kept me writing.

Before I ever contemplated graduate school, my family inculcated me with a desire to explore and learn about the world. This encouragement led in no small way to my choice of anthropology as a field of study. While my research came to focus on the United States, I embraced the worldwide, cross-cultural perspective of anthropology. My interest in aircraft came from my brother, Hank, whose enthusiasm for planes I shared as we grew up. I also thank my sister Becky for advice and support during low times in the writing process, and my parents and sister Judi for unwavering support and belief in me. The Johnson family has also encouraged my academic progress and celebrated each step with me.

Finally, I would like to thank Stephanie and little Alex for their support through these years of research and writing. Alex tolerated his Dad's disappearing to write and always offered an uplifting distraction — a game, a laugh, a tickle — when my thinking got muddled. Steph tolerated the anxiety of waiting for grants, a long separation for fieldwork, and the many ups and downs of writing. She unfailingly supported me through those tough 
times while always offering useful suggestions about actually getting things done, and she sacrificed a great deal to give me time to finish. 



\section{Introduction}

One September morning in 1997 I sat on the tarmac at Oceana Naval Air Station, watching fighter planes fly by and pondering the contradiction between people's love of these machines and the machines' lethal uses, past and present. Then I heard air raid sirens go off. Old-looking airplanes with Japanese markings flew by, and fiery explosions started going off on the far side of the runway. Soon old American airplanes joined the circling Japanese planes, flying after them. An old bomber airplane flew in slowly, as if to land, with only one of its two front landing gear down. The voice of Franklin Delano Roosevelt came over the PA system, after which an urgent narration of the spectacle resumed. Eventually the American airplane "shot down" a Japanese plane, signaled by its trailing smoke. As the performance ended, the narrator urged the audience never to forget the terrible events of that day in December of 1941 and to remember the lesson that the nation must be prepared to defend itself.

This episode introduced me to the "warbird" movement which became the focus on my research. This movement consists of a collection of groups and individuals who collect and restore World War II aircraft and fly them in public performances. The performance described above was presented by the Confederate Air Force, the oldest and largest warbird organization, but many other museums and individual owners fly warbirds. As my description suggests, they are deeply concerned with the memory of World War II and its connection to the nation of today. They perform this concern, however, predominantly through practices with and discourses of the machines themselves. In this dissertation, therefore, I examine the cultural construction of history and technology in American culture by studying both he discourses and practices of the warbird movement. 


\section{The Project}

My initial interest in the reenactment—a Confederate Air Force? Reenacting Pearl Harbor? Simulated bombing?-soon developed into questions about the relationship between technology and history in American culture. What appealed to me about this warbird culture was the ambiguous position of the machines in the center of the activity. Despite the spectacle of explosions, the planes at my first airshow were clearly old, simple, and slow, nothing like the loud and fast jets in the rest of the show. Despite their obsolescence, they were revered. Despite the plane's simplicity, the pilots were clearly welltrained and skilled, as demonstrated by the simulated one-wheel landing. Despite their pokiness, the explosions, smoke, and general din did create a spectacle. The aircraft performed the same kind of glamorization of violence that the contemporary aircraft did, but they added a deep nostalgia to the practice as well. I set out to explore these seeming contradictions ethnographically, beginning full-time fieldwork in 2001 . $^{1}$

I formulated this project as a "follow the object" (Marcus 1995) approach to a multisited research. Warbirds exist across a range of domains and in various forms. Different kinds of owners/restorers/curators govern their movements through different kinds of spaces. Yet the concept of a "warbird" follows these airplanes around in space and through time. In adopting this strategy, however, I did not adopt a solely materialist outlook. I did attend to the material dimensions of the various technological activities of warbird restoration, maintenance, and operation, but I did not privilege the material over the semiotic. Rather, I saw the two as interdependent, without assuming that anything material has inherent meaning or function. Semiotic analysis, for example, can play only a partial role in intervening to fix a complex engine, while a materialist approach would be impoverished in examining why a malfunctioning engine becomes a "bitchy woman" in warbird discourse.

\footnotetext{
${ }^{1}$ My first day "on the job" was September 11, 2001, and I discuss the reaction to events of that day and their influence on the warbird movement in Chapter three.
} 
Research began at airshows, as noted above, where current military aircraft flew along with World War II airplanes. I then attended meetings of a Confederate Air Force (CAF) unit, followed by visits to a number of CAF units around the country. I ultimately settled on one of the largest units, the Southern California Wing (SoCal Wing), where I spent nine months working on aircraft and attending airshows. After some time with that Wing, I started visiting nearby warbird museums and a few restoration shops. I then spent several months alternating between the SoCal Wing and a warbird restoration shop before finishing my fieldwork at the largest airshow of all, the EAA's Airventure in Oshkosh, Wisconsin.

While it may be easy to focus on the machine itself, technologies do not, and cannot, exist on their own. Scholarship in Science \& Technology Studies have shown that technological artifacts are always embedded in extended sociotechnical systems (Hughes 1983) or networks (Law 1987, Latour 1987). From this point of view, the aircraft built during World War II could not stand on their own, despite their fantastic numbers. Each aircraft required not only a trained pilot, but several skilled mechanics, fuel and various vital liquids, adequate spare parts, maintenance and operation infrastructure (air fields, revetments, etc.), maintenance depots, maintenance and repair manuals, and bombs and ammunition, to name just a few elements. Beyond these immediate operational requirements, we must also attend to the cultural conventions and social structures which made these aircraft possible. These include everything from the conventions of war to concepts of technological progress to aircraft manufacturers to the Department of War to the capitalist mode of production. Indeed, we can use these aircraft as an entry into the entire culture. Just like the anthropology of religion can use a ritual to unpack a cultural system, so the anthropology of technology builds out from technological artifacts and systems.

\section{The Anthropology of Technology}

This project fits into the re-emerging field of the anthropology of technology. This ethnographic investigation allowed me to go beyond a simple "reading" of the objects and 
their performances, which might tend to dwell on the militaristic narratives involved. Investigating the day-to-day ramifications of their "choice" (Cf. Lemonnier 1993) to fly their airplanes provided for richer, deeper analysis than the easy (but still important) critique of militarism, which could have been developed after only a few days of research.

The anthropological study of technology has drastically increased in recent years due to the growth of the field of Science and Technology Studies (STS) and to increasing scholarly and popular interest in "high technology" in the form of computers and the Internet. With all of the talk of the "effects" of technology and the "information age," technology has been difficult for anthropologists to ignore. Studying "High Tech" has become a means to revive the Anthropology of technology from its moribund status in Anglo-American anthropology — a status it gained through its association with $19^{\text {th }}$ Century cultural evolutionism. (It had never really disappeared from French Anthropology, the only other tradition with which I am familiar.) Most STS work on technology has been performed by sociologists whose interest lay predominantly in mapping the mutual influences between "social groups" and "technological systems." The anthropology of technology builds on this work, but it takes an ethnographic approach to both technology and culture as emergent phenomena. This project adopts this perspective, but unlike much of the work devoted to unpacking the new, "high tech" society, it focuses on old, "outdated" machines.

"Technology" is a powerful symbol in Euro-American cultures. As Pfaffenberger described it, the Euro-American "Standard View of Technology" sees technology as evolving based on its own, purely utilitarian logic. This evolution, furthermore, is unilinear and progressive (Pfaffenberger 1992). As it "progresses," technology acts as an external force on society, impinging upon it in both positive and negative ways. The positive view of technological progress often develops into what I will call technological enthusiasm, an abiding excitement about the workings and the perceived benefits of technology. The negative view focuses more on the "impact" of technology on society, usually perceived as 
dehumanizing. Both views, however, share a technocentrism: a materialist focus on the machines/objects identified as technological in contrast to the many other cultural forces which construct and guide technological practice. The Standard View forms a master narrative about technology which informs most interactions with machines for American society. The anthropology of technology, when focused "at home," seeks to unpack this master narrative, both to provide insight into Euro-American culture and to intervene in the hegemonic operation of this master narrative.

The anthropology of technology has sought to break the utilitarian logic of unilinear progress in a variety of ways. One tack examines how technological change was underdetermined by the material requirements of an operation or activity, allowing for divergent "lines" of technological change (as in Lemonnier's $(1992,1989)$ work on airplane design). Another approach unpacks the use of "more efficient" machines to deskill workers (as with Noble's (1984) work challenging the improved efficiency of machine tools). A third method demonstrates that the material efficacy of a technology was secondary to its cultural meaning (as with feminist studies of how technological shifts were interpreted to retain their association with masculinity (Cockburn 1981)). While work unpacking the technocentrism of Euro-American cultures goes back at least to Marx's discussion of "commodity fetishism," much of STS work on technology in Euro-America revolves around the unpacking of "utility." The Euro-American concept of technology assumes that technologies are best understood as utilitarian objects.

One approach to unpacking this cultural obsession with utility has been to assert the primacy of a semiotic explanation for technology. From this perspective, "utility" is a potent symbol, a means to read and understand the material object. This view sees all elements of materiality simply as fodder for symbolization. While material processes might place limits of a kind on practice, it holds, those limits are secondary to the symbolic emphases which give rise to the processes: 
For the material conditions, if always indispensable, are potentially "objective" and "necessary" in many different ways - according to the cultural selection by which they become effective "forces" (Sahlins 1976:

Applying this language to a warbird example, the "necessity" of having wings to fly can be applied in a variety of different ways, a point Lemonnier makes in his discussion of aircraft design (Lemonnier 1989). This symbolic reading of technological practice fits well with a variety of anthropological perspectives, including Wagner's (1981(1975)) discussion of the invention of culture, a perspective from which I borrow heavily in this project. Wagner holds that all meaningful action is, in effect, a new creation. Any "context" (a term read as broadly as possible) must be novel, he says, but to make sense of it we have to borrow from "conventional contexts" that we imagine to be somehow parallel. The process "invents" meaning for both the novel and conventional contexts, as the meaning of the latter is shifted by its association with the former. This meaning-making process accounts for the process of culture, the continuous flow of phenomenal experience and the shared meanings constituted thereby. For instance, Wagner describes both technology and advertising in one segment, claiming that what advertising does is invent for its viewers a life that must include the technologies advertised (Wagner 1981(1975): 60-66). People then seek out those products to flesh out the context for their lives that advertising induced them to imagine.

Despite this insistence on the primacy of meaning, the semiotic qualities of objects are insufficient to explore cultural-technological formations fully. Returning to the example of aircraft wings, even though their meaning can vary infinitely and their form can vary widely, some aspect of an aircraft has to produce what we call "lift." Even accounting for limits in our knowledge about what those qualities might be, not just anything can fly. My past response to an example like this would have echoed Sahlins's point, above, arguing that the finitude of possibilities is unimportant because the range of choices is sufficient to allow 
us to ignore any material restrictions on meaning. While that view certainly holds from an interpretive point of view, I now think it underplays the implications of materiality.

While the meaning of objects flows freely within cultural constraints, objects are limited in the kinds of phenomenal experience they can provide. For example, flying, a distinctive feature of warbirds, provides a different phenomenological experience than can be provided by an airplane sitting in a museum, perched on a pole at a military base or resting in a crash site, the other common fates of old airplanes. That experience is not extra-cultural, but it is a different kind of experience that members of the warbird movement find significant.

Furthermore, taking a broad view of warbirds as complex technological systems, flight has to be understood as the result of a range of interweaving materialities and meanings. The Euro-American understanding of "flight" requires that one has to find a means to create lift, to make it move, and to control its movement. One choice (Cf.Lemonnier 1993) (among many possible choices) warbird owners have made to get their airplanes to move, leaded gasoline, has created other material requirements, such as a means to obtain the lead, a current near-crisis in warbird circles. Further, the implication of using leaded gasoline extends the meaning of the warbird's flight into other domains. Leaded fuel has at least two salient material properties: it allows the engines to run at higher compression without detonating ${ }^{2}$ and it introduces lead into the atmosphere, which poisons humans. The result of these two properties has been increasing controversy over the production and use of leaded fuel. The members of the warbird movement fear that the fuel will soon be banned, with the effect that they would not be able to get enough power out of their engines (higher compression means more power). Thus, the desire for that power has focused their attention on the site where tetra-ethyl lead is produced and the sole tanker ship authorized to carry it.

\footnotetext{
${ }^{2 "}$ Detonation" is the premature explosion/burning of the fuel in the cylinder. "Pinging" in car engines is a mild form of this, but severe detonation in an aircraft engine can destroy the engine in a short amount of time. Adding lead causes the fuel to burn more reliably.
} 
The lead's unfortunate side-effect of poisoning humans has led to a political controversy in which, warbird afficionados fear, environmentalists will seek to ban leaded fuel altogether. The warbird movement therefore is fighting to prevent this potential regulation. From the simple choice of fuel, then, we have shifted into the politics of state regulation and environmentalism. We therefore see how material effects serve to extend technological practices and meanings into new cultural domains.

To account for these different dimensions of technological objects, then, I turn to work in STS which has rejected both the materialist utilitarianism of the "Standard View" and the sole reliance on semiotic analysis of technology. These STS theorists see the meaning of action-on-matter as constituted along with the performance of that action and the choice of material/object/tool (Lemonnier 1993, Munn 1974, Pfaffenberger 1999, Pfaffenberger 2001). I share this view, that the relationship between materiality and meaning is mutually constituted. This view follows Latour's Actor Network theory and feminist scholarship on technoscience (Latour 1987, Latour 1999, Wajcman 1991, Cockburn 1981). I do not, however, see this reclamation of materiality as constituting a separate field of "Material Culture" because the emphasis lies in how materiality and meaning are mutually constituted within, not apart from, the cultural formation of the warbird movement (Cf. Handler 2002).

To make sense of this relation between materiality and meaning, this ethnographic project draws on theory from both anthropology and STS. Wagner's theorization of the invention of convention (Wagner 1981(1975)) includes a phenomenological, material component, but only as a source of phenomena on which cultural actors operate. Latour, on the other hand, argues that technological (and scientific) systems always involve the materiality of instruments, machines, weather, and so on (Latour 1987, Latour 1999). He includes them with humans as fellow "actants" who have to be "enrolled" in a technological system in order for it to hold together. For example, one could not have genetic testing 
without the stuff isolated in labs that we call "DNA." The role of material objects or organisms is never determining, however. Nothing about "DNA" requires that humans acknowledge its existence, much less implicate it when determining innocence or guilt in a judicial proceeding or in deciding whether to keep or abort a fetus after a genetic test. The stuff-we-call-DNA has become a crucial, but not determinative, actant in these complex cultural systems.

I follow Latour in not wanting to assume the opposition of subject and object (Latour 1993, Latour 1999). I find this articulation of a "nonmodern settlement" to be particularly helpful in that it "bypasses" the problem of distinguishing between the material qualities of objects and the meanings ascribed to those objects by human subjects. He replaces subjects and objects with human and nonhuman actants, entities which participate in stabilizing a technoscientific system. He argues that neither meaning nor materiality are prior to the formation of these systems, but rather are constituted thereby. In taking this approach, he reflects Wagner's conception of the invention of convention in that meaning is always produced anew out of current phenomena. Latour sees the privileging of either materiality or human intention, social or individual as misunderstanding the nature of technoscience. He focuses on science in action, in which the meaning of data, objects, and group interests are all in flux. Only when a sufficient network of individual actants are enrolled in the system does it begin to stabilize and cohere. As part of his approach, he examines the processes by which these actants "move" through society, "extending themselves" and thereby acquiring stability and facticity. Further, this mutual constitution is not a singular event, but rather an ongoing process. The practice and its meaning are continually reconstructed/ reinvented. This constant invention, however, must account for the carry-over of previous meanings and practices, something not clearly addressed by Latour.

What Latour neglects, as Martin (1998) points out, is exactly the set of conventional contexts that Wagner describes. While Latour argues that technologies are continually 
recreated, Wagner offers a means to conceptualize the relationship between that ongoing creation and existing conventions. At the same time, Wagner's use of phenomena is usefully supplemented by Latour's attention to the workings of material objects. Latour grants objects, materialities, or instruments some agency by making them "actants" within a cultural-technological system, the same status granted to humans. Both can "act" decisively on the system. Altering Wagner's description of "contexts" helps put these different bodies of theory together. Wagner defines contexts as broadly as possible. For my purposes, a context can include everything from a discourse, like technological progress, as a means for making sense of machines, to a specific material environment, like a cockpit, in which individuals can "dwell," developing and deploying tacit knowledge about that environment (Ingold 2000).

We can account for these theorists' different treatments of conventional contexts partly by noting that Wagner seeks to investigate the creativity of culture broadly, while Latour's approach amounts to a Euro-American-specific examination of it. We EuroAmericans create by and for our technological apparati, employing their material processes within our meaning-making in ways that tend to mask the semiotic basis of that meaning. We demonstrate and limit our cultural creativity by investing it in machines. By doing so, we chain our meaning-making to the material workings of those machines, with the result that an airplane that does not fly can disrupt an entire cultural project. Returning to Wagner's comments about advertising, warbird afficionados seek to invent a world in which people incorporate the continued flying of old airplanes into their lives, thereby overcoming technological "progress" and planned obsolescence. The warbird movement therefore must create a world in which these airplanes' flight is crucial.

Drawing on both Wagner and Martin (Martin 1998), we have to emphasize the power of those conventional contexts as the bases for making sense of the ongoing invention of warbirds. Latour at times seems to neglect the web of meanings within which Euro- 
American technoscience takes place. Martin, for example, criticizes Latour for implicitly adopting the cultural model of the agonistic, possessive individual in characterizing scientists (Martin 1998: 27). We can see as "conventional contexts" such important discourses as technological progress, nationalism, militarism, and gender.

\section{Technology in "American Culture"}

Working with grand narratives of what "technology" means in "American culture," however, presents the problem of assuming a holistic, bounded culture. Indeed, we can immediately see the problems of treating warbird afficionados' views of their machines as the "American" stance: it not only would ignore a diversity of views about technology, aviation, the military, gender, and the constellation of related meanings, but it would also reproduce/reinvent the hegemonic status of those views, participating in the marginalization of other views. I do not want to risk naturalizing the unmarked categories of white, middle class, and male as the true essence of American culture, especially since those unmarked categories are especially powerful in the warbird movement. For example, the prominence of the "Confederate Air Force" until only recently cannot be left unexamined with regard to race, and neither can the extensive gendering of the aircraft, among other things. To gain some distance on these hegemonic categories, we have to treat technoscience as what Martin called a "citadel" (Martin 1998). In this case, we have to imagine military technological practices as citadel-like centers of power. In appropriating these technologies and articulating new practices with them, members of the warbird movement reinvent them as citadels, albeit ones continually under reconstruction.

Citadel, however, is a misleading, monolithic term. Latour, for example, insisted that technoscientists operated both inside and outside of science, forming alliances and recruiting allies which could not be predicted at the outset (Latour 1987). If Latour's model sounds like a strange kind of cultural mathematics ("We just need to enroll one more small-sized social group and we'll be a fact!"), the strangeness reflects the problem of articulating cultural 
boundaries which has so plagued anthropology in recent decades (Cf. Brightman 1995). Rather than calculate some point at which a network reaches critical mass and creates a fact, then, we should think of this fact-building and network or project-extending as rhizomic (Martin 1998). That is, it does not function entirely from the top, down, but rather wends its way through the soil of society, spreading to where it can. The citadel, therefore, is shot through with connections, both inside and outside its walls. For example, the increasing prominence of the Tuskegee Airmen in warbird airshows has to be seen as an attempt, albeit a problematic one, to address racism within the warbird movement, even though it reproduces other aspects of the hegemonic conception of military technology, like the gendered control of killing machines. The Confederate Air Force found that rebuilding an airplane to "honor" the Tuskegee Airmen proved a useful strategy for deflecting, at least superficially, questions about its name, bolstering their argument that the name should be seen as a "joke," and not a racist statement. In breaching the citadel of the CAF's unmarked whiteness, then, the CAF sought a high-profile aspect of black history without significantly altering the hegemony of whiteness in the organization or the warbird movement as a whole.

The "follow the object" strategy this project uses at first seems like a nifty escape from the problem of false holism because it seemingly lets the object's movement trace out the boundaries of the "culture." Yet given these particular objects' received meaning within the dominant discourse in the United States, this approach also risks naturalizing the "Standard View of Technology." By relying solely on the contexts in which the airplanes appear, which almost by definition are "friendly" to the objects and those meanings, I would miss the many contexts in which those objects would be received differently. I therefore practice an ethnography of technology which situates the local practices within the larger framework for perceiving technology. I follow the object as it moves rhizome-like through society, while I recognize its comfort within the citadel at the same time. 
Another difficulty with a number of theories about technoscience is that they adopt implicitly the model of the virtuoso scientist or engineer who single-handedly forces the world to accept his (it is gendered) idea or machine. In Hughes's important works, for example, the "sociotechnical system" always seems to be the creation of such towering figures (Hughes 1989, Hughes 1983, Hughes 1987). As mentioned above, in Latour's work the establishment of technoscientific facts/machines at times seems to be the work of a master scientist/engineer who manages to strategically "enrol" all of the right groups by "translating" his fact/machine in such a way that it becomes indispensable to their own work and projects (Latour 1987). I apply Latour differently, however, seeing the various steps of enrollment and translation as cultural processes performed by individuals but producing shared, if still multiple, meanings. Thus, the spread of a plane's historicity is the collective work of the warbird movement, but also those people for whom the plane's historicity becomes important or useful. Once again, we have to conceptualize culture as an emergent process, albeit one which occurs within structures of power that operate as conventional contexts.

\section{Outline of Chapters}

The dissertation takes this idea of constant invention/sustainment and applies it to key areas of the warbird movement. The first chapter examines how the objects themselves are invented as historic, how warbird afficionados and the objects together constitute a practice which creates historicity. The second chapter looks at the invention of an idealized, militarized nation in the past through warbird performances. This usable past of the nation shores up and extends the militarization of the present nation, and it also undergirds the ongoing "war on terror." The third chapter further unpacks the connection between the past and the machines, arguing that warbird afficionados romanticize the past of human-machine relations and seek to experience that past, albeit through a nostalgia which emphasizes loss 
over connection to that past. The final chapter examines how warbird work invents a gendered agency with machines, a "masculine competence."

The scope of these chapters seeks to capture the articulation of the local with the extra-local, even the global. While the first chapter examines the local production of the object's historicity as a cultural-technological enterprise, the second chapter jumps to the application of this historicity to the project of militarist nationalism, a project with effects ranging from the local to the global. Few nationalisms have ever had the reach that American nationalism has today, making its local production always a concern of the rest of the world. Mirroring in some ways the self-absorption of this nationalism, I then turn back to the local for a consideration of the ambiguous place of old machines within a hegemonic framework devoted to the belief in technological progress. I finally return to the individuals involved to examine how their practices reinforce a model of gendered selfhood which is dependent upon competence with machines. 


\section{Chapter One: The Warbird Movement}

The Warbird movement emerged in the mid-1960's, when the Confederate Air Force really began to expand and a group called Warbirds of America formed around the revived air races at Reno, Nevada. The warbirds themselves represented a small portion of the overwhelming wartime production run. Most of the aircraft had had other fates, including the smelter, foreign militaries, and corporate fleets. As these planes were retired, they gradually acquired the status of historical artifact, and eventually became the collectibles that they are today. This chapter briefly reviews the history of the warbird movement, following the aircraft through these steps, from their postwar disposal up to their current collection and restoration. It then reviews the different groups of warbird owners and afficionados who are involved in the movement, and I conclude by briefly outlining the two major contexts of the warbird movement, the hangar and the airshow.

\section{Wartime Production and Postwar Disposition}

For warbird afficionados the postwar destruction of the World War II air fleet was a cultural and historical tragedy. The production statistics from the war are so extreme that they seem incomprehensible, especially given the very small numbers of military aircraft produced today. Where the United States Air Force purchased only 21 B-2 bombers (Anonymous n.d.-b) and 100 B-1 bombers (Anonymous n.d.-a) for the current fleet, during World War II the military bought 12,726 B-17 (Anonymous n.d.-d) bombers and 3,960 B-29 bombers (Anonymous n.d.-c). In total, the United States produced almost 300,000 aircraft between June 1940 and August 1945 (Veronico, Grantham, and Thompson 2000: 9). To keep these aircraft flying the military also had millions of spare parts produced, many of which continue to exist today. Given this scale of production, one can imagine the surprise

of the early Confederate Air Force members to find that none of several different types of aircraft were available only fifteen years later. The warbird movement was driven in part out 
of this contrast between abundance and surprising scarcity, as I will describe below. How that sudden scarcity came about, however, deserves some consideration as well.

\section{Disposing of Wartime Assets}

The thousands of aircraft produced during the war presented a problem once hostilities were ceased. The military did not need so many, especially the older types. Further, a committee convened prospectively to study the problem of surplus aircraft, had argued against allowing too many domestic surplus aircraft, lest the supply of planes reduce demand for domestic production, thereby damaging the aircraft industry. As a result, the government chose to sell or give as many aircraft as necessary to selected militaries of nations with which the United States wished to foster good relations, to sell an addition number for domestic private and commercial use, and to scrap the remainder (Veronico, Grantham, and Thompson 2000: 11-21). This disposition deserves greater examination than I can provide here, but a brief review will offer some understanding of the background to warbirds' emergence.

Most warbirds flying today came from planes sold to Americans for civilian use or to foreign governments for military use. A significant portion of the surplus aircraft, however, were sold for scrap. After the war the military gathered "surplus to requirements" aircraft at various storage depots around the country. Given the sheer space needed to store so many aircraft, most of these storage depots were located in the South and the West. One

of these sites eventually became the Aerospace Maintenance and Regeneration Center at Davis-Monthan Air Force Base, where aircraft are still stored for future rejuvenation (often for sale to foreign governments) or prepared for scrapping. The scrapping process usually involved first the removal of important spare parts and components from the planes, and then the breaking up of the planes for insertion into a furnace. The vast quantities of metal in 
these thousands of aircraft, then, quickly became a valuable commodity. ${ }^{3}$ We should also note, however, that the government was concerned, even mid-war, about the surplus of airplanes stifling the capitalist demand for production of new, better aircraft (Veronico, Grantham, and Thompson 2000: 11-17). This concern motivated the scrapping of aircraft, though the approximately 35,000 aircraft that were sold to the public would seem to be sufficient to fulfill the government and industry's concerns (Ibid: 11).

Pictures of the storage depots - fields full of aircraft — haunt warbird afficionados today, and they are a common feature in warbird magazines and at warbird museums. One large museum, for example, posted an entire article about postwar storage and disposal of aircraft at the airfield where the museum was located. The afficionados' longing for the thousands of bombers, fighters, and other aircraft scrapped after the war reflects the contradiction between the capitalist drive to produce new, better weapons and the attachment to the machines bred by their functioning as a physical framework for memory (Halbwachs 1992(1925)) and by the not-uncommon personification of machines in American culture.

The progressive logic of the capitalist system rendered these aircraft obsolete, as did the United States's growing competition with the Soviet Union ${ }^{4}$, but the aircraft were freely available for transfer to friendly, second-tier militaries abroad. In making arms transfers and sales to foreign governments, the United States government did not want to flood the world arms market, out of fear that they might be used against the United States or that they might spark instabilities abroad, especially in Latin America (Kaplan 1975: 408-9). On the other hand, in Latin America particularly, the military wished to maintain ties established during the war and to protect a "Southern flank" (Ibid). The planes were often sold again by these

\footnotetext{
${ }^{3}$ The transformation of the airplanes from front-line weapons to collections of commoditized materials to heritage artifacts would be worth considering, though I only investigate the second transformation here. While the conversion of warplanes into postwar consumer goods like cookware and appliances was often mentioned by warbird afficionados, I have not pursued the topic myself.

${ }^{4}$ For a short but useful account of the relation between the demand for the production of new commodities in a capitalist system and the competition between and creation of new weapons, see Paine (1974).
} 
foreign militaries, gradually circulating from the core capitalist countries to the semiperiphery, finally ending in the periphery. A number of P-51 Mustang fighter planes, for example, went to Sweden, from which a smaller number were diverted to participate in the creation of the state of Israel, as the United States and other European powers had declined to arm the Jewish forces in the creation of the state of Israel. Many aircraft from the United Kingdom went to British colonies. Many of the surviving examples of the late-war/postwar Hawker "Fury" came from the then-colony of Iraq, from which a warbird collector purchased the bulk of the type that fly today. The Brazilian government was flying American B-17 bombers from the early 1950's through the 60's, and other Latin American air forces sought more B-17's as late as 1967 (Caidin 1990(1968): 452-3). Over the years, these aircraft gradually moved to smaller and poorer countries. This trend is epitomized by the 1969 "soccer war" between Honduras and El Salvador when the sides sought out two types of American World War II fighter planes, the North American P-51 Mustang and the ChanceVought F4U Corsair, and hired a number of American mercenary pilots to fly them in battle (Anonymous 2003). Other planes were put to new military uses in the United States. Some bombers were refitted as multi-engine trainers, while other aircraft became target drones for aerial target practice. A few of the fighter planes were recalled to service during the Korean War, no longer top-line fighters, but still useful as ground support. At least two types, the B-26 "Invader" bomber and the C-47 "Skytrain" were converted for special uses in the Vietnam War. My data include only anecdotal accounts of the post-World War II military usage of these aircraft, but the planes clearly served in that role for many decades after the war.

\section{Corporate Owners}

Many of the warbirds which circulated were not fighting aircraft, however. Cargo planes and transports went south along with the fighting aircraft, and many continue to fly in those locales. As demonstrated by the 35,000 aircraft sold domestically, non-military uses 
of the aircraft predominated at home. While many of the aircraft stored in depots were sold for scrap, most of the warbirds that survive today were also purchased there. Companies bought thousands of them for commercial uses, and they often converted the planes significantly to meet their new functions. Other people bought airplanes to use for sport or leisure flying. These aircraft often stayed in the United States, moving gradually between industries as they were replaced by newer, more capable aircraft. Eventually, these aircraft were retired and left derelict, scrapped, or restored to become a museum piece or warbird.

The aircraft sold to corporations played a wide variety of roles, but initially the major uses were transportation and cargo hauling. Many air freight companies bought and used World War II surplus aircraft, most famously a company called "Flying Tigers." The name came from the founders, who were among the famous American pilots - the American Volunteer Group, known as the "Flying Tigers" for their shark-mouthed aircraft — who went to China to fly missions against the Japanese before the United States was drawn into the war by the Pearl Harbor attack. Airlines like these used surplus World War II aircraft for decades, and a few of these aircraft still fly, especially abroad. Many more aircraft were converted into transports. While most aircraft were individualized conversions, some were converted into new lines of aircraft. The "On-Mark Marketeers," for example, were luxury conversions of B-26 "Invaders," sold as executive transports, while the "Cavalier Mustangs" were upgraded versions of the P-51 "Mustang," also sold as business executive transports, though they could only hold one or two people. As the planes were superseded by newer ones with lower operating costs, the World War II airplanes were converted to more exotic uses or were sold abroad. Many World War II planes were used as "firebombers" to drop fire retardant on forest fires. A number of these planes still fill this role, though a few recent, well-publicized crashes of old aircraft have led to calls for upgraded airplanes. Other planes were used to spray pesticides. A number of aircraft also became display pieces for businesses. One famous gas station/restaurant had a B-17 bomber placed on top of it, a plane 
which eventually became a flying warbird. Another gas station had a P-40 fighter plane on top, which also became a warbird.

With so many of these aircraft still flying long after the war, a large market for aircraft maintenance and parts emerged. While I have no data on the continuation and spread of the skill required to maintain the aircraft (such as whether military-trained mechanics were granted civilian aircraft maintenance licenses), the vast stores of parts which survived the war did became a common focus on warbird discourse. Just as industry produced staggering numbers of aircraft for the war, so they produced huge caches of parts, which businesses bought up after the war. ${ }^{5}$ These lucky entities instantly became invaluable to the aircraft industry, and they are known in the warbird world today as "original surplus dealers."

While former World War II aircraft became common sights at airports, they also had a visible presence was in the movies. A number of companies purchased these airplanes to be featured in movies about the war or to serve as aerial photography platforms. World War II airplanes featured in many movies both during and after the war, and their presence continues today. ${ }^{6}$ Further, many of the movie airplanes found their way into warbird collections. A number of museums today have airplanes from Tallmantz, one of the important World War II aircraft-flying companies. Three movies in the 1960's and 70's gathered large numbers of World War II aircraft which went on to various warbird collections. For Tora Tora Tora the filmmakers gathered American aircraft and created replicas of Japanese aircraft (of which no original examples remained because they were systematically destroyed after the war $)^{7}$ out of American trainers. The Battle of Britain

${ }^{5}$ I have no data indicating whether parts' stores were scrapped like aircraft were.

${ }^{6}$ Computer-generated images have begun to replace images of actual warbirds in movies, a development that warbird afficionados find distasteful. One warbird pilot who has flown for movies complained that the computer versions' maneuvers were obviously impossible, while other enthusiasts said they would much rather see "the real thing."

${ }^{7}$ The symbolism of destroying all of the Japanese aircraft highlights the ferocity of the Pacific War and the ease with which affect can be objectified in machines. Surely the cultural figure of the kamikaze, directly connected to the aircraft, would have contributed to this thorough destruction because of the metonymic connection between plane and pilot. 
gathered many flying British aircraft and borrowed variants of German aircraft that were still flying for the Spanish Air Force. Catch-22 gathered a number of B-25 bombers. Almost all of these aircraft are in warbird collections now, and might not have survived except for the movies. The Japanese replicas from Tora Tora Tora mostly went to the Confederate Air Force, which now uses them in an eponymous airshow act.

\section{Private Owners}

Many aircraft (the only datum I have is the figure of 35,000 aircraft sold to civilians, including corporations) also were sold to private owners, most of whom used them for leisure or sport flying. The small trainer aircraft, for example, were sold to many private individuals. One ad listed a range of these small aircraft for between $\$ 875$ and $\$ 2,400$ (roughly $\$ 9,200$ to $\$ 25,000$ today) ${ }^{8}$ which probably made them too expensive for anyone but an upper middle class person (Veronico, Grantham, and Thompson 2000:10). The ad suggested that the aircraft could be used for "flight instruction, personal transportation, crop dusting, ranch or forest patrol and other purposes" (ibid). These myriad possibilities include both leisure and professional use. Crop dusting, in particular, was an important use for these aircraft. The larger, much more complex fighter aircraft cost more, from $\$ 1,500$ to $\$ 3,500$, though prices ranged widely over the years (Veronico, Grantham, and Thompson 2000:26). This disposal of aircraft was an ongoing process, as the military gradually surplused World War II types over the years. By the time of the warbird movement's emergence, planes were still being sold for public use and for scrap.

People who bought the larger warplanes as sport or leisure planes soon found out that they were too expensive and complex to maintain easily. Even as late as the end of the 1960 's, after the warbird movement had begun to grow, many people would question why a private person would want to own something so big, complex, and expensive as a warbird. Such was the case with one now-retired airline pilot I met who bought and flew a fighter

${ }^{8}$ This statistic was taken from "The Inflation Calculator," at http://www.westegg.com/inflation/. 
plane for several years in the late 1960's. He had worked as a truck mechanic in the military, which enabled him to do some of the maintenance work himself, but even with this background he had a difficult time with the aircraft. He enjoyed flying the plane, and even working on it, but he sold it after a few years because the work and expense were too great.

The most visible private use of these aircraft after the war was in air racing. Air racing had been quite prominent prior to World War II, with later heroes of the war like Jimmy Doolittle becoming famous for their exploits. After the war air racing was dominated by World War II fighter planes, mostly American-made types. This popular motor sport came to an end in 1949, however, after a horrific crash at an air race killed not only the pilot, but a family whose house was destroyed. Air racing did resume a decade and a half later, in 1964 in Reno, Nevada, and it continues there today. World War II aircraft have dominated air racing since its resurgence. Only a very few non-military aircraft have had any success in air racing, though the planes that do race are substantially modified from their wartime configuration. Racers add new engines, changed propellers, shortened wings and tails, and streamlined fuselages. They also modify their engines so they can run them at pressures twice the wartime maximum. All of these modifications, however, were performed on World War II aircraft. Warbird enthusiasts have mixed feelings about these changes. Some revel in the power of these former warbirds, while others, like one well-known British collector with whom I spoke, see the modifications as an abomination. ${ }^{9}$

As late as the 1960's and 1970's most flying World War II aircraft still played a variety of different roles; they were not yet forced into the "living history" category. They were sport planes, utilitarian haulers/sprayers (all cargo planes, B-25's, Tigercats, TBM's, B-17's, B-24's, PB4Y's), air racers, abandoned hulks, restaurant or theme park novelties, etc.

\footnotetext{
${ }^{9}$ Many American warbird enthusiasts share the view of this Brit, but he suggested that Americans were more willing to make such modifications to a "piece of history" in the name of getting a faster, more powerful, machine. These aircraft, of course, have a different place in the United Kingdom, where they are seen as the saviors of the country during the Battle of Britain. This tension between historicity and machine enthusiasm does not often arise in the American warbird world.
} 
Since that time they have increasingly been pushed into the category of "warbird" by the interests in them as scarce novelties and their costs. They lost their utility due to their age and need for greater maintenance. The maintenance costs got too high, so many companies bought newer aircraft and private owners sold their planes. The growing interest of collectors also drove their value up. For private individuals, planes that had been affordable on an upper middle-class salary — doctors, lawyers, and airline pilots — were soon priced out of their range.

\section{How "Warbirds" Came About}

The warbird movement did not begin in earnest until the early 1960's, but a few collectors began buying World War II warplanes for historical purposes well before then. These early collectors included the founders of the Confederate Air Force, which is still the largest warbird group and the major warbird group with which I worked. I mark the beginning of the movement from the time when the historicity of the aircraft really began to be emphasized. As I noted above, many people bought surplus aircraft after the war to fly for fun or for profit, but very few were purchased with a preservationist goal. Even after the cultural heritage groups were well underway, however, it took another couple of decades before "warbirds" became a significant collectible.

While my research focused on the Confederate Air Force, it was not alone in collecting warbirds, even during its earliest days. In fact, the CAF adopted the drive to "preserve history" after some other groups and individuals. One individual in particular, Ed Maloney, starting collecting World War II warplanes that he thought were important very early on, in the late 1940's. In the late 1957 he founded a museum that he called simply, "The Air Museum," because there was no other museum like it in the West (with the advent of other museums, "Planes of Fame" was appended to the name). He was nearly alone in his collecting passion, and he managed to preserve a number of quite rare aircraft, including the prototype of the first U.S. fighter jet (the YP-59), another aircraft which had both a piston 
engine and a turbine engine (a Ryan Firebolt), and one of the few surviving German fighter aircraft (the Messerschmitt 262). The only other organization collecting rare aircraft in a similar way at the time was the Smithsonian, and its collection was greatly boosted by the efforts of Air Force General "Hap" Arnold, who set aside a number of aircraft for it.

If Ed Maloney was considered a little eccentric in his day, but has since become a preservation hero, warbird afficionados continue to look upon Walter Soplata, a collector based outside of Cleveland, Ohio, as the quintessential eccentric airplane collector. He acquired fame in warbird sectors for his extensive collection of rare aircraft, including famous late 40's air racers, parts of the largest Cold War bomber (the B-36 "Peacemaker"), and the prototype P-82 "Twin Mustang." Starting with the growth of the warbird movement in the sixties, these rare aircraft drew a variety of interested buyers, all of whom Mr. Soplata turned away. He said that he only wanted to preserve them, not have them fly, so he rejected every offer. ${ }^{10}$ His farm was a kind of Mecca for warbird afficionados, though, and they came to gaze upon his wrecks - exploring wrecks coming a close second to watching an airshow as a favorite activity of theirs.

Where Ed Maloney successfully translated his eccentric collecting into a flying museum, we might say that Walter Soplata's application of the preservationist discourse imperfectly meshed with common understandings of it. Where Maloney cleaned up his aircraft and presented them to the public, Soplata merely held on to them, preserving them from the smelter but leaving them to the ravages of age and weather. These two men, then, highlight the workings of the preservationist discourse, that it favors not just preservation, but preservation and public presentation.

\footnotetext{
${ }^{10}$ This point of view is not uncommon among aviation museums, who view the flying of the aircraft as too risky. Modifications necessary for safe flight also compromise the authenticity of aircraft, in the view of many.
} 


\section{The Confederate Air Force}

Where these individuals from the beginning sought to preserve aircraft, the Confederate Air Force (CAF) began as a flying club. In the 1950's a group of south Texas farmers and crop dusters wanted to fly the fun and glamorous fighter planes that they missed out on during the war, so they formed a flying club and bought a couple of fighter planes. This flying club developed into the largest warbird organization and the largest warbird collection. The CAF's prominence led me to focus my research on one of its units, in Southern California. The story of the CAF's emergence and change offers useful insight into the changes of the warbird movement. The CAF became a model for the rest of the warbird movement, though the organization itself eventually had to address its problematic name.

The CAF started as a leisure group for a group of World War II veterans. Several original members had been World War II bomber pilots, while others, like their revered founder, Lloyd Nolen, had been instructor pilots, a skill so valued that they had stay in the United States to train others to fly. ${ }^{11}$ Mr. Nolan first purchased a P-40 "Warhawk" fighter plane in 1951 to fly for fun. He soon sold it in hopes of buying a better airplane, the P-51 “Mustang (Anonymous 1975: 15-17)." These aircraft, however, were recalled to military service when the U.S. committed troops to Korea. In 1957, Mr. Nolen, joined by four others, bought a P-51 "Mustang." One day someone — whose anonymity remains a part of the CAF story — painted "Confederate Air Force" on the P-51. The group enjoyed the joke so much that they appointed themselves "Colonels" and "Sergeants" in the Confederate Air Force, though they soon changed all of their ranks to Colonel (Ibid: 17-19). The next year they bought two F8F "Bearcats." They flew them with skillful abandon, going fast, flying low enough to cut grass, tail-chasing or "dog fighting" each other, and "buzzing" each other's houses - generally doing the things in airplanes that they thought were the most fun.

\footnotetext{
${ }^{11}$ This theme of compensating for what one missed runs throughout the history of warbirds, although it shifts from military pilots who did not get to fly the high-status fighter planes during World War II to the common warbird pilot today who occasionally fantasizes about what it would have been like to fly the planes during the "Good War."
} 
The group soon began seeking new types of aircraft to fly. They were not satisfied with just these two aircraft types, which not only expresses the logic of capitalist production, but also reflects the desire of all pilots I have met to fly new types of airplanes. They expressed the wish to get certain types of airplanes "in their logbook," the textual record of their piloting. This "logging" works as a kind of possessive individualism, an objectification of the pilot's identity as a pilot (MacPherson 1962, Handler 1988). Airshows offered another incentive to add new types of aircraft. The CAF's first step beyond leisure flying came when it was invited to fly in an airshow at Kingsville Naval Air Station in May, 1960 (Ibid: 19). The show performance was well-received, and this success, along with the revival of air racing, began to institutionalize warbirds as an airshow act. The nascent CAF soon received invitations to fly elsewhere.

In pursuing new types of aircraft, the CAF members sought out fighter planes first, collecting a total of 9 by the end of 1961 (Anonymous 1975: 25). Through this collecting the members found that the different types they sought out were hard to find. As they sought each new type of aircraft, they found they had to search further than expected. ${ }^{12}$ It was this realization of scarcity that fostered their drive to preserve the aircraft. To that end, they became a nonprofit corporation in September of 1961. Nonprofit status eased the cost of their collecting and playing passions because the organization could offer a tax deduction to anyone willing to donate parts, services, or even airplanes. This ability allowed the CAF and other warbird groups to survive financially in future years.

The expansion of the CAF's collection therefore coincided with the adoption of a historic preservation mission. In becoming a heritage group, they were, of course, activating an existing discourse - historic preservation - with an array of associated practices - nonprofit formation, fund-raising, volunteer-seeking, etc . Interest in "heritage" exploded after

\footnotetext{
${ }^{12}$ Given the 35,000 aircraft sold for private and commercial use after the war, I find it surprising that even a few types were so rare. I do not, however, have data on just what types of planes were among those 35,000 sold, nor on how many of each type were sold.
} 
World War II, so reframing the airplanes as heritage objects was be readily familiar both to CAF members and to potential audiences (Kammen 1991).

\section{(Mis)Adventures Retrieving Aircraft}

While the CAF's fame was growing from its airshow appearances, its membership was growing and the collection was expanding. They adopted the goal of getting an example of each type of American fighter that flew during the war, and when that collection was (more or less) complete, they shifted to bombers and foreign aircraft. The rarity of aircraft not only led to the CAF's shift to historic preservation, but it also created a genre of airplaneseeking adventures. Adventure stories about seeking long-lost or badly neglected aircraft would eventually become common in the warbird movement, and stories about these early adventures of CAF members have served the CAF well as creation myths. The early newsletters are filled with misadventures experienced while seeking, purchasing and flying home World War II aircraft. The most famous CAF story, though it comes later, in 1971, is the finding, recovery, and restoration of the CAF's B-29 bomber, nicknamed "Fifi."

Fifi's Recovery

The CAF's quest to acquire all types of warplanes the United States used in World War II eventually led it to seek out a B-29 bomber, the plane used in missions that so devastated Japan late in the war, culminating in the atomic bomb drops on Hiroshima and Nagasaki. After much looking the CAF found that the Navy had a number of B-29's sitting at its China Lake weapons range, where they were used as targets for various munitions. Working through the Air Force, which had given the planes to the Navy, the CAF was given its pick of the remaining B-29's to restore. After choosing one of the planes, they hired a contractor to perform the initial restoration ${ }^{13}$ and sent along of team of selected CAF members to assist (Anonymous 1975: 77). The plane had sat neglected in the desert for 17

\footnotetext{
${ }^{13}$ For some reason, the CAF's 1981 publication devoted solely to this B-29 (McGregor et al. 1981) omits mention of this contractor, which was included in the CAF's 1975 history (Anonymous. 1975: 77). The later publication says only that "a group of CAF Colonels" performed the restoration (McGregor et al. 1981: 22).
} 
years, but in only nine weeks the team restored it to flying condition, though they had to wait a little longer while they had engine components and accessories (like the carburetors) overhauled and plexiglass windows manufactured (McGregor et al. 1981: 24). Upon installation of the overhauled components, they were ready to leave. None of the crew had flown a B-29 before, but they all had experience in similar aircraft (Sohn n.d.). They chose to perform no test flights because they were afraid that the stress of multiple take-offs and landings there might cause mechanical problems they could not resolve. The pilot therefore decided to make the flight all the way from the California desert to the Texas coast, where CAF headquarters was located (ibid). Although the aircraft was in good enough condition to make this single flight, the CAF had to spend three more years restoring it fully and getting it "certificated" for flight by the FAA (McGregor et al. 1981: 24). Such a large project required a great deal of money, and the CAF found a sponsor who had worked on the development of the B-29 program. In exchange for this monetary support, the CAF let him name the plane, and he chose his wife's name, "Fifi."14 The tale of this desert recovery and partial restoration appears in many CAF publications, all of which emphasize both the difficulty of the restoration work (the airplane is enormous and the work occurred in a very short period of time) and the daring of that ferry flight from California to Texas. Similar stories in this genre would later involve the same difficult search, and similar mechanical prowess, but would add more exotic locales, such as Pacific island jungles and the Siberian steppe, corrupt local officials, and often more mechanical complications in flight.

\section{The Confederate Air Force?}

The adoption of the name "Confederate Air Force" was a joke, of course. The Confederacy did not have an "Air Force," at least not one with airplanes. The name could

\footnotetext{
${ }^{14}$ Although I do not do so here, the application of such a dainty name to the type of plane which dropped the first atomic bomb deserves further consideration. Aircraft of all types are gendered as female, but this case seems to merit investigation. It works as a joke for insiders, much like the name Confederate Air Force worked as a joke, but I think it has deeper significance as well. The name echoes the name Col. Paul Tibbets gave his airplane, the Enola Gay, which was his mother's name.
} 
be read as an explicit nod to the narrative of technological progress; i.e., the planes are so old they might as well have flown in the Confederate Air Force. On the other hand, the members clearly took to the name quickly and exploited its symbolic potential for both humorous and serious work. The humor came through the play-acting with antebellum South stereotypes, while the seriousness came from the use of the metaphor's oppositional symbolism. Their mission depended on the understanding that they were doing something important that the government was not in preserving aircraft. Adopting the role of "Confederates," then, gave them a symbol to employ for its oppositional quality and its pop culture associations. While this symbol has proved useful, it has recently caused the CAF much greater difficulty. Its use reflects not only the humor of the founders, but also their position of power within the American class and race system. Only people entirely accustomed to being the unmarked category could blithely pass off the use of the name as a joke.

The CAF's early newsletters, banquets, and awards adopted a romanticized, Gone with the Wind style. Unlike the more serious romanticizations of the Confederacy (Cf. Cullen 1995), the humor used in this one was obviously self-mocking. The name itself was meant as a joke, since the Civil War long predated airplanes. They had a Magnolia Ball and a J.E.B. Stuart-like mythic founder named Colonel Culpepper. Their uniforms and airplanes bore the familiar "Stars and Bars" battle flag of the Confederacy, and the "blood chit" on the back of many uniforms read as follows, ""This is a rebel aviator. If found lost or unconscious, please hide him ${ }^{15}$ from Yankees, revive with mint julep and assist him in returning to friendly territory" (Anonymous 1975:258). Their motto was "Semper Mint Julep," and among their founding objectives were the preservation of World War II aircraft and to "Use all our political influence to have the capital building at Washington turned to face the SOUTH" (ibid: 21).

\footnotetext{
${ }^{15}$ Women were not allowed to be "Colonels" until 1982. Until that time, their only option was to join the "Ladies Auxiliary," called "Culpeper's Angels," and even to join that, a woman had to be married to a "Colonel."
} 
In addition to this playful (for them) symbolism, the Confederacy offered an oppositional symbolism, giving the members a position from which to criticize the United States Government for failing to preserve World War II aircraft. When the CAF's early publications criticize the government for its lack of preservation, they unfailingly describe it as the "Yankee" government. Despite this oppositional stance, however, they benefitted greatly from the largesse of the state and certainly served the goals of the ever-expanding military. One of the CAF's earliest moves was to incorporate as a non-profit organization, making donations tax-deductible and much more attractive. They also received a number of aircraft from the state, either as loans or gifts. ${ }^{16}$ Further, the CAF's early invitations to perform at military bases served to constitute the organization, providing a fundamental impetus to its later success. The CAF's central role in the Heritage and Legacy Flights which emerged in the late 1990's demonstrates the current usefulness of the organization to the military, but even the first military airshow in which the nascent CAF participated was very well received (Anonymous 1975: 19).

\section{Changing the Name}

In 2001 the CAF membership voted to change its name to the Commemorative Air Force, retaining the familiar initials of CAF. The key argument for changing the CAF's name ultimately was the difficulty obtaining corporate sponsorship for its airplanes and its events. At the pivotal meeting in 1999 where the name change resolution was first seriously addressed, a member of the Dixie Wing, based in Atlanta, said that the Wing was having enough difficulty in obtaining sponsors to force them to suggest the name change. Those wishing to change the name were supported by others who argued that the name reflected neither the identity nor the mission of the organization. It was not a strictly Southern organization - when the first separate units were chartered as Wings in 1971, one of them

\footnotetext{
${ }^{16}$ The distinction between loan and gift to the CAF is currently being litigated. Controversy arose when the CAF tried to sell an F-82 "Twin Mustang" fighter plane that they had received from the U.S. Air Force. The U.S. Air Force now claims the plane was loaned, not given. Despite this disruption, the CAF now works as closely as ever with the U.S. Air Force.
} 
was in Minnesota — and the organization's mission had to do with World War II, not the Civil War (Ibid: 79-80). Many who voiced this argument were tired of having to explain the name to skeptical friends and acquaintances. Others, however, countered that the organization's identity was wrapped up in the name, though their use of identity conflated the sense of what something is, its essence, with a marketing-derived sense of brand identity, how a product is understood by consumers

Another objection to the name change followed a line of individual autonomy. Opponents of change said that they did not want to sell out their principles for money, or even worse and did not want to violate their principles just because of "political correctness." Exactly what "principles" were being defended here, aside from individual autonomy, was not clear. In the public debates I witnessed - though I missed much of the debate between when the issue was first officially raised in 1999 and when the membership voted to change the name in 2001 - no one adopted the common line of pro-Confederate rhetoric these days, that the Civil War was sparked by states' rights and not slavery. A few individuals from a CAF Wing in Maryland raised these points with me, but the public debate I heard did not touch on these issues. No one defended "Southern heritage," and no one raised the issue of Southern identity. These latter arguments might have failed, however, given the CAF's spread beyond the borders of the Confederacy. Ultimately, sponsorship money became the predominant force in the name change according to the public statements and private sentiments I heard.

This debate about the name change should not obscure the vital point that treating the Confederacy as a usable past carries the profound weight of the institution of slavery and the structures of racism which have persisted since that time. From this point of view, the antebellum, plantation-like play-acting might be seen as grotesque, both because it masks the slave labor which made that elite life possible and because it demonstrates the CAF members' ability to be blithely ignorant of how their play-acting might be understood. 
Deploying the Confederacy merely as a useful symbolic resource buries the bitter violence of slavery.

Needless to say, the early membership was entirely white, and the membership remains overwhelmingly white. A trickle of African-Americans have joined the group, most notably a few of the Tuskegee Airmen. Some members took pains to point out these members. One member of the CAF General Staff told me, "If there were anything serious about Confederate Air Force and the rebel flag and all that kind of stuff, you would not have General Benjamin Davis [the leader of the Tuskegee Airmen] accepting an honorary membership." Such assertions mirror the perniciousness of structural and unvoiced racism, as if avoiding racist epithets and providing some affirmative action programs somehow ended the long history of discrimination in the United States.

I could not research the Confederate Air Force without addressing, at least in part, the important factor of its name and history. Despite the initial impact of this name, however, my full ethnographic investigation of the warbird movement took a different tack, focusing eventually on the relationship between understandings of technology and of history within American culture.

\section{Who Are the Colonels?}

As I suggested above, the membership of the CAF is overwhelmingly EuroAmerican. ${ }^{17}$ In addition to their ethnic status, several qualities link the CAF Colonels. As one might expect, most are politically conservative and aggressively pro-military. The majority served in the military at some point, though they were not necessarily involved in aviation. The initial members were World War II veterans, and this generation continued to dominant the CAF for its first two decades. In the past two decades, however, the leadership has shifted to the postwar, "Baby Boomer" generation. With this generational shift, the CAF, and the warbird movement more generally, became a means for one generation to relate to

\footnotetext{
${ }^{17}$ In this, and in their politics, they reflect the warbird movement as a whole.
} 
the previous one. Most CAF members and warbird afficionados with whom I spoke were involved, at least in part, because of a parent or relative who was worked with aircraft during World War II. Fathers flew bombing missions; mothers ferried aircraft from factories; and Uncles maintained aircraft on Pacific atolls. These kinship relations for many added an affective dimension to their CAF work.

The operation of the CAF required members from a variety of backgrounds, with a variety of skills. While only upper middle class members could afford the training and sponsorship cost required to fly the planes (though many were trained in the military), anyone could work on the planes, with some supervision. Even still, maintenance and restoration required expertise. As warbirds became more and more expensive over the years, members began to see the annual fee as a cheap way to encounter the airplanes. A few wealthy members are active, but most are middle-class or working class. Despite the initial adoption of equal rank (all "Colonels"), these class differences do play into daily functioning, not least because the wealthier members are able to fly the planes and garner more attention for their donations.

In addition to social class, the age of members plays an important role in the daily functioning of the organization. Many of the active mechanics, pilots, and leaders of Wings are retirees. The FAA-mandated retirement of airline pilots when they turn 60 has helped create this pool of available labor. Retirees have the time to guide tours through a warbird museum, work on aircraft three days a week, and perform the daily tasks of a large organization. The large size of the Wings in Phoenix and Southern California is no accident, as those areas have large populations of retirees. ${ }^{18}$

\footnotetext{
${ }^{18}$ The CAF had a large Wing in Florida in the 1970's, but that group split away from the CAF over disagreements with CAF Headquarters (Caidin 1984). In recent years a Florida Wing has been revived. I have not been able to explore other factors that may play into the relative size of different CAF Wings or other warbird groups. I would imagine that the population of military veterans would play a significant role, as well as the presence of a military ethos, as has been the tradition in the South.
} 
The symbolic Southern identity of the organization was reflected in its membership for many years. While two of first four CAF Wings established in 1971, were outside of the South, the Minnesota Wing and the New Mexico Wing, the bulk of the membership remained Southern. Even today, Texas has the most CAF units, with twenty, compared to six in California, and the most aircraft, fifty-two, compared to nineteen in California. Over time, however, the connection to the South gradually dwindled, culminating in the 2001 name change. The Wing with which I spent time, the Southern California Wing, was one of the largest and most active CAF units, and the units in St. Paul, MN, and Phoenix, AZ, were similarly situated. While the CAF members from the South whom I met did have an interest in, and a felt tie to, the Confederacy, the California members never spoke of it. Another indicator of this identity's waning comes from the use of the "Colonel" title. In the CAF's early literature, the title was used constantly as part of the antebellum play-acting. In California, however, I almost never heard anyone use the title. I would argue that this fading is part of a larger trend in which the CAF is integrating with the rest of the warbird movement that has emerged since the CAF's founding.

\section{Other Warbird Organizations}

After the CAF and the other early collections formed in the early 1960's, and air racers began making warbirds prominent, the warbird movement began to grow. Over the next three decades warbird flying would become one of the most visible forms of aviation. Most airshows today feature at least one warbird, and many shows are devoted entirely to warbirds which come from a variety of collections. The major trend in the warbird movement has been from individual, upper-middle-class collectors to large collections belonging to wealthy businessmen. A number of non-profit, volunteer-based museums, like the $\mathrm{CAF}$, have formed but the collections of these businessmen dominate the warbird world.

In 1964 a group called Warbirds of America (WOA) formed as an association of warbird owners. It grew out of the Reno air races and initially formed so that the owners of 
these increasingly rare aircraft could share information and expertise. Within a few years it became a division of the Experimental Aircraft Association (EAA), which exposed the much broader audience of general aviation pilots and enthusiasts to it. While I have little data on the early activities of WOA, I can say that it has since become an umbrella group for all warbird owners and organizations. A number of small, local WOA chapters have been founded across the country where warbird owners can gather to work on their airplanes or to fly together. The organization also works nationally, hosting the warbirds at the EAA's big, annual airshows - "AirVenture" in Oshkosh, WI (formerly known simply as the Oshkosh Fly-In), and "Sun "n Fun" in Orlando, FL — which feature the largest and bestknown warbird performances outside of the CAF. At these shows WOA hosts a variety of sessions where warbird owners, organizations, and mechanics can share important legal, maintenance, and operational information. In 1993 they added a separate event, the National Warbird Operators' Conference, for more extensive sharing of this information. As part of EAA and in conjunction with the CAF, WOA has lobbied to defeat regulatory and legislative restrictions on warbird activities and to create rules for warbird operation which they find acceptable.

As more and more individuals started flying warbirds, new organizations formed to facilitate sharing information. WOA served as the umbrella group for many of the rarer warbird types, but many type-specific organizations developed, too. Some organizations were ad hoc, like the B-17 cooperative, an affiliation of organizations flying the B-17 bomber (of which fewer than a dozen are flying). This group shares information about the peculiar maintenance requirements of that airplane and also pools the resources of the different owners to produce parts, like tires, in quantity to reduce the unit cost. Other type-specific organizations were more formalized. The North American Trainer Association (NATA), for example, formed in 1985 to pool expertise and information about the AT-6 line of trainer aircraft built by North American Aviation. Over time the group added other types of aircraft 
built by the company, including the P-51 "Mustang," the B-25 "Mitchell," and the postWorld War II T-28 "Trojan" (Presley 1999). Not only has this organization served as an information clearing-house, but in the 1990's it worked with the FAA, the CAF, and WOA to create a program to certify airshow pilots in formation flying. This type of flying is difficult and dangerous, and the FAA, which has long been sensitive about airshow safety, wanted some formal means to approve pilots for formation-flying at airshows. Today the NATA conducts regular formation-flying clinics where participants can earn a "formation card" that will enable them to fly at an airshow.

\section{Volunteer-Based Warbird Museums}

While WOA links pilots and owners of individual warbirds, a variety of organizations have followed the leads of the CAF and The Air Museum Planes of Fame to create a volunteer-supported, non-profit museum of warbirds. Many of these formed in the 1970's and 1980's. Dozens of small museums exist, but some of the larger ones include the Yankee Air Force in Ypsilanti, MI, formed in 1981; the Valiant Air Command in Titusville, FL, which formed in 1977 and which was a former CAF Wing that split off (Caidin 1984); the Air Heritage Museum, formed in 1983 in Beaver, PA; the MAPS Air Museum, formed in 1990 in Canton, OH; and the Mid-Atlantic Air Museum, formed in 1980 in Reading PA. Many other museums have come and gone as the core groups of volunteers faded away. Others have changed radically, such as the Kalamazoo Air Zoo, in Kalamazoo, MI, which switched from a mostly flying warbird museum to an entirely static museum which offers flight simulations and other "experiences" of flight.

Many warbird museums built up around some specific locality, event, institution, or individual, giving them narrative frameworks for their collection. The American Airpower Museum in Farmingdale, NY, for example, formed to collect aircraft built there by Republic Aviation. The Yankee Air Force formed to commemorate the massive production of the Willow Run plant (though they have been frustrated in their attempts to acquire one of the 
aircraft assembled at that plant). The Richard Bong museum in Superior, WI, albeit a static, not a warbird, museum, formed to honor the famous pilot in his hometown. Other museums formed around an aircraft, like the Vintage Flying Museum, in Fort Worth, TX, which developed around a B-17 bomber that a doctor had purchased. He acquired the plane in 1979, but when the personal expense became too great, he created the museum in 1990 and donated the plane to it. The museum soon began to collect other aircraft as well, all supported by donations.

Most of these museums restore and maintain their own aircraft. Like the CAF, the labor is almost entirely that of volunteers, often retirees with some prior level of mechanical skill. Many of these restorations are extensive, like the Mid-Atlantic Air Museum's restoration of the very rare P-61 "Black Widow." That museum formed in 1979 with the purpose of recovering the wreckage of a specific P-61 airframe from Papua New Guinea, and has been working slowly to restore the corroded wreckage since it was fully recovered in 1990 (Rambow 2006). Sometimes these museums restore and/or exhibit aircraft for other, larger museums, like the U.S. Air Force Museum or the Smithsonian National Air \& Space Museum. The Kalamazoo Air Zoo, in Kalamazoo, MI, for example, is restoring a one-of-akind aircraft, a Curtiss XP-55 “Ascender," which belongs to the Smithsonian.

These small museums often host annual airshows, both to raise funds and to present their historical lesson. The Mid-Atlantic Aviation Museum's annual World War II weekend is among the largest and most diverse of these shows. It features not just a warbird airshow but also an extensive "living history" reenactment of World War II with encampments and ground vehicles. Many other museums send their aircraft to shows like this, which reflects the widespread cooperation between these warbird groups. While museums surely compete with each other for donors, for available parts and airplanes, and for notoriety, they also work together on a range of issues in addition to sharing their aircraft. Most of them participate in Warbirds of America and the groups for specific warbird types. These museums hold 
many warbirds, but the bulk of them are held by private owners and the wealthy collectors who transform their personal hobbies into museums.

\section{Private Owners and Wealthy Collectors}

The EAA's Airventure in Oshkosh, WI, probably the largest annual warbird airshow, offers the best snapshot of the warbird world. Each year this show attracts over ten thousand aircraft of various types, from general aviation Cessnas to vintage flying boats, and frequently well over one hundred warbirds. The bulk of these warbirds are trainers of various types, most of which are owned by private individuals. The fighters, bombers and other aircraft, however, normally belong to various warbird museums. A few of these come from volunteer-supported museums, but many more come from the museum collections of wealthy businessmen. While private owners still hold the majority of aircraft, these collections of rich men have become the most visible presence of warbirds, both at big shows like Airventure and in the warbird media (which consists mostly of calendars and monthly magazines, though a number of warbird airshow videos are produced each year). The predominance of these wealthy collectors has been the most significant change in the warbird world over recent decades, as they have both elevated the visibility of the planes and turned them into elite collectibles.

\section{Private Owners}

From the end of the war until today, private individuals have bought and flown World War II warplanes. In the beginning many purchased fighter planes, but they often abandoned these due to the expense of operating and maintaining them. A few upper middle class professionals, however, have been able to fly the powerful fighter planes, though the planes are quickly becoming too expensive even for them. One doctor I spoke with defended his choice of a postwar Hawker "Sea Fury" fighter over the more famous P-51 "Mustang," arguing that the "Sea Fury" flew faster and more comfortably, even though it is much cheaper. In another case, a group in Half Moon Bay, California bought a P-51 "Mustang" 
to fly collectively. The group formed at least as early as 1971 and shared ownership, expenses and maintenance duties on the airplane. The expenses have become so great, however, that they strain the group. To save money, many individual pilots work on their own airplanes. I met at least two engineers, for example, who restored their own aircraft over many years. For these men, the technical challenge of restoring such a complex machine on their own was a great pleasure and an all-encompassing hobby.

As I mentioned, while some of these private individuals do manage to support a larger aircraft, many of them restore and fly the smaller trainers. Yet even one of the most common aircraft, the AT-6 "Texan" and related models, remains a large, complicated, and expensive aircraft. Many pilots said that it is harder to fly than the bigger fighter planes. Like the engineers, many of these trainer owners enjoyed the challenge of rebuilding and maintaining these aircraft. With the growth of WOA and the training in formation flying, these individual owners have a range of fora for learning from and having fun with each other. Indeed, one of the attractions of coming to a large airshow like Airventure, where an owner's AT-6 might be one of thirty in attendance and one of over one hundred warbirds, is the chance to fly for the public in large formations. While these formations are carefully overseen by the FAA, the pilots seem to enjoy them as much as the early CAF pilots enjoyed flying their aircraft. As these comments suggest, the individual owners emphasize their enjoyment of their airplanes, often even more than the planes' historic importance.

\section{Wealthy Collectors}

While the private individuals mostly come to Airventure to fly for fun, many of the wealthy collectors come to compete. Warbirds of America runs the prominent concours d'elegance competitions at the EAA's annual Airventure airshow in Oshkosh, Wisconsin, the largest annual gathering of aircraft in the United States, and its Sun-n-Fun airshow in Orlando, Florida. At these competitions, like the long-standing automobile exhibitions from which the term concours d'elegance is taken, competitors display their aircraft for evaluation 
by experienced judges. ${ }^{19}$ The planes are parked in rows with their components exposed so that the judges can see the depth of care taken in the restoration and maintenance of the vehicle. In this forum wealthy collectors compete to win a "Grand Champion Warbird" trophy. Prior to the 1990's, individual owners and nonprofit museums would also compete, hoping to be recognized for the hard work they had performed to restore the aircraft. These competitions gradually became arenas for wealthy collectors to compete with each other over who could go to the greatest extreme, both in time and expense, to recreate an "authentic" warbird. These collectors increased how much they spend on aircraft, with each year bringing some new development which boosted the cost of restoration. Today collectors rarely spend less than one million dollars to restore a winning fighter plane. Like the CAF and other volunteer-based museums, these wealthy collectors have benefitted greatly from the nonprofit tax deductions. In most cases, they set up a nonprofit museum, which they often control, to which they donate their collection of aircraft. They therefore get to enjoy the aircraft while also receiving deductions for the donation. Further, the museums attract volunteers who help maintain both the facilities and the aircraft.

A few collectors began gathering warbirds in the 1970's, but many of the current collections began in the 1980's and 1990's. Among these are the Lone Star Flight Museum, founded in Galveston, Texas, in 1985; the Cavanaugh Flight Museum, founded in Dallas, Texas, in 1993, Fantasy of Flight Museum, founded in Miami (now in Polk City, Florida, outside of Orlando) in 1985; and the Yanks Air Museum, founded in Chino, CA, sometime in the 1980's. The backgrounds of these collectors are diverse, but most are corporate executives. These collections and many others are located in relatively mild climates and often close to sites where aircraft were produced, but warbirds are based all over the country. In addition to the ones listed above, collections of multiple warbirds exist in Palm Springs,

\footnotetext{
${ }^{19}$ A prominent automobile Concours d'Elegance in the United States occurs each year in Pebble Beach, CA. Its website notes that the term originated in automobile "competitions of excellence" in Paris in the late 1800's (Hawkins on, n.d.). The Pebble Beach competition began in 1950.
} 
CA, Valparaiso, IN, McMinville, OR, Arlington, WA, Sevierville, TN, Norfolk, VA, and Stow, MA.

Kermit Weeks, the founder of "Fantasy of Flight," is perhaps the most visible of these collectors at Airventure. Among the wealthy collectors, he is somewhat atypical because his wealth comes not from being a corporate CEO, but from oil royalties based on his grandfather's explorations in Australia (Farnham 2005). He was a world champion aerobatic pilot before becoming a warbird collector, and his collection of warbirds is the largest outside of the CAF. Many of the planes he has brought to Oshkosh have won awards, in part because he spends a tremendous amount of money having them restored. After they are restored, he takes them to his "Fantasy of Flight" museum in Polk City, FL, where he flies them occasionally. Kermit plans to make the museum itself an important tourist attraction, offering a range of historical exhibits to complement his diverse collection of airplanes.

\section{Collecting Strategies}

These collections may have a selection rationale like the CAF, to collect all historic aircraft from a period, or they may have a more idiosyncratic, personal approach, such as collecting aircraft from the service in which one served. Some collectors purchase only American aircraft as a patriotic stance, while others claim to represent aviation history more broadly by collecting both Allied and Axis aircraft from World War II. Some of these men's collections rarely if ever fly publicly, even if they are kept in a "flyable" state. Others fly only the more common types of aircraft, wary that they might lose the rare ones in some mishap.

The choices that collectors have made in buying warbirds may depend upon the desire for a particular type, but, just as with the volunteer-based museums, the choice may stem from some specific narrative. A plane with a special history might become the center of a collection, as a specially restored, "combat veteran" B-25 "Mitchell" is for the Cavanaugh Museum or the famous Howard Hughes aircraft, the Spruce Goose, is for the Evergreen 
Museum in McMinnville, OR. Finally, a collector might base the collection on some personal tie. One famous collector, David Tallichet, focuses on U.S. Army Air Corps (the wartime precursor to the U.S. Air Force) aircraft because he flew bombers in the Army Air Corps during the war.

If an owner does not choose a specific narrative, he or she may choose "aviation history" as the collection's focus. What counts as historic, however, depends greatly on the point of view of the collector. For example, one airport has two museums, one of which featured a rare aircraft from World War II, while the owner of the other one dismissed that particular type as historically unimportant because, by his estimation, it played no significant role in the war. Thus, for one owner the rarity of the plane made it historic, while the other owner evaluated the role the aircraft played in World War II for its historicity. History also provides a logic for new acquisitions. If a collector with one airplane might choose to expand the collection by acquiring airplanes that somehow relate to or complement that one plane. The owner of a Hawker "Hurricane" might try to purchase a Supermarine "Spitfire" or perhaps a German fighter plane because they were involved in the Battle of Britain.

While all collectors say they seek airplanes out of patriotism and an interest in history, many of them also do so for the adventure of retrieving aircraft. Like the CAF's early adventure stories, the tales these collectors tell reveal the adventure of the retrieval as a primary motivation. One mechanic for a well-known collector, for example, suggested that his boss lived for the search, whether in New Guinea or Alaska, and often grew bored with the aircraft once they were recovered and restored. When the Cold War ended, "aviation archaeologists" swarmed into the former USSR, looking for rare types of aircraft that may have crashed on the Eastern Front and finding a few. The adventure story genre has been extended, then, to searches into other countries. These stories add difficulty of dealing with corrupt officials to the aircraft-recovery-story genre's elements of harsh working conditions, 
rare finds, and technical mastery. The planes pulled out of these crash sites, however, are often in worse condition than the derelict planes found around the United States.

\section{Professional Restoration Shops}

After the adventure of the recovery is over, the wrecks usually go to a professional restoration shop. While volunteer-based museums usually do their own restorations, most of the collectors pay professional restoration shops to rebuild their aircraft. Aircraft maintenance shops have surely existed since the earliest days of aviation, but the emergence of the warbird-specialized shop probably dates to the 1970's, with the expansion of the warbird movement and the decline of the planes' corporate use. Most of the major warbird restoration shops began in the 1970's or later. ${ }^{20}$ In addition to specialization, the work of warbird mechanics has changed as well, with the growth of elite interest, in the emphasis on heritage, and the decline of parts stores.

A few of these shops restore the kind of twisted wreckage that comes from jungle and steppe, but most shops work from worn or derelict airframes that need a lot of cleaning up, repair and replacement. Just as the Airventure and Sun-N-Fun competitions have driven the collectors' efforts in recent years, so they have also affected the professional shops that restore the warbirds. A shop that restores a winning aircraft receives a "Golden Wrench" award, the companion to the "Grand Champion Warbird" award. These awards then become part of the shop's reputation and are prominently advertised. Based partly on these successes, many shops come to specialize in one type of aircraft, such as the AT-6 "Texan" trainer or a P-51 "Mustang" fighter. With this focus, the shop then seeks out all of the spare airframes and parts that it can find. Several different shop owners told me that the sale of

\footnotetext{
${ }^{20}$ For example, Aerotrader in Chino, California began in 1976, Air power Unlimited in Jerome, ID, began in 1988; Tom Reilly's "Bombertown” in Orlando, Florida began in 1971; American Aero Services in New Smyrna, FL, began in 1981, and Gosshawk Unlimited was formed in Mesa, Arizona in 1988.
} 
these spare parts kept the business afloat when work on projects thinned out, as it often does with the vagaries of the stock market. ${ }^{21}$

\section{Wreckage and Parts}

The emergence of these warbird specialty shops has to be the most significant shift in warbird restoration, but beyond this shift, the most important development was the increasing emphasis on mimetic authenticity that came through elite interest in the aircraft. Prior to the rise of the warbird movement, restoration and maintenance of a World War II aircraft meant making an airplane safely flyable, taking off anything unnecessary and adding whatever new components would improve safety or comfort. Mechanics were likely to strip aircraft of their original equipment and upgrade them with new electronics and more comfortable interiors. I mentioned the On-Mark refittings of B-26 "Invaders" above, and they provide an excellent example of this trend. As transport and cargo usages of the aircraft faded, and the warbird movement grew, however, the emphasis on returning aircraft to wartime condition increased. The first step in this movement was the emergence of heritagefocused collections like the CAF, but the CAF took almost a decade even to paint its planes in wartime paint schemes and as late as the mid-70's they were emphasizing that their airplanes had installed the best modern radios in its aircraft (Anonymous 1975: 65-6) . In the early days, it was enough to have a plane understood to be a World War II aircraft, but as wealthy elites became more interested in warbirds, they began to compete with each other on the basis of their planes' authenticity. As the concours d'elegance competitions heated up, the collectors started demanding airplanes that more and more closely resembled the wartime aircraft. This came to mean putting on wartime equipment like guns (legally required to be inoperable), gun sights, and even radios. Today the up-to-date radios and avionics, while legally and practically required, are usually seen as a necessary evil, not a

\footnotetext{
${ }^{21}$ The relationship between the purchase and restoration of warbirds and the economic events affecting elites, such as swings in the stock market, trends in executive compensation, or new tax cuts, would be interesting to explore. I am not sure, however, that reliable and valid data could be gathered because the purchase prices of warbirds are often kept secret.
} 
selling point, of warbirds. A number of expensive restorations have included removable dashboards so that the contemporary equipment can be replaced by wartime period pieces for display at an airshow. Rather than doing anything they can to get the airplane to fly safely and cheaply, many restorers today are expected to go to great lengths to employ as many "authentic" components as possible.

The presence of twisted wreckage in a restoration shop also reflects a shift in warbird restoration. In the 1950's, 60's and 70's, warbird enthusiasts sought out whatever airplanes they could find in decent shape, but the development of the warbird movement saw collectors and museums going to greater lengths to find aircraft, especially rare types of planes of which no flying examples existed. The collectors' interest led them to spend more and more money returning these wrecks to flying condition. Perhaps the most famous example of this is a P-38 "Lightning" fighter plane pulled out of glacial ice in Greenland. The recovery and restoration of "Glacier Girl," as it has been named, received a great deal of publicity, and now the airplane has become a prized act at airshows.

Just as these twisted airframes are returned to new condition, so the supply of World War II surplus parts has had to be supplemented in recent years with newly made parts. Parts have become scarcer and scarcer, so that many components now have to be manufactured. This problem only adds to the cost of restoration (and their capacity for marking the collector as wealthy and conscientious, of course). One restorer, for example, fabricated air vents for a specific medium-sized airplane. The vents were not really needed for normal operation, but without them, the aircraft would not be mimetically authentic. To reproduce them, the shop took molds of old ones and had a run of them made. The final cost, covering materials and labor, came to $\$ 100$ for a small piece of plastic. This example of a minor, inessential component shows how the elite interest in warbirds has greatly increased the value of the airplanes. 


\section{The Mechanics and Others in the Shop}

The people who do this restoration work come from a variety of backgrounds: auto racing, airline or general aviation maintenance, aircraft production, and military air crews. While many had extensive experience with aircraft maintenance, others came only with knowledge of similar mechanical structures. Those new to aircraft could perform functions like sheet metal work, for example, but would need a great deal of training before tackling complicated repair tasks. Even those coming from an aviation background might have little experience with piston engines or with parts overhaul. Many brought knowledge of general aviation aircraft, which transferred to warbirds quite easily. In many ways general aviation airplanes built during and since World War II are simply smaller versions of warbirds. They still use the same leaded aviation gasoline and similar construction techniques. General aviation planes are different, however, in that they are much smaller scale than warbirds, in size, power and speed. Thus, a mechanic with a great deal of general aviation experience often can work on warbirds. A smaller group of people in the shop have extensive experience only with warbirds, either because they worked on them during the war or because they happened to be trained in a warbird shop. This group obviously is much smaller than the others, but was especially the case at a place like Chino, CA, a center of warbird aviation where a generation of "Chino kids" were raised. These young men grew up around the Planes of Fame museum and the other warbird restoration shops there. While this latter group may not have the training that the earlier group does, a few of them have become able mechanics, building on their experience with other machines.

In addition to those mechanics who "turn wrenches" on engines and form sheet metal parts, a shop requires other experts to function. Several shops I visited had a parts expert, for example, a person who worked the phone trying to track down parts, oversaw the shop's parts inventories, and cleaned and refurbished those spares. One shop had a resident artist who painted the nose art and also made a variety of warbird paraphernalia, like leather 
jackets with nose art on the back and surplus dummy bombs with some World War II design on them. Another important figure was devoted to manufacturing the plexiglass cockpit canopies and gun turret bubbles for warbirds. These plastic pieces have yellowed with age over the years, when they haven't been cracked or destroyed entirely.

If a shop did not have these specific experts, they had to send the work out to other specialized shops. The most important outside specialists dealt with engines, engine accessories (like carburetors) and propellers, but many others played some role in the creation of parts. Some metal parts, for example, are standard aircraft elements that a company might sell to any aircraft producer or repairer, or even to a non-aircraft business. The metal extrusions used in wing structures, for example, might be standard pieces out of an aluminum supply catalog. The aluminum sheets used to skin aircraft might also be standard. In this case, however, the restorers sometimes run into difficulty in converting the metallurgical classifications of World War II to metals available today.

In addition to these experts, warbird restoration sometimes requires the white collar expertise of engineers, such as when a part has to be manufactured or an undocumented modification has to be made or simply evaluated. For example, a mechanic at a CAF Wing unit accidently cut deeply into a tail spar when he was grinding away corrosion. Upon seeing the deep gouge, the head mechanic stopped work on the area until he could get an engineer's evaluation of whether the cut would compromise the tail's structural integrity. He sent digital pictures to an engineer with familiarity with the airplane, who after a few days determined that the gouge did not pose a structural threat. In another case, a shop decided to get engineering approval for a process to overhaul a propeller, and they had to go through several iterations of special heat treatments to get the appropriate strength and hardness for the blade. Finally, another shop sought an engineer's approval to use a wing spar made out of a different grade of aluminum than that called for in the airplane's original specification. They had to change grades because the specified one was no longer available. 
Given all of these expertise inputs to the restoration hangar, we have to note that expertise also flows out from the restorers, and not just in the material form of the aircraft themselves. The mechanics and the owners of these shops operate as vital relays for information within the warbird world. Restorers attend the annual National Warbird Operators' Conference and the specialized warbird forums at Airventure, offering their advice and experience on topics for discussion. In addition, they serve as an informational resource, taking calls from plane owners who have questions about general maintenance or about some specific procedure they have to perform. This sharing represents yet another linkage between the various hangars of the warbird world. Now that we have spent some time exploring each of these different kinds of actors in the warbird movement, I will turn to explore explicitly the twin sites of warbird activity: the hangar and the airshow.

\section{The Hangar}

The hangar is where all of the restoration and maintenance of aircraft occurs. While the public face of the warbird movement is mostly the airshow, the hangar is where that public face is made possible. Both sites are necessary research sites, then, and for this project I spent several months each in a CAF unit's hangar and a restoration shop's hangar. I also visited a variety of other museum and restoration hangars. I draw on these experiences to offer a quick sketch and comparison of the CAF and restoration shop's hangars, with some additional discussion of a wealthy collector's museum hangar.

A restoration shop's hangar at first seems to have more of a business focus than the CAF hangars. The shop's hangar is filled with dusty spare parts, specially-made jigs to hold aircraft wings or fuselages, machine tools, and gleaming, half-formed airplanes. Most shops need to be able to rehabilitate old parts, fabricate new parts, test old or new-made components, and perform checkups on airplane systems. Thus, the space of a shop has to be apportioned between these different processes. The bulk of hangar space has to go to the airplanes themselves, but room also has to be made for office space, for machine tools, for 
hand tool storage (the domain of individual mechanics being partly defined by where their tool box stands), for specific overhaul tasks (like a test stand for various hydraulic systems, or a test bench for electrical systems), and for paint stripping/parts cleaning. The workspace is picked up at the end of each day and carefully cleaned each week. Their workers all have extensive skills, or are being apprentice-trained into such skills. The offices and break rooms provide plenty of display space for important warbird symbols: warbird calendars and posters, mementos of airshows and special performances, and awards won.

The hangars of museums like a CAF Wing are quite similar to restoration shops, if a little shabbier. The volunteers are perhaps less devoted to daily cleaning than the paid mechanics, and donations of all kinds, though usually war-related, tend to accumulate in open spaces. The aircraft and their parts may or may not be well-organized, but each aircraft has a space reserved for it. The mechanics for a specific plane manage to mark off their space, but unlike the restoration shop mechanics who can move from plane to plane, marking their presence with their tool box, museum mechanics tend to focus on specific aircraft (though they, too, might mark their presence with a tool box). The tools and equipment are older and of lower quality than in the professional shops, often because they, too, were donated. Unlike the shops, museums have to offer tours, so some provision is made for outsiders to walk through the space, which usually means some informational placards will be arrayed near the aircraft. Sometimes small exhibits describe the ongoing work and ask for donations. The mechanics one finds at these museums include some highly-skilled gray eminences, often retirees, and a variety of others with much less experience, or even no experience, like myself. While the restoration shop workers engaged in a not-quite steady stream of banter, they rarely stopped to have any kind of discussion. The museum hangar, on the other hand, frequently saw long discussions of planes, wives, and politics. In lieu of the shops' collection of awards and trophies, the museum has placards honoring donors and 
especially diligent volunteers, along with pictures of the museum's own aircraft or of any World War II aircraft.

Amongst the donations of World War II memorabilia, office equipment, and furniture, museums receive many spare parts that they may or may not need for their aircraft. These parts clutter up the hangar or storage space until someone can sort through them. They do retain parts that are not immediately useful, however, and not merely because of a hoarding desire or aesthetic taste for old clutter. Parts that could be safely used, called "serviceable" parts, can be traded to other warbird museums or shops. This barter serves the warbird world well, especially when the institutions are rich in old parts and poor in ready cash.

One might think that a business's space, on the other hand, would seem to be at a premium, preventing them from holding large quantities of random parts. In reality, however, the restoration shops, too, collect all kinds of warbird detritus in the hope that it will be useful, salable, or tradeable in the future. Thus, the warbird shops I visited had extensive stocks of spare parts and assorted hardware in various conditions. In this business a twisted wreck that was good only for scrap 20 years ago can now provide the basis of a highly profitable rebuild. Like many museums, therefore, warbird shops have a back yard filled with warbird wrecks in varying states of wholeness and decay. Warbird magazines occasionally have articles exploring such parts stores, highlighting rare airframes or shelves filled with hard-to-find, dusty parts.

The space within a shop or museum is apportioned by the kind of work performed there, by the personality/authority of the person who works there, and by the project underway. The different kinds of work in which a shop, and sometimes a museum, might engage include a full-up, long term restoration, major repair and replacement of important components, minor repair, parts manufacture and/or overhaul, annual inspections, and FAA Airworthiness Directive (AD) inspections. The parts business takes many forms, from 
refurbishing aged stocks of an important part or component to cleaning and inspecting original parts to overhauling parts pulled off of an airplane to manufacturing new parts for an airplane. New parts are manufactured either as a one-off job for a specific project or for a specific project plus several more on speculation that they will be salable in the future at a profit.

In general, projects have their own workspace, and new projects, at least ones of any significant length, will not be initiated without sufficient space. With restoration shops and museums alike, the space apportioned to a project can indicate its status. If the project is generating a great deal of revenue or, for the museum, is making great progress based on volunteer workers and ready funding, then it will be allowed to take up more space. If it is idle, or nearly idle, it will be packed in as tightly as possible, or even placed outside. The project will remain visible, however, as will the supply of spare parts. Projects and spare parts have both practical and a symbolic spatial presences. A large store of parts or project airframes can serve as a display of wealth and can reflect the shop's capacity to serve many different needs, the owner's efforts (and business sense in securing a store of rare parts), and financial stability (given the investment in parts).

One major contrast between museums and restoration shops lies in the duration of the work. Restoration shops, operating each workday with expert, paid labor and using newer equipment, tend to move much faster than a museum might when restoring an aircraft. Even still, a major restoration can take several years at a shop. Once a shop finishes the restoration, however, the plane leaves, often never to return. The plane circulates in the warbird world, and if the restoration was well executed, it will spread the fame of the shop. For museums, however, the plane stays around. The museum mechanics who performed the restoration, then, often continue to maintain it, developing an intimate relationship with the aircraft. These planes do circulate as well, by attending airshows, but they always return, unless they crash or are sold or deaccessioned. 
Thus far, I have explored the contrasts between a CAF museum hangar and a professional restoration shop's hangar, but the third major term here is the wealthy collector's museum. Some of these collectors' hangars do house restoration efforts because not all of the collectors' airplanes are sent out to professional restoration shops. For the most part, however, these hangars devote their space to displays of the aircraft and other collected artifacts. The display space may bear some similarity to the displays in a volunteer-based museum, but often they are much cleaner and more orderly. Since they are a direct representation of the founder's taste and dedication, they frequently have new, attractive buildings, sparkling airplanes, and skilled mechanics. Display spaces are often clean and separate from work space, where they are often mixed in a volunteer-based museum's hangar.

Both volunteer-based and collectors' museums include a variety of other artifacts, some aviation-related and some not. A few collectors' museums adopt a general transportation theme, which allows the owner to exhibit other "rich man's toys" along with the exotic airplanes. For example, the War Eagles Museum in Tucumcari, NM, includes a variety of antique automobiles in its collection. The Cavanaugh Flight Museum in Dallas, TX, houses not only rare warbirds and a few aircraft borrowed from the United States Air Force Museum, but also the owner's aerobatic plane, his executive jet, and his sports car collection. Other museums extend collections only into war or aviation-related items. Probably every CAF unit that has aircraft on public exhibit includes a collection of World War II artifacts that have been donated to them. The owners of these artifacts apparently regard the CAF (and probably any other warbird museum) as good stewards of such war detritus as uniforms, guns, field tools, tents, rations, and various equipment. While wealthy collectors tend not to go in for exhibits of many artifacts, they do include a few selected items (sometimes branching out into aviation more generally). They often include World War II vehicles and usually some plastic or wooden models of aircraft (an easy way to depict 
aircraft that are too rare to find). A surprising number of collectors' museums have an extensive exhibit of World War II aviation-themed, realist art. This field has expanded greatly in recent decades, partaking of the same kind of reductive authenticity that characterizes much warbird collecting. For the art, authenticity means accuracy in depicting specific events and places, with the proper paint schemes, the properly identified participants, and even the exact background for the depicted event. Despite the great deal of effort that museums devote to these displays, they will always remain secondary to the work to get airplanes into flying condition.

\section{The Airshow}

All of the work in a warbird hangar takes place so that the airplanes can fly at airshows, where, according to the crews, the general public will be able to experience what the airplane was like and perhaps learn about World War II in the process. Airshows aim to be family-oriented, military-themed festivals, featuring not only flying demonstrations, but festival food, aviation and military souvenirs, toys, children's activities, and aircraft tours. They are surprisingly popular events; in 1993 (an admittedly dated statistic) they were second only to baseball games in attendance (Kate 1993). Airshows vary in type, but most mediumsized or larger shows today feature at least one warbird, and many shows focus specifically on warbirds. The major emphasis of the shows in the celebration of aviation, especially military aviation. They cultivate a taste for airplanes in their various forms, from the oldest civilian planes to the most recent military aircraft and helicopters. Airshows are not, however, the only places to see old aircraft. Many aircraft, especially military aircraft, exist in museums scattered around the country, but they do not fly.

\section{The Living and the Dead}

Warbird afficionados argue that their aircraft are "living" aircraft, in contrast to the "dead" aircraft on static display in these other museums. Warbird museums and owners fly their planes for fun and for spectacle, exhibiting for the public what the aircraft look, smell, 
feel and sound like through guided tours and aerial performances. Many aviation museums, however, never fly their aircraft. These "static" museums, the most famous in the United States being the Smithsonian's National Air \& Space Museum and the U.S. Air Force Museum, believe that their aircraft are too historic to risk destruction in a crash. The crash risk is very real because several warbirds crash each year, often destroying the airplane. The CAF, for example, developed a reputation for carelessness in its first decades because it crashed and destroyed so many aircraft. When the CAF lost three aircraft in 2004, they stopped all flying in order to hold special safety education classes for its pilots. Even Planes of Fame, which had not lost a plane in decades, had one of its fighter planes crash in the fall of 2005. These crashes not only have led to an increase in safety discussions at warbird gatherings, but they have also cemented the view of the static museums that historic airplanes are best preserved by not flying them.

The wear and tear of operation also expends the aircraft as an historic artifact, not least because parts have to be replaced to ensure safe operation. The advent of extensive, like-new restorations of warbirds have gone further to distance the warbird museums from the static museums. The curators at the Smithsonian, for example, have developed the reputation for carefully preserving as much of the original aircraft as possible. The Smithsonian National Air \& Space Museum's exhibition of the Wright Flyer, installed for the $100^{\text {th }}$ anniversary of the first flight, highlights not only the framework of the original aircraft, but also a piece of the original fabric. Warbird museums, however, balance the concern for preserving those original pieces with the mandate that the planes fly. They therefore tend more toward a mimetic authenticity, preserving not the original pieces but the original form, including new parts whenever necessary to make the plane fly safely. These differences in approach have a variety of implications, but for our purposes here, the major implication is that warbirds fly in airshows, and static exhibits do not. 


\section{Constituting the Warbird Movement}

While airshows allow the aircraft to be "alive," they also serve to constitute the warbird movement itself. They have been fora for the assembly of the warbird movement, its ongoing elaboration and recruitment, and its fund-raising. Airshows featuring military aircraft long predate the warbird movement, but the earliest warbird appearances at airshows were the CAF's attendance at nearby military airshows. They performed aerobatics and staged small air races for the public and received such a positive response from the crowd that they became interested in participating in more shows. These shows encouraged the CAF to expand and spread its fame, and by 1963, the CAF held its own airshow, the first allwarbird show. The Air Museum/Planes of Fame started flying at airshows in 1961, the year after the CAF's first appearance. As I mentioned earlier, air racing resumed n 1964 at Stead Field, near Reno, NV, and World War II warplanes were the stars. The Warbirds of America organization grew out of these air races, as did the specialized use of the term "warbird" to refer to World War II warplanes, according to an amateur warbird historian I interviewed. Since those early shows, warbirds have appeared at hundreds of shows per year, and a number of warbird-focused shows have developed.

In addition to this constitutive role, airshows have become financially important for the warbird movement. While some collectors happily fund the museums out of their own wealth, many others seek to make the collections self-supporting through donations and fees for airshow appearances. At any given airshow, local planes will appear, often for a fee but sometimes offering paid tours for the public. Sometimes a large show will hire a professional warbird performer to appear at a show. These performers offer their services at the International Council of Air Shows convention, which is held each winter and where airshow planners go to attend how-to seminars and to book performers.

In addition to these booked appearances at shows, a few museums send their aircraft on tour each summer, scheduling stops in mid-sized cities where they can sell rides to the 
public to recoup the costs of operating the planes. They use local news coverage to encourage weekday crowds to visit the planes. The most prominent touring planes are a B-17 bomber and a B-24 bomber from the collection of Robert Collings but operated by the Collings Foundation, based in Stow, MA. The CAF's B-29 and B-24 bombers are also an important touring duo, especially given the fame/infamy of the B-29 "Superfortress" — the type of plane that dropped the two atomic bombs on Japan — and the plane's status as the sole flyable example of the type. These tours, like airshow appearances, provide critical funding for the support of the aircraft and the museum organization.

\section{An Overview of Airshows}

Several different kinds of airshows exist, and as I mentioned above, most include some kind of warbird. The biggest shows, aside from EAA's Airventure, are the military airshows, usually hosted at various U.S. Air Force Bases or Naval Air Stations. Other major shows are held just offshore, as with the U.S. Navy's "Fleet Week" in San Francisco or the Chicago Air and Sea show. These large shows often attract hundreds of thousands of people and mostly feature current military aircraft, plus a variety of other acts, including parachute teams, warbirds, aerobatic teams, jet trucks, and gliders. The stars of the show are the current military planes, usually a specially trained demonstration team flying six or more jets in various difficult formations. Often these performances are supplemented with a warbird performance, which serves as an historical background for the contemporary planes. Before these acts the other kinds of performers entertain the crowd, while many mill amongst the planes parked for static display, the military recruitment booths, the food vendors, and the other family activities.

Vintage aircraft shows are usually much smaller and feature historic aircraft from many different eras. They often include a concours d'elegance competition for different categories. For example, the 2005 Watsonville, CA, Fly-In and Airshow featured awards sorted by different "ages" of aircraft ("Pioneer through 1927", "Golden Age 1928-1935," 
“Classic Age 1936-1945," and "Neo-Classic 1946-1955"), different manufacturers (Cessnas, Pipers, Aeroncas, and so on), various categories of World War II and postwar military types (fighter, liaison, trainer, bomber), and "homebuilt" aircraft (Anonymous 2005a). The owners of the vintage, non-warbird aircraft often restore their aircraft as painstakingly as the warbird owners, though with much less expense, due to the size of the aircraft. Local EAA units often host these shows, and they include at least a few warbirds, as the military class of awards suggests. These shows generally feature fly-bys of the major types of plane, plus aerobatics and other entertainments. Warbird-specific airshows, on the other hand, often include reenactments of battles and camp life, attendance of vintage military vehicles, and seminars featuring famous veterans. Wwarbird museums usually host these shows, and thay draw participating aircraft from a variety of other museums. Finally, a variety of small, local airshows occur each year, usually featuring planes based at that particular airport. If these shows have warbirds, they will often have only one or two, and often these will be some kind of military trainer, the smaller and lower status (within the warbird world) kinds of warbirds.

\section{Airshow Spaces}

Given this diversity of types, one cannot easily summarize all of their layouts and sequences, but I will use as my template one of the largest shows, the Joint Services Open House, held each May at Andrews Air Force Base, just outside of Washington, DC. Most airshows have some variation of this structure and schedule. The space of the show divides into three areas: the exhibition area, the hot ramp, and the active runways and taxiways. While most shows have on-site parking, since 9/11 the Andrews show has required people to park far away and be bussed to the show. The busses drop crowds off at two ends of a long stretch of pavement where the static aircraft and exhibits are located. Within the exhibition area, the planes are scattered, with the largest cargo, air refueling, and airborne radar planes grouped at one end, and the large bombers and secret planes (stealth and reconnaissance) at the other. The warbirds are often parked together, as are the Naval aircraft 
and the various types of transport planes. To one side are sets of hangars filled with information booths about various specialized groups within the military, civic organizations, and some aircraft. Next to these hangars a number of ground vehicles are parked, including tanks, troop transports and artillery. The exhibition area is enclosed by plastic fencing and goes up to the edge of an active taxiway, along which planes taxi to and from the runway. The "hot ramp" is at one end of the exhibition area, beyond the bus drop-off spot. Air crews prepare planes here for their performances, and often two of each type of aircraft attend, in case one has some difficulty. While most aircraft start up here, the stars of the show start in full view of the crowd. At the Andrews show, the stars are one of the military demonstration teams, usually the U.S. Air Force's Thunderbirds or the U.S. Navy's Blue Angels, though sometimes the Canadian Air Force's Snow Birds are the featured act. These planes are prepared and started in a strict ritual, with dramatic gestures for the crowd (though they do perform all of the preflight checks that would occur for any flight). The start occurs just beyond the active taxiway at the front of the exhibition area. The performances then take place on and over the runway, though sometimes planes sneak behind the crowd to fly loudly overhead and catch everyone by surprise. All performances take place within a specified, FAA-cleared airspace. Different kinds of performers have different sizes of "boxes," giving them ample, three-dimensional space for all of their maneuvers. With the exception of the surprise fly-over, the aircraft must never fly over or toward the crowd in case some mishap causes a crash. I saw at least one performer who was forced to land immediately after breaking this rule.

The sense of guarded, protected spaces, therefore, is central to the organization of airshows. In addition to the airshow "box" in the air, the base itself is closely guarded and the crowd contained within the exhibition area. If high-profile aircraft attend, they often are roped off from the crowd. I have seen different planes roped off, including the stealth fighter and bomber, the U-2 and SR-71 reconnaissance planes, the B-52 and B-1 bombers, and the 
new F-18F and F-22 fighter planes. These areas may be patrolled by armed guards and dogs. The final protected space is the symbolically produced space of the nation, which is guarded by the lethal airplanes on exhibit at the show. The show narrators frequently invoke the nation as the entity which the planes fly to protect, though this discourse also invokes disembodied concepts like "freedom" as requiring the protection of the aircraft.

Within this guarded space, however, the crowd is supposed to have fun. The food booths generally line the area just behind the seating areas for show-watching. Most shows have a children's play area, with various kinds of amusement, like a "moon-bounce." Big show may even have small theme-park rides set up. Children are also expected to move throughout the exhibition area, however, and to peek inside of the planes's cockpits and interiors. Souvenir vendors, whose booths are often next to the food booths, target children as well, though one could argue that their prime customers are the grown men in superabundance at the show.

\section{Performances}

The schedule of performances builds up to the grand finale, which at the big shows will be the military demonstration teams. Roughly, the performances of any airshow begin with low key acts, such as aerobatics or remote controlled model airplanes. The show will "officially" open with the singing of the national anthem, usually timed with a parachutist displaying the U.S. flag. Following this opening, shows vary in what they present depending on the type of show. All shows have aerobatic performers; most have some kind of parachutist performance; and all but the smaller or specifically vintage shows have some kind of current military aircraft demonstration. Wing-walkers appear frequently, as do gliders, which are usually accompanied by mellow music as a counterpoint to the rest of the day's noise. Big shows often include non-flying performances to excite the crowds, and jetpowered cars or trucks and monster trucks crushing cars are common. All shows include a narrator who uses a booming, radio-announcer-style voice to fill in spaces between 
performers with trivia, anecdotes, and patriotic urgings. Amidst this diversity of entertainment, the major performances are the military flight demonstrations, including the heritage flight, and the reenactments of battles.

\section{Military Demonstrations}

Each service provides demonstrations of its individual aircraft, with the main fighter planes and helicopters having dedicated teams for shows in the East and in the West. The Air Force tours its A-10, F-15, and F-16 fighter planes, as well as its C-17 cargo plane, each with its own narration and an elaborate program. It also provides fly-bys of the F-117 stealth fighter, and the B-1, B-2, and B-52 bombers. The Navy tours its F-14 (though it will be retired in 2006), and variants of its F-18 fighters, occasionally adding a performance of a P-3 submarine warfare plane or an E-2 airborne radar plane. The Marines demonstrate their Harrier jump jet, always a crowd favorite because of its ability to hover and to take off and land vertically, and occasionally perform their helicopters. The Army flies much less frequently, but does do demonstrations with its Apache attack helicopter and variants of its Blackhawk helicopter. If the show takes place at a military base, the services may demonstrate the aircraft that are based there. At Oceana Naval Air Station, for example, they do a "Fleet Fly-By" formation of the fighter planes based there. At the Edwards Air Force Base show, they fly many of the experimental aircraft based there.

The extent of the performance varies greatly. Some fly-bys are only that, a plane flying by once, with some description from the announcer. Other planes fly by from different directions, giving different views of the aircraft, and these often end with the narrator urging the crowd to catch the special "photo pass" on film. The flight demonstrations are much more elaborate, involving a set of specific maneuvers designed to show the plane's abilities. For fighters, these involve slow and high speed maneuvers, maneuvers with high "g" force, ${ }^{22}$

\footnotetext{
22" G" force is a term for the force exerted on the pilot and the airplane during especially tight, accelerating maneuvers. Each " $G$ " is one times the force of the earth's gravity, so a " 9 ' $G$ ' turn" exerts nine times the force of gravity on the pilot. Such maneuvers require extraordinary physical exertion and threaten to make the pilot pass out because the force of acceleration pushes his blood to his legs.
} 
aerobatic maneuvers, vertical climbs, and even simulated combat maneuvers. The announcer plays a critical role in these performances, helping create a combat imaginary for the public. The announcer explains that the aerobatic maneuvers are similar to those used in dogfighting, and emphasizes that the tight, "high g" turns would help the plane gain a superior position on its competitors. The narration mixes this combat imagery with descriptions of the plane's power and speed. With the addition of synchronized pyrotechnics, the performance becomes a spectacle of technological prowess. The narrator may add mention of recent or ongoing combat actions, seeking to tie this spectacle to geopolitics.

In addition to these performances of prowess, most major airshows now have either an Air Force Heritage Flight or a Navy Tailhook Legacy Flight to link past and present machines together in what they hope to be a history lesson. In these performances, warbirds fly in formation with contemporary fighters. These flights came about during the $50^{\text {th }}$ anniversary celebrations for World War II when the Air Force recruited a few skilled warbird pilots to fly with their fighters. The program worked well enough that the Air Force institutionalized it, and the Navy followed suit with its Legacy program. They rely on a few prominent warbird pilots to run the recruitment and training for the warbird pilots. (So far this seems to be only fighters and not bombers, although they have started a trainer heritage flight using the old AT-6 Texan and the new T-6 Texan II.) Normally these flights take place after a demonstration by one of the types and before the demonstration of the other.

\section{Warbirds and Reenactments}

At the major military shows, the warbird portion of the performance is usually limited to a brief demonstration and the Heritage Flight. For the demonstrations, the planes make several passes while the narrator describes them. Warbird-specific shows, however, attract enough warbirds to present a broader retrospective of World War II aircraft. These shows often present the planes in groups sorted by type, by theater, or by period of the war. At a very few shows, these groupings are elaborated into a kind of reenactment of the war, 
featuring special pyrotechnic displays. These reenactments are the most dramatic warbird performances, but a few airshows also feature contemporary military aircraft performing, if not reenactments, then imaginings of wartime or emergency situations.

Warbird demonstrations usually focus on one plane at a time, with the plane starting up, taxiing and taking off in front of the crowd. The narrator offers details on the development of the plane, its technical specifications, its relation to other aircraft, its importance to the war effort, and perhaps some anecdotes about famous battles or pilots. Like the contemporary military demonstrations, the plane passes from different directions, ending with a "photo pass." Often this demonstration segues into the Heritage Flight, with the warbird joining a contemporary military jet for another series of passes.

The warbird-specific shows rarely emphasize just one aircraft. These shows typically fly the planes first according to type, usually putting up the smallest liaison and observation aircraft, then the trainers, then moving progressively through the war or moving between the different services and by type, for example, flying the Navy planes together, then launching the Army Air Corps (the Air Force became a separate service only after the war) bombers, followed by the fighters. The standard practice involves the warbirds flying a set circuit in front of the crowd, in an oval, racetrack pattern. The altitudes and size of the pattern vary according to the type and the type's cruising speed, with the smallest and slowest flying the lowest and shortest patterns. At a big show like Oshkosh, the trainers may fly over in large formations instead of flying the oval pattern, since thirty or more aircraft may attend. The combat aircraft remain in a racetrack pattern, deviating only to launch simulated "attacks." These attacks adds pyrotechnics synchronized with the aircraft's passage in front of the crowd. These pyrotechnics are bladders of gasoline and other chemicals, ignited at a specific time and in a specific pattern to simulate the impact of different types of munitions. The bombers run "bombing" missions, opening their bomb bay doors in sync with explosions on the ground. While they do this, the fighter planes fly well above them, pretending to be 
"fighter cover" for the bombers. Once the bombers have made their runs, the fighters come down for "strafing" runs, synched with small explosions simulating bullet impacts on the ground. After the pyrotechnics are over, the combat aircraft alter their circuit, shifting the racetrack oval so that instead of circling in front of the crowd, they go in front of and behind the crowd. This pattern allows them to make "photo passes" for the crowd in which they come from the right or the left (always the same direction for a particular show), banking the top of their craft towards the audience so that they get a view of the top.

The ideal in all warbird displays is to get as many warbirds as possible into the air. All warbird afficionados I met shared this desire for quantity, and they usually linked this desire, wistfully, to the great quantity of aircraft that flew on missions in World War II. They wanted to have some idea, some experience, that approximated those World War II missions. An important criterion of any warbird show is how many warbirds were there, including both the variety of types and the number of a particular type. Any coverage of a warbird event will include mention of just how many of a particular type flew, especially if the number was unusually high. In recent years, there have been the airshows or events featuring one specific type of warbird, including the "Gathering of Corsairs," "the Gathering of Mustangs," and an annual "Doolittle Raiders Reunion," which attracted as many as twelve B-25's. When I asked why having so many B-25's was significant, one pilot and restorer of B-25's said that it approximated, if only for a moment, the wartime missions. At the Wings over Houston airshow in 2001, the organizers staged a mass flyover of warbirds, putting everything into the air at once, in multiple streams (staggered by altitude), with the aim that they would all be nearly overhead at once.

This desire to represent the war through quantity is occasionally supplemented with attempts to simulate the very events of the war. While all warbird shows use a racetrack pattern display, a few create elaborate reenactments of World War II. These performances, with the CAF's Tora Tora Tora being the most famous, use narration, selection of particular 
warbird types, and special pyrotechnics and flying patterns to mimic several of World War II's famous battles. Some airshows include World War II reenactors on the ground. The aircraft flying overhead may or may not be tied to ground reenactments. The "bombing" and the "strafing runs" may also figure into the ground reenactment with Axis troops feigning losses (the overall message of the performance emphasizing the importance of Allied air power).

Reenactments are not limited to warbird performances, however. Dogfights like the ones in Tora are features at a range of shows, as long as two well-known adversaries are present. If an airshow has an American or British jet warbird and a Soviet one, they frequently will put on a dogfight performance. In these performances, the planes begin separated or with the Soviet Mig in a position of advantage. They then make multiple circuits in front of the crowd, slowly changing position so that in the end, the American plane "shoots down" the Mig.

\section{Aircraft Tours}

Most performances take place in the afternoon, leaving the morning for the crowds to tour through parked aircraft. These tours offer them the chance to interact with pilots and crew of the planes and to learn from the object itself. For many of the crews, these tours can be the most engaging and the most trying aspects of the airshow. They both enjoy the knowledgeable members of the public and get annoyed by the disrespectful and arrogant ones. For warbirds, the tours emphasize history, while tours the contemporary military aircraft seek to build public interest in the aircraft and goodwill toward the military.

Most military planes are open to some form of public inspection. The cargo planes open up so crowds can be awed by their cavernous interiors. The bombers sometimes open their bomb bays, and the fighter planes' cockpits are frequently open for a peek. Some planes are roped off, as I mentioned, and these usually feature a pilot or ground crew member who will answer any questions the crowd might have. Some airshows feature mockups of 
proposed or prototype aircraft - such as a pair of proposed "uninhabited combat air vehicles" I saw at a May 2005 Langley Air Force Base show. These exhibits aim to teach the public about the program to gain its support. All of the planes, military and warbird, include placards with some amount of information about the plane.

The warbirds usually park together, and if enough of them are present, they may park according to size and type. The crowds are then free to roam the lines of planes, comparing different models and different paint schemes. The crowds come with varying degrees of knowledge about the aircraft. As they look a single plane over, they might describe the type's wartime history, the postwar owners of the airplane, the models they built as a child, or the subtle modifications made to this particular version. Others do not try to demonstrate expertise and simply try to learn from the object itself, commenting on its size or novel shape, for example.

The larger planes usually charge admission to their aircraft, which is an important source of funds for many museums. Many planes also include their own souvenir stand, selling aviation-themed toys, hats, pins and shirts. The tour always involves a look into the cockpit, which requires walking through the larger planes or taking a stair up to the wing for the smaller fighters. The crowds move through in orderly fashion, and children tend to stop and pose for pictures in similar places, such as looking out the window or pretending to fire a waist gun. Visitors often ask similar questions about what the plane is, what it did during the war, how fast it can go, and whether it was involved in any fighting. Some will claim to have flown it, or flown in it, though the plane crews say that some of these individuals are just posturing and do not know what they're talking about.

As this criticism suggests, the crew members are ambivalent about interactions with the public. On the one hand, the purpose of coming to the show is to "educate" the populace about the planes, but on the other hand, people ask silly questions, falsely claim experience with the plane, and even poke and prod the aircraft. They enjoy having children come 
through, but they do not like kids to play on the airplane. Veterans, on the other hand, are received warmly. Encounters with veterans during these tours provide the most emotional and satisfying experience for many crew members. Almost every crewmember with whom I spoke related some favorite story that a veteran had shared with them, and this aspect of the experience often seemed to be the most rewarding.

\section{Audiences}

Airshow audiences vary widely but are dominated by men, which is no surprise, since both war and machines are so heavily gendered in Euro-American cultures. While I have not be able systematically to study the question, in the dozens of airshows I have attended, I very rarely saw women unaccompanied by a male counterpart. Men attend with their friends, children, families, girlfriends, and fathers. Many men are current or former military members, displaying the tools of their military life to their families, while others merely describe the planes that they know from childhood model-building, from war books or movies, or from other experiences. This sharing of knowledge seems to be the predominant activity at airshows, as the men narrate the planes for their friends and family. They often come to see their favorite aircraft, about which they offer details of its history or its operation. The other demographics of airshows are somewhat more diverse than gender. At big military airshows, the crowds reflect the ethnic diversity of the military, while in my experience the smaller shows are predominantly white.

Airshows are marketed as, and often become, family events. Many exhibits, from aircraft tours to souvenir stands to food booths, are structured for children. The tours of helicopter transports offer a machine gun which children take turns pointing toward the crowd, posing for a picture. Near the moon bounce an area has been set aside for children to sit in carts designed to look like the various military aircraft in attendance. The souvenirs sold include not only pins and posters but also plastic models and inflatable airplanes. The 
food includes all of the festival favorites: pizza, lemonade, funnel cakes, burgers, and lemonade.

As with any recreational event in the United States, photography plays an important role. Many want to capture all of the major events, shooting photos of the aircraft as they start up on the "hot ramp," getting the best angles they can for capturing the fly-bys (which often include a "photo pass"), and getting all angles of the planes on static display. Many reserve seating by the flight line in order to get unobstructed views. The announcers build on the feeling that the events are historic and therefore photo-worthy, describing the special skill, importance or rarity of each performance. Airshows attract a range of professional photographers as well, and many shows, especially warbird shows, include at least one company which will create a special video of that specific show. Aside from the professional photographers, perhaps the most avid film-shooters are the warbird enthusiasts who come to important warbird shows.

\section{Enthusiasts}

Warbird enthusiasts constitute a special class of audience member. These men - I have never heard of a female enthusiast - follow warbirds as a hobby, not necessarily working on or flying the aircraft, but joining the various warbird organizations in order to have some connection to the planes. They come to airshows both because they love seeing and hearing the aircraft and because they want to see the latest aircraft. Some spent time in the military, while others did not; some are retired, while others still work; and only some are pilots, though they do not fly warbirds. Most of these men track the airplanes they know about and, especially, the ones they have seen. One retiree enthusiast, for example, spoke of his "life list" of plane types and example that he had seen. Such lists give the enthusiast reason to continue going to airshows so that he might see a newly restored airplane, a new paint scheme, a new type of performance, or an entirely new type of airframe. 
In recent years they have developed an extensive presence on the Internet, creating website databases of all warbirds, posting messages on several different message boards and in type-specific newsgroups, and exchanging pictures of airshows and museum visits. Websites like www.warbirdinformationexchange.org or www.flypast.org offer fora for these enthusiasts to meet, to share rumors of new airplanes found, new restorations undertaken, or planes sold. They praise their favorite types of planes or favorite restorations and not infrequently chide others who prefer different types or criticize warbird organizations for safety infractions, exclusions of enthusiasts, or mismanagement.

Despite this extensive online presence and interaction, they predominantly encounter the planes at airshows, where they join others in inspecting and learning about the aircraft present. They especially gather at the largest warbird airshows. I joined a group of them in the days before the CAF's 2001 airshow in Midland, TX. I had come early to the CAF's headquarters to meet the permanent staff of the CAF, while they had come to watch the planes slowly arrive from the various units around country. They used a special radio to listen to communications between the incoming aircraft and air traffic control, announcing the arrival of each example. They speculated about which aircraft would be coming, and when. The fickleness of old airplanes and the rush to complete a restoration or overhaul for the big show created some suspense about which planes might appear. They passed the time between arrivals talking of warbird collectors, restorations underway, past airshows or significant events in warbird history. Given the variety of the warbird movement, they never ran out of topics for discussion.

\section{Warbirders and Warbirding}

While these enthusiasts may outstrip other warbird afficionados in their zeal, with the possible exception of the pilots, I would argue that they share enough characteristics with the other people active in the warbird movement to justify speaking of them collectively, as "warbirders." These individuals all share in the major contexts of the warbird movement, 
the hangar and the airshow, and they also share both discourses and practices relating to the aircraft. In the early days of the movement, we might fairly have distinguished the activities of the Confederate Air Force, Warbirds of America, and the Air Museum/Planes of Fame. While all dealt with World War II aircraft, they rarely interacted or worked together. Yet over the years these organizations, and the many newer ones that appeared, have come to work together, sharing not only aircraft at other groups' airshows, but also information, expertise, and parts. The National Warbird Operators Conference, for example, draws all of these groups together. Most centrally, they share an intense involvement with the airplanes themselves and the problems and meanings derived from "keeping them flying."

If people interested in warbirds can be grouped into the category of warbirders, I would also argue that we can refer to the varied activities in warbird hangars, in restoration shops, at airshows, and on the Internet collectively as "warbirding." Both terms obviously play off of the common term "birder" for a bird-watcher, but that term's suggestion of passive observer would apply, at best, only to enthusiasts. The connotation of a quaint obsession might apply, in the view of some. Other implications, however, do carry over nicely. Birders might be known both for their extensive knowledge of species, while warbirders generally know a great deal about the types of planes and their histories. Similarly, a birder might develop an ear for bird calls, and many warbirders can identify the type of warbird by its sound. The term warbirder is, in fact, occasionally used by people in the warbird movement, though its extension to "warbirding" is my own neologism.

Viewing both the people as a collective, related by their interests, activities and shared contexts, provides a start for further consideration of the dominant themes in the warbird movement. Certain themes run through all of the important warbird sites, and I seek to explore those themes in this dissertation. This first of these themes is historicity, explored in the next chapter, followed by nationalism and militarism, nostalgia, and masculinity. 


\section{Chapter Two: The Historicity of the Airplanes}

The assumption of historicity provides the basis for all of the activity around warbirds, yet what is this historicity? For Euro-American "natives," the historicity of any entity is an essential attribute of it. This chapter, on the other hand, explores the various means by which warbirders invent the historicity of their airplanes. Like any cultural concept, historicity results from ongoing cultural invention (Latour 1987, Wagner 1981(1975)). The emergent nature of this phenomenon, however, must be "masked" in various ways by the natives, because they see historicity as inherent. Here I draw on Whorf's characterization of "Standard Average European" languages to argue that Americans tend to objectify the past in an object, landscape, or performance, such that through them a past can be considered, experienced, or possessed by persons today (Whorf 1956(1939), Cf. Handler 1988). As an inherent attribute of an object, historicity is conventionalized as existing on its own, separate from human creation, but subject to destruction or preservation by humans. Warbirders expend great effort in preserving what they see as the inherent historicity of their airplanes. To unpack their invention of this historicity, I follow them and their machines through the major sites of invention: the hangar and the airshow.

When investigating warbirds, we have to understand that neither the objects nor their meanings have remained constant across contexts (both space and time). First of all, the airplanes themselves have been radically altered over the years due to their postwar uses. The military equipment was removed; the radios were replaced; and the interiors were made luxurious. Beyond these material changes, the schematic conceptions of the airplanes have changed over time. The schemas, or forms, of the airplanes were created during the war and continue to exist (in the form of blueprints, artifacts, pictures, memories, etc.), but these schemas have changed along with the context. The ability to read the blueprints has changed; the tacit knowledge required to work from the blueprints and manuals has changed; memories have become fuzzy; the airplanes which they represent have all been altered; and 
the theories and ideas that went into creating the schemas have also changed. Blueprints and manuals continue to exist, of course, but such a crudely materialist understanding of the airplanes' schemas takes them out of their context of interpretation and use. (Further, even the status of the blueprints and manuals have changed, from information used to work on an airplane to another collectible objectification of the past. A thriving trade in manuals does exist.) Moreover, the relation between the object and its schema has changed. New pieces are made that fit the old schema, and new schemas have been created to fit new circumstances. Bits of the schema have been incorporated into newer aircraft (and other machines), while other bits have been abandoned.

Along with these material and ideal forms of the aircraft, the meaning of the objects is entirely different. One shift in meaning, to paraphrase one warbird museum official, was from "one of a thousand to one in a million." Plenitude has become scarcity, and a "tool" of war has become a "piece of history."23 Since World War II the airplanes have gone from being crucial military technologies, to useful introductions for more complex military technologies, to obsolete military technologies but useful civilian machines, to outdated and hard-to-maintain civilian machines, to junk, only to be reclaimed now as "pieces of history."

While Euro-Americans understand this process as the "natural" evolution of technology, Marx pointed out its necessity to the capitalist mode of production (Marx 1976). The capitalist demand for ongoing succession of commodities gets rendered meaningful as a process of progress and obsolescence. Drawing on Wagner's model of convention and invention, we can argue that obsolescence is, in a sense, invented (Wagner 1981(1975)). The machines are understood to be progressively older and less useful technologies, and this invention has to be masked by the cultural convention of technological progress. The invention, or production, of obsolescence is masked by the depiction of technology as a

\footnotetext{
${ }^{23}$ Of course, even during the war extensive marketing campaigns constructed the airplanes as more than mere tools. They were marketed like today's military aircraft, as keys to national protection, though many differences between the discourses surely exist, not the least of which is the context of the latter: the long build-up of the militarized, national security state during the Cold War, as I will discuss in the next chapter (Lens 1987).
} 
force existing outside of society, yet impinging upon it, created by humans, but advancing by its own merciless logic, not by the capitalist push for profit (Marx 1976, Pfaffenberger 1992). Humans have no choice but to accept the continual "improvement" of machines, by this logic. The obsolescence of warbirds resulted from their material aging, the "advances" of machines around them, the cessation of the planes' production and parts manufacture, and the passing of people who knew about and could work with the technology. Each of these transformations stems not from a natural logic of technological change, but from a cultural formation which demands continual replacement of its machines. This production of obsolescence involves the working together of different "actants," to use Latour's phraseology, including military officials, government regulators, parts suppliers, airlines, corporate executives, airplane manufacturers, and the objects themselves, the airplanes. Even aging has to be culturally produced as the relentless passage of time and the material degradation of objects, rather than a choice that was made not to address that degradation of materials (Lemonnier 1993). In some ways this last choice is the one warbirders decide not to make. What warbirders do, in contrast to the "natural" flow of technological evolution, is preserve the obsolete.

\section{Inventing the Enduring Object}

Miller (1987: 124) argues that objects work well to mark time because they perdure. We cannot universalize this time-marking quality of objects because concepts of time and of objects vary. For example, Miller points to the Churinga of the Australian Aborigines as objects which objectify time for the group (Ibid.: 59). The notion of Dreamtime, however, is anything but the empty, homogenous time of Standard Average Europeans, passing in measurable units. The "past" marked by the Churingas differs radically from an airplane's evocation of World War II. The Dreamtime still has an effect on events today, while the strongest claim warbirders can make is that "those who forget the past are doomed to repeat it." Indeed, the chronotopic convention (Cf. Bakhtin 1981) of nostalgia sees the past as 
forever lost and separate, as I will discuss in chapter three. Similarly, Miller notes that objects come to bear the marks of history, and warbird restorers go to great lengths to preserve the marks of war. Yet the idea that such marks represent ties to events in the past takes a dramatically different form amongst the Apache, for example, whom Basso (1988) describes as seeing history inhering in the landscape. This history, far from being a set of completed events in a spatialized-as-distant time, continues to exist and occur in the landscape, influencing people today and influenced by them. For warbirders, their airplanes objectify a distant, unchanging and (mostly) unreachable past. Many of my interlocutors did celebrate World War II as an event which created the United States of today, but it remains (or should remain, in their view, despite the efforts of "revisionist" historians) uninfluenced by the present. Their relation to that materiality, therefore, differs drastically from the Apache conception. The Apache grant agency to the object/landscape in a way that warbirders cannot, despite their objectification of history in the airplanes. We are left, then, not with some inherent quality of objects - marking time or objectifying the past — but rather with specific cultural beliefs about the objects and the material processes they undergo. As I noted above, airplanes existed during the war and were used afterward, up until the present day, but how that perdurance is rendered meaningful requires ethnographic investigation.

Even arguing that these airplanes have perdured is misleading, however, because, as I will show, a great deal of work has gone into sustaining the idea that these are the same objects as the wartime ones and as such are "pieces of history." Warbirders employ typologies to connect the present aircraft to the past, treating the present aircraft as a token of those types (Silverstein 2005). Yet I will show that these objects and their meaning must be continually reinvented. Today's airplanes cannot be claimed to be "the same" because they are materially refashioned while also being integrated into new systems of practice and meaning. In making this argument, I draw on the insistence within Science \& Technology 
Studies that technological objects or artifacts are merely parts of complex systems, so that when the system changes, our understanding of the artifact must change as well. Indeed, these airplanes were junk at one point, demonstrating how the system of meaning can shift radically. Contrary to the "Standard View of Technology," then, a technological artifact does not stand on its own.

To envision the shifts in meaning that came with the succession of contexts, we can imagine the meanings of the aircraft as links in a chain stretching through (Euro-American) space-time back to World War II. For each link (meanings were surely more fluid than the metaphor of a chain link suggests, however), different meanings were constituted through the interaction of discourses and material practices. For example, the historic nature of warbirds was secondary to the founding of the Confederate Air Force. Its founders were all World War II veterans who mostly did not get to fly the glamorous fighter planes in combat, so they purchased a couple of fighters to fly for fun. Going from wartime usage to postwar play, the airplanes shifted from front-line fighters to postwar surplus items, from military tools to civilian airplanes, and from lethal warplanes to playthings. These transformations integrated a variety of discourses, practices and materialities, including the discourse of technological progress (which classed the machines as obsolete and not needed by the military), the plenitude of airplanes produced during the war (which led to a postwar drawdown of the aircraft), the wide scattering of the aircraft (which led to now-famous adventures in finding, buying, and ferrying the aircraft, adding to the "fun"), the convivial gathering of men around the CAF's home airport (a group that might support the purchase and maintenance of several aircraft), the myth of the fighter ace (that the pilots might want to playact), the income which enabled them to purchase and support an aircraft, the relatively new aircraft which had few major maintenance requirements (which, along with the massive surplus of spare parts produced for the war, made a casual hobby cheap), lenient government regulation (which did not get in the way of the "fun"), and the wartime training that enabled 
these pilots and mechanics to be skilled enough to "have fun." This quick example demonstrates the disparate elements which came together to stabilize the first incarnation of the CAF as a for-fun flying group. The integration of such a diversity of elements discursive and material — to stabilize such a system has been called "heterogeneous engineering" (Law 1987), and such heterogeneity would also characterize the CAF's future efforts to make their airplanes into "pieces of history."

\section{Spreading Out}

After they had stabilized their flying club, the CAF had to work to sustain it and even extend it, incorporating new members, finding and buying new airplanes, and performing in their first airshow at a military base in 1961. As they extended this practice, they eventually transformed it into a form of cultural heritage, adopting the discourse of historic preservation, incorporating as a nonprofit to take advantage of laws allowing tax-free donations, and marketing themselves to military airshows as both a spectacle of wild-but-skilled flying and a means to "honor" the past. With this shift to heritage practice they began "spreading out" the historicity of their aircraft. The notion of "spreading out" historicity comes from Latour (Latour 1987). He argues that technoscience has to build up its facts and machines by getting more and more people to believe them and use them, in effect, spreading them out. The more they are believed and used, the more stable, coherent, and, in a sense, "true," they are. This notion might at first seem like an odd mathematics of social groups ("All we need for the theory to be accepted is to enroll the $8^{\text {th }}$ grade class of Springfield high school!"'), and Latour does not clearly show where (or when) a contested theory or device becomes a "fact" that holds or a "machine" that works. Rather, his understanding of these articulations is fluid, not unlike the relationship between individuality and sociality sketched out by Sapir (Sapir 1938). Social interaction, especially speech (Sapir 1912) depends upon a set of shared understandings, and with the right circumstances (including the exertion of "heterogeneous engineering"), those understandings can be altered. Latour does not believe that a fact's 
"holding" depends upon which social group backs it, however, because he argues that society, including the social groups that make it up, is a product of technoscience (Latour 1987:141-144). We are therefore left with more or less effective "heterogeneous engineers" or, in Latour's terms, network builders.

I noted a key difficulty with this model in the Introduction, however. It assumes an almost clean slate, free from pre-existing cultural categories and relationships of power. ${ }^{24}$ Rather than make this assumption, then, I argue, along with Martin (1998), that technoscience (and warbirding) begins within a "citadel." The citadel consists of hegemonic understandings of machines, gender, nation, and persons. Translating this phrasing into Wagner's terms, the citadel consists of especially powerful conventional contexts which get readily applied to whatever novel context crops up. By this logic, the constant invention of warbirding depends upon the continual redeployment (and reconfiguration) of such hegemonic discourses as technological progress, nation, gender, history, and possessiveindividual personhood. Following Latour, however, this process of meaning-making implicates not only these discourses, but also material objects and practices. Indeed, some of the everyday phenomena of warbirding require warbirders to reach well outside of their citadel to draw on a variety of agencies. In some cases, they even have to translate their machines, practices and discourses into new terms in order to salvage their invention of warbird historicity, as they may have to do if leaded gasoline no longer becomes available, an issue I will discuss below.

At first the analogy between a technoscientific fact "holding" and a machine being "historic" may seem strained, but I have suggested so far, and hope to show below, that this analogy works well. Its virtue lies not in the diversity of theory it covers, but in the insight shed upon a specific technological practice which, in my view, cannot be examined

\footnotetext{
${ }^{24} \mathrm{~A}$ further difficulty with this view is that the technoscientists burst upon the scene as Euro-American-style, possessive individuals (MacPherson 1962). We cannot universalize this model of personhood, but for my purposes here, it adequately characterizes the actions and motivations of warbirders.
} 
adequately by drawing solely on one or another body of theory. I will illustrate these general statements about warbirders' invention of historicity with a specific example. An airplane operated by the Commemorative Air Force will illustrate many of the processes described above. Following that discussion, I will conclude the chapter with a brief discussion of warbirds owned by collectors to add some additional elements which come from the practice of individual owners.

\section{The China Doll}

The Southern California Wing of the Commemorative Air Force (the Wing or the SoCal Wing) sponsored, maintained and flew a large cargo airplane classified as a "Curtiss C-46 Commando" as a warbird. The SoCal Wing named their C-46 "China Doll," and it has long been their flagship. "China Doll" serves as an excellent example for unpacking the invention of warbird historicity for two main reasons. First, the type of plane is not well known, which serves to highlight the efforts the Wing made to render the plane historic in their own eyes and in the eyes of others. In other words, they could not fall back on a general familiarity with the plane to justify its representation as an historic object. Second, as a large, slow, and ungainly cargo plane, the aircraft lacked the glamour and excitement culturally associated with smaller and faster fighter planes. Nor did it have the fame of the bombers. In a sense, then, the work devoted to restoring and presenting the plane as historic came to be justified almost entirely on the Wing's invention of its historicity.

The plane was designed and built by the Curtiss Aircraft Company, designated as a C-46, and officially nicknamed the "Commando." According to the history compiled by the Wing, the airframe ${ }^{25}$ that became "China Doll" was manufactured for the U.S. military in July 1945 (Fleishman). The military used it for military transport and cargo until the

\footnotetext{
${ }^{25}$ When I need to refer to a specific airplane today, rather than a type of plane, I will often use the term "airframe," rather than airplane or aircraft. This usage differs from that of airplane maintenance, where airframe refers to the whole of the airplane except for the engines. A certified mechanic receives an "Airframe and Powerplant," or A\&P, license, with powerplant referring to the engines.
} 
early1950's, when it was declared surplus and sold to a private cargo operator. ${ }^{26}$ It was used to haul cargo for several decades until the 1960's or 1970's, when it was modified to become a pesticide sprayer. In 1978 the plane was sold to the (then) Confederate Air Force (CAF), where it was based initially in Texas. A short time later, when the plane needed new engines, the CAF shopped the plane around to different Wings to see who might be able to pay for the engines and generally to ensure the plane's upkeep. The newly formed Southern California Wing sought out the C-46. Once the airframe came to the SoCal Wing, it received a new name, new paint and new engines and was gradually restored to well-functioning status, as I will describe below.

This account of "China Doll" has so far described its changes over time, in some sense reproducing the assumption of object perdurance and stability which I seek to examine. I take this genealogical approach in order to establish the grounding from which warbirders invent the object's historicity. The historic importance which the Wing attributed to the aircraft was neither self-evident nor salient in the previous cultural system. This "heritage" object was, after all, hauling cargo and spraying pesticides only a few years before it became a "piece of history," and planes just like it continue to haul cargo. Historicity, then, is by no means a necessary quality of the aircraft to foreground. The plane could just as easily have become scrap, its recycling perhaps even heralded as a wise use of resources. We therefore have to examine just how the historic identity of the aircraft was built and has been maintained since the SoCal Wing acquired the plane. The establishment of CD's historicity required that that quality was spread out in time and space and used by others in their own "projects." As many actants — human and nonhuman — as possible needed to be enrolled as participants in the object's historicity. To pursue these elements, I followed the airplanes

\footnotetext{
${ }^{26}$ The movement of warbirds over time is itself a fascinating topic that I cannot pursue fully here, but I will note that it formed a global circulation, moving from Euro-America to nations in the southern hemisphere and then back North again. Many other warbirds today were recovered wrecks, taken out of Pacific jungles and the Siberian steppe. The movement involved shifts in status, from the latest in technology to second-rate weapon to completely obsolete weapon (trash) to "piece of history" and elite plaything. The movement of CD, while it involved a number of different statuses, did not trace the global routes that many warbirds have.
} 
to the major contexts where their historic importance was constituted and performed. I divide these contexts here roughly into the hangar and the airshow, the primary sites for "the invention of the convention" that warbirds were flying "pieces of history."

\section{The Meaning of China Doll}

Before I begin the discussion of the hanger, I should discuss the obvious implication of race and gender in the airplane's name and nose art. The name "China Doll" is a pun. On the one hand, it refers to the most famous World War II mission for that type of aircraft: flying over the Himalayas ("the Hump") from India and Burma into China to deliver supplies to the national Chinese. The plane's powerful engines were well suited for this difficult route, but hundreds of planes were still lost in the terrible Himalayan weather. Like the CAF Wing which first sponsored the airframe, which had used the name "Humpty Dumpty," the SoCal Wing sought to establish this mission as the basis of the airframe's identity, rather than the many other uses to which the plane was put during and after World War II. On the other hand, the name and nose art also refer to a sexualized Chinese woman. Such depictions were common in nose art of the time, and they certainly reflect the place of the Asian female more generally in the erotic imagination of Euro-Americans. Such depictions not only indulged the erotic imaginations of wartime warplane crews (and that of warbirders today), but they also served to feminize and reduce the Other they represented (and even infantilize them, given the further echo of the name, a child's toy doll). Even though the Chinese were nominally on "our side" during the war, such depictions subordinated them and mirrored the racism of the time, reproduced today in the name of misguided verisimilitude, i.e., to make it "like it was." This use of and justification for nose art is widespread in the warbird world, though relatively few airplanes depict Asian women. To avoid, as best I can, reproducing these ingrained representations, I will substitute the letters CD for "China Doll" for the remainder of this text. 


\section{The Hangar: Restoring and maintaining the Aircraft}

Warbirders do all the maintenance and restoration work on their airplanes in the hangar. They gather there and socialize, develop and deploy mechanical and organizational skills, accumulate stores of spare parts, solicit donations, guide touring visitors, and develop individual relationships with the airplanes at the center of their activity. The material transformation and sustainment of the aircraft all takes place in the hangar, but the hangars also serve as a museum to contain the airplanes, related artifacts, and, in some sense, the very work which takes place on the airplanes, a point I develop further in chapter three. Much of the hangar work involves direct interaction with the aircraft, through which warbirders invent the airplanes' historicity for themselves as much as for others. This invention occurs both through routine maintenance of the aircraft and through the involved restoration of warbird "projects."

The hangar and the airshow are tied together by the demand that the aircraft fly. Warbird afficionados argue that static displays in museums are "dead" airplanes, while warbirds provide the experience of "living" airplanes. As the movement's motto, "Keep 'em flying," shows, flyability is a distinguishing feature of warbirds. To that end, they repair and modify the airplane as they see necessary to render it flyable. The work required to keep the

airplanes flying spreads warbirding well beyond the hangar, involving myriad outsiders in the airplanes' historicity, as we will see below when we examine the search for a specific warbird part. While this repair work is guided by a discourse of authenticity, the need for flight also introduces contradictions within the drive for authenticity. They often have to replace old, "original" parts for newly-made, but authentic, ones. Warbirders deploy a rhetoric of safety to mediate this contradiction, but aesthetics play an important role as well.

\section{Routine Maintenance}

As my brief account of CD's history above showed, an airplane like it requires a great deal of work to fly. In this work the skilled labor of mechanics, the efforts of organizational 
builders, the material qualities of airframes and spare parts, and the interest of various outsiders all have come together to establish the network of practice $\&$ meaning which sustains the aircraft. Even something as mundane as aircraft maintenance requires a surprising array of "actants," in Latour's terms.

In this section we will see that the maintenance work actively constitutes the airplane as historic. Like artifacts (or words), cultural practices and meanings are subject to rot and degradation if they fall into disuse. A technoscientific fact/machine has to be continually sustained to cohere as a cultural faith and practice. For the SoCal Wing, the web of historicity that they weave for (and with) CD has to be refashioned and supplemented continually. First and foremost, the network requires the constitution of the Wing itself as the agency for the maintenance work. The skilled humans, the spare parts, the gasoline and oil, the airframes and engines, and all manner of tools which make up the Wing are constantly in flux, requiring daily attention on the part of Wing members to sustain the aircraft. Further, the Wing has to establish ties well outside of the hangar. Parts suppliers, for example, open up and go out of business, forcing the maintenance officials to recruit new people from unusual places, as we will see in the discussion of a scarce spare part. As Latour points out, one cannot predict the people, meanings and materialities that must become involved in order to stabilize a technology (Latour 1987: 162).

We can say that not only does the Wing construct "CD, the piece of history," but in a sense CD constructed (and continues to construct) the Wing. Prior to the airplane's arrival, the SoCal Wing was a social club gathering monthly for dinner. The airplane's arrival served as a focus for attracting the mechanics, pilots and donors whose activity would build the Wing. The airplane provided a field for the performance (often self-conscious) of skilled labor, but it also placed material demands that changed the Wing. These material demands, however, cannot be seen as separate from the specific technological practice which is mutually constituted with $\mathrm{CD}$. For example, the CAF required the sponsoring Wing to 
purchase new engines for the plane, both because they were deemed necessary and because the purchase would demonstrate the organization's ability to support a large, expensive aircraft. This requirement forced Wing members to recruit donors whose gifts would motivate them to come out and work on or enjoy the airplane. Similarly, it led mechanics who wanted to work on the engines to donate both money and time. Over the course of a few years, then, the arrival and ongoing demands of the aircraft (the CAF's requirement for new engines, the work, skill and materials required to "restore" and to fly the plane) changed the Wing from a group that met at a restaurant to discuss World War II aviation to a group of pilots, mechanics, and administrators all working together to sustain a flying aircraft.

The historicity of the aircraft also played a role in the Wing's construction. To pursue donors, visitors, pilots, and mechanics they invented the plane's historicity by developing a narrative of its historic importance, drawing on stories about "flying the Hump," its obvious contrast with aircraft manufactured today, and personal experiences with the aircraft type, as I will describe below. They therefore remade the object itself symbolically, inventing its historicity so that they could remake it materially.

Donors and fund-raisers are central to the organization's success, of course, but my interest focuses mostly on the workings of the mechanics and pilots. The skills these individuals deploy are not only critical components of this technological practice, but they also become objectifications of history themselves at times. What sets the hangar apart from the airshow, aside from the need for donations, is the centrality of mechanical - as opposed to piloting - skill. The hangar provides the frame for the acquisition and performance of mechanical skills seldom used elsewhere. One mechanic, for example, was attracted to the hangar because he had a fondness for the "round" engines CD used. ${ }^{27}$ This fondness for the

\footnotetext{
27"Round" or radial engines were a type of piston engine commonly used on aircraft and in helicopters until their replacement by turbine, or jet, engines. A radial engine is characterized by the cylinders radiating out in a circle from the crankcase, so that the engine looks something like a flower. The other common engines used at that time were a "vee" engine, in which the cylinders were arranged in two rows which formed a "vee" when seen from the front or rear and an "opposed" or "flat" engine, where the cylinders were positioned opposite each other linearly, in a horizontal plane.
} 
working of specific types of old machinery (which I explore in chapter three) has kept him involved for twenty-plus years. Others, however, come to the hangar with none of these skills but are interested in acquiring them. In both cases, the hangar foregrounds these skills, which are explicitly understood as historic.

The remaking of the aircraft and the invention of its historicity, however, require more than donors, mechanics and an airframe. The web or network, as I have called it, of participants in the aircraft reaches well outside of the hangar. The need for parts requires the enrollment of whole classes of people who would not be involved in a static museum display, for example. Warbirders needed overhaulers for old propellers, carburetors, and engines; dealers in the remaining World War II-surplus parts and in new-made parts; metal and hardware suppliers, specialized petroleum product makers; certified flying instructors; special regulatory provisions and officials; mechanics with old airplane experience; and so on. Some of these specialized needs require rare skills, while others are shared by many other businesses. One maintenance official described the extensive work he performed to build a network of suppliers. He emphasized the personal bonds he formed with tire dealers, parts suppliers, and metal works, but this supply network also incorporated and extended the airplane's historicity. Others often gave this Wing official discounts on their products because, he said, "they believe in what we're doing." In other words, the Wing's maintenance of the aircraft matters because the plane is historically important, and the plane is historically important because the Wing has done such a good job of making their work matter. As we will see in the following example, such interested outsiders can determine the existence of the practice.

\section{The Case of the Tail-Wheel Lock}

While I was at the Wing, they encountered a significant parts difficulty with CD: the lack of a small part called the tail-wheel lock threatened to ground the airplane. While any airplane can be grounded due to the lack of a part, parts shortages pose special problems for 
old, rare aircraft because no new parts are being made commercially and the scarcity of planes makes tooling-up to make parts unprofitable for businesses. A six-inch long piece of metal, then, could be responsible for grounding a 110-foot-wide, 15,000-pound airplane. In exploring this part, we can see the efforts the Wing has to go to in order to fly their airplane.

The tail-wheel lock locks the wheel into a straight-ahead position, which keeps the tail wheel from swivelling wildly while the plane is taking off and landing. Without a lock, the wheel swivels freely. A lock-less, swivelling wheel does not make landing or taking off impossible, but it does make both much more difficult and dangerous because the plane "shimmies" violently as the tail wheel swivels and spins at high speed. As one experienced pilot told me, "you know that [the violent shimmying is] not good for the airplane." The lack of a lock for the tailwheel, then, might not make flying impossible, but over time would damage the airframe such that it would have to be scrapped. The Wing therefore needed more locks.

I need to offer a brief aside on technological determinism here. All of these factors - the grounding of the airplane due to safety concerns, the scarcity of parts, the issue of "profit" in making new parts — occur within a cultural system of technological practice. Nothing inherent in the machine or the part makes the shortage or the grounding inevitable. One could imagine a cultural system in which flying the plane until it rattled apart would be acceptable, for example. Further, a different cultural system (one not devoted to planned obsolescence, for example, though such a system might never have developed the aircraft in the first place) might have avoided the shortage of tail-wheel locks. Moreover, the Wing did not have the money to fly the airplane often enough to keep its pilots highly skilled in the aircraft. The lead pilot at the Wing, for example, one who had thousands of hours "in" the type of airplane, said he was not "current" enough in it now to try the "three-point" landing ${ }^{28}$

\footnotetext{
${ }^{28} \mathrm{~A}$ "three-point landing" is one on the two main wheels and the tail-wheel at once, as opposed to a "wheel" landing, on the two main wheels, settling onto the tail-wheel only as it slows down significantly. The three-point landing is harder but allows for shorter landing distances, making shorter runways usable.
} 
that he used to perform all the time. The pilots flying cargo in C-46's in Alaska, however, do have the "currency" in the plane and perform that type of landing all the time (Deakin 2004). The dearth of locks became an issue when out-of-practice pilots forgot to disengage the lock before turning the aircraft, either while taxiing or while towing with a tug. Inpractice pilots might retain the tacit knowledge always to disengage the lock after the landing roll. (The level of currency might not be a factor, however, because the company in Alaska has no spare tail-wheel locks, either.) Within the extant cultural system, however, the lack of a tail-wheel lock would force the grounding of the aircraft.

Returning to the case of CD and the tail-wheel lock, the Wing has a shortage of a critical part, produced by the current use of the machine. The strategies the Wing has pursued to remedy this problem demonstrate the ways in which they create and sustain their technological practice as an historic enterprise. While I was working at the Wing, four different approaches to the problem arose, though not all of them were considered seriously. The first, a short-term solution (possibly only suggested as a stop-gap measure), was to contact a nearby Air Force base museum that had a static C-46 on display and ask if they could switch out a broken tail-wheel lock with an intact one (the part was internal, and therefore not visible to the visiting public). I do not think they pursued that method. A second approach came after one member met a South American pilot who flew cargo in C46's some years ago. After swapping stories about flying the aircraft, the CAF pilot learned that a number of crashed C-46's existed in a mountain region in South America. Over dinner after an airshow, he fantasized about embarking on an expedition to South America and the crash sites, with the aim not only of having an exotic vacation, but also of collecting from the wrecks parts in critical shortage, like the tail-wheel lock. A third, more realistic, approach, came from a Wing member who asked a machinist friend to try to make a part, promising that the parts and labor would be deductible as donations to the Wing (a not-forprofit corporation). His friend did make a part which closely approximated the original, 
though I think the fit was just slightly off. The last I heard of it, there was also the question of the metal needing to be properly heat-treated to have the appropriate strength for the function. Either way, this part did not solve the general problem of the shortage because it had not been manufactured according to the FAA requirements for parts used in the Standard-class aircraft used for transport. CD was not a transport-certified aircraft, however; it bore the more lenient "Experimental" classification, meaning that it did not have to abide by the much stricter requirement of transport aircraft. The airplanes used by Everts Cargo in Alaska, however, were transport-rated, as was the CAF's other C-46, Tinker Belle. The Wing had for some time worked closely with Everts, the most prominent other C-46 operator, to obtain parts and to share useful information. In fact, the last "original surplus dealer" ${ }^{\prime 29}$ of C-46 parts had donated his entire inventory to the SoCal Wing and to Everts when he passed away. Everts needed parts that were made under an FAA "parts manufacturing authority," or PMA, so that they would be certified for use in their aircraft. The downside to this approach, of course, was that instead of getting a stock of free tailwheel locks from a retired machinist who thereby received a tax write-off, the Wing would have to purchase the parts newly made.

In thinking through these different approaches, we can see to what lengths the Wing has to go to keep the plane going and sustain its historicity. The first option (getting the part from a static museum display) would have only been open to them because they had established themselves as an historic preservation organization and because the airplane is understood to be historic enough to $b e$ in a museum. The Wing therefore participates in the more general discourse of historic aircraft and historic objects which set aside different types in museums. The second option (going to South America), however, highlights the age of

\footnotetext{
29، Original surplus dealer" was a phrase I heard a number of warbird restorers use to refer to those commercial enterprises that purchased large stocks of spare parts from the military when types of aircraft were eliminated from the fleet. Like stories of finding the legendary "airplane found in a barn," stories of finding (and buying) the stock of an original surplus dealer abound in warbirding. One specialist in a type of trainer, for example, said that much of his business depended upon the steady sale of parts, the supply of which he had obtained cheaply from an unknown dealer in Louisiana.
} 
the aircraft (they have been around long enough for wrecks to accrue around the world), the leisure nature of the work on the airplanes (the trip being easily transformed into a vacation), and the importance of airshow displays, not only for "spreading out" the plane's historicity, but for encountering people who had experience with and knowledge of the airplane. The third option (a friend's machining the part) involves not only the aircraft-work-as-hobby dimension, but also the critical role played by federal not-for-profit status. Further, we might argue that the personal nature of the volunteer work at the museum produces a different result than work performed for a commercial enterprise. The Wing member felt no qualms, apparently, about asking a friend to perform this work. Such favors performed by friends are, in fact, critical to the success of the Wing. They include many discounts from parts suppliers and service providers who have gotten to know the wing members and felt they were doing worthwhile things. The fourth approach (combining with Everts to have the parts made new) highlights what is a common approach for warbird groups. Many band together to seek out rare or unavailable parts. The few operators of the B-17 bomber, for example, formed a B-17 co-op which has made bulk orders of such items as tires. The alliance with Everts on the tail-wheel lock would have required the Wing to sacrifice, by paying for the parts instead of getting them donated, but in the process they would have reaffirmed their connection to Everts and to the future supply of parts and shared expertise.

To warbirders, this example would highlight common-sense strategies undertaken to solve a practical, not a symbolic, problem. Yet the pursuit of this one part does open up the ongoing work of historicizing the aircraft. First of all, having the airplane fly is crucial to their performance of its historicity, and this example exposes some of the techniques and knowledges deployed to that end. Not being able to fly the aircraft is not an option, so the organization has to pursue whatever means it can to get the plane to fly. More than its role as an historic aircraft, however, its status as the definitive aircraft of the Wing plays a role in the urgency. One could not imagine the Wing without the $\mathrm{CD}$, while one could easily see 
the Wing's Hellcat or Convair move on. In fact, the airplane become the official airplane of its town, Camarillo, in August, 2005. Second, solving the problem of the shortage appeals to Wing members because it constitutes a relationship with machines that they see as characteristic of old, historic technologies, but not new ones. One retiree mechanic at the Wing described to me the great pleasure he felt in coming up with solutions to problems for the airplane he crewed. He designed and installed a fire extinguisher system, for example, and loved the feeling of accomplishment he gained when it was approved by the Wing and put into the airplane. This work afforded him the agency that warbirders desire and that they understand as available through old machines, a topic I explore further in chapter three. The tail-wheel lock, then, offers a chance to explore one's cultural-technical creativity. This is a chance for problem-solving, and many Wing members pondered it. When I was there, the shortage came up frequently in conversations, with members speculating about where one could be found and whether the C-46 would ultimately be grounded because of the lack of this small part. Third, this kind of interaction with the airplane, in addition to affording agency, constitutes the airplane as historic. The scarcity of parts evokes the scarcity of airframes themselves, sparking longing memories of the gross abundance of planes and parts after the war. The scarcity, in contrast to (and in part because of) previous abundance, produces a sense of the plane's age. In having to work so hard to find parts for it, in seeing the airplane break in this fashion, in looking to museums as much as to parts suppliers, they experienced the aircraft as old.

Yet, again, I have to point out this scarcity as something produced by a cultural system. To counter this scarcity, to sustain the flying aircraft, the Wing has had to explore a variety of ways to refashion their web of historicity. They had to consider what warbirders would understand to be the practical, material requirements of the plane: shimmy-free takeoffs and landings, small hunks of carefully-formed metal, and proper heat-treating for parts. They also had to contemplate various other elements that they had to control in order to 
sustain the aircraft's flight: friends who have the tools and skill to machine parts; non-profit tax laws motivating donations; a "belief in what the Wing was doing;" a cycle of technological obsolescence which fated aircraft to move south, where they might crash into mountainsides; an extensive leisure or hobby practice which constructed labor as a use value, as opposed to an exchange value requiring monetary compensation; the possibility of combining a leisure "vacation" to South America with a leisure hobby; FAA regulations governing the manufacture of parts used in aircraft; the short-field landing ability of the C46 which allowed for its profitable operation in Alaska; and the relative amount of time spent landing and taking off in an old airplane. As Latour argued (1987), these assemblages do not easily break down into materiality and meaning, subject and object, but rather come together somewhat as equals, as potential "actants" in a cultural system. For the tail-wheel lock, most of these elements may prove to be essential actants, allowing the plane's tail-wheel to again become an unproblematic "black box." Future parts shortages will involve some of these actants, but surely will introduce others as part of the continuous refashioning of the web.

\section{Reconstituting Lost Skills}

The creativity required to keep the airplanes flying, then, is an enjoyable experience for the Wing members, but the skills they deployed in this labor acquire other meanings as well. The work involves the performance of "historic" skills, abilities no longer used in most airplane manufacturing and maintenance. For some, the work allows them to acquire those skills, while many others, like the lover of "round engines" mentioned earlier, are drawn to the Wing to employ long-neglected skills. I develop this point more fully in chapter five, but here I would like to point out that the web of historicity includes not only the "practical" application of skills felt to be necessary for the plane's operation, but also the cultural objectification of those skills as themselves historic.

As with any aviation organization, the pilots, not the mechanics, at the Wing receive the most emphasis. The cultural authority of pilots has long existed and surely derives both 
from class associations and the earliest public understandings of aviation, which emphasized the daring of barnstormers and World War I "aces." I point out this disparity to emphasize that, despite the power of pilots within the Wing, the mechanics receive a great deal more emphasis than they might at an airline or in the military. In some ways, mechanics' skills are seen as objectifications of history, just like the airplanes. The highly skilled older mechanics wield great authority at the wing, and their abilities are the subject of Wing-wide admiration. Their understanding of the machine is often understood as related to the historicity of the machines, and therefore is itself important, rather than merely a means to the end of flying the airplane. Wing members (and warbirders more generally) are concerned that the passing of these skilled individuals will mean the loss of their knowledge. Even the most skilled and knowledgeable of the younger pilots and mechanics defer to, and occasionally are quite surprised by, the knowledge of the older mechanics. For example, one of the most skilled pilots and ardent devotees of old airplanes was surprised to learn that the cylinders on an early model of a particular engine were the same as those used on another common engine. (The ramification was that many more spare cylinders would be available for the engine.) An older mechanic had mentioned this merely in passing, as if it were common knowledge. Such easy pronouncements constituted this person, and others, as repositories of important but threatened information, just as the airplanes themselves are conceived to be important but threatened. Further, this mechanic has himself become concerned about the loss of his knowledge and hopes to capture it by writing a book. Such objectifications, even selfobjectification, play an important role in constituting the aircraft as the historic subject or referent of that knowledge.

In some cases, mechanics are objectified as historic because of their connection to airplanes on which they work. One crew chief, for example, works on the same kind of aircraft that he maintained at the end of World War II. The plane is painted to represent the ones he worked on, suggesting further the equation of its historicity with his own. For the 
mechanic, this kind of connection also involves the "relationship" with the airplane which I discuss in chapter three as being so important to warbirders. The objectification of mechanic with airplane can also be seen in the use of wartime mechanics as authorities to vouch for the authenticity of restorations, as I discuss below.

Pilots, on the other hand, are less subject to the same cultural objectification of their skill because so many continue to learn to fly the old aircraft. Indeed, the CAF's continued flying of the aircraft depends upon the ability to train new pilots. That said, some pilots do inspire awe for their experience and skill. Similarly, wartime pilots are also objectified as historic, though more for their participation in great events than for their current skill. Several pilots told of feeling linked to the wartime pilots by sitting in the same cockpit, but this kind of "experience of history" is not itself objectified as historic. The mechanics, however, were subject to this history talk, and the hangar time offered them the chance to perform skills which were felt to be disappearing. ${ }^{30}$ To a degree, they could also display their virtuosity, their ability to improvise, in the restoration of aircraft, but this restoration work could not be claimed to be "historic" in the same sense because it involved erasing long years of decay and making aircraft "like new."

\section{Restoration Work}

Restoration is a special form of aircraft maintenance in which the airplane is remade so that it can fly again. Many restorations begin not from aged-but-working airplanes but rather are created out of twisted wreckage, sometimes from recent crashes and sometimes from corroded World War II wrecks. Given such radical remaking, warbirders devote a great deal of effort to shoring up the identity of the objects, effort which requires them to construct elaborate typologies and to establish strong links between the contemporary airframe and the wartime aircraft. As we will see, restorations are guided alternately by the ideal form or the

\footnotetext{
${ }^{30}$ To be fair, several mechanics disagreed with the common warbirder view that expertise would be forever lost with the passing of the wartime generation. These mechanics argued that any careful mechanic could develop the skills necessary just by doing the work.
} 
classificatory identity of the airplane — its "type" — and by the airframe as it stands — a "token" of that "type" (Cf. Silverstein 2005). Further, contradictions between the evocation of type versus the instantiation of the token lead to different discourses and practices of authenticity, using "safety" as a mediating term.

The bulk of CD's restoration took place in the 1980's, and for the Wing restoring it meant remaking it as an "authentic" C-46, to the best of their ability. We will explore below the extremes to which different warbird groups go in pursuing "authentic" restorations, but $\mathrm{CD}$ provides an adequate example of the process. This labor required the erasure of many material traces of its past. The biggest change was to replace the skins that had been altered to fit pesticide-spraying nozzles onto the airplane. The complete overhaul also replaced many other parts, the full inventory of which I do not have. Many additions were made, however, to increase its period feel. The plane received not only new engines, but new artifacts like World War II-era radios, a navigator's table, and a “jump line” for paratroopers. The radios served as an important focus during later airshow tours, as they helped frame the airplane as a very old machine.

Restoring the plane meant not only putting the working parts back into wartime configuration, but also making the airplane "look" like a World War II airplane. The biggest visible transformation was the plane's new paint job, complete with a name, nose art, and wartime military markings. Adding the appropriate paint, name, nose art, and military markings has been a vital component of the warbird movement. These elements transformed the aircraft from merely large or fast aircraft into military-looking planes. The shift was only allowed by the FAA in the late 1960's, so photographs from the early days of warbirds are somewhat disorienting for warbirders today. The lack of military markings on the warbirdshaped aircraft strikes them as anomalous. In fact, the warbird magazine Air Classics runs a regular feature called "Before They Were Warbirds" featuring pictures of these aircraft in various civilian liveries. The addition of paint, name and nose art also is critical for 
establishing the identity of the aircraft as warbirds, differentiating them from common, general-aviation planes as well as from each other.

The work of restoring CD built the Wing, as I suggested above. As the Wing applied new sheet metal, installed a new floor, built a navigator's table, installed World War IIperiod radios, and cleaned away the thirty years of corrosion and dirt, they formed connections to suppliers, recruited skilled workers, found willing donors, located workspace, sought invitations to airshows, established relationships with military organizations, and so on. In other words, they built alliances that "spread out" their cultural-technological practice so that it might persist.

While restoration work involves a great deal of alliance-building and skill-using, its central goal is to conventionalize an airplane as an historic object. Conventionalization is merely another form of invention, but it is an invention that masks itself. Conventionalization renders an idea innate, part of reality, which makes it the ground against which we can perceive invention as figure. Restorers, however, would argue that their labor merely elicits historicity which is innately contained in the object. Through all of the restoration work, the innate historicity of the airplane serves to "motivate" them to preserve it (Wagner 1981(1975)). This historic identity, however, has to be rendered salient through warbirders' "preservation" of the "piece of history." A crucial step in this elicitation links the airframe in the present with the airplanes that were used in the war.

\section{Aircraft Identity}

The work on $\mathrm{CD}$ had to mask its invention by conventionalizing the airplane as a specific piece of history: a Curtiss C-46 Commando. The physical and visual transformation of the airframe accomplished, in part, a transformation of the aircraft's identity, but even with the "correct" paint job and mechanical configuration, this identity was multiplex. In different contexts the airplane/airframe is identified as registration number N53594, serial number 44-78663, CD, "she," an "old country girl," "the old whore," the airplane, a Curtiss 
C-46, "the Doll," "a big lump," a uniquely effective airplane, a former plane of companies called Riddle, Zantop, Universal, Ortner Air Service, Plymouth Leasing and Rosenbaum Aviation, and a C-46 "F" model, among others. These identifications attend to different aspects of the object's materiality, its performance, its classification, and its specific background. The Wing has to render these different identities coherent with each other, which they do by subsuming them to the type identity as a World War II aircraft they sought to highlight. They accomplished this end in two steps: first through the use of aircraft typologies and then through the invention of ontological links to the war.

This range of identities had to be subsumed to a representation of the airplane as historic, a feat accomplished by linking the contemporary aircraft to the wartime ones. The wartime paint job, as noted, has become an index of an historic airplane. The "nose art" on CD extends this association with the war. While the plane's nose art does not copy (to my knowledge) that of any wartime aircraft, the Wing's history of the plane emphasizes that its nose art was the last designed and painted by a famous wartime nose art artist before he died (Fleishman). The art's link to the war exists not only through the style but also through the artist, who was himself historic. Further, both the art and the name attempt to recall the famous "Hump" mission. All of these efforts to link to the war, however, depended on a synecdochic connection between a plane identified as a token of a particular type now and the many tokens of that particular type which operated during the war.

According to the Wing's reconstructed history of the airframe, the plane never participated in any wartime mission. A tension therefore exists in the aircraft's identity, between the individual airframe's history and that of the type identity they sought to highlight. ${ }^{31}$ The Wing's display of the aircraft itself suggests a framework to pursue the interaction of its identities as "CD" and as "a Curtiss C-46 Commando." On board the plane

\footnotetext{
${ }^{31}$ I should also point out that the heavy emphasis on the Hump mission is itself a reflexive assertion of historicity which would have been impossible during the war. The Hump pilots and crews would not have understood their efforts as THE important mission for the C-46, nor would they have objectified the C-46 as the war-winning Hump-hurdler while the event was ongoing. Only with historical reflection does the "Hump" become so central to the C-46's identity.
} 
the Wing has two bulletin boards of pictures for public viewing, one devoted mainly to pictures of CD's restoration and the other devoted to wartime pictures of the plane flying the "Hump" mission. The first board shows the invention of CD-as-token through the SoCal Wing's work. The pictures depict Wing members working on the airplane in various states of its disassembly, preludes to the "CD" that visitors experience. The second set of pictures seeks to conventionalize the history of the C-46 type as the Hump-hurdling hero, with wartime shots of the airplane in the air and other elements from the Hump mission. These pictures invited the synecdochic linkage to the wartime airplanes. I take this pictorial dichotomy as a binary distinction which pervades warbirding, distinguishing the airframe-astoken (the object or airplane in the present) from the airplane-as-type (the wartime-based classification and grouping of airplanes which were used in the fighting). Warbirders commonly articulate the typologies of warbirds in order to subsume the identity of their particular airframe under the type.

\section{Typologies as Tools/Strategies}

A key technique for establishing the historicity of warbirds is the development and discussion of typologies. Through these classifications warbirders not only delineate the type's distinguishing features (and its schema or ideal form), but they also connect the token object in the present to the wartime aircraft. Typologies therefore provide a naturalistic ground of historicity from which a restored aircraft can be felt to provide the experience of history. Warbirders invoke the typologies in every activity and context where the airplanes appear.

Warbird typologies derive from the wartime classification of aircraft. This combination of bureaucratic classification and corporate marketing built an elaborate system to sort out the different aircraft by military service, function, engine used, modification, and so on. For example, the plane called the P-51 Mustang was classified as a "pursuit" plane, hence the P. It was the fifty-first design in the "pursuit" class, so that gave it the number 51. 
It went through several different models (A, B, C, D, Historicity and K), using different engines and structures, and having different performance characteristics. Any of these modifications of the P-51 could have been the basis for creating a new type, but the P-51 branding persisted. A change in predominant use, however, did alter the classification, as the "attack" version of the aircraft was called an "A-36 Apache" while the "reconnaissance" version was called an "F-6." These variations show that classifications are never absolute but rather the work of culturally situated actors (actants) ordering data from a particular point of view (Ford and Steward 1954). In that sense, then, the type-identity of an aircraft is anything but an inherent aspect of the object. Rather, type identity is a cultural production.

Typologies establish the distinctive features of different airplanes. The variations of the P-51, for instance, derive from differences in engine (the Allison-made V-1710 in the A model and the Packard/Rolls Royce "Merlin" in the later ones) and canopy type (the "Razor Back" in the A, B, and C models, and the "Bubble" type in the later ones), among others. Enthusiasts pursue these features into finer and finer detail, and this detail offers both a field for establishing expertise and an expansion of potential "historic" experiences of warbirds, as enthusiasts seek out each of the particular subtypes. Restorers, on the other hand, use these distinctive features to construct their aircraft's identity, choosing from among features materially extant on their "project" airframe and features they seek to create for their project. Warbirders conventionalize the typology today as an inherent dimension of aircraft identity which they can use to guide their restorations, sort their collections, plan their acquisitions, and schedule their airshows. Pilots seek to fly the various types so that they can collect them in their logbooks.

Since World War II these typologies have been handed down, and thereby transformed, through popular media about the war. As a child I read through books depicting the "P-38 Lightning" and the "P-51 Mustang" — including brief histories of the types, detailed drawings of the aircraft's structure and colorful displays of different squadrons' 
paint schemes — and played with plastic models of a "B-17 Flying Fortress" and a "B-29 Superfortress." Others saw the aircraft in movies, from wartime films through the later films in which today's warbirds were used for realism to today's ultra-authentic blockbusters. While a full examination of these different media for communicating the typologies is beyond this study, we can note their role in filling the gap between the typologies used in wartime and the classification of aircraft today. During the war the typologies established brands (such as the Grumman "Iron Works," known for producing strong and solid aircraft), guided procurement, and structured combat and other missions flown. Typologies were a means to understand both corporate product lines and the military's inventory of weapons, its capabilities. $^{32}$

It is not merely the context in which they typologies are used that has changed, however. Their content has shifted as well. In a footnote earlier, I mentioned the impossibility of seeing the C-46 as the heroic Hump-hurdler during the war because its identity is a reflexive construction. The same holds for these typologies, as today's classification would add to the wartime branding and sorting of military airplanes any of the significant wartime events in which the type was involved. This addition of meaning or connotation could include a modification made to a specific group of aircraft in the field during the war or even the configuration of aircraft to perform a mission in a specific theater, like the P-51's gasoline drop tanks used when escorting Allied bombers on long missions. The enthusiasts' diligent cataloging of wartime production and modification events therefore incorporates elements well beyond the interest or use of wartime institutions in creating the classification.

A variety of specialized activities emerged which use, sustain, and elaborate warbird classifications. The books, magazines and movies I described above articulate them.

\footnotetext{
${ }^{32}$ This cataloging of capabilities through typologies does not necessarily map onto the actual uses of the machines in the war. A "pursuit" plane might be used for ground "attack" as well, for example.
} 
Aviation archaeologists spend a great deal of time researching wrecks to be able to identify - thereby using and reinventing the typologies - the twisted and corroded metal they recover. Archival researchers track airplanes of specific types from the factory, through various military assignments, and then through various companies or foreign militaries. Often they seek to catalog as many examples of one subtype as possible. Their research finds many ready recipients who purchase their books and view their websites. Each enthusiast generally develops a favorite type to which he pays particular attention and then seeks these types out at airshows whenever possible.

Airshows and museum displays are critical for the development of typologies because they place a diversity of airplanes together, suggesting both commonality (they are all pieces of history) and difference (each is a different type, developed and used for different purposes). By placing warbirds side-by-side, airshows allow viewers to learn the distinctive features of the types, and the tour guides and performance narrators point these out whenever possible. Typologies, in turn, provide the basis for airshows, as planners seek to have as many different types of warbirds, or as many of a single type, as they can. Further, airshows employ typologies by finding syntagmatic connections between past and present planes, like the "Flight of the Cats" which featured a range of old-and-new, Grumman-made aircraft named for cats (Wildcat, Hellcat, Tigercat, Bearcat, Panther, Cougar, Tomcat).

Contradictions often emerge, however, between the airframe-as-token and the airplane-as-type. We can see these contradictions at airshows, when the viewing public encounters an aircraft presented as a token of a particular type. Enthusiasts, for example, might point out that the "Grumman F6F Hellcat" in the SoCal Wing hangar includes features from two different subtypes, the F6F-3 and the F6F-5 versions (Coombes 1998). On the other hand, I have listened to non-enthusiast viewers talk through their first sight of a specific airframe, looking it over to learn about the type and to see how the authoritative material object in front of them matched their concept of the type. Mostly their comments fell along 
the lines of, "I didn't realize it was so big." These viewers also would not question the identity of the aircraft, but rather would use the material presence of the airplane to gain some insight into the wartime type.

This relationship gets slippery, however. The wartime classification operates as both the ontological basis of the aircraft and the teleological aim for the reconstruction. At the same time, the airframe itself gets evaluated for its faithfulness to the type and operates as a material token which viewers can use to experience the type.

\section{Warbird Ontologies}

Invoking the type allows for all of CD's disparate identities - including the personification of this airframe, its classification by the FAA, its place on different companies' inventory sheets over the years, its different missions for the postwar military, and so on - to be subsumed under a single term: China Doll the C-46. Despite the airframe's lack of involvement in World War II, the SoCal Wing had little difficulty in creating for the public a link to the wartime planes. Despite the material changes made to the airframe and despite the plane's stateside history, the Wing connected to those wartime C-46's through the typology: it was produced during wartime as a C-46 and it corresponds to the ideal form of the type. Warbirding therefore starts from the wartime typologies, not the postwar and recent "lives" of the airplanes, to articulate the ontological status of the aircraft.

Just as Latour (1999) argues that the production of scientific knowledge depends upon "circulating reference," which connects a scientific paper to some dimension of the material world, warbirds have to have some linkage to World War II through a typology. Latour argues that science connects ideas or theories to reality not across an absolute chasm between word and thing, but rather through a series of small connections between matter and concept, a chain of references. Each step of reference begins with a material form and ends with an idea, concept, or sign, with a small leap between word and thing at each step. For 
example, a set of soil samples is fitted into an interpretive device which allows a soil scientist to "read" a hectare of soil, and in the next step this soil-filled array then serves as the matter which gets coded by standardized measures for use as raw data in the next step. At each step, something of the prior step is preserved while much is erased, but every step is traceable back to the original context. Further, the chain has to be sustained continuously, else the "fact" would cease to hold because it would cease to refer to the (relatively) unabstracted reality with which the scientist began. Warbirds, on the other hand, connect not to some material reality but to the "real" events of the war. Even though those events are "lost to history" at this point, warbirders must maintain a chain of reference to those events for the planes to remain "historic." The typologies provide the substance of this chain of reference.

Highlighting the ontological status of the "airplane-as-token" requires attending to those dimensions of the material object (i.e., the airframe) which can be connected to its wartime production as a token of the type. These linkages can be documentary (paperwork or other media articulating the object's presence in a unbroken chain of contexts, ultimately ending in the time of World War II) or material (some scar or trace which suggests presence during the war). Highlighting the type alone on the other hand, attends to the (ideal) form of the airframe as it exists in veterans' memories, wartime photographs, book descriptions, technical manuals or factory blueprints. In this sense, if it has the proper form of a warbird, then it is understood as matching the type, rendering it historic.

The most common and powerful way to connect to the wartime typology comes through a documentary link to a wartime-produced aircraft. The documentary records usually contain a series of steps, tracked through the civilian registry maintained by the FAA. Documentary identification of an aircraft begins with numbers: the factory serial number, the military serial number, and the Federal Aviation Administration (FAA) registration, or "N" number. The use of the serial numbers establishes the origin of the aircraft in question so that where and when it was produced can be traced. The serial numbers represent an aircraft 
that was made, though the work of connecting that aircraft in the past with one in the present can be quite difficult. These serial numbers form the basis of identity for the FAA, and the FAA connects that original identity to an identity plate (data plate) attached somewhere to the airframe. As long as an airframe/token has a data plate, with some exceptions, it has a legal identity. For warbirds, however, the issue is less clear because airplanes often are restored from pieces of a variety of airframes, each with its own data plate. In some cases, a restorer/owner might have just the plate from one aircraft while the bulk of the airframe comes from a different aircraft, which lacks a data plate for some reason. This is called building an aircraft "around a plate," and has happened with a number of flying warbirds that were restored using the data plate from an airframe that had been destroyed in a crash. If no plate is available or the aircraft cannot be assigned to a specific data plate, then it does not get classified as the desired type of aircraft. It becomes instead an "experimental" class aircraft and is identified as made by the individual registering the plane, not the wartime factory. ${ }^{33}$ For example, the airplane in the SoCal Wing hangar that they present as a "Grumman F6F Hellcat" was found as an abandoned hulk without an identity plate. As a result, it is officially registered not as a "Grumman F6F Hellcat," but as an "S \& S Special Grumman F6F," named for the people who restored it (Coombes 1998). From the FAA's point of view, the airplane is not a "Grumman F6F Hellcat." This regulatory identity — which is relevant but not determinative for warbirders - therefore integrates the form of the object, the documents demonstrating its identity and the material trace of the machine's (or some other machine's) past, the data plate. The data plate is the most important material trace of wartime identity, but other traces of the war exist which can be read out of the object.

\footnotetext{
${ }^{33}$ Just to confuse matters, I have to introduce another "classification," the regulatory classification administered by the FAA. This classification limits what the operator can do with an aircraft: carry passengers or cargo, fly only for exhibitions like airshows, or fly recreationally. The FAA classification of warbirds varies, depending on the lengths to which the original manufacturer (or some company since) went to get the type certified. If no effort was made, the planetype often is classified as "experimental," a class that includes home-built aircraft as well. The experimental class has the lightest restriction and oversight of construction, maintenance and inspection, but those airplanes have strict limits on when and where they can fly. Other, more rigorous, classes include restricted, limited, and standard, covering everything from small general aviation planes like Cessnas to the largest airliners.
} 
They prize combat damage over all other wartime traces, as I will discuss below, but they also enjoy the marks left by soldiers and factory workers on the aircraft.

For $\mathrm{CD}$, the regulatory identity is unproblematic. Its official identity began in the factory, where it was produced under contract with Curtiss construction number 22486 and military serial number 44-78663. When the plane was sold for civilian use, it came under civilian regulation and was given the identification number of N53594, which apparently led later to the nickname "Ol' 594" or "Ol' 94." 34 The FAA records show a succession of corporate owners, ending with the Confederate Air Force. The important dimension of these successive owners for the aircraft's identity is that they can be linked together to connect to that plane coming off the assembly line in 1945. Note, however, that such a connection did not hold for the Wing's "Hellcat." In that case, the documentary link to the war was broken, but the airframe was still accepted as a Hellcat because it materially matched the type's schema, as described above.

In pursuing the aim of making the airplane just like it was, fitting the token to the type, warbirders draw on the authority of both received schema of the type and the qualities of the airframe/token itself. When restoring an aircraft to be/of particular type, the schemata guide the remaking of the material object. The restoration work on $\mathrm{CD}$, for example, was guided not only by skilled mechanics and pilots who drew on long-ago experience with C46 's or similar aircraft, but also by a collection of blueprints which lent their schematic authority to the Wing's work on the airplane. If they were ever challenged on the correctness of their restoration, they could pull out those blueprints. Such has never occurred with CD because the object's connection to its wartime production as a token of the type is relatively well-documented. Even when the material object is radically altered by adding all-new materials, however, the object's typological identity (and therefore its claim to historicity)

\footnotetext{
${ }^{34}$ This nickname suggests the ease with which aircraft identities proliferate, since something as seemingly impersonal as a number becomes part of the airplane's personification.
} 
can remain intact if the object fits the schema, or the ideal form, of the type. Warbirders often alternate between attending to the token's fit with the type's schema and to its documentary connection to the type in tracing their referential connection to the wartime airplanes. Indeed, the alternation between these modes of identification allows restorers to cover ruptures in the airframe's connection to the past, as with the Hellcat, as well as with aircraft "built around" a data plate. Only when a connection is entirely severed does the ontological status of the aircraft come into question. When the connection fails, the airplane will be called a "reproduction." For example, one company has built a number of World War II German jets using an "original" as a model. In that case no material linkage to an original airplane can be produced, but the schema — drawn from an object as model matched exactly. Similarly, when an aircraft deviates from the schema, its type identity might be challenged, rendering it a "replica," like the $1 / 2$ scale home-built kits that exist. The tension between the current instantiation of a warbird and the material and schematic link to the type provide the basis for much debate within warbirding about authenticity, replication, and reproduction.

\section{Authenticity}

As I described above, most of the surviving warbirds filled some kind of utilitarian role after World War II for which their configurations were altered. The result was that no airplane which had flown much since the war could possibly have stayed in its wartime state. Given these many changes from the wartime types, warbirders developed a tremendous concern for authenticity. The dominant definition of "authentic" in warbirding is an airframe/token which resembles its wartime type-configuration as closely as possible, including such hard to find items as gun sights, bomb racks, and gauges. In recent decades, collectors who compete in concours d'elegance have gone to extraordinary lengths to achieve greater and greater authenticity. While this view favors adherence to the ideal form 
of the type, a minority of warbirders — though a majority of aviation museums — favor preserving the airframe/token's own traces of history.

One experience I had at the SoCal Wing demonstrates the felt need to keep the airplane "like it was." We were repairing/restoring the lavatory on a postwar passenger aircraft the Wing had recently acquired. We replaced the "lav's" floor (the bodily liquids accelerated corrosion), and then we had to deal with the pipe which drains the "lav" contents. According to the retired airline pilot with whom I was working, the cap to this pipe was called the "Honey Bucket cap," to satirize the nasty job of draining it. Age and corrosion had sealed the cap shut, and it resisted all of our efforts to remove it. I suggested that we just cut it off because no one was going to use the "lav" anymore. Further, the cap was behind a panel, so no one would see it. The retired pilot I worked with rejected that idea, however, saying that it had to keep its original part. Since this work was pleasurable leisure for him in his retirement, preserving the cap could have merely been an enjoyable challenge, yet the ease with which the authenticity discourse sprang to mind and with which it ended the debate indicates its power.

In warbirding there is a tension between having the same experience of the object as people did during the war and encountering material traces of that war, which is another way of interpreting the different experiences of "history" one might have with the ideal form (type) of the airplane and a specific token of that type. These different relations to the past lead to different logics of authenticity and different understandings of historicity. On one hand, having an object materially identical to the ideal form of the wartime type is felt to offer the same experience, or almost the same experience, as the wartime flyers had. On the other hand, like many sacred objects, some warbirds derive their significance from their copresence/contemporaneity with wartime events. In this latter sense, having an "original" airplane or part is what matters, and the object takes on an aura of historicity through its material, not formal, link to the past. The latter form of authenticity — the airplane as relic 
— is what drives museum collections like that of the Smithsonian Institution, while the former — seeking the experience of the functioning artifact — is what drives warbirders to fly their airplanes.

\section{Traces}

Miller argued that objects are often implicated in temporal discourses because the passage of time leaves traces on them, and warbirders do delight in reading the marks of time in their airplanes. This delight, however, applies only to some of time's marks. The marks that matter most to warbirders are those left during World War II. Fewer warbirders appreciate the marks of the airplanes' aging and use since the war. I never met a warbirder who found significance in the corrosion of metal in warbirds, for example. This chemical process does demonstrate the passage of time (though many factors can accelerate or decelerate it), but this mark of time was only a negative trait to be corrected, not a positive trait to be admired. ${ }^{35}$ The same holds for post-war alterations to a plane's configuration. Warbirders do not get excited about the drop tanks, sprayers and retardant residue left from years spent fighting forest fires as fire bombers. They also object to evidence left by a warbird's days as leisure plane, such as the "de-militarized," luxurious cockpits on P-51 fighter planes. Most restorers today tear out the luxurious appointments, replacing them with every bit of wartime hardware they can find. Stories of airplane restorations frequently describe the efforts made to "correct" these marks of postwar use so that the plane could be returned to its wartime configuration. The marks that matter, then, are the marks of war. This narrow historical view leads some warbirders to look for traces of the past in the machines where World War II was inscribed "into" the machine. During restoration and repair, they do indeed find interesting traces of the war, like messages written by the factory workers who built them.

\footnotetext{
${ }^{35}$ The work that warbirders do to erase these marks, however, becomes part of the process of inscribing the object with contemporary meanings, meanings linked to those who do the work today, as I will explore later in the chapter.
} 
For CD, no trace of World War II combat could remain because the airframe never went overseas. The Wing did spend a great deal of time removing evidence of postwar use, however, and they added a variety of "period" artifacts. The navigator's table, for example, was a special project which the Wing's carpenter modeled on one in a C-46 museum display. The Wing also added a few small artifacts, like navigator's headphones and an aerial map of China, to heighten the sense of historicity.

In discussing collecting, Appadurai (1996: 75-6) notes the desire for visible signs of age, called "patina," on collectibles. This aesthetic taste for patina makes many an object more valuable to collectors, but the same does not hold for warbirds. Warbird restoration involves a powerful aesthetic sensibility, ${ }^{36}$ but despite the attention given to the historicity of the airplanes, this sensibility favors the erasure of temporal traces. One might expect that the taste for old machines would include the presence of this patina, but the most-praised restorations look brand-new and the most-commented-on airplanes are perfectly clean and shiny.

In some cases an old part, an "original" part, may be "serviceable" - meaning functionally adequate and safe — but may be rejected on aesthetic grounds: it's too scratched or dented to clean up well. Visible damage to a serviceable part violates the current aesthetic of warbirding. The metal should be shiny, and perfectly formed; the paint should be pristine and pretty. Owners seek to erase the visible signs of age unless those marks resulted from war. If the damage came from combat, however, the owner/restorer would do everything possible to preserve and highlight it. For example, one shop restored a plane that had received combat damage in Italy. This damage clearly came from combat because it had been patched up in the field. When the shop went to restore this damage, they found that they could preserve the patches but not the combat-damaged skin underneath. That under-

\footnotetext{
${ }^{36}$ This aesthetic includes not only the "authentic" paint jobs discussed above, but also a taste for "industrial" design, the sound of piston engines, and so on. I discuss this aesthetic further in chapter four.
} 
skin was too corroded to use. As a result, they used axes to inflict their own "combat damage" on a new piece of aluminum. They tried to duplicate the original tears in the skin. With the newly created "combat damage," they could now re-apply the World War II-era patches. By preserving the patches, they were understood to have preserved, in part, the authenticity of the combat damage, even though the "original" damaged skin had to be discarded for safety reasons.

Despite the exception of combat damage, warbirding generally privileges the schema over the material object. The effect on warbird practice is significant, as substituting newmade parts which match the original schema for original, corroded ones allows the airplane to continue flying. This prominent warbird owner describes, without noting the paradox, newly made, more authentic parts:

I found out that ... someone's making these farings for a propeller, the authentic, original way. For a while they weren't available authentically, they had to be built up with components, these farings, but there's enough demand for that, and I think the ability to duplicate the process on a consistent level with modern materials to make a new faring that essentially uses the same materials and is the very same profile as the old faring. You know, as years go by, more and more things are going to be available.

This passage not only presents the paradox of making old parts in a new, better way — I did not ask how the part could use both "modern materials" and "the same materials" as the original - but it also notes that in the future, more and more authentic parts will be available for this type of warbird. If one focuses on the "original" object, this usage makes no sense. (It reminds me of a road sign I used to pass that advertised "Antique tables, made daily.") Yet when one focuses on the schema - the issue of modern materials aside - the usage is perfectly reasonable. Even the future expansion of authentic parts makes sense to 
warbirders, as parts manufacturers come to feel that enough warbirds exist to invest in making new, authentic parts. ${ }^{37}$

This understanding of authenticity has to be distinguished from the definition used by non-warbird aviation museums. A museum like the Smithsonian Air \& Space Museum wants all of the "original" parts of an aircraft — the same metal, the same fabric — in as close to working form as possible. This point of view leads them to pursue techniques of material preservation and restoration, with the aim of reviving corroded or rotting metal and fabric. By contrast, warbirds often include new-made parts because the old ones were too worn-out to use safely. Warbirders like to have the original parts, but they also want to fly their aircraft. They have therefore elaborated a logic of authenticity which focuses not on the object itself, but on the wartime schema of the type.

Mimesis, Originality, and Safety

Many warbird collectors today spend a great deal of time and money restoring their aircraft as authentically as possible, and while the CAF cannot hope to restore their airplanes as authentically as many private collectors, they have adopted the discourse of authenticity as a means to present their aircraft. Consider the detail in this passage about the CAF's B-24 Liberator:

In 1968 , the Liberator was purchased by the CAF for a price of $\$ 24,000$. Initially registered N12095 (later changed to N24927) and named Diamond Lil, it has flown since 1971 painted in the colors of an LB-30B/B-24A of the $98^{\text {th }}$ Bomb Group, Pyramiders of the $9^{\text {th }}$ Air Force in North Africa with serial \#402366. Initially retaining its C-87 solid nose and cabin windows, it has since been given an early B-24 nose that has made the aircraft look much more like the bomber it represents (March 1997: 29).

\footnotetext{
${ }^{37}$ This economistic thinking reflects another of the symbolic foundations of American "pragmatic" thought. The "law" of supply and demand and the necessity of profit are naturalized as the basis for human action (Sahlins 1976).
} 
This passage catalogs minor aspects of the airplane and its history (see chapter four for a discussion of enthusiasts' taste for this detail), while at the same time acknowledging, through "constructivist confessions" (Gable and Handler 1996: 573), just where the airplane deviates from its"original" existence as a cargo plane. CAF members would insist, however, that the airplane is now an authentic B-24 bomber. An "authentic" airplane in this usage is one that has the form of a wartime one, where an "original" airframe retains all or most of the parts from the wartime plane. I use the terms mimetic authenticity and originalist authenticity to mark this distinction, and they map roughly onto the distinction between the authenticity of type (mimetic authenticity) and the authenticity of the token (originalist authenticity) that I made earlier.

Warbirding has a great deal of debate, with no consensus, over what counts as a restoration, a reproduction, or a replica. Some privilege originalist authenticity posit formulae based on the percentage of "original" parts, with a restoration being mostly original, a reproduction being less than half original, and a replica having no original parts. Others focus on mimesis of the original form so that a replica would be a $3 / 4$ scale airplane, while a restoration would be anything of the right form with at least some original parts. The debates quickly get complicated, as they implicate aircraft identification plates ("data plates"), production processes for parts, production sites, acceptable substitutions for practicality and safety, and so on.

Warbirders also take the pragmatic stance that they have to add new parts because the airplanes have to be flyable. Indeed, within this technological system, the need to fly often works directly against the desire to keep original pieces, creating a contradiction between flyability and preservation. Skins have long ago corroded; no one makes the right replacement parts for certain carburetors; the wiring has failed. Further, some elements are too dangerous to use. The gauges used radioactive paint, now banned; the old wiring was wrapped in fabric that emitted cyanide gas when burned — and fires are always a big risk in 
aircraft. Warbirders have therefore developed a discourse of safety as a means to justify their preference for mimetic over originalist authenticity.

To warbirders, of course, safety is mere common sense. What counts as "safe," however, has resulted from a long cultural negotiation. It has been culturally produced through interactions between mechanics, engineers, pilots, federal regulators, and, yes, airplanes that do not crash and parts that do not fail. In this sense it reflects Latour's thinking of technological activities as integrating very different kinds of actants. By their reckoning, safety plays an important role in sustaining their technological system. Without the assurance of safety the plane's status might slip from "piece of history" to "aged plane endangering the public." Safety as practiced in this technological system, however, is not easy. The proper inspections, maintenance and restoration expertise, and parts all cost a great deal of money. Further, the right training, skill and judgment required to avoid crashing also require effort and money to acquire. We will explore some of these issues further in chapter four. For purposes of this discussion, however, we can see that safety provides a powerful, accepted rationale for altering the "original" object so that it can fly and thereby provide an "authentic" experience of the machine.

\section{Authenticity as Invention}

Authenticity in warbirding is very much understood as an achievement of the owner and restorer; in other words, the owner/restorer creates (i.e., invents) the authentic airplane through part manufacture, archival research, part recovery and refurbishment, skilled assembly, and careful documentation. This invention requires a ground of historicity against which it can construct its authenticity. Only an historically important object would be worthy of such attention, they might say. Restoration therefore extends the invention of warbird historicity by conventionalizing history as the motivation for creating a warbirds' authenticity. 
The historic importance conventionalized here, then, is just as much an invention as the authenticity, but historicity in this case differs greatly from other historicities which might be produced, such as the veteran's stories I discuss below. The focus on the authenticity of the objects masks/hides the events and contexts to which those objects were supposed to refer. Both mimetic and originalist authenticity obsess over the material form of the object and produce a materialism which highlights the object, present and past, over other potential pasts that might be evoked. Once this slippage occurs, authenticity becomes the basis for evaluating the ability of that objectification to accurately represent the past object (whether in substance or form), rendering it materialist. While much research in Anthropology has shown that a focus on material objects need not imply materialism - I think of the Aboriginal Churinga (Durkheim 1995(1912), Lévi-Strauss 1966) and Gawan canoes (Munn 1974) as two quick examples — in warbirding the translation of historicity into authenticity produces a materialist technocentrism. This conventionalized historicity is one of technological workings, not of people, a point I explore further in the next chapter.

\section{Historicizing the Doll at the Airshow}

While the work at the hangar was critical in constructing CD as a piece of history, the broadest presentation of this historicity occurred at airshows, where the plane performed for thousands of people at a time, as opposed to the tens of people who visited the Wing's museum hangar each day. The defining feature of a warbird, after all, is that it flies, and warbirders felt that large groups of people witnessing this flying best presented the plane as a "piece of history." As airshows exhibit contemporary planes as well, airshows and warbirders have devised strategies to separate the contemporary planes from the historic ones. Airshows construct a frame which classes warbirds as historic, while the phenomenological presentation and the narration of the plane also constitute the plane's historicity. 


\section{An Historic Appearance}

The earliest airshows highlighted airplanes as technological marvels and as tools for heroic aerobatic feats such as the "house crash" one elderly warbirder told me had been his most popular performance (which apparently was exactly what it sounds like). ${ }^{38}$ Possibly before, but definitely after, World War II, airshows added the celebration of current military technology to the standard performances. In the late 1940 's, for example, the United States Navy's aerial demonstration team, the Blue Angels, first formed. It may not have been until the 1960 's, when the CAF first took its airplanes to nearby military shows, that airshows started to feature older aircraft along with the contemporary (military and civilian) ones. At the very least, since the CAF's first shows in the 1960's, airshows have often emphasized historic aircraft as well, with some shows highlighting only historic aircraft. The emergence of the theme of "historic aircraft" at airshows has produced an overarching dichotomy between contemporary and historic at most shows. We will see that, given this dichotomy, the only available frame for presenting $\mathrm{CD}$ at an airshow was as an historic object.

This contemporary/historic dichotomy provides an organizing principle for all aspects of an airshow. Most shows have some contemporary military aircraft for crowds to examine, plus a few modern aerobatic planes, and perhaps a medical evacuation helicopter. They also have some historic aircraft, either vintage civilian planes or warbirds. In addition to the airplanes, airshows have souvenir stands where people can consume aircraft-themed products - T-shirts, pins, posters, plastic models, photographs, books and even imitation nose art which again divide into historic and contemporary categories. Crowds that see a World War II P-51 fighter at the show, for example, can buy a plastic model to build, a wooden model to put on a desk, a T-shirt depicting the plane, or a poster of a warbird version in flight. Alternatively, they could buy the same souvenirs for a contemporary F-15 fighter plane.

\footnotetext{
${ }^{38}$ I am aware of no comprehensive survey of airshow history in the United States, so I rely here on my impressions of the change in emphases over the years.
} 
Airshow organizers always encourage the audience to meet the pilots, and the military's flight demonstration pilots always have sessions where people can ask questions and learn about the life of pilots and crew. Most warbird-related shows have a tent where people can gather to hear stories not from the current warbird pilots, but rather from World War II veterans. ${ }^{39}$ Airshow performances highlight the old and new planes separately, and in recent years have had them fly together in "Heritage Flights," mixing discourses of historicity and technological progress. In sum, warbirds' presence at the show is structured by the historic/contemporary dichotomy across a range of contexts.

In presenting both kinds of planes, airshow organizers emphasize the importance of each. The contemporary planes matter because they are impressive, "high-tech" machines which are currently "defending freedom" as well as being big, loud, fast, and complex. Their display tends to overwhelm the viewers. The contemporary planes are there to highlight what the latest machines are and what they can do, as best as they can display at a show (there is always a huge gap between the planes' performance as "weapons systems" dropping smart bombs from 20,000 feet and shooting missiles from hundreds of miles away — and the aerobatic displays of the airshow). Older planes can, at times, fit into a similarly sublime role, such as when they start their engines or take off. (Indeed the ambiguity of a warbird's place in scheme of technological evolution — powerful machine or obsolete relic — crops up frequently in warbirding, as I explore in chapter three.) An old plane can also stand out because of its physical appearance - it just looks different and unique, or it resembles their image of "historic aircraft" acquired through various media — or because of the narratives presented by the warbird groups or by the airshow narrator. The import of warbirds may be familiar to most attendees, who have some knowledge of World War II

\footnotetext{
${ }^{39}$ The big airshow at Oshkosh, Wisconsin, actually features discussions from both warbird pilots and World War II veterans, though these exchanges are characterized by the warbirders' extreme deference to the veterans. I have not seen this approach elsewhere.
} 
aircraft through various media, but it is also always reinvented at the show through the planes' staging, the narrator's description, and the plane crew's comments.

In presenting $\mathrm{CD}$ the Wing takes pains to make their activities with the plane fit into the historic frame. The spatial organization of airshows varies, but historic planes usually are grouped together. ${ }^{40}$ CD's place in this grouping, coupled with the souvenir stand underneath and the uniformed attendants charging admission to go inside the plane, marks it as something important enough to merit the airshow crowd's attention. The plane also is usually identified in the airshow program, sometimes with a description and pictures of it. The various contemporary aircraft may be scattered in different ways, especially at the large military airshows with many different types of planes. The Wing members' military-style uniforms (once Confederate grey, now mostly khaki) also mark the plane as something significant and military-related (and they unambiguously identify the social situation of the plane tour as visiting an important artifact). The paint job also plays a central role in signaling the plane's intended role at the show. The unambiguously (to the trained eye) military markings, as described above, serve as an index to the plane's historic status.

The success of wing members in establishing the historicity of their airplane is shown in the welcome they receive at different airshows. Airshow narrators mention CD as a regular, giving a sense of the plane's time-in-role even to first-time viewers. At performances I attended, the announcers often praised CD, saying they were glad to have it back and noting what a nice job the Wing had done with it. While my data do not extend to the public at large, aside from my few encounters with visitors to the plane, the presence of the aircraft at airshows also leads to its presence in the warbird media, which in turn further "spreads out" its historic status.

\footnotetext{
${ }^{40}$ Unlike the temporal structure of the performances or the carefully arranged space of a museum, the planes are not arranged in any kind of order, allowing each person to find her own way. The "education" people are receiving, which I suggest is simply the having of a personal encounter with the plane, is available with any plane, precluding the need for crowds to be directed in a pattern of "organized walking" (Bennett 1995: 6).
} 


\section{The Experiential Contrast with Current Aircraft}

For warbirders, the critical difference between their airplanes and planes in museums is that they fly. A flying airplane is a "living" airplane, while one parked in a museum is a "dead" one. They believe that one cannot truly know an airplane without seeing (as well as hearing, smelling and feeling) it operate. Their invention of aircraft historicity foregrounds this phenomenological experience of the airplane. The experience of the plane includes more than its operation, however. The painstaking effort the Wing undertook to restore CD to something resembling a wartime configuration pays off when the touring public, especially veterans who flew in the plane, feel like they are having the experience of a wartime airplane. The feeling of historicity derives in part from implicit or explicit contrast to contemporary aircraft and technology, including planes appearing at the show and technologies from viewers' everyday lives. The qualitative differences between current and old aircraft, therefore, contribute to the experiential production of warbird historicity.

The contrast between old and new aircraft is both dynamic and static, apparent when they are flying and when parked. In both of these circumstances, a variety of qualitative features can be read and experienced as old and historic, given the airshow's framing. To many in the audience, the features which distinguish old and new are apparent, already part of their system of understanding, but for those who cannot immediately distinguish between a contemporary jet and a World War II cargo plane (or rather, identify them as a contemporary jet and a World War II cargo plane) the narrative invention of the aircraft will "educate" them, as I describe in the next section.

The differences in performance include not only how they fly, but also the framing for their performance. Generally, the warbirds are slower, quieter, and, in warbirders' eyes, more graceful than the contemporary planes. Warbirders sharply distinguish between the loud, piercing sound of a jet fighter's engines and the quieter, rumbly sound of a World War II piston-engined fighter plane. The performance routines share some characteristics, which 
are especially evident when the planes fly in formation. They make the same kind of passes in front of the crowd and have the performances staged and the planes narrated in similar ways. For the most part, however, the newer planes demonstrate their capabilities, while the warbirds reenact portions of the war. Contemporary jets roar by at high and low speeds; they perform loops, rolls, climbs and dives; they turn in as tight a circle as possible, with the narrator emphasizing the " $\mathrm{g}$ force" the pilot withstands in the maneuver; and sometimes they perform simulated bombing runs or strafing runs, with accompanying pyrotechnics. The emphasis throughout, however, remains on the capabilities of the aircraft. While narrators make reference to recent or ongoing combat, I have never heard them describe a performance as a reenactment of that combat. To that end, contemporary aircraft rarely appear in groups of two or more, so they always highlight the capacities of the individual planes. Almost all warbird performances, by contrast, explicitly make reference to the war. The CAF's World War II Airpower Demonstration explicitly imagines different battles that the airplanes are fighting in, but other demonstrations group airplanes by type, theater and period of the war, allowing the narrator to discuss particular episodes of the war involving those aircraft. Further, these displays rarely involve "pushing the limits" of the aircraft to show their full capabilities. Most warbirders argue that the planes are too valuable to perform aerobatics or other "hard" flying that could be performed in a specially-designed aerobatic plane. The emphasis is not on what the machines can do, but on what they did (or, dropping their attribution of agency to the planes, the events with which they are connected).

As I mentioned above, CD rarely flies in a show, but even when parked on static display, it and other warbirds contrast with contemporary aircraft. At that point all of the work that the warbirders did in restoring the aircraft to period condition is shown off. Even to the untrained eye, the paint, the radios, the switches, and so on all "look" old. (Of course, the eyes of the American airshow-goer are not untrained, but long experienced in "reading" machines for signs of their age and obsolescence.) For CD in particular, its "taildragger" 
configuration shows its age. It was one of the last big aircraft to have a tailwheel instead of a nosewheel, so its nose sticks high into the air while its tail touches the ground, clearly differentiating it from the contemporary airplanes parked nearby. Inside the plane, the tailwheel setup means that the floor slopes upward about fifteen degrees. ${ }^{41}$ Its paint is white instead of the understated grey or green of contemporary military planes, and its markings are more prominent. The airshow audience can learn to read any of these elements as indicating the plane's status as "historic" instead of contemporary.

To the trained eyes of pilots and mechanics, on the other hand, the plane looks old and unwieldy. A knowledgeable pilot or mechanic comes to warbirds with a range of knowledge about different aircraft, allowing them to "read" the warbirds as "primitive," simple, or even clever solutions to now-obviated problems. The bulbous shape lacks entirely the sleekness of contemporary aircraft (one of the plane's longtime nicknames is "Dumbo," attesting at least to its operators' aesthetic evaluation of the plane relative to other aircraft). They also can read them as difficult to fly or simple to work on, as I discuss in chapter three. While these experiences of mechanics, pilots and aviation outsiders are crucial for constituting the plane's historicity, the Wing members' and show-goers' narratives about the plane complete the task.

\section{War Stories}

If seeing an airplane fly offers some understanding of it, hearing and telling stories about it provides a different kind of account. Both warbirders and members of the public tell "war stories" about the airplanes at airshows, sharing both unique and common experiences of the aircraft. I use "war stories" both literally and metaphorically as a mode of narrative recounting (heroic, masculine) past episodes related to the aircraft. As we will see below, these involve either direct experience with combat or interesting experiences with the

\footnotetext{
${ }^{41}$ Kids enjoyed sliding down the floor until a Wing member shooed them away, saying the plane was not a playground. The Wing members, therefore, are careful to police the aircraft display as something requiring some solemnity, as I describe below.
} 
aircraft, but all go some way toward constituting the aircraft as historic. Narratives of various kinds are performed at the airshow, from the myth of the war experience (Mosse 1990) to the myth of the flying ace to the myth of the lone genius inventor. The narrative of historicity also appears in various ways and from different sources. Media representations play an important role in drawing crowds to see warbirds, and once the crowds are there, the warbirders, especially for less familiar planes like $\mathrm{CD}$, spend a great deal of time policing their planes' historicities. The warbirders also invent the planes' historicities for themselves further through interactions with war veterans.

\section{Policing CD's Identity}

Wing members seek to "educate" the public about the type and "what it did" during the war. In other words, having conventionalized the airplane as a C-46 and invested it with significance through all their efforts, they take steps to invent the plane for the viewing public as a vital piece of history. Most of the public, however, has little knowledge of the aircraft, which forces Wing members to spend a good deal of time policing, if you will, the identity and importance of the airplane. They have to establish it both as historically important (and therefore worthy of display next to other, more familiar, types) and as unique (a "Hump-hurdling C-46" as opposed to another heroic type).

They affirm its historic importance mostly by recounting the mission "flying the Hump." Sometimes they refer people to the photographs on the bulletin board, but mostly they describe the mission, emphasizing the tremendous losses that occurred in the terrible Himalayan weather. The high loss rate serves to elevate the heroism of the pilots - and the airplane, which is usually personified through these discourses - so that the plane fits in with all of the fighter planes and bombers that actually "fought" in the war, i.e., fired or dropped weapons. The mystique of the war experience is thereby extended to the aircraft. The interest in this mystique shows in the frequent questions, mostly from children, about the plane's armament or fighting. In my encounters, they often asked if it carried guns or 
bombs and if it shot down any "Zeroes" (a Japanese fighter plane). The Wing members and I had to admit that it had no armament, but that the mission was dangerous and required bravery nonetheless. We also sometimes pointed out that it did carry ammunition and bombs to fighting planes in China. ${ }^{42}$ These discussions of the plane's importance depend upon both the Wing members' narratives and the (reconstructed) materiality of the airplane around them. Framed by the old radios, the navigator's chart, the old navigator's headphones, and the industrial-era design of the aircraft (which involved a pragmatic aesthetic, with exposed, labeled parts and components), the stories about World War II service become more believable and coherent.

Members also have to police the distinction between the C-46 and its close analogue, the C-47. The C-47 was and is a much more familiar airplane, having become iconic for World War II paratrooper drops over Europe. It also was produced in much greater numbers and used much more widely by airlines and cargo companies (where it was called the DC-3). It resembles the C-46 in that both are fairly large, two engined, "tail draggers." Wing members get irritated by the frequent insistence that the plane is actually a C-47. Most members assume that people who insist they have flown in the type actually flew in a C-47. In other cases, visitors criticize the airplane as being much worse than the C-47, an opinion that many who have flown them both share. Even still, the members take pains to defend the aircraft, praising its cargo hauling abilities and pointing to the type's success on the "Hump" mission, which the $\mathrm{C}-47$ could not perform.

In defending the C-46, the members not only shore up the plane's historicity, but they also invent the aircraft as a uniquely effective airplane, working against the progress discourse that would depict the airplane as merely obsolete. In a pattern that repeats throughout warbirding, the C-46 is depicted as both obsolete and uniquely effective. At

\footnotetext{
${ }^{42}$ In some ways the work required to "educate" the public about the C-46 marked the Wing as a connoisseur of historic aircraft. They did not collect the obvious airplanes, after all, like a fighter plane, but rather spent a great deal of time restoring an important but unglamourous airplane.
} 
airshows and in other public discourse, Wing members describe the C-46's difficulties and capabilities. On the one hand, they have to admit that it is currently obsolete and was not even widely adopted after the war like the C-47/DC-3 because it was much more difficult to fly. On the other hand, it remained in usage as a cargo plane for a long time and is used today by a few companies. Wing members often mention Everts Cargo, which flies C-46's in Alaska, arguing that the C-46 does a job no other airplane can, carrying the heaviest possible load into extremely short, rough airstrips in remote Alaska. (The marginality of airplane operations in Alaska, interestingly, allows for the claim that the plane is not obsolete without disrupting the discourse of technological progress. In other words, the plane can be both old and obsolete and the most effective tool for use in an isolated location.) The need to mention Everts along with the Hump mission suggests the power of the narrative of technological progress. The machine needs to be presented as uniquely effective for its historic importance to be sustained.

While the Wing members spend their time policing CD's historicity and importance, the historicity and importance of many warbirds is already well established. The fighter planes, for example, are mostly well-known to the people who attend airshows. As a result, the "policing" those owners/guides have to do is somewhat different. Sometimes they emphasize whatever unique feature of the aircraft they have chosen to exhibit, while other times they defend some aspect of the plane that seems unfamiliar to most people. For example, one restoration of a P-51 fighter used a kind of "rear-view" mirror that was familiar to warbirders from its common use on the British Spitfire. The owner had to point out that the specific plane he was restoring his P-51 to represent, that of a famous American "ace," had used that mirror. Unlike the C-46 crews, then, this owner faced a public that knew too much about the type.

Media help build cultural understandings of machines in the first place, especially given the enthusiasm surrounding military technologies that I describe in chapter two. Media 
then extend these understandings into the specific realm of World War II aviation. Books, movies, television and magazines build up ideas about the airplanes as central actors in the war, actors that one can then go see at museums and airshows. It is beyond this project to examine the myriad representations of these airplanes that people encounter prior to attending an airshow, but I can offer a few suggestive examples.

My own exposure to World War II aircraft came through my brother's plastic models and books about World War II airplanes. He was fascinated by aviation from an early age and this fascination was focused on World War II. This World War II warplane focus occurs throughout children's (boy's) toys and books. Children's books tend to highlight what are felt to be the significant dimensions of the adult world into which kids will grow, and given American technocentrism, a lot of this includes technologies like airplanes, which are felt to appeal naturally to young boys. ${ }^{43}$ In many cases, the war itself disappears entirely from the media representation of the aircraft, such as the many children's books which feature World War II aircraft merely as instantiations of "airplane," free of any reference to the war. World War II aviation, then, provides a field for children's learning and memorization, like farm animals or dinosaurs. ${ }^{44}$ Another fine example comes at the end of the movie Saving Private Ryan when, in the midst of the brutal fight in the city between the Americans the Nazis, the hero is mortally wounded while two American fighter planes swoop in to save the day for the rest. The planes - which were P-51 Mustangs, icons of Americans technological prowess in the warbird world - capture technological enthusiasm perfectly in their sudden appearance and their apparently effortless ability to save the day. While this example depicts

\footnotetext{
${ }^{43}$ It occurs to me that the opposite could be said as well, that all of the farm animals, fantasy talking animals and so on that populate children's books are meant to construct a separate children's world. Nevertheless, ABC books, especially, seem to be filled with important elements from everyday life, and airplanes are one of these elements. Even when an airplane in a kid's book is not marked specifically as World War II military, its form is often recognizably from a World War II plane, suggesting that these airplanes to some extent form a basic airplane schema in American culture, with the other two forms of airplane schema being a jet fighter and an airliner.

${ }^{44}$ I know no literature on this topic, but kids do seem to learn/be taught to focus on memorizing vast catalogs of information, like all of the Presidents, the many different types of dinosaurs, or even all the World War II aircraft. Presumably this has at least some relation to (or else is merely useful to) consumer capitalism, with its world of detailed classifications and fine (but important!) distinctions between models, all in the interest of planned obsolescence.
} 
the glory of World War II airplanes, the planes' brief appearance does not allow for the enthusiasts' reveling in detail. That detail can be found, however, in a movie like Pearl Harbor, which was well-known in the warbird world for gathering many different types of warbirds to aid the verisimilitude of the film, or in one of many books and television programs that focus on specific portions of the war or specific airplanes. Any television special describing the Battle of Britain, for example, will include some discussion of the "Spitfire," the British plane that become a popular icon for the fight against the Germans. On the "Discovery Wings" channel (now the Discovery Military Channel), which was very popular with the people at the SoCal Wing, one special in particular stands out as encapsulating the approach to the war. This special sought to examine all the different aircraft that fought in all the wars of the $20^{\text {th }}$ Century, picking the best from each war and then the best overall. It reviewed various features and capabilities of each aircraft, as well as how they were used in the war. Not surprisingly for an American-produced documentary, an American plane from World War II, the P-51 "Mustang," won the best overall (1997).

These few examples, then, demonstrate some of the information and expectations that the public brings to airshows. Most people recognize old aircraft, some by name or type, some by association with a movie. A few know the types and some histories of the planes. In bringing this understanding to the encounter with the aircraft, however, we have to differentiate between it and the complex triangulation between the conception of the aircraft as a token of the type, the understanding of the type's relation to the war, and the experience of encountering the artifact, as narrated at the airshow. The meaning produced by the airshow encounter, then, cannot simply follow a script from a show or the narrative presented by the warbirder.

\section{The Ambiguity of Historical Reference}

In the "Hump" mission, the C-46 has a "story" that Wing members can tell the public. Despite the appeal of the story, however, other histories of the airplane often come up during 
tours. The airplane encompasses a diversity of memories/histories, many with reference to the war, but many with equally strong references to different pasts. These diverse histories coexist, both in the maintenance hangar and at the airshow, and their divergence rarely comes up, masked by the continuing reference to the object itself. Yet the divergent references matter when we examine the cultural work required to establish the plane's historicity because they greatly increase the range of narratives on which the Wing can call in doing this work.

The discourse of the Wing itself demonstrates the easy slippage between different pasts. As mentioned above, the provenance of all warbirds is carefully researched, whenever possible, although in most cases the years between a plane's deaccession from the military and its acquisition by the current warbird group are generally ignored. The "staff historian" of the SoCal Wing explored some of CD's history, however, uncovering the different corporations that owned the airplane over the years and talking to people who worked for those corporations (Fleishman). Even though these corporate operations had no tie to "the history" that warbirders argue is important, the Wing historian still gathered information about those years and the Wing highlighted it in their discourse about the plane. At one point they put an old picture on their website of the plane parked at a New Jersey airport, ready to haul cargo for the company that owned it. Different Wing members also continue to encounter information about the plane, such as the newsgroup posting on "Missile Power" described above. These little bits of information about the postwar, pre-warbird airplane not only reinforce the chain of reference linking the airplane to wartime C-46's, but they also demonstrate the ambiguity of CD's historicity. Is it historic because of World War II or because it was a useful cargo plane after the war? Both responses fit the discourse and practice of the Wing, allowing for a broader historicity, incorporating not only more of the airplane's - both the token airframe that became CD and the C-46 type - time but also more people and contexts, all of which spreads out the plane's claim to be "historic." 
For warbirds more generally, the divergent reference goes beyond an airplane's life as a corporate aircraft. Warbird museum groups often hold on to airplanes for a long period of time - in contrast to many individual collectors who "churn" their airplanes every couple of years. Over this period of time, the plane comes to be marked by the group in ways readable only by the group. Thus, on $\mathrm{CD}$, one can look at the nose art and think of the World War II veteran who first painted the picture in the early 1980's or the member whose wife repainted it a decade later. One can look at the wood floor or the navigator's table installed by a member who was a skilled carpenter. One can carefully unlock the tailwheel lock and think about the mistakes made by previous Wing pilots who ruined other tailwheel locks. All of these little aspects of the airframe lend themselves to a collective memory tied to the group (this does work in Halbwachs's (1992(1925)) sense), not to the glorious history of the type. The Wing highlights these memories, of course, in the photo montage of restoration pictures. These pictures do serve the function of reminding people that the airplane was restored and is maintained through Wing members' hard work and expense, but they also present the historicity of the aircraft as intimately tied to the Wing itself.

Despite CD's historic object status, displayed at the hangar and the airshow, not everyone approached the plane as an object of "Good War" heritage. One SoCal Wing pilot, for example, was drawn to the plane because of early childhood memories of civilian C-46's hauling cargo into a nearby airport and later experience flying the type for the CIA in southeast Asia (Deakin 2004). Visitors to the aircraft who say they flew in the type in the past often see it as just a military transport (contrary to its heroic role in the Hump mission), and occasionally people with civilian experience approach, such as a pilot who hauled meat in the type in South America. His description of blood from carcasses flowing out of the tail upon landing met up with the CAF pilot's stories about hauling refugees and pigs out of towns in Vietnam to extend the aircraft's historicity from the Hump-hurdling World War II hero to a more mundane cargo workhorse. Even these mundane stories, however, play an 
important role in the plane's historicity in that they accumulate past events that can support assertions that the plane was a "grand old bird." Indeed, most of the posts on the C-46 enthusiast group on Yahoo (n.d.) involve uncovering the postwar, civilian history of various C-46's. The World War II mission is what the CAF seeks to highlight in its discourse and practice, but they are perfectly willing to accumulate allies in their production of C-46 historicity, even ones with non-military connections to the plane.

These non-military connections are always subsumed to the grand narrative of World War II historicity, however. The following passage comes from an online newsletter of a different CAF group, one that had considered sponsoring the CAF's other C-46, the Tinker Belle.

We gave tours of Tinker Belle to around 1,000 people over the course of the weekend. The big highlight for me was meeting some folks who had flown C-46's during the war, and one gentleman who thought, based on the history of Tinker Belle (ex Zantop freight hauler) that he had flown her during the 1970 's. Every time I meet a veteran, I thank them for their service to our country. . . . (Pence 2001)

This passage shows the easy way in which different histories get blended together via the aircraft, and then get framed by the claim to militaristic patriotism. The writer easily connects the activities of a World War II C-46 pilot with a corporate pilot from the 1970's. In this shift, the emphasis moves from the participation of the C-46 as a type in World War II to the flight operations of a specific airframe, in this case, Tinker Belle. These two people with very different backgrounds then are treated as equally authentic, because they each had a past with the C-46, whether as type or as token. The CAF member's enthusiasm also shows the power that veterans' accounts of the aircraft wield. 
Veterans' Stories

Veterans' stories predominate as the most authoritative form of discourse about warbirds, and warbirders highly prize these accounts. For many warbirders, the chance to hear stories from World War II veterans is what motivated them to join a warbird group and what keeps them attending airshows. Almost every warbirder could tell me about a deeplyfelt encounter he or she had had with a veteran seeing his (or her, as they occasionally had a Women's Air Service Pilot as a visitor) old airplane again. For some veterans merely seeing or being in the airplane sparks long-dormant memories of events and people past. Many memories are of friends killed, while others merely remembered the exciting events of their youth. The airplane serves as material cue for these memories, a physical framework for memory (Halbwachs 1992(1925)). Some vets are able to recall tacit, embodied knowledge of the aircraft, like one fighter pilot who closed his eyes and did a cockpit check, touching all of the controls to see if they were set up properly. These stories are key to the memory practices of warbirding, elements of which I will explore throughout the dissertation. In this section, however, I will explore the role of this story-telling in conventionalizing the historicity of the airplane itself.

The visiting public has many different things to say about the airplane. For the Wing members dealing with the public, the people who talk about the airplane - as opposed to the vast majority who merely walk through with little comment - fall into two distinct classes: the BS-ers and the "ones who were really there." The BS-ers think they knew more than they do and make claims about the airplane that, based on Wing members' experience, are clearly wrong. Often they are the ones who insist that the plane was a C-47. The "ones who were really there," on the other hand, are quiet at first, looking around the airplane and recognizing familiar structures and components. One Wing member said he could always tell who these individuals were by their thoughtful demeanor, and he would allow them to sit up in the cockpit, from which most visitors were barred. They would sit in the pilot's seat 
and touch the various controls, lost in reverie. In these situations, the Wing member, formerly the narrator of the plane, becomes the listener, or at the very least, a fellow pilot, swapping stories. At this point, the vets either start crying or open up and tell stories about flight experiences, and sometimes both. It is a powerful interpersonal encounter. ${ }^{45}$ As I mentioned, all warbirders seem to treasure these shared moments. Interestingly, however, they rarely establish a permanent connection with these individuals. Once the shared moment passes, the veteran leaves with his memories, and the warbirder has another veteran's story to keep or to tell other Wing members.

These shared stories have many important features, but here I would like to consider their role in constituting the plane's historicity. First, the "BS-ers," while annoying, do contribute to the history-building process in that their tales presume the plane's historicity as the ground for their own exploits. Even if they get the history wrong, as warbirders would have it, their practice has to assume historicity to begin with. Their "mistakes" constitute a history that they get "wrong." Second, the "ones who were there" play a special role in that they affirm the plane's connection to the distant, heroic past. Anyone telling stories about the "Hump" mission in particular serves to authenticate the plane's importance, if only for that Wing member and for those to whom he tells the veteran's story. This authentication then allows the Wing members to argue anew for the plane's historic importance, and the stories, when repeated, help "spread out" the planes historicity.

The authority of veteran's experience also works in another way to conventionalize the airplane's historicity. The experience of the war, in fact, does not need to be mediated by veterans at all, at least not in person. For some warbirders, the machines testify most clearly to that experience, albeit in a limited way. This middle-aged CAF member was

\footnotetext{
${ }^{45}$ I discuss the role of these emotional experiences as mediators of distant imagined events (like World War II or today's war in Iraq) in chapter two.
} 
devoted to the B-17 bomber, through which he felt he could establish at least some link to the war experience:

I'll close my eyes, just sitting in the radio man's compartment, I can just imagine all this stuff, being shot at, what it was like being scared, cause then I can hear the noises of the plane, the vibrations and everything. So in a way I can get that feeling. . . . I can remember what it was like, but the actual feeling won't be there.... But I do try to look at it from their perspective, all the bad times they had. Being shot at, the food, the living conditions, all that. I told people I know that were, 'I can't feel the same, I can't relate to what you went through.' I can kind of relate, because there are experiences that are kind of parallel, but the experience is not going to be the same. The feeling may be the same, but the experience is not the same. . . I can't have their exact experience, but I know that.

This passage conventionalizes the experience of the machine as the experience of a certain kind of history. He says that he could have the same experience of the machine that World War II crews did, but he notes that the framing of that experience is entirely different. Here, then, the historicity of the machine has to be conventionalized so that the machine can provide the same kind of machine-experience as occurred during wartime, even if his nostalgia produces an unbridgeable gap between past and present. The gap between the experiences is foregrounded while the invention of the experience of the machine as itself the experience of history is backgrounded.

\section{Materiality and Memory}

Such imagining of war events "out from" the machines, sitting in cockpits and imagining aerial battles or touching an aircraft and remembering/imagining what it was like at a particular battle suggest a crucial relation between material objects and memory. Nora (1989) suggests that Euro-Americans no longer have collective memory, by which he means an integrated, lived-in memory which he locates in primitive and peasant societies. Instead, he argues that they have to objectify their memory in "lieux de mémoire" so that they can experience it. Rather than adopting this Romantic perspective that they are living in the times after the Fall, I would argue that this objectification of memory is merely a specific form of cultural invention. This current regime of memory tends to conventionalize memory as a set of things one can possess or experience directly through objects, again, something 
like Halbwachs's (Halbwachs 1992(1925)) theory of collective memory, while at the same time inventing ineffable dimensions of the past which cannot be objectified into an artifact or possession. As the archives expand, then, so does a constant sense of loss to accompany them, even though the loss is just as much an invention as the archive. That sense of loss deeply informs warbirding, as can be seen in the fear of the planes' grounding, the longing for the thousands of scrapped airplanes, the obsessive cataloging of all warbird "survivors," the frequent mention of the thousands of World War II veterans who die each day, and so on. All of this is not to say, however, that the memories warbirders experience through the airplanes are wrong. Certainly they relate to events of the past, but they are also reinvented through the process of warbird display, through the coming together of veterans' stories and the object foci of those stories. Further, the fact that they relate to events of the past does not explain their significance today.

These memories clearly are cued by the physicality of the airplane. Warbirders described the memories flooding out of veterans upon seeing and touching the airplane again. The material object, then, plays a critical role in this memory practice. We have to note, however, that the plane's physicality was a cultural production of the warbird groups. The attempt to recreate the wartime type and its appearance at an airshow within an historic frame, as a "piece of history," not to mention warbirders' location of veteran's memories at the center of their practice, play important roles in setting up these weighty encounters and pre-figuring their meaning. Specifically, they occur within the frame established of the aircraft and they thereby adopt the technocentrism of that framing. They may involve memories of friends lost, but they frequently involve something they did with the airplane or an attempt to recall how something works. They work through the airplane to reach the past. This technocentric memory production plays an important role in reinforcing the historicity of the aircraft itself. 


\section{Beyond the CAF}

Despite CD's utility in illustrating the invention of warbird historicity, we have to look to other warbird groups and owners to get a full sense of the topic. As I described in the first chapter, the Commemorative Air Force is the largest of the non-profit museums. A few other museums are similarly situated, most notably the Planes of Fame museum in Chino, California, but the majority of warbirds belongs to wealthy collectors and private individuals. Collectors are ultra-wealthy men - I know of no women in this role - who own a number of airplanes, and often donate create a museum and, for tax purposes, donate their aircraft to it. Many private owners, while wealthy, are not super-rich businessmen like the big collectors. They own only one, or maybe two, airplanes, and they are not connected to a museum.

Over the years the activity of these groups has changed from a leisure or sport practice to a heritage practice, as historicity has become more central to the warbird movement. The discussion above illustrates the ways in which the CAF have emphasized the historic importance of their airplanes, but two dimensions of rich collectors and individual owners' historic practices deserve comment. First, the collectors have to some extent displaced historicity with a logic of competitive authenticity. Second, individual owners as a group have held contradictory views of historicity, either downplaying it altogether or cultivating personal contacts with veterans.

\section{Authenticity as Competition}

Sometime in the late 80 's or early 90 's (different people date it to different aircraft), collectors began spending a lot of money to restore an aircraft with the goal of winning the "Grand Champion" award in the concours d'elegance at EAA's Airventure and Sun n' Fun airshows. As the years passed, the competitions became more and more intense for both groups of people. The factor that has driven these collectors has been authenticity. While they would insist that they were preserving a "piece of history" and "honoring the veterans," 
airshow competitions have made establishing the highest possible level of authenticity their major concern.

As a group, they pursue mimetic authenticity, meaning, again, that an airplane has as close to its wartime configuration as is possible, using new parts whenever necessary but preserving "combat damage" when present. All aspects of the plane are supposed to be reproduced exactly. The paint has to be the right type and the exact color. The parts, even new-made ones, have to have the correct part number stamped on them, as they would have had in the 40's. One restorer went so far as to research which parts inspectors would have been working on which day and then reproduced that inspectors' rubber stamp for a part. One prominent collector has lately been restoring his planes to look better than they did coming out of the factory. While this desire seems absurd, it stems from the contrast between factory and craft production. The planes were originally built on an assembly line, where speed was of the essence and aesthetics took a distant second to function. Warbirds, however, are restored by hand, by skilled craftsmen who can agonize over the plane's appearance.

As mentioned above, the discourse of safety plays an important role in justifying these like-new restorations. One airshow judge told me that he prefers safety-induced alterations to the original form and would not deduct authenticity points in the competition. There was a case, however, where the owner or restorer ignored these safety limitations, using the same wiring fabric that could produce cyanide. This safety compromise - as it was seen by the restorer and by the warbird world - was made not in the name of retaining the original part, but in the interest of perfect mimesis.

Some warbird afficionados, however, argued that these big, expensive restorations got authenticity all wrong. Two different critiques arose. First, they argued that the whole point of restoring the airplanes is to fly them, to perform for as many people as possible, but the gross expenditure required to make a "99 percent authentic" airplane kept the owners 
from wanting to fly it. To get the real experience of the airplane, in this view, it need not be so perfectly mimetic, but it should fly.

The second critique holds that this quest for perfection as more about the ego of the owner/restorer than about the historicity of the airplane. The chronotopic convention (Bakhtin 1981) here is different from that in other warbirding contexts. At the CAF the airplane's historicity was somewhat ambiguous, referring mostly to events (and objects) of World War II but also to the Wing's own past efforts. The collectors' ultra-authentic airplanes, however, refer much more to the owner/restorer's efforts in the present. They are meant to be historic in the sense of a singular achievement (by the owner/restorer) in the present. Restorations can be "historic" in the new level of authenticity they have reached. One airplane, for example, was described as historic in the following senses: the type was historic, the airframe had combat history, the level of restoration was historic, and the restoration of a plane that shot down six enemies was historic (i.e., the restoration of a plane with that amount of combat history). The critique of such conflations of "historic" holds that the quest for authenticity has become a quest for "the best" rather than a quest for historicity. Seeking "the best," a title effectively conferred by the Concours d' elegance at Oshkosh, has therefore been elaborated into a hugely expensive and involved pursuit of the ultra-wealthy. This status competition has rippled through warbirding leading all warbirders to defend the authenticity of their particular machine.

\section{Play, Historicity, and Identity}

Despite the visibility of the super-rich collectors who compete in these intense authenticity competitions, many warbirds are owned by individuals. These individual owners bought their airplanes not only because of their historicity, but also because of the glamour associated with them, especially the "fun" of flying fast in "historic" machines. The fun of owning a warbird, appearing at an airshow or just flying with friends - like that of "winning" the authenticity competitions - does involve personal aggrandizement, but it 
precipitates historicity in the process. Thus, playing World War II fighter ace indulges the pilot's ego but also reproduces the myth of the fighter ace. Owning and flying a plane which is understood to be historically important reproduces that historicity, while at the same time operating on the owner/pilot's identity. Painting an airplane like a fighter ace's elevates the owner through connection to that individual, but it also opens a space for exploring the stories of and about that person. Yet owning a warbird just for "fun" can also contradict the solemn reverence for historicity that warbirders see as appropriate.

It would be a mistake to ignore the role of play in warbirding, for many pilots become evangelical about the enjoyment of flying. Hundreds of books have been written about the joy of flying, and for many warbird owners, the most enjoyable form of flying is in their warbird. The fun of this flying derives in part from the high performance of the aircraft, relative to other civilian planes. The CAF was initially formed for the sole purpose of allowing the members to enjoy flying fast airplanes. Tales of their antics are woven through the CAF literature, including such feats as flying low enough to pass between hangars or to cut the grass with their propeller. Indeed, one warbirder mentioned that one change wrought by September $11^{\text {th }}$ was that warbirders were less likely to "buzz" each others' houses. Another said he wanted to fly World War II Navy planes to experience the thrill of the hard landings they made on aircraft carriers. This fun, however, occurs within a certain frame of historicity, for the "play" of this flight often mimics wartime or military maneuvers. For example, pilots especially love "tail-chasing" each other in simulated dog fights. One warbirder mentioned this performance as the best part about flying at an airshow (they enjoy this even though the conclusion is scripted: the American plane always wins). They also love the challenge of flying in formation, another military-related performance, and also a chance to demonstrate the technological competence I discuss in chapter five. Finally, every pilot at some time imagines himself in the place of the World War II pilots, though such reverie is always tinged by a sense of loss that those times — and sometimes those people - are 
passed. This passage, from a young pilot training to fly warbirds, demonstrates the complex mix of technical competence, play, and historic reverence that these pilots experience:

You could say, "Hey, I'm flying these airplanes or I'm participating in the Confederate Air Force because I want to honor veterans." But when you're the pilot of a Mustang, you're the pilot of a Mustang. It's just the greatest thing in the world. It doesn't matter if you have all these other accomplishments, you're a Mustang jock, and that's that.

The figure of the "Mustang jock" implies not only the possession of skill (being able to handle the powerful and complex airplane) and economic success (being able to afford the airplane), but it also evokes the figure of the Mustang itself, a combination of what is understood to be the historic importance of the airplane (its role in winning the role) and a reverence for the machine itself (understood as an historic technological achievement, aside from its wartime role). ${ }^{46}$ Assuming the role of the "Mustang jock" does depend on a certain framing of historicity, then, but it also includes the sublime joy of being the pilot of a fast, powerful machine.

Owning warbirds also provides more than fun, fleeting connections to historicity. For many, once the initial fun and glory of flying the warbirds wears off, they find satisfaction in developing ties to veterans, just like at airshows. This passage describes how one warbirder built a lasting relationship with a group of veterans.

Well, my airplane is painted [a color] because I bought it that way. And I really didn't know anything about the fighter group or the name or the color, and so once I had it, I found the veteran who flew that paint scheme in World

\footnotetext{
${ }^{46}$ The "Mustang" has an aura surrounding it based on a variety of factors. It is understood to have eliminated the fighter threat to American bombers because it was the first fighter to fly far enough to escort them into Germany and was a better fighter than the German planes. Warbirders see it as classically beautiful, with graceful curves. Warbirders love the sound of its engine, the British-designed Merlin. It also has a creation myth: from initial drawing to flying prototype in 120 days, a kind of engineers' fantasy, especially in today's climate where fighters take decades to design and field. The plane therefore acts as a multi vocal symbol for historic importance, national prowess, mechanical (design) prowess and gendered skill, mastery of violence, and technological progress.
} 
War II. I found that the paint scheme was applied to commemorate him. So I met him, and I joined the veterans' group. I'm an honorary member and take veterans for rides in it, and try to improve with any scrap, you know, photos or whatever, improve the paint scheme to be more authentic. So every number or location or something, try to replicate that. There's a story associated with that or why people did that or this. So you know, just as I described, it's pretty encompassing of how I'm involved with this airplane.

We can see here how warbird practice serves to constitute historical practice. The owner established a link to this particular veterans' group through his airplane. Owning the plane helped establish a connection that he nurtured by attending reunions, seeking stories, and so on. That connection then furthered his attempts to make his airplane more authentic, feeding back into the construction of a connection to the past.

\section{Churning Airplanes}

Other owners, however, simply sell the airplane when they get past the initial excitement of flying it. For some owning a particular warbird is simply another personal achievement to mark, like running a marathon or climbing a mountain. Yet there is something of a paradox in the central role that historicity plays in warbirding and the ease with which owners sell off their planes. One might think that historicity of the aircraft would singularize it, taking it out of the realm of commerce, and yet the fundamental contradiction between use value and exchange value within a capitalist system always seems to emerge. These owners find no difficulty in commoditizing the plane as well. While the aircraft's shifts between these statuses depend upon an important shift in the airplane's relationship to persons. Collectors who buy aircraft employ a discourse of historicity to valorize their purchase, thereby emphasizing its use value. They are "preserving a piece of history" for future generations. They are mere stewards of this object, but inherently tied to it. In some 
cases they become deeply invested in it personally, while others merely build up a collection to have as a means of possessing history (which we also might treat as a kind of exchange value, depending on how that possession is presented). (Indeed, a collector should have a relationship with the planes, as many criticized a prominent owner for never once "visiting" his aircraft. It is not enough to have an airplane, one must have a relationship with it.)

At the same time, these airplanes are constantly understood in terms of their monetary value. As noted at the start of the chapter, one warbirder characterized the transformation of the airplanes over time from "one of a million" to "one in a million." In other words, the product created by the thousand in wartime factories has become today's scarce relic. We might add, however, that many warbirds also become “one for a \$million," given the high cost they garner at sale. This quality of monetary value is never far from warbirders' minds, even the non-collectors. Indeed, many tales of warbird discoveries over the years revolve around how cheap they used to be relative to today, suggesting that a prescient person could have made a lot of money. This tension between use value and exchange value is familiar within American culture, as it applies to most important possessions, like a home.

Museums in particular have difficulty with this tension when they deaccession airplanes, either to alter the logic of the collection or to make money for operating expenses, aircraft purchases, or restoration costs. One museum in particular encountered a lot of criticism when it sold some of its assets. To counter this criticism, defenders of the museum shifted from a discourse of singularity-based-on-historicity to one of individual property rights: the museum's owner paid to collect the airplane in the first place, so he has the right to do what he wants with it. This shift is common in describing and interpreting the churning of warbirds. A wealthy person is one who "succeeded" in business, meritoriously profiting from hard work and ability, and he "gives back" that wealth to help "preserve history." When he sells the plane, however, he is rightfully earning profit on his "investment." Historicity provides the basis for both use value and exchange value, singularization and 
commoditization. It not only makes the object "important" historically and inherently worthy of preservation as a public service, but it also makes the object "valuable" to other collectors who desire some connection to this historical importance.

The involvement of these wealthy businessmen also creates difficulties for museum groups like the CAF in that their escalation of the cost of planes contradicts these groups' drive to preserve them. In other words, historicity as exchange value threatens historicity as use value. The parts, airframes, engines, insurance, and training have all become much more expensive. Warbirders speak wistfully of being able to buy an engine cylinder for $\$ 50$ in the 70 's, when they cost $\$ 900$ today. This increase in cost comes not merely from the exhaustion of spare parts stores, but also from the increasing interest from wealthy collectors. Everything related to warbirds has become much more expensive. A plane that cost $\$ 100,000$ in 1975 now costs $\$ 1,500,000$.

At the same time, the money to be made from these historicities-as-exchange-values also expands the range of actants involved, further extending the plane's historicity. As the cost has escalated and as the taste for rare types has grown, so have the lengths to which collectors will go to find and restore a plane, which has drawn even more humans into the warbird restoration business. Aviation archaeologists now travel to distant locations to recover wartime wrecks; archival researchers seek out documentation of wreck sites; and government officials and businessmen seek to exploit the demand by marketing (or intervening to receive a bribe) wrecks in New Guinea jungles and on the Siberian steppe. Former Soviet factories have restarted production on wartime aircraft, while others have taken on warbird reproduction. The cost has also enrolled more nonhumans, as restorers will bring back planes that had been so badly mangled that they would have been left to rot two decades ago. 


\section{Conclusion}

We started with a group and an airplane, and the airplane became "China Doll," the "piece of history" through the group's exertions, while "the Doll" helped constitute the SoCal Wing. The complex process of building up warbird practice has depended closely on the invention and the conventionalization of historicity, while historicity also depended upon the construction of aircraft identities linking current-day aircraft to wartime types. These types provided the basis for pursuing logics of authenticity, which then were employed in restoring the aircraft. Authenticity, however, came to have personal connections, as collectors competed at airshows to be the creators and possessors of "the best" warbird. Yet airshows also provided a context for the public performance of warbird historicity, drawing implicit and explicit contrasts to contemporary planes and reinforcing the central cultural tenet of technological progress. The focus on the object's historicity throughout this chapter sets the stage for how that historicity is employed for further cultural ends in the remaining chapters. 


\section{Chapter Three: History, Nationalism and Militarism}

The warbird movement developed out of the belief that the planes themselves are history. In the previous chapter we examined the invention of airplanes' historicity and their operation as "frameworks of memory." This chapter also examines the invention of "history," but it focuses on how airshow performances depict the World War II United States as a model for today's nation. Rather than examining how warbirders invent the historicity of their airplanes, this one looks at how warbirders employ that ascribed historicity to invent a past that proves quite useful in contemporary life and politics. In presenting their airplanes as "pieces of history" at airshows, warbirders seek to inculcate a particular lesson about technology, the nation, and militarism.

As any historical representation draws on the understandings and aims of the present, we have to examine airshow performances as productions of the past which have entailments in the present. Warbirders draw on popular narratives about the "Good War" to imagine an ideal Nation, which they then perform through battle reenactments and aerial demonstrations. This imagining takes World War II as a usable past which should instruct United States citizens in the present. I conclude by discussing the attacks of September 11, 2001. I argue that warbirders momentarily hoped that those attacks would spark a return of their ideal nation. That this transformation did not occur has led some warbirders to depict $9 / 11$ as a failed Pearl Harbor.

\section{The Ideal Nation}

The imagining of the nation has become a commonplace notion, and just how nations are imagined - both the form and content of a nation as well as the means of imagining it — has been the focus of a variety of research projects. In this section I will examine what warbirders imagine the ideal nation to be to set the stage for an examination of how they use their machines to perform this nation. They see the United States of World War II as the ideal nation, a common view today (Adams 1994). They share with many others the longing 
for what they see as a unified nation, a community of purpose, which was to win the war (ibid). Out of this unity came great strength as well, they say, such strength that the Axis powers could not resist the combined determination of the American people. Warbirders therefore imagine an ideal nation with specific qualities, qualities that they then find lacking in the contemporary nation. In deriving this ideal nation from World War II, warbirders elaborate both a positive vision, which serves as the basis for nostalgic longing, and a negative vision, which results from the imagining of external and internal threats to the nation.

\section{The Good War and the Ideal Nation}

The idea that World War II was an exemplar of the ideal nation reflects the widely held belief that World War II was "the Good War," or, even “The Best War Ever" (Terkel 1984, Adams 1994). For warbirders, this view stems mostly from media representations of the war and from the personal stories of veterans and relatives which so appeal to warbirders. Media representations about World War II have been central to public understanding of it since the earliest days of the war itself. The news reels, hundreds of military-approved, patriotism-inducing movies, and military-contractor advertising all depicted the war as noble (Adams 1994). Since the war, movies, books, and TV shows and documentaries have furthered this Good War myth, most lately transformed by discussions of the Holocaust and the "Greatest Generation." Countless warbirders recommended books to me about the war which carried the "Good War" point of view — Band of Brothers, Citizen Soldiers, Flags of Our Fathers, and The Greatest Generation, just to name a few (Ambrose 1992, Ambrose 1997, Bradley and Powers 2000, Brokaw 1998). Each of these books tells stories of soldiers as brave and self-sacrificing while enduring the horrors and hardships of the war. In focusing on war's hardships, however, they seek, ultimately, to elevate the war and the experience of war, not question its very foundations. War becomes a field for the production of intense friendships with one's "buddies." This mode of war-story telling contrasts sharply with older 
accounts like The Warriors, which investigate those horrors of war as personal trauma, without romanticizing them or the connections made to "buddies" (Gray 1959). No one ever recommended such critical, yet popular, books as this one, Slaughterhouse Five or Catch-22 (Vonnegut 1969, Heller 1961).

\section{Shifting the Frame: From Personal to National}

For warbirders, the personal stories they hear at the hangar and at airshows also fit into the "Good War" frame in that they tend to celebrate the war rather than detail its horrors. If they do detail the horrors of war, those experiences can be folded back into the Good War myth by employing a discourse of noble sacrifice. As White argued, these personal, emotional, and individual stories serve as affective mediations of imagined, distant, and large-scale events like the war (White 1999). To conceive of the war itself, the grand narratives of the "Good War" and the "Greatest Generation" often silence competing narratives from veterans of harrowing experience. An airshow video provides an example of this reversion to the grand narrative. A favorite theme for these videos — and for warbird airshows generally — is to reunite a particular fighter or bomber group from the war that is associated with an airplane appearing at the show. One video featured a group that flew a certain bomber and had them telling stories and singing songs about the plane. The veterans gathered for photographs in front of the plane when one of them described the sheer terror of flying the bomber missions (Pool and Crew 1987). The moment broke the celebratory frame, but the flow of the video passed right over those comments to maintain the "Good War" frame.

Warbirders' focus on the nation in airshow performances and much of their discourse contrasts sharply with the "veteran encounters" described in the previous chapter. Where those encounters centered on authentic experience of another person's memories, whether stories from a veteran or imagined experiences of a deceased relative, the airshow performances depict the nation in action. These encounters differ, then, in the level of 
reference, from the individual to the collectivity. This seeming contradiction is resolved, however, by the role of the airplanes, which mediate both kinds of meaning-production. Warbirders use the aircraft to create an emotional experience with a veteran, while their performances invent the nation-in-action. Such a dual-level cultural production reflects the multivocality of symbols which has been common sense at least since Turner (Turner 1967). It also reflects views in material culture studies, which has emphasized the ability of artifacts to encompass differing, even contradictory, meanings from differently situated cultural actors (Miller 1987).

\section{The Positive Vision}

The positive vision of the ideal nation focuses on qualities of the World War II nation which lend themselves to celebratory rhetoric and nostalgic longing. They are positive in that they stem from ideals of what the nation should be, rather than from what the nation is forced to be by the various threats it faces. Unity and strength, in positive terms, reflect Dumont's argument that nations are "the normal form of the global society in the individualistic universe" (Dumont 1970: 33). Unity and strength (or the lack thereof) become qualities of that individual.

The imagined unity of the ideal nation reflects what Dumont called the nation as a "collective individual," in contrast to a collection of individuals (ibid). In the nation-ascollective-individual, the citizens all are intimately tied to the nation, identifying themselves with the nation first. In the nation-as-collection-of-individuals, the nation contains disparate groups who may identify more with their group than with the nation. Warbirders argue that the World War II nation was such a collective individual, and they lament the transformation, often seen as occurring during the 1960 's, of the nation into a collection of individuals. ${ }^{47}$

\footnotetext{
${ }^{47}$ The opposition sketched here between collection of individuals and collective individual is perhaps an understatement of Dumont's characterization. For Dumont, the collection of individuals was simply a group of persons who chose to live together in society, and the notion of society or the nation as a larger entity was very weak, if it existed at all. The collective individual was just the opposite; there was no recognition of individual human beings, only the homogeneous collective citizenry. The contradiction between these tendencies was contained, however, in that "the two conceptions must be ranked, so that one prevails upon the other: either the human individuals composing the nation, or the
} 
Certainly this imagining of the ideal nation is political, but for many patriotism is also a happy, effusive emotion, a love for the nation fostered through the myriad ways in which they interact with "America." ${ }^{48}$ Thus, their vision of the ideal nation amounts to a desire for a certain kind of feeling. The two dimensions of this feeling are "togetherness" and "strength." Many warbirders described World War II to me as "a time when the country came together," in contrast to the current state of the nation, when, as one CAF official put it, "People these days are so separated out and singled out that there is no group feeling, no solid country feeling." The longing for this togetherness usually becomes nostalgia, a desire for something that is felt to be past. It also reflects a sadness at that loss.

The ideal of "strength" may seem out of place here, but that, too, is often expressed as a kind of longing and explicitly contrasted with the present. The appeal for strength depends upon the articulation of threat to the nation, as I will describe below, but within this desire for strength also exists a longing for the feeling of being strong. One prominent CAF member compared the nation-as-individual to a high-schooler who had to be strong enough to fight off bullies. This depiction of the nation as a teenager reflects the emotional weight of the need to be strong. Being strong feels good to warbirders, on its own terms.

\section{The Negative Vision}

As the image of nation-as-teenager-fighting-bullies suggests, warbirders (and many others) envisage the nation-as-individual to exist in a Hobbesian state of nature where it is constantly under threat from other, individualized nations. Belief in such threats to national existence is critical to the project of nationalism because these threats serve to constitute the nation. Handler (1988: 51) describes this process for Québécois nationalism, arguing that a "negative vision" allowed Québécois nationalists to define their nation in opposition to the

nation as a whole, will bear the main stress, but not both at once" (Dumont 1970).

${ }^{48}$ And it does seem to be "America" in this discourse, not the United States. Perhaps the latter sounds too formal to capture the emotional connection. 
threat of linguistic and cultural pollution. For the Québécois, the threats to the nation were as much internal as external, and the same holds for warbirders. Their "negative vision" of the ideal nation focuses on both external and internal threats, positing solutions of strength and unity, respectively, to those threats.

\section{Strength Against External Threats}

Warbirders' imagining of the ideal nation takes the Axis powers during World War II as the exemplar of the external threats facing the nation. One warbird performance described those enemies as "the greatest tyrannies ever known attempted to enslave the world." The superlatives they use run throughout warbird discourse and reflect the popular view that World War II was a "Good War" because the nation fought for its existence against terrible enemies (and won). Warbirders derive a moral imperative from this belief in external threats, then and now, which is that the nation must pull together and arm itself against these threats. They think, however, that most people do not adequately recognize this threat and that World War II was the last, and perhaps the only, time the nation responded appropriately to the threats it faced. A BBC video from the 70's, for example, captured one of the CAF's founders pleading for greater military strength (Salmon, Wooldridge, and Carr 1981). He said that he did not know why "the Russians" had not invaded the United States because it obviously was so weak. The same logic prevailed in the high school analogy described above.

The CAF official who made the high school analogy added a further dimension to strength: assertiveness. "You know, the bullies will pick on you until you fight back, and then all of the sudden they don't pick on you." Thus, being strong only matters if one "fights back," what we might call strength with agency. (Perhaps this is how conservatives could see the United States as "weak" during the 1990's when it was by far the dominant military power in the world.) This idea, too, has its roots in the ideal nation of World War II, when, according to many different warbirders, the United Kingdom and France "appeased" the 
Nazis, which only emboldened Hitler and spawned the catastrophic violence of the war. After Pearl Harbor, the United States dropped its isolationist tendencies and its willingness to accommodate "appeasement," and it did what needed to be done. Returning to the idea of the nation-as-individual, the individual here must possess and assert agency. It must stand against the "bullies" of other nations. Warbirders" desire for the nation to "stand up for itself" was demonstrated most powerfully for me at an October, 2001, airshow when the crowd erupted with delight at the announcement that the bombing had begun in Afghanistan. Everyone seemed relieved to be doing something, finally, against "the terrorists." "Doing something," of course, meant doing violence, the only assertiveness that warbirders would accept not only as legitimate retribution, but also full personhood. Despite this desire for strength and assertiveness against external enemies, in many ways warbirders focused their efforts on countering threats from within.

\section{Unity Against Internal Threats}

The longing for the "togetherness" of World War II long often leads warbirders to act against what they see as internal threats to that unity. These threats are both active and passive. Their main rhetorical efforts work against the active threats of "political correctness" (PC) and "liberal bias." The critique of political correctness, which is consistent with their emphasis on assertiveness, is that it renders the nation too timid, too wary of offending someone. Indeed, the foil for the strong American nation during World War II is the weak, effeminate French. ${ }^{49}$ For the Confederate Air Force, "political correctness" led to the unfounded attack on the organization's name, just as it has led to other attempts to erase history, in their view, such as the exhibition of the Enola Gay at the Smithsonian. "Liberal bias" on the other hand leads to the questioning of American institutions like the Presidency, the military, and free enterprise/big business. Both threats actively undermine fellow-feeling for other Americans and loyalty to the nation, eating away at the will to be a collective

\footnotetext{
${ }^{49}$ That this discourse is implicitly masculinist should be no surprise.
} 
individual. One could easily see this point of view as an implicit attempt to reclaim the unmarked status that warbirders nostalgically ascribe to the white men of World War II.

The passive threat to the nation comes from people losing sight of the nation as a whole, becoming too wrapped up in their own lives. As one head of a warbird museum put it, "For some years, it's been secondary to be a patriot, and I think that's a bunch of crap." Here he emphasized that patriotism should come first, before personal concerns. This characteristic, too, they ascribe to the "Greatest Generation," who unquestioningly, the story goes, threw themselves into the necessary war. Today's generation, by contrast, has become spoiled and self-centered.

\section{Policing Patriotism}

Warbirders' efforts to fight against what they see as the threats to the nation can take extreme rhetorical forms. At the very least, they spend a good deal of effort policing the patriotism of those around them. Their patriotism partakes of the same intolerance which has become widespread after the attacks on September $11^{\text {th }}$. Warbirding has long worked in the same way, rejecting any criticism of their view of the "Good War." This form of patriotism seeks to shout down dissenters. It grows out of the sense that a real threat to the nation exists within the United States and must stem from a sense that the Vietnam War was lost at home, not abroad. This sense is another form of the "negative vision" of nationalism in that internal dissent is depicted as the major source of division preventing the incarnation of the nation as a unified collective individual. This sense shares in the rhetoric of conservatives who have managed in recent decades to present themselves as a minority within the nation, one being victimized by left-wing ideology, coded as "political correctness" as I described above. Representing the hegemonic stance of nationalism as being under threat is quite a trick, but it works in warbirding.

The example of the Enola Gay exhibit at the Smithsonian's National Air \& Space Museum highlights the way this conflict works out. Although the Air Force Association was 
the leader in killing the original, critical exhibit of the airplane, the warbird community strongly voiced their support. Their complete success in getting Congress to pressure the museum to change the exhibit, however, has not changed the sense that their vision is under threat. It seems that as long as anyone dissents from their view, their vision of the nation is threatened.

I experienced the policing of dissent at an airshow when I unwittingly drew the wrath of a warbirder for being insufficiently patriotic. At the Oshkosh AirVenture in 1999, the show was officially opened with a jump by the Liberty Parachute Team. This team was introduced as a group of relatively old members, and the announcer exalted the flag they would carry. He called it "Mega-Glory," describing its tremendous dimensions, 34 by 59 feet, the largest flag with which anyone jumps. I generally dislike watching parachute jumps because I find them a little silly and watching them hurts my neck, in addition to my general objection to the militancy of American nationalism. I therefore moved away from the flight line to fill up my water bottle during the jump. I must have had some unpleasant look on my face during the performance because as I got my water, a man asked me, "Are you from a foreign country?" Surprised, I said, "No." He replied, "Oh, so you just hate the United States, then.” Very surprised, I thought for a minute and said, "No, I just think 'Mega-Glory' is a bit too bombastic." Despite my rejection of his policing, I was nonetheless humbled, and I have been attentive since, respectfully removing my hat when appropriate. ${ }^{50}$

\section{What about "Freedom?"}

In attributing only two central qualities to the ideal nation, unity and strength, I have intentionally omitted another which crops up frequently in conservative (and progressive) rhetoric in today's politics: "Freedom." From “Operation Enduring Freedom" to "Operation Iraqi Freedom" to "Freedom Isn't Free," the word is nearly ubiquitous at this time. Yet I

\footnotetext{
${ }^{50} \mathrm{~A}$ good Durkheimian would point out that I violated the ritual's taboos, which was clearly true. While remaining a critic, I have come to be more respectful of these rituals.
} 
have omitted it thus far because warbirders do not employ it to draw a contrast between the ideal nation and today's nation. I have never heard a warbirder argue that liberals/progressives oppose freedom specifically or that freedom was lacking in the United States today. Many do chafe at impingements upon their individual autonomy, especially by government regulation, but no one argued that an authoritarian state exists or is sought by their internal opponents. Rather, they revert back to the passive threat posed by average Americans, and especially by liberals/progressives. By this argument, the failure to appreciate and to fight for freedom characterizes today's nation.

\section{Pearl Harbor as a Necessary Catastrophe}

For warbirders, Pearl Harbor provided the ultimate demonstration of the threat to the nation, which is why Pearl Harbor is both a catastrophe and something to celebrate in the warbird world. ${ }^{51}$ The catastrophe of Pearl Harbor was the death and destruction wreaked there, but the positive development, in the eyes of warbirders and many others, was the transformation of the nation wrought by the attack. It took the trauma of Pearl Harbor, a moment in which all citizens felt wounded simultaneously (Cf. Anderson 1991(1983)), for the nation's citizens to realize their collective identity and unite in the war effort against the Axis powers.

Pearl Harbor transformed the nation, imbuing it with the two qualities of the ideal nation: unity and strength. Warbirders see Pearl Harbor as the answer to both kinds of threats, internal and external. As the CAF's narration of its Pearl Harbor reenactment puts it, "Our greatest naval base lay in ruins, along with our complacency. . . . But out of the ashes of early defeat rose the phoenix of future victory. A nation ... found itself united and determined to fight" (Moll 1987: 52). The internal divisions, then, disappeared. Upon hearing the news, the story goes, people simultaneously committed to the war. Everyone had

\footnotetext{
${ }^{51}$ I did hear people talk about wanting to do something to "celebrate Pearl Harbor Day." With the exception of D-Day and the Doolittle Raid, Pearl Harbor is the only war event day routinely "celebrated" by warbirders. They also celebrate the patriotic holidays.
} 
a "when I heard the news about Pearl Harbor" moment that they could relate later. This experience of simultaneity provided a powerful unifying force. In this narrative, the attack on Pearl Harbor fused the divided nation into a whole and energized it for war. All of the veterans whom I met said that that day "changed everything."

The transformation also brought out the nation's latent strength. The "Good War" myth holds that the Pearl Harbor attack transformed the nation by throwing the citizenry into a determination to fight the threat of the Japanese. Before the attack, warbirders say, the nation was divided, or in the word of one CAF member, "the country was not as focused . . There were significant protests against America's involvement in World War II. There were major protests and objections of [sic] the lend-lease bill . . . They didn't want to get involved with the wars." The "protests" and isolationism reflected not only internal disunity, but also the unwillingness to assert strength. With the Pearl Harbor attack, the nation began to arm itself against the enemy and to assert its power.

The contrast between the prewar and post-Pearl Harbor nations can be seen in the language warbirders and others use to describe the attack. Those World War II veterans who participated in the war are generally referred to as "veterans," but people who fought in the Battle of Pearl Harbor (which is never called that, interestingly) are called "survivors." The implication of being a "survivor" of an "attack," as opposed to a "veteran" of a "battle," is that one did not have the agency to fight back. The transformation wrought by Pearl Harbor fostered national agency and enabled the nation to strike back. This assumption of determined strength and unity was the transformation from a "collection of individuals" into a "collective individual" (Dumont 1970: 33).

\section{Performing History, Producing a Usable Past}

This narrative of national transformation guides much of warbirders' public activities. They narrate and perform "the history" of the war, seeking thereby to induce again such a transformation. To unpack warbirders' public history activities, we first have to examine 
what they claim "history" to be and how they relate the past to the present. In the previous chapter we examined how warbirders invent the historicity of their aircraft, and here we will examine what that history is and what they do with it. They see history itself as a set of facts, a bunch of events that occurred in the past which we can and should learn about more or less objectively (Handler and Gable 1997). They see these facts as immutable, but they also worry that the facts could be forgotten or even misrepresented and obfuscated by political agendas. This "Just the Facts" version of history therefore must be preserved and publicized. Warbirders employ their machines to do so, taking advantage of American technocentrism to lend authority to their account. Through airshow tours and performances, they establish World War II as a usable past in pursuit of the ideal nation.

The narrator of the CAF's Pearl Harbor reenactment invokes a "chamber of the imagination" to create a kind of time machine which simulates space of the past in the present. Within this time-space, events unfold which do reflect events in the past, but we cannot understand them as unproblematic representations of that past. All such representations stem from the categories, values, and beliefs of the present, with which they have to be coherent to be understood and accepted. Further, this space is "simulated," but I would not argue that it is a simulacrum. Seeing it as such could lead us to underestimate the felt power of the representation, and it could also suggest that another representation, authenticated by some other authority, might be somehow more objective or free of presentist bias. I would prefer to see the "simulated" battle as an invention, a novel performance which seeks to establish itself as a conventional representation of what the war was like (Wagner 1981(1975)). Such invention, far from meriting criticism as being "made up," is in fact the very essence of culture; it is the way culture works, as I described in the previous chapter. I proceed, then, by exploring how warbirders invent the history of the war using their machines and by attending to the meanings they conventionalize in the process. 
"The History"

Proponents of the "just the facts" version of history present it as free of bias, and warbirders understand their performance of that history as correcting existing bias with those facts. Like the "negative vision" of external threats to the nation described earlier, the nation's history is also felt to be threatened, but threatened from within, not from without. The threat matters greatly to them, both because "history" is an inherent attribute of the nation itself and because its loss means Americans cannot "learn" from it. The sources of the internal threat are passive neglect and active, liberal bias. To counter these possible threats, warbirders present their own version of history publicly at airshows.

One of the more striking phrases I heard from a involved an attempt to downplay the spectacle of airshow performances. He said that the spectacle — he was mostly referring to the non-aviation and non-warbird events, like jet trucks, aerobatic flying, and even currentday military aircraft demonstrations — drew the crowds, and once the crowds were there and awed by the spectacle, you could "reinforce that with the history" of the war. By "the history" here he meant the narration of the airplanes' flight, but the phrase nicely captures the warbirder conception of history as singular and fixed, while also threatened by neglect and obfuscation. The neglect of history comes about through laziness or self-absorption (which warbirders interpret as signs that the country is "different" today than it was during the war). Warbirders of all ages fulminated against the poor teaching of history in schools today, citing examples of children and teenagers who did not know basic "facts" about the war. For example, one teenager did not know that Pearl Harbor was attacked by the Japanese or even that the United States fought against the Japanese in the war. These "kids," in this view, are too wrapped up in themselves, spoiled by their Baby Boomer parents - and TV, the Internet and video games ${ }^{52}$ — to be properly aware of their past. In contrast, warbirders

\footnotetext{
${ }^{52} \mathrm{My}$ data do not show this, but I suspect these entertainment technologies provide another contrast in the minds of warbirders between the computerized world of today and the industrial machines of the past. I would guess that the contrast would work along these lines: erector sets and listening to the radio (figured as requiring imagination and productive) versus video games and television watching (figured as entirely passive and wasteful).
} 
see the "kids" of World War II as the products of the Depression's deprivation, seasoned thereby into ready self-sacrifice for the larger cause that was the war. Actually, they never seem to suggest that the World War II generation "knew history" any better — though such a nostalgic view of schooling in the past is certainly common among conservatives - only that they were more geared toward personal responsibility and individual achievement. They understand these qualities as derived from enduring the hardships of the Depression.

The active threats to "the history" today are liberal bias and "political correctness." While they criticize the schools for not teaching "the history" at all — many commented that the high school text books have only two or three pages on World War II - they criticize colleges for furthering "revisionist" history, which they see as coming from liberal history professors and other cultural "elites." 53 The bias of this "revisionism" is the most potent internal threat they face and a favorite target for them. They use the term to critique any challenge to their militarist, nationalist point of view. For members of the Commemorative Air Force, the criticism of their name has long rankled, and they have railed against the political correctness of questioning the name, as I mentioned in the first chapter. Further, a number of warbirders complained about the military's recent policy of banning from military airshows aircraft bearing "nose art" with naked women. In all of these cases, warbirders interpret the challenges to their point of view and their practices as challenges to history itself. The questioning of the Smithsonian display undermined the "fact" that the bombs saved millions of lives on both sides by ending the war early. The challenge to the CAF name ignored the "facts" that the name was a joke, was the product of harmless "Good Old Boys," and bears no relation to the Confederacy. The challenge to the nose art ignores the "facts" that these pictures were actually painted by air crews during the war and that the

\footnotetext{
${ }^{53}$ I should point out that the conservative understanding of "elites" or the "intelligentsia," refers only to liberal thinkers at universities or other influential media or policy positions. They exclude such cultural elites as business executives, the increasingly powerful conservative think-tanks, politicians, and the wealthy. Often the contrast is drawn in terms familiar throughout American history: the European-style hierarchy of these cultural elites (often located on the two coasts) versus the plain-spoken, frontier-conditioned regular American (located in the middle of the country).
} 
horniness of young men at war is basically harmless (Cf. Enloe 1983). To counter these challenges, then, warbirders present their "Just the Facts" version of history.

\section{Just the Facts versus Being a Good Patriot}

Most warbirders see their activities as strongly patriotic. This patriotism derives not merely from their beliefs — their ardent backing of the military, their celebration of all things American - but also from their activities as warbirders. They understand the preservation of warbirds themselves as a patriotic act — one that even the Government fails to do at times — because the planes themselves are the history of the nation. As the saviors of the nation's history, they become its steward also, an important responsibility which grants them a position of hierarchy within the nation. Their preservation work and the objective authority of the airplanes themselves entitle them to speak about the nation's past and to counter both internal and external critics of the United States. This patriotism, however, also manages to encompass contradictions when warbirders include elements seemingly at odds with American nationalism, like the use of the Confederacy described in the Introduction or the celebration of Axis aircraft described below.

"Just the Facts" discourse would, on its face, seem to preclude advocacy of patriotism. Mere reportage should not celebrate some dimension of the event, especially when considering the absolute brutality of the war (Cf.Dower 1986). Warbirders, however, see their overt patriotism as a form of Just the Facts history. World War II was a "Good War," in their view, and they fight to maintain that view of the war. They therefore fall into a "structural hypocrisy," a literalism which denies its own rhetoric (Crapanzano 2000: xxvi). If they were truly interested in "the facts," then they would be receptive to new understandings of historical evidence from that time. They are not receptive, however, and they seek to drown out opposing points of view. This is not to say, however, that the problem with their account is that they get it wrong. Rather, I argue that their difficulty lies in the failure to recognize the cultural contingency of any understanding of the past. 


\section{Performing the Ideal Nation}

As I have argued thus far, the most potent presentation of warbirders' "History" occurs through their airshow performances. These performances invent an ideal America which they hope to revive. To unpack this invention, I will focus on the most popular warbird performance, the CAF's Pearl Harbor reenactment, which they call Tora! Tora! Tora! (Tora), after the movie of the same name. This performance tours the country, usually appearing at twelve shows a year, and it is always one of the best-received airshow acts.

Tora begins with the narrator addressing the audience, "Close your eyes for just ten seconds. When you open them you will be in a time machine, a giant chamber of the imagination that has taken you back [x] years" (Moll 1987: p.34). He then describes a slow, peaceful morning in Hawaii, set to quiet, slack-key guitar music. ${ }^{54}$ This idyll is then broken by the sound of planes flying in from the side, followed by large explosions of gasoline set off on the ground, which simulate the planes' attack. The planes begin circling and continue their "attacks" for about ten minutes, producing a great chaos. When the gasoline bombs explode, they create a tremendous flash of flame, followed by dark smoke. The audience can feel the heat of the flash, then hear the boom and feel the concussion of the explosion. The aircraft are quite loud for propeller-driven planes, and their speed and motion through the smoke overwhelm the audience's senses. If possible, they will add to the confusion by having a bomber simulate a one-wheel landing in the middle of events. At first the "attack" goes badly for the Americans, with the circling "Japanese" planes burning up a lot of airfield grass. Soon, however, the Americans manage to launch a fighter plane to face the attackers. This fighter plane "dogfights" a Japanese plane, and the Japanese plane is always "shot down," a noble ending to the ignominious day.

\footnotetext{
${ }^{54}$ The only female narrator I have heard at a warbird performance was at EAA's Airventure, in Oshkosh, Wisconsin. The woman is a well-known and respected pilot, and she played the role of an authoritative commentator on the specific types of warbirds flying in the performance that day. Every other commentator I have heard was male, and certainly the authoritative voice on machines is gendered as male.
} 
While the planes fly and charges explode, the announcer exhorts the audience with "the history" of the attack. He emphasizes the treachery of the "unprovoked" attack on "American soil," 55 and offers several vignettes of sailors suffering, dying, and struggling to fight back. This urgent narration alternates with recordings of air raid sirens and of FDR giving the "day of infamy" speech. Then the narrator solemnly asks the audience to "Listen to the sounds of war."

At the CAF's annual headquarters show in Midland, Texas and the ensuing show in Houston, Tora serves as the opening act for the CAF's "American Air Power Demonstration," a reenactment of the major American World War II battles. At these performances, the "victory" at the end of Tora initiates the series of unbroken victories that culminates in the bombing of Hiroshima. The intervening demonstrations all involve many planes and explosions, but Tora's duration, and tight choreography set it apart. Further, Tora's elaborate chaos stands in stark contrast to the solemnity of the nuclear attack. The dropping of the atomic bomb, the single-most violent act of war in human history, involves only a solitary airplane, accompanied by a massive ground explosion. ${ }^{56}$ It takes the chaos of Tora to lead to the almost understated power of a fully armed nation. The transformation of the nation that Tora depicts, therefore, works both on its own and as the first of a series of battles. Taken as the first of many battles, it marks the transformation into the ideal nation which the other battles merely work out. Taken on its own, however, it depicts the nation's transformation, but also suggests the ever-present threat to the nation which might cause another transformation into the ideal nation.

\footnotetext{
${ }^{55}$ The "American Soil" in question was, of course, a colony at the time, as wonderfully parodied by a story from the satirical weekly, The Onion, "Dastardly Japs Attack Colonially Occupied U.S. Non-State" (Dikkers et al. 1999: 60).

${ }^{56}$ On several occasions, the pilot during this reenactment was Paul Tibbets, a CAF member and the pilot of the Enola Gay, which dropped the first atomic bomb (Salmon 1981).
} 


\section{Authenticating the Performance}

The goal of the spectacle is to make the crowd feel like spectators at the actual battle. The CAF members feel that their combination of the "authentic" planes and large explosions produces the desired effect. One member described the effect of the explosions, "When you're standing there, you feel the heat. You feel the explosions in your gut. That's nowhere near what the real thing was like, but it's so much different than anything else they've experienced that they'll never forget it." Thus, presenting a fiery spectacle provides for them a kind of phenomenological authenticity, at least a partial experience of war. Like any reenactment, equating it with the events of the past is deeply problematic, ${ }^{57}$ but warbirders lend their performance authority by appealing to the authenticity of the objects themselves and sometimes to the authenticity of veterans.

The funny thing about "just the facts" history in warbirding is that it finds support in the apparent "objectivity" of warbirding's central objects, the airplanes. The felt authenticity of the experience depends upon a slippage between the experience of the machine and the experience of history. For warbirders, the machines are "pieces of history" and the experience of their operation is itself the experience of history. Thus, they argue that when they fly the airplanes in groups from roughly the same period and couple those flights with pyrotechnics, they provide an "historical" experience. In practice, however, the airplanes themselves become the focus of historical study. The problem with this point of view is that it involves a substitution of the experience of the artifact with the original context in which the artifact was created and used. Despite the many recontextualizations of the artifact along the way, they present the aircraft as representing the original context. The original context, of course, is impossible to reconstruct and experience (Handler and Saxton 1988). What this

\footnotetext{
${ }^{57}$ Handler and Saxton (1988) examine some of these problems, including the contrast in framing between experiencing events as they unfold and retrospectively performing events understood to be vitally important, historic occurrences.
} 
process does, then, is introduce a materialist understanding of history. It invents a technocentric past by conventionalizing the airplane as history itself.

Treating the object as a "piece of history" places the burden of historicity on the object itself, leaving it open to challenge. In other words, the idea that the performance is accurate because the airplanes are accurate suggests that one must police the historicity of the planes. Warbirders answer this challenge most often by translating history into "authenticity." Thus, a great deal of activity in warbirding involves attributing authenticity to the airplanes-as-constituted, as discussed in the previous chapter. Just to review the argument laid out there, warbirders seek to get the object "right," meaning just like it was during the war, and then treat that fully authenticated (a process all to itself) object as the real experience of history. This view also leads warbirders, especially wealthy collectors, to see authenticity as something measurable and therefore something which provides the basis for competition.

The centrality of authenticity might seem to be contradicted by the use of "replica" Japanese aircraft in the Tora performance. I would argue, however, that warbirders see this compromise as necessary, given the lack of Japanese aircraft in existence. Further, the replicas were all made from American World War II trainers, preserving a "wartime feeling" in their operation. Finally, the fact that these replicas were made for a movie, Tora! Tora! Tora!, one that was treated as the most true-to-life account of the attack at that time, grants them a further degree of representational authority.

At times warbirders use veterans and their stories more directly to authenticate their activities. For example, a Tora performance I attended appealed to the authority of Pearl Harbor "survivors" by invoking them as co-participants in "remembering" Pearl Harbor, thereby authenticating the Tora performance. At the concours d' elegance competitions, the authority of veterans is often invoked to assert the authenticity of some aircraft feature. (If the wartime crew chief says the plane looked like that, the competition judges are loathe to 
question him, even given the problems of remembering events sixty years ago.) One collector even brought a plane's crew to the airshow to be with the airplane as an authenticating gesture. They were the crew of the plane that his aircraft was restored to represent, and the owner had special jackets made which bore the "nose art" of the airplane. Such activities are rhetorically framed as "honoring" the veterans, but the emphasis is clearly on the airplane itself: the veterans "honor" the plane. Sometimes an airshow will feature a famous veteran flying a warbird. The Oshkosh Airventure, for example, featured "American hero" and World War II veteran Chuck Yeager flying an airplane painted like his wartime aircraft, and he was accompanied by his wartime wingman, another famous flyer, "Bud" Anderson. Having these individuals involved in airshow performances reinforces both the feeling of historic importance and the linkage to the "Good War."

\section{Technocentrism}

As the efforts to authenticate the reenactment of Pearl Harbor suggested, warbirding exhibits a thoroughgoing technocentrism. Like the Tora performance, all of warbirding foregrounds the airplanes, reflecting a fundamentally technocentric view of the war and of the workings of nations. At airshows, machines sketch the performance space out; machines act within it; machines are the only visible elements. Airshow narrations - and most warbird publications as well - emphasize the types of airplanes flying, along with their manufacturers, weapons, and flight characteristics, urging the audience to focus on them. Their interpretation of the nation at war is therefore performed by the airplanes. Machines synecdochically evoke the nation, but the overwhelming focus on the machines serves to displace other means of imaging the nation such that "America" becomes inextricably tied to its technology. This displacement proves critical for establishing the ideal nation warbirders seek. Technocentrism both gives them a focus for unifying the nation participation in the machines - and provides the material embodiment of the strength they seek: warplanes. They work this technocentrism into their nationalism in a variety of ways. 
They understand the airplanes as the agents of the nation at war; they see the American character as being machine-oriented; and they see the machine as reflecting or embodying the genius of the nation.

Returning to Tora, we can see the technocentric focus not only through the performance, but also through the narration. Mixed into the account of the battle at Pearl Harbor are strangely clinical descriptions of the aircraft-as-technologies. The narrator outlines the types of planes, their development, their weapons, and their use in the attack, as in this snippet:

The Aichi D3A Dive Bomber had a 200 lb. bomb between the wheel wells. As that aircraft rolled over, it came down on top of the United States Battleship Arizona. It dropped the bomb, and it went through the quarterdeck, right alongside the number 2 Gun emplacement, when it exploded, that great ship exploded with such force that lifted it from the water, when she settled back into the ground, 1,200 of America's sons [inaudible] where they sleep today. The Nakajima M5N Kate with a specially-designed torpedo in the wheel wells.

The emotional punch — and nationalist framing — of "America's sons" "sleeping" in the sunken ship adds a felt weight and importance to the tale, but the passage also includes a range of seemingly unnecessary detail. This detail colors in the scene with technological facts and devices, demonstrating the acute focus on machines in this worldview. The planes include not merely a couple of bombers or a dive bomber and a torpedo bomber, but "The Aichi D3A Dive Bomber" and "The Nakajima M5N Kate." Further, the narrator relates the details about the weapons used, "a $200 \mathrm{lb}$. bomb between the wheel wells" 58 and later describes the development of a special torpedo for the attack. This contrast draws the focus

\footnotetext{
${ }^{58}$ This phrase can be read to ascribe a sexual potency to the Japanese attackers and aircraft (the feminization of aircraft notwithstanding), implicitly contrasting with the helpless ships on the ground receiving the bombs (Cohn 1987). I would not go further into the erotics of violence, but I do believe the imagery suggests the operative hierarchy, soon to be reversed by the "awakening" of the nation.
} 
to the aircraft and combines with the spectacle of the performance's noise, smoke, explosions, and movement to foreground the airplanes as the key actors of the battle.

\section{"The History" of Machines}

As this narration suggests, the "history" of the World War II nation often becomes focused on "the history" of the machines themselves. This machine history works two different ways, either displacing a focus on the wartime nation altogether or becoming the means through which warbirders can understand and experience that nation. Thus, the "history" of both the technology and the war are reinvented through the extension of meanings between their two contexts.

On one hand, warbirders often used the airplane itself as a means to understand the war. Returning to the example of the cargo plane called "China Doll" described in the previous chapter, the CAF Wing members grew interested in a particular theater of the war, the China-Burma-India Theater, where its type, the C-46, had a leading role. They began reading books about the theater and were especially interested in hearing stories from veterans of that theater. In other words, the experience of the machine fostered an interest in the portion of the war involving their aircraft. The planes provided purchase for grasping the infinite complexity of the war. Many others started from a different direction, having some personal tie to a particular type of airplane, such as through a relative who flew it. When they got involved with a plane, however, they often built on that association and pursued information about the war relative to the type of plane, involving either their particular link to it (where their relative flew/serviced/built the plane), or the history of that specific airframe. ${ }^{59}$ For example, warbirders' strong interest in the "Doolittle Raid" stems not only from the idea that it was the first strike back at the Japanese after Pearl Harbor, but also from the central role that one common type of warbird, the B-25 "Mitchell," played in

\footnotetext{
${ }^{59}$ The identity of airplanes, however, is particularly slippery, as I discussed in the previous chapter, so knowing about "that particular plane" is more complex that one might expect.
} 
that attack. As the first strike back, it represented the early "awakening" of the nation, but it was the starring role of the B-25 which leads to the frequent "reenactment" of the raid at warbird airshows. The battle highlights the warbird, so it gets presented. Further, one warbirder I met was associated with that type of plane, and as a result had become interested in and involved with the reunions of the "Doolittle Raiders." He agreed that he never would have developed that interest or involvement without his prior association with the type of aircraft.

On the other hand, warbird magazines and books also use the war as an means to talk about airplanes. Their stories often revolve around one specific airplane or type of airplane, or perhaps one squadron's progression through successive types of aircraft. An article in a British magazine popular with warbirders in the U.S., for example, described several aerial battles against a particular type of Japanese plane (Edwards and Wittredge 2000). The authors argued that they were exploring a relatively unknown theater of war, but almost the entire article involved descriptions of the airplanes flying and fighting. Another article described the restoration of a rare type of aircraft. The article, rather than beginning with detail about the restoration itself, started out with an unusual battle in which the aircraft was involved. It was an American-built aircraft that the French had ordered before the war and that the Americans ended up attacking when they invaded Vichy-held north Africa (O'Leary 2005). Nominally the point of the article was to learn something about the war, but the center of the piece always remained the aircraft. The plane was a key to this narrow historical tale, but the tale in the end served just to valorize the aircraft itself as a rare, interesting, or important piece for the collector.

These modes of history-making, then, create a technocentric understanding of that history. History was understood as either of the machines or through the machines. The same kind of machine-linkage occurs when articulating the lives of United States citizens during World War II as well. I do not mean to say that all ties to persons get erased by this 
technocentrism, however. I described in the previous chapter the importance of veterans' stories in warbird practice, though even those stories at times devolve into stories about airplanes rather than humans.

\section{Americans and Their Machines}

The technocentrism of warbirding is guided by the understanding that Americans are inherently machine-oriented or machine-minded. Warbirders of all kinds articulated this machine-orientation as a form of self-understanding and as a means of distinguishing their American-ness from other nationalities. This shared participation in machines ultimately serves as a unifying force for warbirder nationalism, a quality that they can recognize and appreciate in their fellow Americans. At times, however, this machine-orientation developed into a technological enthusiasm which outstripped all of the other discourses at work in warbirding, from the "Good War" to the ideal nation.

Of the major qualities warbirders ascribe to the ideal nation, "unity" at first seems least connected to technology. According to the standard view of technology, it exists separate from society, impinging upon it but not part of it (Pfaffenberger 1992). The horizontal unity of citizens which plays a central role in the "Good War" myth and the vision of the ideal nation is eminently social. Yet the technocentric filter warbirders use depicts this unity as produced by and experienced through machines. The attacking airplanes were the proximate cause of the "fiery transformation" wrought by the Battle of Pearl Harbor, of course, but warbirders also see machines themselves as a unifying force. The machine-nation association, in warbirders's view, extends to all of the citizens. One middle-aged pilot and mechanic, who grew up working on and flying airplanes, insisted that an interest in tinkering with machines was a fundamental element of (implicitly gendered) American character, setting it apart from that of other nationalities.

You're touching on something, too, that I've never heard anybody talk about, for instance, an American kid growing up, what's he do? Rides skate boards, 
jumps off of walls and breaks his legs. Okay, guys in France don't do that. Kids in Italy, then Scandinavia, you know what I mean? ... The kid spirit is part of this airplane thing. It really does, I think, follow that. Not to take away anything other countries do, but it's just so different. You meet people from other countries and they can't even, you're from outer space. "What's this all about? Airplanes? How can you do that? Wouldn't you rather go to a nice restaurant or something?" "Yeah! After I get done flying, sure!" It's the way we're brought up, that's where the seed starts, what we're exposed to. It's what we're made up of. I mean, [kids in] Africa don't even have a dream of doing this, because it's so far out of touch.

In this view, Americans are inherently interested in (and good with) machines in direct contrast to French, Italian and Scandinavian people. This distinction marks a clear boundary between Americans and the rest of the world, whether by interest, as with the Europeans, or by opportunity, as with the Africans. It also locates this machine-orientation in child-rearing, arguing that the enculturation into machines is central to American society. This upbringing imbues Americans with a machine nature, as the "seed" grows until Americans are "made up of" an interest in machines. The preference for tinkering with and operating machines is also contrasted with the enjoyment of a "nice restaurant," implicitly contrasting a taste for leisure in other countries with a desire for agency with machines in the United States, a point I develop further in the next two chapters. This shared interest in machines also works to constitute the nation as a whole, as all of the (male) citizens are linked by shared participation in technology.

Warbirders read their machine-orientation into the past, describing how deeply the citizens of World War II invested themselves in their machines. One CAF member, a middle-aged artist with a deep fascination for the World War II era, insisted, for example, 
that the World War II nation had an ethos where each person tried his or her hardest. ${ }^{60} \mathrm{~A}$ riveter would try to make this the best rivet she'd ever done, and then she'd try to make the next one even better. One woman he had read about could not sleep if she had not done her best. This effort, he said, stemmed from the feeling of national unity and connection to the people fighting overseas. This individual was fully engaged in her work, and by extension, the nation as a whole was fully engaged in its work. Such sentiments are reflected in the accounts of workers being heavily invested in the aircraft they made, as when one warbird magazine article commented on one group of factory workers "signing" the $5,000^{\text {th }}$ airplane they produced, "It must have been a great thrill for the workers to see a gleaming bomber rolled out of the completion hangar covered with their signatures, knowing that the aircraft would soon be in action against the Axis" (Jackson: 52). This image of involved workers not only idealizes World War II labor as unalienated, as I discuss in the next chapter, but it also connects workers to each other, to "the boys" fighting overseas, and to the entire nation.

When Technological Enthusiasm Outstrips "The History"

Warbirders in general understand themselves and their activities as deeply patriotic, yet their technological enthusiasm at times outstrips their patriotism. A number of people are drawn to warbirding, in fact, just to work on or fly airplanes, without reference to the nation. Even those who see themselves as true patriots, however, at times subsume their patriotism to their technological enthusiasm, usually by shifting from a discourse of patriotic celebration to one of technological development.

Given their insistence that collecting airplanes should be patriotic, warbirders' obvious enthusiasm for Axis aircraft, especially German aircraft, seems out of place at first. Despite the vilification of the World War II enemy, the warbird movement demonstrates great enthusiasm for Axis aircraft. Nazi and Imperial Japanese pilots have become frequent

\footnotetext{
${ }^{60}$ The normal gender association of men with machines was complicated by the mass influx of women into the workforce, conventionalized as "Rosie the Riveter."
} 
guests at airshows and seminars and have even become members of warbird groups. They are "aviators of proven courage in war" (Salmon, Wooldridge, and Carr 1981). A former Luftwaffe General was welcomed "like a football star" to CAF headquarters, for example (Ibid.). I also attended a CAF meeting where a Luftwaffe pilot spoke about his experience flying during the war. Not surprisingly, he was not encouraged to offer any descriptions of fighting Americans (perhaps he was rendered safe because he only fought on the Eastern front, against the Soviets). Instead, he initially spoke about his experiences after the war, coming to The United States. When he did finally start talking about the war, the crowd only seemed interested in his description of flying the German planes. As a counter-example, another meeting I attended featured a Tuskegee Airman describing his war experience. The crowd thoroughly enjoyed his comparison of the different aircraft he flew, but he also said that he would have flown for anyone, even the Nazis, if they would have given him a plane, because he loved flying. His lack of nationalist sentiment was received uncomfortably, as it suggested not some amoral love of machines, but an implicit critique of the idea that the nation was unified. The racism he experienced, in other words, kept him from sharing in the crowd's celebratory nationalism. At this point, the nationalist model either breaks down in favor of glorying in the planes themselves, or becomes more subtle, valorizing patriotic service to one's nation even if the service is to a former opponent.

Axis aircraft in a museum's collection do not cause the stir that one might think. Indeed, the Tora reenactment features replica Japanese planes, pilots wearing Japanese pilot regalia, and a waving "rising sun" Imperial Japanese Naval Flag. Warbirders mentioned sometimes encountering objections from the public at airshows, especially objections to German aircraft bearing the Swastika, but they argued down these objections by saying that the aircraft were needed to have an "accurate" depiction of the war. This "just the facts" discourse serves to mask their enthusiasm for machines by saying that the machines are merely necessary for "accuracy." They need to have the enemy planes so that they can 
display "the history" just as it happened. In this view, their representations of the past are acceptable because they are merely literal presentations of the war. To be "accurate," they need to have an enemy against which to fight. The presence of the Japanese planes here is not supposed to conjure images of the horrific acts of the Japanese, but to represent, in a spectacular but bloodless way, the machine-on-machine "action" of the war.

\section{Machines as America}

Warbirders understand themselves as inherently machine-oriented, but they also come to see the nation in their machines. They frequently frame the machine-relation in terms of the nation-as-possessive-individual, arguing that the airplanes are an essential possession of the nation (Cf.MacPherson 1962). In this sense, they argue that preserving the aircraft is itself a patriotic act. Warbirders also go further in connecting the nation and the machine, articulating synecdochical links between the airplanes and the ideal nation of World War II. These connections take a variety of forms, from demonstrating qualities of the nation, to objectifying the genius and the strength of the nation, to acting for the nation.

One of the best encapsulations of warbirders' association of airplanes with the nation came from one young (early 30's) pilot who argued that the airplanes were essential pieces of Americana:

Cessnas are not really responsible for making this country great. And neither are Pipers or the Bonanzas, but if you look at Americana, you could say, "Well, a Ford Mustang or Chevy Camaro is Americana, or a '57 Chevy," as far as cars go. And in airplanes, Americana would be the P-51 Mustang or the Corsair. Most people who don't know anything about airplanes could recognize a P-51 Mustang, "The Cadillac of the skies," a quote, stealing from a movie. It was all about winning a war against aggression, about making a machine that's the best of the best. And that particular airplane's got this incredible story of being an idea on a factory blueprint to an actual 
production flown airplane in less than 120 days, which is just incredible. I mean, we went from Orville and Wilbur Wright flying for the first time in 1903 to a 400 mile an hour P-51 that could fly up to 35,000 feet in 1943 . Lots of aeronautical achievements in a very short amount of time.

He begins by pointing out that mundane general aviation aircraft did not "make this country great," warbirds did. Like the Camaro or Mustang cars, certain warbirds are so essential to Americanness that most Americans could identify them without knowing anything else about aircraft. Not only do these airplanes embody American-ness, but they also demonstrate the genius of American design and production. The "P-51 Mustang," for example, was destined to be the "best of the best," and it was designed and built in only 120 days. This airplane was also the pinnacle of an impressive American cycle of American technological development, from first flight to 400 miles per hour in 40 years. This effusive praise of the machine demonstrates the easy slippage between a technological artifact and the nation which produced the artifact. The machine embodies the nation in this passage, demonstrating its prowess and capability.

This warbirder was not the only one to connect industrial development to the qualities of the nation. Almost any appearance of the P-51 Mustang at an airshow included the mythic story of its rapid production. Further, warbirders frequently came to equate the industries operating during the war with national greatness. We saw above how warbirders imagine the assembly-line work as a unifying force, but warbirders also lauded "American industry," as a key possession, even an embodiment, of the nation.

\section{The Strength of the Nation}

Warbirders understand national agency, and especially the "strength" for which they plead, as embodied by or objectified in machines. In their view, the result of Pearl Harbor was not simply a unified nation, but also a nation devoted to the production of war materiel. "American industry began the greatest mobilization of production resources in history" 
(Baldwin et al. 1987: 7). This mobilization of weaponry materialized "strength" in war machines. The Tora narrator lauds the "technology and industrial might of the men and women of American industry," and warbird literature is filled with praise for American industry's productivity during the war, often depicting World War II simply as a battle of production: "The Axis was swamped in a sea of American war production" (Baldwin et al. 1987: 6). ${ }^{61}$ Unlike the wars of today, which are advertised as clean wars of precision strikes, ${ }^{62}$ warbirders seem to see World War II bombing as a matter of putting more planes into the air to drop bombs on the enemy, making the possession of productive industry a kind of weapon. Most warbird publications include some photograph emphasizing the quantity of production, though these photographs, which implicitly contrast plenitude in the past with perceived scarcity today, also emphasize the nostalgic longing of industrial romanticism, which I discuss in the next chapter.

This emphasis on industry, despite paeans to "free enterprise system," does collapse the distinction between aircraft production and the nation itself. For example, one publication describes the U.S. as a homogeneous entity of production: "In less than 24 months after Pearl Harbor, the U.S. had become one giant factory with raw materials and millions of pieces and parts endlessly flowing toward assembly lines" (Baldwin et al. 1987: 7). Mirroring this asserted unity of the nation, different industries cooperated for the war effort, apparently dropping their peacetime competition: "Sewing machine companies made gyroscopes, typewriter manufacturers produced machine guns, Westinghouse built GEdesigned radars and Goodyear manufactured F4U Corsairs for Vought" (Ibid1987: 7). While

\footnotetext{
${ }^{61}$ Even ten years after the Cold War, I never heard a warbirder refer to the massive production of the Soviets as a key factor. The Lend-Lease of aircraft to the Soviet Union comes up often in warbird publications, especially in articles devoted to aircraft that were sent to the Soviets in large numbers, but no one mentioned the large-scale production of tanks and aircraft. They could have done so, however, without breaking their technocentric frame. As I discuss in the "patriotism" section, their insistence on a "Just the Facts" view of history serves to elevate their technological enthusiasm over their patriotism, which allows them to "celebrate" the technological achievements of other nations without losing their claim to patriotism.

${ }^{62}$ Despite all the "smart bombs," the total tonnage of bombs dropped in wars today vastly exceeds that dropped
during during World War II.
} 
this quotation retains the companies' brand names, it collapses the competitive distinctions between them, articulating a Dumontian collective individual.

Machines as Agents

In discourse and in performance, warbirders also conflate the nation and machine by making the machines into the agents of the war. The Tora performance, for example, marks the transformation of the nation into its ideal form by shifting agency from the Japanese planes to the American ones. At the start, the air is filled only with Japanese planes. Midway through the performance, a lone bomber, described by the narrator as unarmed, pretends to land on one wheel. At the same time, a single American fighter plane takes off. By the end of the performance, the agency has begun to shift to the Americans, and the American plane shoots down a Japanese one. In the full reenactment of World War II, the ensuing "Doolittle Raid" shows the Americans first asserting their agency fully. In these performances I believe we see that warbirders understand the nation's agency as requiring the use of machines. The tragedy of Pearl Harbor, in this view, lies in the inability of the American planes to take off and fight the Japanese planes and in the lack of "good" planes to match the Japanese Zero (a point sometimes contradicted by praise of the American planes at the time).

Warbirders also depict the aircraft as the agents of war in their accounts of the war. For example, in a passage entitled "Lest We Forget," the voice of the mythical leader of the then-Confederate Air Force, Col. Culpeper, obscures the referent of its message:

The historic combat aircraft of the Confederate Air Force are aircraft which defended our Nation and won the skies on every battlefront of the globe in World War II. . . . Some rose to fight at Pearl Harbor-They fought in the Coral Sea . . . They bombed and fought in daylight raids over Europe ... They fought over the heads of Allied soldiers from Normandy to Berlin . . . 
and on to Japan - To final victory over the Rising Sun and the Swastika. (Baldwin et al. 1987: Back Cover)

In this passage, the "they" who "fought in the Coral Sea" and "bombed and fought in daylight raids over Europe" refers at least as much to the airplanes as to the aircrews. By preserving these "historic combat aircraft," then, the Confederate Air Force was preserving the very combatants of the war, and as combatants, these airplanes embody the nation itself.

Ultimately, the machines become a common substance of Americans. Where most discussions of nationalism look to some shared substance or essence, whether it be blood, kinship, or land, as providing the basis for horizontal community, the very substance of nation-ness, warbirding looks to the airplanes. This conflation of technology and nation is not unique to warbirding, however; the space program's rockets, for example, have long been conflated with the nation, as have different automobiles. I have already argued that technocentrism is an important discourse within American nationalism, and warbirding provides another powerful example. Yet this focus on the machines has additional, powerful effects besides fostering a nation-feeling. Focusing on technology inevitably precludes attending to other significant dimensions of nations and war.

\section{Technological Obviation}

The enthusiastic technocentrism of warbirders foregrounds the aircraft and their role in World War II, but at the same time it masks other aspects of both the war and the airplanes' use in the war. Specifically, reveling in detail about airplanes serves to mask the divides which existed in the United States during the war and which exist today, contrary to the repeated emphasis on 'unity' during the war. Further, technocentrism has the even more pernicious result of effacing the violence performed by those embodiments of national "strength." 
I call this masking "technological obviation," as a much-simplified variation on Wagner's theory of symbolic obviation (Wagner 1978, Wagner 1981(1975)). ${ }^{63}$ Technological obviation in warbirding works in a series of metaphorizations. First, warbirders use the airplane to synecdochically invoke or connect to the domain of the war as a whole. Second, that part-for-whole relation also works as an internal metaphor (Sapir 1977), connecting the domains of World War II and machines such that the domain of machines comes to "color" the domain of the war as a whole. I argue that this "coloring" of the metaphor becomes so powerful that it transforms discussion of the war almost entirely into discussion of the machines. We might also say that technological obviation renders the machine the figure and the scene, in this case the war or some aspect of the wartime nation, into the ground. These metaphorizations are created and reinforced not merely rhetorically, but also phenomenologically through the reenactments.

The notion of technological obviation grew initially from the famous article on "defense intellectuals" by Carol Cohn (Cohn 1987). She sought to discover how "defense intellectuals" could strategize nuclear war, which would kill millions of people. What she found was that they had crafted a language which precluded, and here I would say obviated, any discussion of the fate of humans on the ground. All of the talk focused on targets and yields, having to do with missiles ("ours" and "theirs"), not bodies. In Wagner's terms, they conventionalized weapons as rational, calculable means of fighting, obviating the horrendous destruction they would cause if they were ever actually used. I argue here that technological obviation in warbirding works in similar ways, masking both the divisions within the nation and the violence caused by the use of the aircraft. I roughly map these two kinds of obviation onto the qualities of the ideal nation sketched throughout this chapter: unity and strength.

\footnotetext{
${ }^{63}$ My usage differs significantly from Wagner's. Where Wagner argues that obviation is characteristic of myth and action in "differentiating" cultures, he sees Euro-American culture as collectivizing. Obviation is the central means of culture production in differentiating cultures, in his view. Here I argue only that it plays an important role in relating to machines.
} 


\section{Internal Threats: Obviating Difference}

The first obviation that interests me occurs when warbirders seek to conventionalize the World War II nation as a unified, collective individual. Warbirders' propensity to see the ideal nation in the machines serves to efface, or obviate, other dimensions of the war. As with most nationalist ideologies, warbirders articulate a World War II nation that links all citizens horizontally and simultaneously. The transformation wrought by Pearl Harbor eliminated these divisions, and warbirders read the resulting unity through the airplanes. Indeed, the emphasis on the machines today serves to obviate the very real distinctions that existed during the war. It effaces other cultural boundaries of religion, political party, ethnicity/race and class, if not gender. ${ }^{64}$ Even groups marginalized during World War II can be included in technological enthusiasm, and the association through machines ultimately conventionalizes wartime homogeneity.

They see unity through participation in machines in a variety of ways, some already mentioned. The factory workers who collectively invested themselves in the airplanes they made was discussed above. The magazine advertisements of airplanes - which have become collectibles for warbirders - also suggest a kind of unity through machines, in that they argue that $\mathrm{x}$ airplane made by $\mathrm{y}$ corporation is out there, fighting for the nation and paid for by your war bonds. The airplane synecdochically invokes the nation. The horizontal linking of citizens through participation in machines erases significant differences and divisions between them. Indeed, this disappearance of division is a central component of warbirders' imagining of the ideal nation.

Within this technocentric frame, one cannot consider other aspects of the machines or the society which produced them, so those aspects are obviated. One remarkable magazine story, for example, recounted a female Air Transport Auxiliary pilot's wartime

\footnotetext{
${ }^{64}$ The question of gender can be muddled at times, as when female pilots fly warbirds or, in another case, when a woman focused not on the war hero pilots and crews but on the heroic efforts of female nurses in medical evacuation planes.
} 
experience as a ferry pilot (Curtis 1999). She described how the ban on women ferrying combat aircraft was lifted mid-war, giving her the chance to fly a wide variety of aircraft. This policy shift was an important story in the history of gender and technology, but the article quickly subsumed that story to a description of all of the different kinds of planes she flew. The listing of plane types, complete with identification numbers for the specific planes, fell into the warbird enthusiast's discourse of excessive detail, while at the same time evincing the longing warbirders today have for the experience of all those different aircraft, especially types that no longer exist. Thus, a story which could potentially elicit the gender equality of the war becomes a story about the love of and longing for aircraft.

The persistence of the name Confederate Air Force (finally changed in 2001) and the organization's enduring popularity in warbirding indicate the lack of an interest in the racism and segregation of the war (not to mention the Civil War). I would argue, however, that this persistence depended upon technocentrism, as the machine focus merely subsumed all other concerns about unity in the nation, during the war or even today. Like the factory workers signing the airplane they made, everyone was unified in support of the war. Racism didn't matter because everyone was involved in the same militarizing enterprise. By extension, the ideal nation today would also have everyone unified in support of national strength.

When attention does shift to the divisions of the war - as it must, for now, in this post-Civil Rights era — the airplane focus serves to take the edge off the harshness of those divisions. Most warbird museums now have exhibits on the Women's Air Service Pilots and on the Tuskegee Airmen. Despite this nod to inclusion, the emphasis of these exhibits remains on the machines over the discrimination. Often they highlight just how good women and African-Americans were with airplanes, belying the wartime myths of inferiority. Yet including them in the club of the machine-oriented often shifts the subject into the kinds of planes and missions they flew, again obviating the prejudices of the time. Another "Good War" myth idealizes the experience of bomber crews that consisted of people from different 
backgrounds. The shared experience of flying and fighting in the airplane, in this story, allowed them to transcend class, racial, ethnic, and religious differences. They came as different people, with different backgrounds and through the plane, they transcend their individuality, becoming the larger individual that is the plane's crew. This idea is important to the "Good War" myth that the war united the disparate parts - ethnic, racial, geographic — of the United States. It parallels the image of the Army platoon as the American melting pot, a common theme in World War II movies to this day (Adams 1994).

The import of disparities before and during the war could even be turned into an advantage when it came to operating these machines. Another warbirder saw the harshness and deep poverty of the depression not as an indictment of class relations in America, but as a kind of training ground for future fighters. He argued that having to hunt for food, as poor and rural people had to do during the depression, made them into good shots, which enabled them to shoot down more enemy aircraft. While this view may be idiosyncratic, it does reflect a broader sense that the "Greatest Generation" earned its nobility through sacrifice and hard work. By the same token, some discussion of the Tuskegee Airmen focuses on their resentment as a positive force in their development of flying skill. They had to serve as examples, so they worked especially hard. Again, the machine focus overrides possible critiques of the American system.

\section{The Obviation of Violence}

"the spectacle of television images (which told the story not of war but of weaponry) . . . constituted the [Gulf War's] representation" (Sturken 1997:

While warbirder emphasis on national unity obviates wartime social divisions, the most important obviation of warbirding, in my view, involves the representation of war. In general, warbirding obviates the violence of war by translating the discussion of war into the discussion of machine types and of the machines' history, as well as into the spectacle of 
reenactments. These three kinds of technological obviation all serve to reinforce the "Good War" myth by emphasizing the positive result — playing to the crowds' technological enthusiasm and nation-feeling — and effacing the brutality of the machines' actual usage. Indeed, the displays tend to tell "the story not of war but of weaponry."

Warbird discourse generally emphasizes the characteristics and types of machines over the violence they inflict. Warbird books and magazines, for instance, always foreground the type of airplane used in any kind of mission, even when the stories describe tragic deaths or valiant acts. Airshow narrations, again, similarly take pains to emphasize the details of the aircraft and obscuring the violence of the war. For example, one flight demonstration of a warbird ${ }^{65}$ immerses the crowd in paragraphs of great detail like the following:

It was the first aircraft to utilize the Pratt and Whitney R2800 engine, thus the requirement of the huge 1200 pound Hamilton Standard propeller to convert the 2400 horsepower provided into thrust. The "Dash-One" variant is the sleekest and best flying of all Corsair types and in an independent survey conducted by the Army, it was judged to be the best all-around, propellerdriven fighter of World War Two! (2005b)

This passage echoes the clinical detail of the Tora narration, described above. It focuses on the plane's components ("the Pratt and Whitney R-2800 engine" and the "1200 pound Hamilton Standard propeller") and its type (the "Dash-One" variant"). The passage also demonstrates the emphasis warbirders place on the history of aircraft and their development, describing this airplane as "the sleekest and best flying of all Corsair types," and even "the best all-around, propeller-driven fighter of World War II." This kind of description appears

\footnotetext{
${ }^{65}$ I noted in the previous chapter that warbird performances normally focus on "what they did" instead of "what they can do." Performances of contemporary aircraft tend to focus on the latter. The warbird performance described here, however, is one of the few which does highlight "what it could do." This exception does not undermine that previous point, however, as the import of the warbird always remains its role in World War II. With regard to technological obviation, the performance of "what they did" also obviates the violence of the war, as I will describe below.
} 
in any warbird performance. Warbirders particularly like to compare the different airplanes' merit to figure out which one is the "best." I have even seen a recent academic study of which airplane turned better, a study which can only serve as historical trivia (Ackroyd and Lamont 2000). Such discussion does not merely emphasize machine-talk and machine trivia over other ways of understanding the war, but the immersion in detail about machines' relative capabilities also precludes discussion of the violence machines do to people (Cohn 1987).

Non-flying airshow displays similarly emphasize technological enthusiasm over other dimensions of the war. The static displays and the souvenirs sold seek to develop an enthusiast's "taste" for different aircraft. The static displays at an airshow set the tone for the day. In the morning the planes are all parked where the public can approach, look them over closely, and often ask questions of the pilots or crew. These moments are when the veterans of the war are often led to tell stories about their experiences. Often these static displays resemble (if they are not, in fact) concours d' elegance, with the planes laid open to allow close inspection of their restoration. Here the crowds can learn the details of the machine directly — the color, size, and shape — and learn to distinguish one from the other. The emphasis lies in revealing the hidden interiors of the aircraft, showing off the careful restoration of the most mundane components of an airplane. The planes on display sit in one metonymically-linked group, all fabulous machines of yesterday. Similarly, the souvenirs sold at airshows, whether by warbird groups at their airplanes or at one of many vendor tents, focus on the types of aircraft. T-shirts are most popular, and one can find many warbird shirts at any airshow. Vendors also sell pins, books, plastic and wooden models, and videos, all of which focus on some type of aircraft.

The flight demonstration from which the narration above is taken involves the plane performing high-speed turns, twists, and rolls while the narrator describes the capabilities of the airplane. As the text suggests, the emphasis is entirely on the machine itself. Further, 
when warbirds are used to reenact the war, the emphasis on flight characteristics like speed and turning fades, and the story describes instead the succession of aircraft through the war, offering some details about the development and evolution of different kinds of planes and often comparing the various types on display. This emphasis on detail couples with the phenomenological experience of the pyrotechnics' non-destructive violence to produce the space of "war" as a site for the application of technological wonders rather than grotesque violence. The violence of war becomes spectacle in the reenactments. Here war is an abstract struggle between nations in which machines are the agents, and no bodies are involved. The introduction of pyrotechnics does not reduce the obviation of actual violence. The spectacle of explosions is intense and startling, but no bodies are blown apart; no one gets hurt (Gusterson 1991). I do not mean to plead for casualties, simulated or real, in the name of some misplaced quest for authenticity. Reenacting war is grotesque enough as it is. Rather, I argue, again, that the performance's enthusiastic focus on a machine obviates the effects of its use, in this case, the violence it inflicts. The explosions emphasize the power of the machines without acknowledging the destroyed buildings and bodies that result from that power.

\section{Materializing the War}

An important element of warbirders' "just the facts" view is their technocentrism, which both focuses their interests in the war on the machines and produces a systematic blindness to other dimensions of the war. Such blindness is common in the American understanding of technology and history (not to mention militarism, as I will discuss below), demonstrated, for example, in the recent unveiling of the atomic bomber Enola Gay at the Smithsonian. A news article quoted John Dailey, Director of the Air \& Space Museum, 
This time, said Dailey, the plane will be displayed along with other notable World War II artifacts, and the descriptive text "delivers the facts and allows the people to understand these facts within the context of their own beliefs. ...We are displaying it in all of its glory as a magnificent technological achievement."

In the end, despite passions over its place in history, "it is an aircraft, it is a machine," said Dik Daso, a curator in the aeronautics division of the museum. "It represents the hundreds of thousands of airmen who participated in that conflict. We must remember that this airplane is a part of our history and it is a part of who we are" (Trescott 2003).

The curators insisted that the object could speak for itself, that any discussion of its use to kill thousands of people would be an intrusion into the story of the object itself, not to mention an intrusion into the celebratory tale of American technological achievement. Reading history through the objects, far from providing an "objective" history, produces a systematic blindness to non-material dimensions of the war. This view of history-making suffers from the problem of pre-selection (in that the machine is already highlighted as the significant factor (Cf. Gable and Handler 1994)) and represents a technological fetishism. Such fetishism impoverishes both historical and cultural understanding by narrowing it to a story of machines.

The materialism of warbird performances works very well in their invention of World War II. Warbirders combine the popular narratives of the "Good War" and the "Greatest Generation" with the technological spectacle of the airshow to establish the authority of their account of the past. They then naturalize that past as the true essence of the nation's existence, drawing on the authority they've created to depict and pursue their ideal nation. This process seems tautological, but I argue instead that the two fields of meaning - 
representations of World War II and technological performance - mutually constitute each other. They alternate as convention and invention (Cf. Wagner 1981(1975)). In other words, they use the airplanes to create a new technological spectacle, which they want to conventionalize as the common wisdom of what the war was like. At the same time the conventional wisdom that the war was a "Good War" informs their invention of warbirds as a form of heritage.

My own discussion of tech obviation might be accused of materialism in that I argue the vital dimension of these machines lies not in their present use to create a usable past, but rather in the metonymically linked domain of performing violence. The linkage I make depends entirely on the material object itself, the persisting object that links these two contexts. (Well, at the very least I go along with warbirders in linking these two contexts of the airplane-as-heritage now and the airplane-at-war then.) In making these links, I follow the trend of the field of science and technology studies, which tends to use material objects (technologies and laboratory apparatuses) and scientific theories as the basis for constituting its realm of study. If there is a difficulty with my own materialism, aside from the potential impoverishing of the subject into an anti-war diatribe, it is one that characterizes all anthropology, which persists based on its ongoing invention of other cultures (Wagner 1981(1975)).

\section{The Technological Sublime}

Another way to understand the play-violence of reenactments is to examine them as a form of the "technological sublime." In his work, The American Technological Sublime (1994), David Nye connects machinery to nationalism by arguing that the sublime experience of technology strengthens nation-feeling. The sublime, an experience "of awe and wonder, often tinged with an element of terror," (xvi) is a momentary dislocation of experience produced by viewing some overwhelming object of nature or technology. For Kant, the sublime sparked a sense of superiority over nature because of the ability of human reason to 
grasp the magnitude of what the senses could not (Ibid: 7-8). In the United States, the experience of the natural sublime, such monuments as Niagara Falls and the Grand Canyon, led not to a sense of the superiority of human reason, but instead "was woven together with the nationalistic language of exceptionalism, so that Niagara became a sign of a special relationship, or a covenant, between America and the Almighty" (Ibid: 22). As the United States became more industrialized, the size and power of technological objects-railroads, bridges, space rockets—came to be seen as reflective of the nation itself. This greatness, however, is "not absolute but comparative. Not only are its objects soon obsolescent; they are often consciously constructed and perceived as demonstrations of greater power and expertise than an adversary possesses" (Ibid: 241). These comparisons were most obvious during the space race of the Cold War. Warbird performances employ just this kind of sublime experience to reinforce their techno-nationalist discourse.

While the technological sublime is central to warbirders' nationalism overall, I have waited until now to describe it because it highlights well the workings of technological obviation. The sublimity of warbird performances occurs within the technocentric frame of the airshow, which highlights the machines and only the machines. The sensory assault of the explosions and speeding planes, the rapid narration (and recorded air raid sirens of Tora), and the storyline of a nation under attack all overwhelm the viewer, instilling a little fear. It produces an imagined space of battle in which the powerful airplanes embody the nation and its strength. The technological sublime then brings us full circle. From the initial displacement of the nation into the machine, the machine is now reincorporated into the nation as the embodiment of its power, yet without the violence it inflicted. Having obviated the violence of war in the performance, warbirders are then able to draw on the nobility of "service to the nation." The warbird demonstration narration above includes only a single sentence about the war: 
“The Commemorative Air Force FG-1D Corsair Flight Demonstration Team is dedicated to reminding all Americans of the great bravery and sacrifice made by young men and women [sic] flying these aircraft in defense of our great nation and our freedom" (Ibid)!

This euphemistic talk of the "defense" of the nation obviates the violence of war just like the technological obviation of the performance itself. This language clearly borrows from the frequent, recent use of epithets like "Freedom will be defended." Such understandings obviate not only the motivation for war, but also the violence involved in war.

\section{The Usable Past}

Warbirders perform at airshows for many reasons, but one of the most important to them is to spread their specific form of nationalism. As has been implicit throughout this discussion, they treat World War II as a "usable past." The usable past connects past and present; it imagines that the past could be, and should be, made present. While warbirders argue that preserving the aircraft in itself is a worthy cause, they also exhort their audiences with the "lessons" of the war. The mantra "Those who forget history are doomed to repeat it" drives their interest and their proselytizing. For them World War II is the exemplar of what happens when a nation is not "strong" or "unified" enough.

White has argued that, given the dichotomy between history as commemoration and history as pedagogy, historical activities never fit neatly into either one (White 2004). Thus, warbirders describe what they do as commemorative (and are deeply committed to the idea of honoring the veterans), but their practice and rhetoric are almost entirely pedagogical. For example, the introduction to the reenactment of World War II includes the exhortation, "We who experienced those years should not forget them, and the younger generation of Americans should be made aware of the accomplishments of this nation during that period" (Moll 1987: 34). The idea of making young people "aware of the accomplishments of this nation" runs throughout warbirding. Similarly, warbird groups frequently use the phrase, 
"Lest We Forget," a vague statement which they often interpret to mean that the "lesson" of World War II — the need to be "strong" and "unified" — should not be forgotten.

\section{The Lesson of Pearl Harbor}

"We must also be reminded that this nation-and the free world-must never be caught asleep again as we were on December 7, 1941, and that we must always be as relatively strong as we were in 1945 when these machines were first-line combat aircraft." (Moll 1987: 34)

This passage captures the central "lesson" warbirders seek to inculcate: the devastating Pearl Harbor attack caught the nation "asleep," i.e. weak and divided, but transformed the nation into its ideal form, strong and unified. Most warbirders hold some version of this view, but it is not unique to warbirders. A popular lesson drawn from World War II, for example, has been that "tyrants should not be appeased," meaning that an aggressive military stance is the answer to any perceived threat (Cf. Adams 1994). This desire for an assertive nation fits the warbirders' ideal of strength. Further, both the "Good War" myth and recent discourse about the "Greatest Generation" hold that the nation came together after Pearl Harbor to fight a just and necessary war.

If these "lessons" about World War II and even, to an extent, the aircraft of World War II are not unique to warbirding, what sets warbirding apart from general conservative discourse about the war? Unlike movies and other discourse, warbirding turns this lessonteaching into a technological practice, and a military one at that. The emphasis on technology, of course, is not unique to warbirding. The West has generally seen itself in terms of the complexity and capability of its machines (Adas 1989). Warbird performances do not occur in isolation from other representations of these technologies, either. In fact, most airshow attendees, especially boys and men, come with some knowledge of the aircraft of World War II. Much of the mythologizing of World War II technology has been accomplished before anyone arrives at the show. Most of the warbirders I met had a story 
about how they first learned about the aircraft as boys playing with toy airplanes, building plastic models, reading comics, and playing video games. Popular movies like Saving Private Ryan depict the airplanes heroically for older audiences, and video games often feature warbirds prominently. Warbirding draws on all of these elements in its practices, letting afficionados further develop their taste for the planes and imagine themselves and the planes in action during the war. As I argued above, the concrete experience of these airplanes and the sublimity of the performance serve to reinforce the lesson that the World War II nation was an ideal nation that should be emulated today.

\section{Militarization of History/“History" as Militarization}

The passage quoted above argues that the United States should be "as relatively strong as we were in 1945." This stated desire for the relative strength that the United States had after three and a half years of total war nicely captures the operative worldview here, that the ideal nation must be thoroughly militarized. ${ }^{66}$ They understand machines to be at the center of history, and through the machines they militarize history as a usable past and perform history as militarization. In other words, they both employ historical discourse to continue the project of militarization and understand "the History" of the United States as one of (beneficial) militarization.

By militarization, I mean the readiness to accept a "military definition of the situation" and the devotion of substantial societal resources to the development of military power (Johnson 2005, Lutz 2001). Lens (1987) describes the post-World War II emergence of a state of "permanent war," where, contrary to prior history, the United States maintained a large standing Army and constructed a second, more powerful, and secret government

\footnotetext{
${ }^{66}$ One wonders, however, if the United States is again approaching that level of expenditure as a percentage of the budget, if not of the GDP. According to one writer, military expenses - Defense department, war operations, nuclear weapons, intelligence, and veterans' care — will approach 3/8 of the total federal budget in fiscal year 2005 (Johnson 2005).
} 
devoted to "defense" of the nation. ${ }^{67}$ This emergence, in turn, installed a "military definition of the situation" as the dominant point of view within American culture (C. Wright Mills cited in Lutz 2001: 85). The "military definition" constituted a powerful way of seeing, interpreting everything primarily as it related to "national security." This militarized consciousness began with World War II, continued through the Cold War, and has accelerated with the "War on Terror" (Lens 1987, Lutz 1997, Lutz 2001, Lutz 2002). In addition to this national security framing, militarization involves the devotion of societal resources to military projects. The "military-industrial complex" of the early Cold War marks the postwar emergence of this dimension of militarization. Production and preparation for war became the permanent war, with the understanding that the nation should constantly be ready to participate in a large war, again, despite the historical precedent of the military always demobilizing after war (Bacevich 2005). When the Cold War ended, conservatives decried the "drawdown" of the military, yet despite some cuts a substantial shrinkage never occurred, largely because the military, hoping to preserve the strength and status it had gained after recovering from the debacle of the Vietnam War, successfully created a requirement that it should be ready to fight simultaneously two major, regional wars (Ibid).

Warbirders both inherited and contributed to this process of militarization. Their understanding of the post-Pearl Harbor nation, and its contrast with the present day, clearly demonstration their militarized view of "the History." The national unity they ascribe to the World War II nation is not just a surge of fellow feeling, but also a "[determination] to fight." These passages capture the central thrust of their view: "the American attitude changed overnight. Isolationists became war hawks, the armed services were swamped with waves

\footnotetext{
${ }^{67} \mathrm{By}$ "secret" here I do not mean to imply an unknown conspiracy. Rather, the secrecy of the national security state is out in the open, well known in fact, if not in specifics. "Conspiracy theories" about what goes on in this second government abound, but I am more interested in the widely and easily accepted existence of a government completely unaccountable to the public, despite all of the rhetorical deployment of "democracy" and "freedom" which supports this system.
} 
of volunteers" (Baldwin et al. 1987: 7). The transformation of isolationists into "war hawks" supplants the isolationist nationalism with a militarized nationalism. When warbirders reflected on what made World War II a "Good War," the unity that they so praised was a unity in support of the war and the military. The "volunteers," factory workers and parents of soldiers, in this view, came together to support the war. Support of the war and in support of "the troops" comes up repeatedly. This view of the nation is one of a collective individual, undivided and willing to fight. The further element of militarization, the organization for war production, plays an even more central role in warbirding. The entire enterprise focuses on celebrating the tools of war, and they understand "strength" almost entirely in terms of the quantity and quality of these tools.

As a usable past, then, warbirders include all of these characteristics of the World War II nation in their view of the ideal nation. Starting with their basic understanding of the nation, their Hobbesian worldview — where the nation is constantly under threat — reflects a "military definition of the situation." In a Hobbesian world national security is always under threat, no matter what diplomatic relations or institutions have been established. The answer to this threat can only be strength, back by a unified populace. The open-ended nature of this threat leads warbirders to the absurd plea for extreme military prowess noted above. Indeed, the militarization of the United States has largely resulted in this plea being granted. The massive expenditure on the military today occurs largely without regard to any specific, obvious threat. It has largely become strength for the sake of strength. Technological enthusiasm helps further this policy, as demonstrated by the current debate over the fighter plane called the F-22. Many articles on the airplane highlight it as a technological wonder, masking the question of whether the aircraft is actually needed. It was developed to "penetrate" the Soviet Union and defeat its best fighter planes, but the end of the Cold War, which removed the "threat" the plane was developed to answer, did not end 
the program. Rather, despite its enormous cost, it was left largely unchanged after the Cold War, with its number cut by two-thirds.

In the their "military definition" of history, students in schools should learn all they can about the great battles, like the attack on Pearl Harbor, the Doolittle Raid, D-Day and even Hiroshima. ${ }^{68}$ Further, this "military definition" of the nation looks to the military as the ultimate source of all things good in the nation. As this warbirder put it, "We, as a country, ... forget sometimes that the only reason that we're this way is because people are willing to put their life on the line to ensure that we have this." This passage not only highlights the Hobbesian worldview, but it also captures another peculiar feature of militarization. This feature holds that the military's strong, assertive "defense" of the nation is the necessary cause of all the nation's institutions and values.

\section{Militarization at the Airshow}

The main role warbird performances play in the ongoing militarization of the United States is the connection of the war machines of the past with the military aircraft of today. The connection of old and new constructs paradigmatic linkages between the domains of the old and new aircraft, the "Good War" and ongoing military actions, and the "battlespaces" in which they are used, then and now. Since the first days of warbirding, the airplanes have appeared at big military airshows where the stars of the show were contemporary aircraft. These old and new aircraft were paired in the Air Force's Heritage Flight and the Navy's Tailhook Legacy Flight. This pairing constructs a metonymic connection between them, putting them together in the domain of technological marvels. The qualities and associations of one aircraft carry over to, or color, the meaning of the other. The old planes bring with them — the narration emphasizes this - their successes of the past and their association with the "Good War." These associations then work through the pairing with the

\footnotetext{
${ }^{68}$ I cannot recall the Holocaust coming up in such lists, though the Holocaust is absolutely part of the framework making World War II a "Good War," even though the moral imperative of shutting down the death camps emerged in public discourse only in recent decades.
} 
contemporary planes to color the meaning of the new planes, lending them the heroic aura of the old planes. Warbirds' association with the ideal nation carries with it the implication that the new aircraft could be the key to restoring that nation, a point warbirders make explicitly. Similarly, the warbirds' association with (what is perceived to have been) a mortal threat to the nation - the feeling that the aircraft were "necessary" - also carries over to the new aircraft, making them the answer to the current threats. This valuation of new aircraft, then, lends support to the idea that more and more of them should be produced. The performance also encourages a parallel development of enthusiasm for the technologies. I described above the importance of technological enthusiasm for obviating the effects of military technologies, and the same process applies for contemporary aircraft.

The pairing also instantiates a discourse of technological progress which differentiates the aircraft as steps in aircraft evolution. This way of understanding machines lends itself to pursuing ever-better aircraft, driving the expansion of production for war. (Warbirders at times dispute the extent to which that sequence involves improvement. The nostalgia discourse of warbirding may deprecate the contemporary aircraft, but in most cases enthusiasm for old airplanes is entirely compatible with enthusiasm for new ones.) As I mentioned, the end of the Heritage Flight in some way re-establishes the evolutionary order, where the much faster, heavier, computerized and complex current aircraft differ radically from the older planes. This order persists through most of the airshow, as the maneuvers the planes perform in their separate acts are different and the way of talking about them is different. Their narrations share a discourse of technological enthusiasm, but the warbird narration focuses on the heroic events of the past, while the contemporary jets are described most often in future, hypothetical terms. They do mention participation in the Gulf War and the wars in Afghanistan and Kosovo. In the previous chapter I described this distinction as between "what the airplanes did" versus "what they can do." I would argue that the 
discourse of technological progress depends upon the notion that the "doing" of the old aircraft is past, even if they remain powerful machines.

\section{Producing Battlespace}

The airplanes' paradigmatic linkage of World War II and today, then, colors the understanding of the United States' current military engagement with the rest of the world (this held true even before the Iraq and Afghanistan wars). We can look at the airshow performance as the production of a space of war (Lefebvre 1991). Tora's "chamber of the imagination," in this view, becomes a carefully filtered construct for depicting not just the battle of Pearl Harbor, but also, in a metonymic extension, all aerial battles and "battlespace." 69 The cultural work that Tora performs here is crucial: it projects the image of war as technological spectacle back onto the battlespace of today. The Tora reenactment not only obviates the material and bodily effects of war in the past, as described earlier, but the imaginary space of their deathless usage in reenactment also gets mapped onto the actual battlespaces in which they are used today. We can best see the insidious nature of this airshow "fun" by considering the Iraq war. In my limited exposure to the "Shock and Awe" coverage it came across as little more than a larger version of the Tora pyrotechnics, all spectacle, no obvious death. In a similar case, on October 7, 2001 I watched the B-1 bomber perform high-speed flybys in Midland, Texas, after the announcement that the bombing in Afghanistan had begun. While the crowd was thrilled to be "hitting back" after 9/11, I felt a disconnection between the imagined space of war created by the techno-wonder flying in front of me and the reality of the bombs that same type of plane was dropping on central Asia at the time. The crowd's enthusiasm for the inception of violence, on their behalf, had to depend upon this slippage to some degree. Even the blood lust and satisfaction of "hitting

\footnotetext{
${ }^{69}$ While I use the term battlespace to emphasize the imagining of three-dimensional spaces of movement and activity, the military in the past decade also has shifted from using the term battlefield to battlespace. The military aims to expand the understanding of "war-fighting" as involving three dimensions, including ground combat, aerial combat, aerial surveillance and satellite communications. The ongoing militarization of all spaces, then, is a topic worthy of further discussion.
} 
back" depends upon the obviation of the killing of innocent civilians (unless, of course, no such conception of innocent civilians exist, as when the enemy is racially demonized). Oneton bombs do not make "precise" and "surgical" craters.

\section{9/11 Was a Failed Pearl Harbor}

The kind of patriotism warbirders espouse flared up after the 9/11 attacks, testing whether warbirders' idealized nation might be reborn. I had written previously that their idealization of World War II, and the key role of the Battle of Pearl Harbor in initiating that war led them to long for another such transformative event. Immediately after the 9/11 attack, many people looked to Pearl Harbor as the relevant event for understanding what would surely be a dramatic transformation of the nation, and warbirders were no different. My first day of full-time fieldwork was September 11, 2001. When I approached a group of men standing around chatting, one said, "Oh, you're not interrupting anything. We're just trying to figure out how to kill some sand niggers." This vehemence recalled the great desire of Americans in 1941 to "kill some Japs." Yet these passions faded (though the prejudice has not), and despite some positive benefits that a few warbirders saw in the aftermath of 9/11, most saw 9/11 either as a failed Pearl Harbor or ultimately rejected the analogy altogether.

Immediately after $9 / 11$, the discourse at airshows was more stridently patriotic than previous shows, but not as much as one might expect. The new patriotism was strong, but the old patriotism at these shows had always been oppressive. Nevertheless, the patriotism had a new theme, a new unity to encourage, as this narrator's conclusion to the October, 2001, performance of Tora! Tora! Tora! shows,

Announcer \#1: I suspect, ladies and gentlemen, that the terrorists who killed our $6,000^{70}$ people on September the $11^{\text {th }}$ is [sic] going to find that same

\footnotetext{
${ }^{70}$ This inflated casualty figure stems from the confusion about the death toll for months after the attack.
} 
resolve in the American people. ... America's sons and daughters go to battle to protect freedom throughout that world, regardless of where that enemy comes from, whether it's Pearl Harbor, or Vietnam, or Korea, or the Persian Gulf, these people will be annihilated by the greatness of America, the greatest free nation in the world!! .. .

Announcer \#2: Yeah, we were surprised on December the $7^{\text {th }}, 1941$, but we won. And we were surprised on September $11^{\text {th }}$ of this year, and folks we will win this one, too, just like World War II.

The inclusion of Vietnam, Korea, the Persian Gulf and the invasion of Afghanistan as wars that "protected freedom" was characteristic of airshow discourse before $9 / 11$. What was new was the opportunity to equate wars past with the present day. I also found the substitution of "Pearl Harbor" for World War II in the narration to be a telling indication of the centrality of that battle for warbirders' understanding of the war and the ideal nation. It was Pearl Harbor, in a sense, that made World War II a "Good War," and it was September $11^{\text {th }}$ that made the "War on Terror" a necessary war.

We saw earlier that warbirders idealize the World War II nation as unified, strong, and assertive. Given the United States's status as a hyperpower, the quality of strength was not lacking, and the military actions of the post-9/11 Bush Administration could never be described as timid. That leaves unity as a major distinction between the World War II nation and the "War on Terror" nation. The unity that warbirders sought after 9/11 was not merely a disappearance of differences, but rather a militarized unity, a nation tied together by its acknowledgment and support of the military. This bellicose warbird restorer best captures the extreme of this sentiment:

The ideal situation in this country would be for the people, the younger generation to recognize the veterans as the true heroes of this country instead 
of rock stars and basketball stars. To have some comprehension that these guys went out and put their life on the line for this country. So that we could be free to do what we do today. They don't understand that. They don't get it. And maybe they just got a little inkling of it with this September 11th thing. I hate to say it, but maybe that was the best thing that's happened to this country in 20-30 years was to have us slapped in the face right here in our own face for a change, just like the Japs did at Pearl Harbor, to get our ire up a little bit and say, "What the hell's going on here? ... [Our] younger generation needs to understand that there's something here to protect and preserve. Otherwise, they wouldn't have the freedom to be able to go out and sing their stupid rock songs and crap like that. . . . I hate to be cold-hearted about it and say that the September 11th thing was what we needed to get moving again, but I think it was. It's a shame that 3,000 people had to die because of it, but you know what? Twenty-one hundred died at Pearl Harbor, and several hundred thousand died during World War II. Three thousand is nothing if it gets us on the right track again. So that's part of our history. We've got to be teaching that.

This passage highlights much of what this chapter has covered. First, he demonstrates his "military definition of the situation" by basing all of civil society on military sacrifice. (He also demonstrates what some would say is a typically American disinterest in the rest of the world by counting only American casualties of World War II.) Second, in the ideal nation, the younger generation would be properly taught history so that they acknowledge their debt and not idolize musicians and professional athletes. ${ }^{71}$ Third, this appreciation would be

\footnotetext{
${ }^{71}$ The inclusion of basketball stars here clearly invokes race and with it all of the racist stereotypes of young African-American men to track with his critique of the younger generation: lazy, arrogant, shiftless, self-absorbed, lacking a work ethic, undeserving of their wealth, and so on.
} 
shocked into them by the attack. Many others agreed with this speaker, arguing that the benefit of the war was a much greater awareness and appreciation of the "sacrifices" of people in the military. As might be expected, they tended to objectify this respect for the military in the technologies employed during the war, the airplanes. One warbird museum docent commented, "When people have been under the gun, so to speak, and to a minor extent they have since $9 / 11$, they begin to look at defensive things, if you want to call it that, a little more meaningfully. They can appreciate, maybe to a little extent, what happened on December 7th, and get an idea then of what all this stuff meant in that context." A CAF mechanic said that people starting coming to warbird museums and airshows in order to "touch basics." The "basics" here clearly mean the airplanes themselves, in their role as "pieces of history."

Most warbirders ultimately saw $9 / 11$ as failing to transform the nation into its ideal state. For many, the feeling of anger and passion, so evident in the comments on my first day at the hangar, quickly faded. A significant number of warbirders, including all the World War II veterans with whom I spoke, later rejected entirely the equation of 9/11 and Pearl Harbor. They felt that Pearl Harbor initiated a response much more powerful than 9/11. This veteran, for example, lamented the rapid fading of common feeling, "But I had never seen a nation pull together so quickly and so heartfelt [as it did after Pearl Harbor]. This 9/11, the thing's over with already. People are forgetting about it, they're ripping off the contributions people are making. ... 9/11, it was a horrible thing, but I think the impact of it is about over with. ... I can't say enough about what I saw as a young man after Pearl Harbor. The way this country turned around." Another veteran argued that the difference lay in the effect on everyday life, "Of course, theoretically I guess there's a war going on now, but it wasn't comparable to the way it was then because it would hit home." The lack of everyday involvement in the war represents the failure of the ideal nation's militarized unity to return. 


\section{Conclusion}

I conclude by examining where discussion of warbirders' invention of a usable past has led me, to the ongoing militarization of the United States. Warbirders' imagining of the ideal nation has been accompanied the ongoing militarization of U.S. society. The spread of military bases abroad and at home, the growth of the defense industries, the increased dependence of universities on military research funding, the expansion of the defense budget, and the routinization of military technologies and military service have all become central to American culture and society. This growth has necessarily produced militarized spaces as it has proceeded. Within these spaces the nation and military technologies have been conflated, such that the experience of the weapon is an experience of the nation itself. Further, this militarized space has been purged of its bodily violence, becoming an arena of technological aesthetics (Masco 2004) and enthusiasm, which in turn structures our understanding of the weapons and what they do. As airshow audiences look back to World War II, they are led to imagine which fabulous Axis aircraft was engaged in a thrilling dogfight, instead of the millions of people killed in that war, and as they look abroad to the war against terrorist groups, they imagine their beloved machines flying daring missions, not the explosions of bombs on the ground. They have no room to consider the larger context, to understand what's happening on the ground to the intended and unintended body-targets. They then employ this usable past to make sense of today's world. 


\section{Chapter Four: Industrial Romanticism}

Warbirders love old machines. They probably have a general or specific interest in World War II as well, but that machine love is what keeps these men toiling away on yearslong restorations. This love of old machines, however, challenges common American understandings about technology. It embraces the hegemonic faith in technological progress, yet it focuses on the functionally obsolete machines of the past and sees them as more authentic than those of the present. ${ }^{72}$ For warbirders the machines afford the experience of agency-with-machines that has become critical to personhood in Euro-America. Contemporary technologies do not afford this experience of agency. These afficionados have also developed an extensive techno-aesthetic to elucidate this contrast further. What is most striking about warbirding, in the end, is its mixing of an enthusiastic taste for powerful machines with a Romantic longing for a departed past.

The "Standard View of Technology" (Pfaffenberger 1992) encompasses both of the traditional American understandings: technology as the creator of progress and as the destroyer of authentic human existence. The progressive view sees technology as the means for humanity's unraveling of Nature's secrets and ultimately the tool for mastering and controlling her (gender implications intended) for the betterment of humankind. The discourse of technological progress constructs the industrial revolution as a great step towards this control over nature. Romantic discourses also depicted the Machine as an agent of change, but the change was for the worse. For American Romantics, at least since the mid-19th Century, the machine's place has been outside the garden, and its intrusion into the garden has been despoiling (Marx 1964). The Romantic view saw the past as a place of tight-knit community, of authentic connection between persons but also good, honest, and

\footnotetext{
${ }^{72}$ Here we treat "technology" not as some abstract or universal category, but rather as a specific phenomenon of Western capitalism, with its cycles of commodity production and consumption. Thus, obsolescence is less a "natural" occurrence than an entailment of this specific system. Change is not inevitable; it's cultural.
} 
hard work. The Industrial Revolution was a point of rupture, separating a tightly-knit, "close to nature" past from an alienated present.

An Industrial Romanticism has emerged in recent decades, a romanticism which focuses on the Industrial Age and its material remnants. While they see no "rupture" in society as a result of the Industrial Revolution, and they believe wholeheartedly in technological progress, they do feel alienated from today's machines. The old machines, by contrast, afford an agency through their operation and required maintenance which these afficionados understand as necessary to selfhood. In this chapter I explore three dimensions of this more authentic world of World War II technology, its configuration of technological progress, the human agency involved in building, maintaining and flying the old airplanes, and the aesthetics of warbirding. I conclude by beginning to outline a more extensive Industrial Romanticism to encompass other forms of industrial heritage practice.

\section{Progress and Romanticism}

The crankshaft of an engine transfers the force of the pistons' motion to the propeller and the engine accessories that produce electricity, hydraulic pressure, and so on. It must sustain tremendous weight loads from all sides with no distortion. In one of the large radial engines of World War II, this crankshaft weighs around 150 pounds and makes a full revolution 45 times a second at full power. I had a number of conversations with warbirders about this crankshaft, so it serves as a useful entry into their understanding of their airplanes. The implicit amazement in my introduction to this piece of the engine already betrays the first aspect of their understanding, their enthusiasm for technology. Drawing on knowledge and experience acquired through visits to engine overhaul shops, reading books, watching computer simulations, and operating the engine, these warbirders rhapsodized about the crankshaft. They pointed out how carefully this hunk of metal had been engineered to withstand the forces acting upon it. They spoke with awe of the speed of operation. They lingered on the durability of these crankshafts over time, a much longer period than had been 
contemplated in their design. All of these comments highlight their embrace of technology, a keystone of technological progress. While warbirders definitely see their machines as qualitatively different from today's machines-a difference I will explore in the next section-the difference they construct does not follow the old anti-technology line. Warbirders enthusiastically embrace technology, rejecting many of the common Romantic critiques of industry and machines.

\section{Enthusiasm and Progress}

Where Romantics see the machine as disrupting Nature or the pastoral, warbirders exhibit an enthusiasm for machines. In part this feeling arises from these specific machines' synecdochic links to the "Good War" (Terkel 1984) to the "Greatest Generation" (Brokaw 1998), and so on, but their enthusiasm is for the machine itself as well. We see it not only in effusive descriptions of their machines, as noted in the crankshaft example above, but also in their love of mechanical speed and power, and in their celebration of technological progress.

Warbird discourse draws on a long-standing American love of machines as means to convert fuel into noise and movement. This love of machine power is evident in the crowds drawn to watch an airplane's engine start at an airshow. The start is part of the airshow event, allowing the spectators to get close to all that power. Watching one start up, a retired mechanic described how he used to lie underneath Navy fighter jets during engine tests, to see if anything went wrong. He loved being overwhelmed by all that power, and he saw watching the older engines start in the same light. Even I experienced this sensation, as I commented one day when working in a warbird hangar, "When [the plane] did engine runs yesterday, it completely dominated everything going on. So loud and powerful, right next to the hangar. I just wanted to drink it in." The machines are powerful enough to provide a sublime experience, and here they fit in a series with all other powerful machines. 
A taste for machine power, therefore, does not require an interest in the newest airplanes. Warbirders do favor older machines over newer ones, but they clearly do not understand their machines as obsolete. Unlike an old tractor, for example, these airplanes are large, complex and powerful machines. They are by far the most powerful machines one could own (though only wealthy individuals can afford them), and they go faster than almost anything else a civilian could have control of. Every year at the Reno Air Races, modified versions of these airplanes compete in what as billed as the "fastest motor sport." Even though the recent winners have been modified from their World War II configuration, sometimes drawing twice the power as wartime use, they still start with World War II technology.

On the other hand, warbirders do not mistake their machines as being at all equivalent to any recent military aircraft, as evidenced by the quaintness they see in the "Soccer war" between Honduras and El Salvador in the late 60's, a war in which the opposing pilots flew two different kinds of American World War II fighters, and in which some warbirders of the day participated, almost as a lark (Anonymous 2003). Airshows, too, highlight the difference between warbirds and contemporary military aircraft through the demonstrations of both kinds of planes and the occasional formation flight. (These performances conflate "capability" with the speed and maneuvers demonstrated at an airshow, but so does this discourse of technological progress.)

\section{Plenty of Progress}

Warbirders' technological enthusiasm fully embraces the notion of technological progress. Their discussion of the airplanes is just as likely to include mention of tremendous technological advances during the war as mention of the heroes of the "Greatest Generation," which is a staple of all popular World War II-related discourse today. This passage from a warbird restorer captures their enthusiasm for this progress. 
The historical end represents [what] took place during World War II. . . . It's always been amazing to me, the rapid advance of technology, say from 1935 to 1945 . The ... advancement in the performance of aircraft in the ten-year span is phenomenal compared to what's happened prior to and after that. At the end of World War II, you had aircraft that were over $400 \mathrm{mph}$ and prior to that if you had over 100 miles an hour, you were doing great.

Where a Romantic view might lament the rapid change of technology, this restorer speaks of it with awe. He uses the date of 1935, presumably to include some of the famous World War II planes, the design of which began that year. The passage also makes a point popular with warbirders, the short time in which aircraft top speed increased. Such quantitative measures of aircraft performance come up frequently, making an easy calculus of "progress." Even though most warbirder discourse about airplanes has more nuance than "faster and higher," any public discussion of the airplanes, from airshow narration to museum placards to airplane tours, will include many of these quantitative measures. Such quantitative measures represent an important means of comprehending machines for Americans, but their use as a means to celebrate warbirds as embodiments of technological progress runs through all warbird discourse.

\section{Displaying Progress: The Heritage Flight}

The most popular warbird display, and the most visible depiction of technological progress in warbirding, is the "Heritage Flight" or "Tailhook Legacy Flight" at airshows. In these performances, warbirds fly in formation with contemporary military aircraft. Normally the flight follows a "demonstration" of the jet, in which the pilot performs different aerobatic maneuvers, accompanied by a military narrator who sings the praises of "your [the audience's] F-15 Eagle," for example. The jet then leaves the show "stage" to join in formation with the old aircraft and the group returns for a choreographed series of passes in front of the crowd, flying from different directions to offer the multiple "photo 
opportunities" for the crowd. They end their performance by "breaking," or flying off in different directions. Throughout the performance the airshow narrator, often accompanied by the same jet demonstration narrator from the Navy or Air Force, tells the "story" of these airplanes and emphasizes that the performance the audience is seeing is itself "historic." The warbird description follows the bombastic praise of the previous jet demonstration, lauding the aircraft that "defended freedom" during World War II. The narration also includes the same enthusiastic relation of numbers that we saw earlier in discussing the crankshaft. The following passage describes a particular fighter plane:

The P-51 was designed as a single-seat, long range escort fighter-bomber, powered by a 1,500 horsepower Packard, or Rolls-Royce, Merlin, inverted $\mathrm{V}-12$ cylinder inline water-cooled engine. It had a maximum speed of about $445 \mathrm{mph}$, a ceiling of about 25,000 feet. Combat radius was 325 miles on internal fuel, 750 miles with two 150 gallon tanks. It carried six .50 caliber Browning machine guns, two 500 pound bombs and 8 three inch rockets in place of long-range drop tanks.

This passage shows the quantitative discourse of enthusiasm, gathering disparate details about the airplane together in a numerical dump. It evinces a particular way of knowing machines which enables comparison of different airplanes. Here the machines are boiled down to specific characteristics, with all the particularity of historical context removed, all of the history of the object and its type erased so that it can be grasped "by the numbers." While some of these numbers are important in learning how to operate the machines, they do not encapsulate the planes' significance to the war effort. Combat radius, for example, only has meaning when matched with the distance from bases and targets (for example, one significant quality of the P-51 "Mustang" was that it was the first fighter able to escort bombers all the way from bases in the United Kingdom to Berlin), not to mention the type of mission flown (escorting bombers, attacking ground targets, supporting ground troops, 
etc.). The progress discourse encourages comparisons between planes on these terms, even when it amounts to the faint praise that the airplanes have some overlap.

USAF Announcer: "It sure is a tribute to the engineers who designed the North American P-51 Mustang all the way back in the early 1940's. The performance of the Mustang was so advanced for its time that there's a significant overlap between the P-51's performance envelope and that of the F-15."

Flying these airplanes together and emphasizing their overlap place them in a kind of equivalence. The cultural production of this temporary sameness has important effects on the ways in which military technologies old and new are understood.

These "Heritage" pairings produce important sets of meanings for warbirders and for the military. Heritage Flights connect warbirds to the latest and greatest military hardware, forming a metonymic link which constitutes their airplanes as objects of technological prowess. The equivalence of old and new produced by the demonstration of a "significant overlap" in capability eliminates the stigma of being merely obsolete, valorizing the airplanes according to the hegemonic progress discourse. For the military, on the other hand, the Heritage Flight associates their current planes with the "legends" of World War II aerial combat. This connection to the warbirds' glory is imbued with the received wisdom about World War II as the "Good War" and heartily expounded by the performance's narration. In this way the brute power of the fighter jet, and by extension contemporary American military power, acquires a metonymic link (as opposed to the synecdochic links the warbirds themselves create to the war) to the nobility now popularly associated with World War II. Not only does this link associate current airplanes, and by extension current military uses of those airplanes, with the "Good War," but it also renders the capabilities of these airplanes comprehensible. Where fighter pilots speak of the airplane as a "weapons system," basically a speedy platform for using powerful radar to target and launch missiles and to drop laser- 
guided bombs, the connection with World War II suggests aerial heroics and skillful dogfighting. Thus, the contemporary jets come to seem more like bigger and faster versions of the old dogfighting airplanes, instead of the qualitatively different "weapons system." All kinds of warbird and military aviation media put contemporary planes in progressive series with warbirds, but these heritage flights do it especially well.

The end of the performance, on the other hand, eliminates any sense of equivalence. During the fly-by's, the older aircraft are usually louder than the jet, because they are flying closer to their limits. When the planes "break" at the end of the performance, however, the jet pilot lights the plane's afterburner, ${ }^{73}$ instantly drowning out all other sound at the airshow. By comparison, the warbird pilot keeps flying along as before, now obviously much slower, quieter and less powerful than his former companion. With this example we reach the limits of the progress discourse's applicability to warbirds. While warbirders rely heavily on the convention of progress to inform their understanding of their airplanes, they cannot avoid that same discourse's relegation of their airplanes to the past, as I will discuss below. Yet before we discuss their rejection of a portion of the progress discourse, we have to see how they reject certain critiques of that discourse.

\section{Rejecting Critiques of Technology}

Warbirders not only embrace their machines enthusiastically, but they also reject common critiques of technology. While they do have criticisms of current technology, as I will explore in the next section, they do not fall back on the pre-industrial/industrial contrast in making their critiques. Warbirders see the wartime period these machines represent as a peak of human connectedness (within the United States) and of authentic national and local community. Pastoral and primitivist romantics, on the other hand, saw the machine as the bearer of individual dependency and anomie, taking humanity away from its ideal agrarian

\footnotetext{
${ }^{73}$ The afterburner is a portion of the engine, generally on military planes, which dumps fuel into the exhaust gases at the rear of the engine. The resulting burning propels the engine forward much faster, but it burns fuel at a higher rate and makes a tremendous amount of noise.
} 
or natural state (Marx 1964). Warbirders also do not share the fear of "autonomous technology" that Winner (1977) described, in which critics argued that technology was getting beyond human control.

Warbird discourse about the factory best highlights how they reject critiques of technology. Other Romantics view the factory as a site of dehumanization, as it is depicted in Chaplin's film, Modern Times, for example. In this view, a human becomes subject to forces outside of himself, and he must adjust to the schedule of the production machines and use his body to perform one of hundreds of a minor tasks before the product is complete. In Marxist terms, the worker is alienated from his labor (Marx 1976). Warbirders, however, see the factories of World War II not as sites of dehumanizing and alienating labor, but as sites where motivated individuals invested themselves in making tools of war. In this view the factories that churned out enormous quantities of aircraft were particularizing, not dehumanizing, in that all of that labor was directly connected to the "boys" on the front lines. The workers even inscribed themselves into their products, warbirders point out, writing encouraging messages to plane crews.

Many warbirders mention the factory work as part of the unified nation waging total war. They enthusiastically describe the output of those war years, drawing on the most effusive discourse of industrial progress, as in this CAF publication:

In less than 24 months after Pearl Harbor, the U.S. had become one giant factory with raw materials and millions of pieces and parts endlessly flowing toward assembly lines for small arms, ammunition, construction materials, radios, artillery pieces, vehicles, ships .... and warplanes (Baldwin et al. 1987: 7).

This passage celebrates the transformation of the United States into "one giant factory," where unimaginable quantities of war materiel were produced. These written accounts usually include pictures of the work in progress, often with smiling workers signing the 
aircraft. We also saw the pro-industrial sentiment of this passage in the earlier airshow narration.

Their use of progress discourse also shows that warbirders do not share the fear of autonomous technology identified by Winner (1977). He described growing concerns, especially among scholars, that technology was developing according to its own logic, that the needs of the machine were outweighing the needs of humanity. Two common foci of this fear are military-related, nuclear weapons and the catch-all of the "military-industrial complex." Nuclear weapons are a prime example of anti-technological rhetoric today, but warbirders generally speak favorably about the use of the atomic bomb to end World War II. They strongly objected, individually and through their organizations, to the proposed exhibit of the Enola Gay in 1995, which raised questions about the decision to drop the bomb. Warbirders also have no objection, and in fact strongly favor, the "military-industrial complex" about which Eisenhower warned. The critique of the military-industrial complex raises the fear that weapons production has developed its own momentum, leaving interested citizens and even policy-makers powerless to stop the escalation of weapons procurement. Warbirders, however, support expanded purchases of weapons. Indeed, many interpret the commemorative phrase "Lest We Forget" not only as a plea to remember the war dead, but also as a plea to "remember the lesson of Pearl Harbor," thereby retaining military spending at a high level. Warbirders therefore clearly do not share the idea that military technology needs to be reined in. Rather than fear that technology is getting out of human control, warbirders seem to fear a disconnect from the machines. As I will discuss below, what they want is a relationship with the machines around them, not control.

\section{Progress Is Past}

While warbirders embrace technological progress and reject many of the critiques of technology, they still see something more in the technology of World War II than that of today. Many warbirders express a complete lack of interest in contemporary airplanes, 
saying that they have no "personality," that jet engines just hurt their ears, and often that the airplanes are simply too complicated. In these criticisms they do not abandon the discourse of technological progress; rather, they shift the point of emphasis from the present to World War II. The following passage captures just how warbirders both embrace a progress discourse and set World War II apart as a different, better kind of progress.

I mean, we went from Orville and Wilbur Wright flying for the first time in 1903 to a 400 mile an hour P-51 that could fly up to 35,000 feet in 1943. Lots of aeronautical achievements in a very short amount of time. Since then, we've progressed to jets, and I don't think that technology has peaked the way it did in such a short amount of time between the teens, twenties, thirties and forties.

This passage almost presents World War II as the end of a kind of progress. In most cases warbirders stop their discussion of technological evolution at the World War II era, as if the airplanes were both the apex and the end of that line of evolution. This notion can be seen, for example, in their view of piston engine development in aviation, since World War II-era airplanes (like the Messerschmitt 262, Gloucester Meteor and the Lockheed P-80) began the shift to turbine engines, eventually leaving piston engines for small, general aviation airplanes, as well as automobiles and trucks. The smaller general aviation engines are thought to be of inferior quality, and warbirders tie the current car and truck engines to World War II by pointing out how the innovations made in the design of aircraft have only recently have filtered into automobiles, where they have been lauded as technological leaps. Warbirders enjoy the thought that these 'innovations' are 60 years old. Here again they shift the locus of progress from the present to the past.

When warbirders do criticize today's technology, their critiques parallel Romantic critiques in that they depict current technology as disconnected from human life. Their longing for the past incorporates machines instead of rejecting them. They do not criticize 
machines for being beyond human control, but rather for being distant from humans, as I will describe below.

\section{Warbirds and Agency}

A range of qualitative differences exist between today's technology and that of the past, but the differences that warbirders emphasize revolve around the agency which warbirds afford them and around the technoaesthetics (Masco 2004) of warbirds. I will discuss technoaesthetics below, but for now I would like to consider agency. The appeal of warbird practice is shown by one recently retired CAF member's comment that the great thing about the old airplanes was that "a human could work on them." This view can be stated simply: warbirds allow for human agency, while newer technologies do not. ${ }^{74}$ They enjoy the experience of this agency in working on and flying the airplanes, an experience which implicitly they see as lacking in their daily interactions with other machines. To examine what they understand this agency to be, I would like to consider three aspects of it: the requirement for hard, skilled work, the need for unalienated labor, and the presence of a mutuality with machines.

\section{Warbirds Require Hard, Skilled Work}

While all machines require skilled interaction (Ingold 2000), what appeals to warbirders about their machines is the specific skilled interaction they afford. ${ }^{75}$ While warbirders can employ basic skills that most "handy" men are understood to possess in American culture - I will explore "masculine competence" in the next chapter - this technological practice also requires skills acquired over years of aircraft work and operation.

\footnotetext{
${ }^{74}$ Just to be clear, I am not arguing that new machines are somehow outside of society. They are qualitatively different in their maintenance, but they are also imagined, designed, built, and maintained by culture-bound humans. The contrast, then, is a felt one by warbirders.

${ }^{75}$ The notion of what is "required," however, has to be seen as specific to this technological practice. While I personally have no doubt that certain transformations of a material object must be made in order for it to fly, what "ready to fly" or "safe to fly" mean for these complex machines is a cultural understanding. That different understandings might prevail can be seen, for example, in the disparity between wartime plane crews, often numbering a dozen or more for a plane, and current warbird maintenance staffs, which may have a quarter that many people devoted full-time to a big airplane. Similarly, the uses to which the airplanes are put have to play an important role in interpreting what is "required." A wartime combat flight posed risks that a flight to an airshow would not.
} 
Warbirds are complex enough to require this skill to operate safely, while not so complex as to require special tools, diagnostic computers, or specialists for particular systems, like all current-day military aircraft. The experience of agency with warbirds, then, involves skilled, "hands on" work

\section{Before the Remove-and-Replace World}

The planes' mechanical structure, as opposed to the electronic and composite structures of today's machines, plays a critical role in their work and the concomitant experience of agency. In the view of warbirders, computer chips do not allow for agency, either in maintenance or operation. The new electronics require only "remove-and-replace" maintenance in which a technician plugs a computer into a machine to diagnose a problem. Using the tool, he finds the faulty part, unplugs it and plugs in a new one, all of which requires understanding only what the diagnostic tool tells him to do, not how the machine itself works, as older machines required. With the disappearance of purely mechanical, i.e., non-electronic and non-computerized, machines, the repair jobs became either too easy—plug in a new part—or too complex—repair an integrated circuit, which is possible, if economically impractical. The felt authenticity of the industrial past, by contrast, now lies in the skill and hands-on work required to troubleshoot the machines' problems.

The skills developed and deployed in warbird work range from the simple, like using a drill properly, to the complex, like fashioning a complexly curved engine cowling or installing a spaghetti-work of hydraulic lines. This work can be physically demanding, like reaching into tight spaces to rivet or screw in a part, but it also requires extensive, embodied knowledge. It qualifies as "hard" work in both physical and intellectual senses. The mechanical workings of warbirds do provide less skilled warbirders the opportunity to experience agency in performing the work. I had no experience going into my research, but was able to perform such basic tasks as stripping paint, disassembling parts, and drilling out rivets. Such "grunt" work can be experienced as satisfyingly concrete. The "hard" 
intellectual work requires not only extensive "book" knowledge of systems, materials, and so on, but also extensive tacit knowledge. Several warbirders described to me the need for mechanics to use all of their senses, looking for stray bubbles in paint that might indicate corrosion underneath or unusual stains and drips that could indicate loosening of parts. This ability to "sense" the airplane takes a great deal of time to acquire, and warbirders therefore highly prize it. The warbird mechanics I met immensely enjoyed the agency of deploying their skills. Newer airplanes, in this view, provide less opportunity to deploy such embodied skills. They are so complex that diagnosing their problems requires computerized diagnostic tools.

Mechanics therefore romanticize a time when understanding of internal combustion engines was necessary to work on an airplane, but pilots also romanticize the old machines as requiring much greater skill to fly than those of today. A passenger jet today requires the pilot merely to push a button to start the engine, while the old airplanes require the pilot to listen actively to the engine, adjusting the mixture as necessary to keep the engine firing. Doing it properly requires a lot of experience. Today's civilian planes are easy to fly, with the difficulty lying in plotting the course. Even the most difficult task in aviation, landing on an aircraft carrier, can now be performed automatically, according to one warbirder, although those pilots land unaided at least half the time to retain proficiency. Flying warbirds, on the other hand, can be easy in that the airspeed is slow enough to navigate onthe-fly and to set up landing approaches with greater ease than with today's faster jets. Even still, warbird flying has less margin for error, as with a certain two-engine cargo plane, for example, which could have severe difficulties if an engine lost power, and a loss of engine power is much more likely with the reciprocating than with jet engines.

The understanding that working with the older airplanes is harder and more skilled applies even to combat. The ultra-complicated weapons systems in today's military aircraft, once they are set up, can be simple to operate, in contrast to the machine guns on World War 
II aircraft. The new "look and shoot" and "fire and forget" missiles indicate simplicity of use, while one middle-aged warbird pilot, who had had many conversations with World War II veterans, emphasized to me that the World War II pilots had to be good shots to use their guns effectively. The best ones developed this skill, he said, because they were country boys during the depression and had to hunt for their food. As a result, they knew how to "lead" their targets in order to hit them. This story depicts privation as motivating hard work and fostering skill and achievement, all of which warbirders seek in flying their airplanes.

The challenge of flying old airplanes involved not merely hard work and skill, but also physical exertion and danger. One mechanic and machine-tool worker in his early 50's contrasted the work of test pilots in the old days and today: "Back then, you got into the airplane, you went out and flew it and came back and told somebody how it flew. You know, that's seat of the pants flying." He then noted that these venture-into-the-unknown flights occurred without the hundreds of hours of simulator experience today's test pilots have before their first flight. The romantic image of the intrepid test pilot climbing into an aircraft for its first flight is greatly diminished today in his view, the sense of adventure and risk lost. In comparison, pilots frequently compared flying today's aircraft, especially airliners, to driving a bus. This bus analogy invokes a variety of meanings, but above all it de-glamorizes the pilot and his skills. Bus driving poses little risk and is not difficult; it demands little of the pilot.

\section{Computers, Real Engineers and the Love of Machines}

The mechanic who lauded the old "seat of the pants" flying in contrast to simulated flight training tied this contrast to the computerization of new airplanes, which require being a "computer genius" more than being a good pilot. The computer recurs in warbird discourse as a kind of cheat or short cut which takes the sense of work and achievement out of aircraft. Returning to our crankshaft example, that technological wonder was created without the help of computers. Several warbirders lauded the pencil-and-paper engineers of the 30's and 40's 
because they designed complex, sturdy airplanes with slide rules, not computers. These "real engineers" had to "overbuild" their airplanes to provide a margin of safety, but in the process they made something that would last for decades. In contrast, computer-aided design has allowed recently-produced airliners to closely match their stated allotment of flight time without exceeding it. This ability to design on computers has robbed airplane building of some of its challenge, in the view of warbirders.

While this emphasis on computers might lead one to explain this Romanticism by the passing of the industrial age into the information age, I would caution that such a conclusion may be too facile. More than the computer, warbirders see the coming of the jet as the key technological change after World War II. In the military, as in the airlines, turbine engines began to replace piston engines right at the end of the war. This transition from piston to turbine engines happened before the widespread use of computers, but warbirders frequently analogize the piston-to-jet change to the computer revolution. ${ }^{76}$ Like the discussion of computer simulation and computer-aided design above, jet engines rob handy American men of machine agency because they are much more complex and require special skills, tools and facilities to maintain.

\section{Simplicity}

The emphasis on difficulty and complexity constitutes the agency of warbird work, but most warbirders see their airplanes as relatively simple machines. In some cases they trace that simplicity to the genius of World War II engineers, who they say were clever enough to devise simple solutions to complex problems, but in general they argue that the machines were just simpler then, making them accessible to the individual mechanic of today. In the following passage, this aviation author highlights the virtues of this simplicity:

\footnotetext{
${ }^{76}$ Although jet warbirds are becoming increasingly common, most warbirders cling to the association of "warbird" with the World War II warplanes. Indeed, common usage requires the addition of "jet" to the term warbird when discussing a turbine engine-driven airplane; no one ever says "reciprocating engine warbird" or some variant. They do talk about "recips," but such usage occurs when introducing the engines to people accustomed to turbine engines.
} 
Construction of these old airplanes was stone-simple, with most of them heavily overbuilt, using standard, even primitive, construction techniques. Generally, they were designed for field maintenance and repair, under combat conditions, and this works to the advantage of the modern owner. Today, it is relatively easy to fabricate almost anything for them, right down to the level of main spars and other primary structure. All it takes is knowledge, time, and money (Deakin 1998).

While this passage does not reflect it, most warbirders see this simplicity as the elegance of design mentioned above. Note that the simplicity the author emphasizes involves working on the airplanes. This quotation comes from an article seeking new pilots and mechanics, so the author may overemphasize the airplanes' simplicity, but for most warbirders, simplicity implies accessibility to the kind of skilled work that they find fulfilling. One active airline mechanic, for example, said he liked working on warbirds because of their simplicity. He could, for example, just look at the electrical system and understand it.

This back and forth between simplicity and complexity produces a kind of middle ground where machine complexity supports the discourse of progress-these are large, powerful, hard-to-handle machines-without being too complex for non-professionals to work on them. Such a middle ground echoes the "middle landscape" which L. Marx (1964) argued was characteristic of pastoral romanticism in the $19^{\text {th }}$ Century United States. That landscape, the landscape as farmland which Jefferson idealized, mediated between the wilderness of nature and growing cities. Simplicity and complexity in Industrial Romanticism, then, mediates between pre-technological primitives and the current-day alienation from technology.

\section{Warbirds Involve Unalienated Labor}

A second dimension of agency that warbirders see in the airplanes is the unalienated labor used in their production, maintenance, restoration, and operation. Unlike the factory 
work of today, the production work on the old machines involved a connection with the machine itself or with "the boys" who would use the airplane overseas, as discussed above. These airplanes, in this view, resulted from an authentic human-machine relation, and this relation precluded the workers' alienation from the product of their labor. This authentic connection in turn led to better quality products, again, in contrast to today's machines. To establish this connection today, however, warbirders resort to craft production, building their airplanes by hand, instead of on a factory assembly line.

\section{Wartime Labor of Love}

The planes were designed by people who loved their work, according to warbirders. They genuinely loved machines, especially airplanes. They were the talented, unaided-bycomputers engineers discussed above, who saw inherent value in the work, as this passage from a leading CAF flight instructor in his mid-60's suggests:

[I]n the 30s and 40s, all the best and the brightest engineers were working with recips [reciprocating engines], and virtually everything we know about them comes from that era. Those people were ENGINEERS in the classic mold, and knew their stuff. What they did with primitive tools is astounding, and just about everything we're re-learning today was known then! Starting in the 50s, all the "best and brightest" gravitated to turbines, and it wasn't long before the general attitude was, "recips are dead." The old knowledge and "corporate memory" died, the marketing folks took over at Lycoming and Continental, and today we see the results. There may be a few real engineers left, but I don't see much evidence of that at the factories (Deakin 2002). [Emphasis in the original]

The "classic mold" of engineers were those who felt personally invested in their work. This love, and their genius enabled them to do "astounding" things with "primitive tools." Their genius has been allowed to winnow away, however, because everyone got caught up in 
turbine engines - the major separator of warbirds from today's planes. The agents of this shift were the "marketing folks," people who lack a true love of and connection with machines. The shift, however, did not mean that development of reciprocating engines stopped. Companies continued to make them, but the engineers who did the work lacked the same involvement with the machines. The old knowledge therefore dissipated, leaving today's warbirders to "re-learn" it.

Like the passage's writer, many warbirders marvel at the "real engineers" who designed the World War II planes, reflecting the "Standard View of Technology's" (Pfaffenberger 1992) location of technological progress in exceptional geniuses. At the same time, they again displace technological progress into the past, in that this expertise has dwindled. Another person said he occasionally looks at an airplane part or assembly and thinks, “They don't build it like this anymore. They must've had good engineers back then." Again, warbirders mix their enthusiasm for technological progress with the sense that this progress stopped sometime after the war, or if it did not stop, it continued without the same kind of human connection between designer and machine.

The wartime airplane designers loved their work, but the factory workers also did their work out of love. They worked out of love for their country, first of all, driven by a sense of national purpose and unity, a sense warbirders distinctly see as lacking today, even in the post-9-11 world. This unity marks World War II as a different kind of time, as I showed in the previous chapter. If love of country was too diffuse to guide daily labor (and the sacrifices warbirders laud, like food and fuel rationing), they also worked with their loved ones in mind, building weapons for their husband, father, fiancee, or brother. The machines therefore embody ties to the nation and to other people, and working on them performed those ties for those workers.

The result of this unalienated labor, warbirders say, was higher quality than we have today. If each worker felt connected to the ultimate user of the machine, the thinking goes, 
he (or she, in the case of "Rosie the Riveter") would do her best work. Thus, the parts made during the war were much more reliable than those made today. The crankshaft discussed earlier, for example, has now operated without problem in engines for 60 years. According to one warbirder, "It [failure of crankshafts] basically never happens [in the World War II aircraft], unless they have another failure. They have crankshaft failures all the time in light airplanes, brand new ones! So the technology, those guys knew what they were doing." The quality of old machines therefore contrasts the shoddiness of today's products, and it stems in part from the expertise and involvement of the wartime designers and builders. By contrast, the unmotivated, alienated labor of today produces parts in much greater quantity, but with occasional lapses in quality. One longtime warbird restorer said that the tried to salvage World War II-era electrical switches whenever possible because they would last much longer than new-made ones.

Warbirders might trace the lack of quality today to the lack of national unity and purpose, but they also object to the way that things are made today. Earlier we saw how today's electronics do not allow for the same level of human intervention, but another critique warbirders make is of today's throwaway society. The very industrial scale of production that warbirders celebrate for producing hundreds of thousands of aircraft during World War II now creates products that are cheaper to throw away and replace than to repair. One person, for example, complained to me that he had no choice but to replace a $\$ 400$ computer on his car to fix his tachometer. He would much rather have repaired the part himself, if he could have, but repairing the complex computer would have been much more expensive, for him or anyone else.

\section{Today's Labor of Love: Craft (Re)Production}

Echoing those comments about throwaway car parts, one CAF mechanic said, "You're just throwing a lot of money away when you look at the quality that's in [a new car]. Then you go look at one of these restorations. Now that's quality!" This comment again 
criticizes the quality of current assembly-line production, but it contrasts current-day warbird restoration, not World War II work, to that production. Despite this person's conflation of the quality of warbird work today and that performed during World War II, the process of restoring a warbird looks nothing like aircraft production during the war. Restoration resembles craft production more than the assembly line production. The scarcity and variation of warbird aircraft makes industrial scale restoration impossible, and restorers usually work one airplane at a time. ${ }^{77}$ This craft production allows warbirders to see their own labor process as unalienated, and though they sometimes say they feel a "connection" to the factory workers and mechanics of World War II, no one ever suggested to me that they were performing the same kind of work. To attempt the same kind of work, I believe, would be to undermine their insistence that aircraft production on such a scale could involve unalienated labor.

The restoration methods that warbirders use often recall the past, but not necessarily the past of World War II production. One person, for example, described the choices one might face in manufacturing a part, emphasizing the authenticity of a hand-fabrication method never used in World War II production. He said that, on the one hand, you could program a computer-controlled machine to make the part. On the other hand, you could do something much harder and use the old skills of working metal to fabricate the part. By using the computerized process, he said,

there's something lost in the art of manufacturing things. . . [T]he skilled craftsman is going by the wayside. You become a button pusher. But out here [in the warbird hangar] you get back to the basics because you're back to riveting and you know, you're not hot wiring a piece of foam and glass

\footnotetext{
${ }^{77}$ There have been a couple of instances of restarting industrial production elsewhere, as with the reopening of the Yakolev assembly line in Russia to remake Yak-3's, what I heard was some Russian fabrication of Japanese Zeroes, and the Flugwerks in Germany where they are making new-build Focke-Wulf aircraft. There's also the Texas Airplane Factory, where they have manufactured small lots (around five) of rare types. All of these operations, however, are very small scale, with none of the subcontracting of parts typical of regular production. They might better be called cottage industries.
} 
over it to that shape, you're forming it with a leather hammer and a bean bag, stuff like that, to beat something into shape. So it's an art. You can learn that here. There are some incredible people here that can do that. That's a part of it, I guess, that's kind of interesting to watch. That's why I say some of this stuff really is a work of art. When you see the craftsmanship that's involved in it and things like that. It's just, you know, some of the work is flawless. It's good to see that.

He lauds the "art" involved in making or repairing a part, in contrast to the "button pusher" operating a machine. Not only are there people at the hangar who can do this, and do it regularly, but a budding warbirder can learn that skill, that art, from these craftsmen. The skill required to fashion or repair these parts, however, would not have been routine in a World War II factory because all of the parts were mass-produced, stamped out of molds. ${ }^{78}$ Warbird work, on the other hand, provides for this exercise of skill, allowing for the unalienated labor spent in creating a personalized part for an individual machine.

And these machines are highly individualized. Adopting Kopytoff's term, these planes are singularized, not commoditized (Kopytoff 1986). They have been singularized by the passage of time, with the destruction of most World War II airplanes, and their postwar modifications to serve various civilian uses. They then appear to warbirders as unique and valuable objects, worth tracing down individually by serial number and cataloging nearly obsessively. The planes are also singularized by the ongoing labor of warbird mechanics. The "biography" of a warbird often includes the various people who have worked on it. Thus, one museum official said that he could look over the various parts

\footnotetext{
${ }^{78}$ I cannot be certain that wartime plane crews in the field did not perform this kind of work. What little I know about them suggests that they were resourceful in putting combat-damaged planes back together to fly again, presumably without large stocks of structural parts. My suggestion here that the skills this warbirder lauded were not present in World War II aircraft production comes not from a deep knowledge of that history, but rather from discussion with other warbirders about the difficulty of producing parts today that were stamped out by the thousand for World War II factories.
} 
of the museum's World War II bomber and see the various tasks he'd performed on the airplane. Like the World War II factory workers, he inscribed himself into the airplane.

Some warbirders do criticize aircraft production today, drawing the contrast to highlight the unalienated labor of warbird work. Professional mechanics-in contrast to volunteers at museums - tend to draw these contrasts, because they more often have experience in both the warbird world and the aircraft production or airline maintenance world. One mechanic contrasted his work and a friend's work on the B-2 stealth bomber. Where the warbird mechanic was able to work on a whole airplane, more or less autonomously, his friend working on the B-2 had been confined to a very small area for riveting, with tarps and drapes hiding all detail of the rest of the plane so that he had no idea what he was actually working on. The production of the B-2 was distinctly alienating, but so also is the day-to-day process of working on aircraft under operational pressures. Another mechanic told me that he greatly enjoyed working free of that pressure. Warbird mechanics do face pressures, whether from museum founders and staff (who want to have an airplane ready for a show), clients (who pressure mechanics to minimize the amount of expensive, by-the-hour labor), or shop foremen (whose job is to get a job finished safely without letting mechanics indulge in unnecessary tinkering), but they have greater ability to dictate how long and how thoroughly they can work on a problem. At an airline, for example, the mechanics work overnight to get an airplane prepared for the next day's flying, and the pressure to get the airplane back in the air is tremendous. While most mechanics would never sign off on work that was insufficient, they might not be fully satisfied with the job.

Work at a museum hangar faces no strong operational pressures, allowing the mechanics time to chat with each other about the work, to teach and to learn useful skills that they didn't have. Earlier I noted the need, not to mention the desire, to "re-learn" what the wartime mechanics knew about the airplanes. The need to replicate that knowledge (really, create new knowledge about similar topics), to the extent that it is possible to do so, allows 
warbirders to conduct research and explore. Such exploration feeds their desire for agency with machines, and they experience such self-driven work unalienated. This ability to engage the machine drives the volunteers at museums to show up at the hangar, week after week. They commonly say, "You couldn't pay me to work this hard." Even at a professional restoration shop, the mechanics spend a significant amount of time poring over blueprints to get the tubing, the paint color, or the rivet lines just right. These diverse tasks allow them to engage their work in ways that an assembly line worker, or even an airline mechanic would not. They say that they could be paid much more if they worked for an airline or for an aircraft manufacturer, but they choose to be paid less because they enjoy the work a great deal more.

\section{Having a Relationship: Mutuality}

The craft restoration and maintenance of warbirds allows for long periods of intimate contact with the machines, and this intimacy is one of the most enjoyable dimensions of warbirding. Where Winner (1977) described Romantics' (and other critics') fear of "autonomous technology," in which technology was seen as breaking free of human control, warbirders fear the lack of mutuality with technology. They want to have a relationship of understanding and interdependence — intimacy — with a place for human agency. They dislike today's technology because they do not have this mutuality with it. These machines are impersonal and alien to warbirders, but they do not fear that these machines will take control of society. The agency they experience in working on warbirds, as well as the unalienated labor involved, provides for an intimacy with warbirds, and their perception that the machines have more "personality" than today's machines contributes to their sense of connection with them.

The scale of warbirding allows warbirders to form a holistic relationship with a particular airplane, in that one person can play the central role in rebuilding or maintaining an airplane. One retired mechanic contrasted his work on a space program with his warbird 
work: 'Everyone's a little expert. You've got the oxidizer valve man. You've got the turbo pump man. You've got the thrust chamber man. They've all got their input. But the intimacy wasn't there at all." While this same warbirder was enthusiastic about his space program work-like other warbirders, he was no luddite- he longed to have a greater responsibility on a project, and he had that with the warbird he crewed. He could install new systems in the airplane, like a fire suppression system that he designed. He could look at the various parts of the airplane and see himself inscribed there. In this sense, he echoes the mechanic described above who enjoyed the autonomy of warbird work in contrast to industrial production work.

This discourse of connection and intimacy, however, did not turn into a discourse about control and domination. Contrary to the "civilizing" model so common in the early rhetoric about machines, these men did not seek dominance of the machine. Warbirders rarely used a language of control in discussing them, choosing instead terms of relation, as if the machine were a person. A pilot talked about what flying in the cockpit of a warbird felt like: "I feel completely at home there. I feel like I'm a part of the machine, a functioning part of the machine. And the airplane feels like kind of a functioning part of me." This same "part of the machine" discourse came up in many different accounts of flying beloved airplanes.

The intimacy that warbirders have with a machine, however, varies according to the duration of their interaction with it. Professional warbird restorers, for example, have less long-term interaction with particular airframes than the volunteer warbirders do. The pros may work on one project for a few years, but then they move on to a different project. They also do a variety of much shorter-term tasks, even working just on specific parts that will go on airplanes they have never seen. In contrast, museum volunteers can work on the same aircraft for decades. If, on the other hand, a professional has been singly responsible for an airplane's ground-up restoration, he may feel a special connection to that airplane. 
The differences in intimacy are reflected in the language these warbirders use. At a restoration shop, for example, mechanics frequently talked about "the airplane," as long as it was clear which airplane they meant. When telling a story about a particular aircraft, they might say, "The airplane lost a hydraulic line once." The members of the CAF's Southern California Wing, on the other hand, would rarely say "the airplane" or the relatively formal, "the C-46 Commando," preferring instead to use its name, "China Doll" or a shortened "the Doll." Similarly, the F8F Bearcat was called "the Bear." On the other hand, if professionals have spent a significant amount of time working on a single airplane, they may refer to it fondly, as one mechanic would mention the name of a plane that he took from being "pretty torn apart" to flying and winning awards in different concours d'elegance. Mere long term association, however, need not produce the same kind of familiar intimacy, as was the case with one large airplane that received significant repairs at a restoration shop. The mechanics, as well as the shop owner, felt that the airplane's owner did not maintain the airplane properly. As a result, I never heard them refer to the airplane by its familiar name, preferring to use its owner's name (i.e., the "Jones" Corsair) or, as the shop owner once said, the "Jones Lump."

\section{Personality}

The singularization of airplanes allows warbirders to attribute specific personalities to them. This "personality" gives warbirders a means to feel a connection to the airplanes. Several themes recur in descriptions of warbirds' personality. The first we might call the imperfections of the past. The attraction is that they cough, smoke, and chug in their starting. The airplanes do not start up automatically, at the push of a button; the coughing and smoke suggest some resistance, an independent will in the airplane. In this sense, the personality of warbirds stands in contrast to the anonymity of current aircraft. Today's military jets all sound exactly the same, warbirders claim, while many can tell the type of warbird just by 
hearing it. ${ }^{79}$ The accumulation of years of wear, corrosion, and modification also individuates the aircraft, and these histories add to the sense that they may have their own identity.

These personality traits extend to qualities that make warbirds much more difficult than current aircraft. Mechanics complained about certain types of airplanes that were built far too complexly and praised ones that were elegantly or cleverly designed. These qualities then inhered in the airplanes' personalities. Similarly, pilots enjoyed flying the most challenging aircraft, feeling like they had interacted with them somehow personally.

The taste for warbird "personality" also constitutes an aesthetic, as I will discuss in the next section, but here I have focused on how it ties back to the feeling of agency warbirders experience through their airplanes. The mutuality they feel in interacting with the planes, that sense of holistic connection and intimacy, plays a central role in the feeling that they are really "doing" something with the machines. Similarly, their experience of warbird work as hard, skilled, and unalienated labor, coupled with their insistence that the wartime labor was also unalienated, reinforces their sense of agency.

\section{The IR Aesthetic}

In examining the discourse about old machines, different aesthetic features like those of an airplane's "personality" kept recurring, suggesting an underlying technoaesthetic (Masco 2004) for warbirds, and perhaps for a more general Industrial Romanticism. World War II airplanes developed not only out of the different technological systems into which they fit - the design and production methods, the knowledge about materials, structures, and stresses available, the beliefs of the engineers, corporate heads, military generals about what constitutes an effective airplane, the combat tactics and missions for the aircraft, etc—but

\footnotetext{
${ }^{79}$ Clearly not all jets sound the same. I heard an airshow announcer once describe the three most distinctive-sounding jets, though even he said many of the others sound alike. The points to emphasize, however, are that warbirders find the different sounds of planes to be an important aspect of their personality, and that they do not find such differentiation in contemporary aircraft.
} 
also from the aesthetic preferences of that time. The aesthetic preferences of warbirders, on the other hand, exist in tension with machine aesthetics today. They see current machines as quietly, invisibly efficient and reliable, while the old machines are noisily, visibly cantankerous. Where new machines are miniaturized, the old ones are giganticized. The old machines fill up the senses in ways different than today's, overwhelming warbirders with (the suggestion of) mass and power, and to experience the sublimity of these machines, warbirders go to great lengths to recreate them.

The dominant cultural understanding of machines holds that aesthetics are merely superficial, that function rules design (Sahlins 1976). Despite this insistence that machines are merely functional, aesthetics play a role in all dimensions of machines, from initial design to functional components to stylistic additions or surfaces. Despite all of the discussion about Apple computer's stylistic revolution in the late 90's, for example, with the first iMac overthrowing the era of the beige box PC, the beige box was its own powerful aesthetic of unglamorized functionality. Further, one might argue that aesthetics played a role in the premature demise of the all-wooden airplane. Schatzberg (1994) described how aircraft designers in the 1930's and 40's replaced wooden aircraft with aluminum ones, even though the British wooden warplanes called the Mosquito and the Hurricane were very successful. The preference for metal over wood, whether one calls it aesthetic or ideological, as Schatzberg does, could not be reduced to function. Warbirders themselves discuss the airplanes as if function were the sole determinant of the airplane's form, with changes in airplane design since then attributed solely to functional improvements. At the same time, however, they express an aesthetic preference for the World War II aircraft. Like the beige box PC's, warbirders use an aesthetic of functionality - it looks like aesthetics came last, therefore it must be purely functional — to express their preference for some airplanes, such as the "built like a bridge" Grumman aircraft. At other times, however, they talk about the 
graceful, "classical" curves of the P-51 Mustang, as if technoaesthetics and functionality were perfectly joined in the airplane.

\section{The Sensuality of Warbirds}

When afficionados talk about why they like the old airplanes, they usually refer to some sensation that the aircraft provide. I titled this section I use the term sensuality because warbirders experience the sensations of the airplane bodily, drinking them in. In part this bodily absorption relates to the connection with machines described above, that what they miss about old machines is having a visceral connection to them. These sensations also provide a sublime experience, however, which I will discuss below. The dominant sense to which they refer is vision, but warbirders also emphasize the more tactile experiences of the planes' operation, sound, touch, and smell.

\section{Visuality}

Tichi (1987) has suggested that the visuality of machinery — seeing the workings of the machine - was an important dimension of modernism because it gave an immediate sense of the age's machine power, which distinguished the time from previous eras. The modernist taste wanted the working parts to be visible. Warbirds show this trait in their visible mechanicality, to coin a phrase, where today's machines have their workings hidden away. ${ }^{80}$ The operation of piston engines involves the highly visible movement of the propeller, and its internal workings - the pistons moving up and down and the crankshaft turning — are easily imagined as well. They have moving parts; they have gears turning to do the work. Turbine engines, on the other hand, are less visually interesting because they employ "high tech" fan blades merely spinning, if at phenomenal rates of speed. Seeing and imagining the pushing, pulling, spinning, and back-and-forth of warbirds' operation are

\footnotetext{
${ }^{80}$ They are so hidden away, in fact, that they become secret. At an airshow recently a pilot standing by his new F-18 fighter plane threatened to confiscate someone's camera if they took a picture looking up the engines' air intakes.
} 
important for warbirders and, I would argue, are central to the aesthetic of Industrial Romanticism.

The visuality of these airplanes makes their functioning tangible. Perhaps best exemplified by the spinning propeller, their operation is physically obvious. If the propeller isn't spinning, the engine isn't operating, and the plane won't fly. The propeller's kinetic power both thrilling and dangerous. Its linkage to the thrill of machine power is evident in this young pilot's comment: "There's nothing that could compare with the thrill of just rocketing down the runway with 1600 horsepower in front of you, swinging a ten foot prop at $2800 \mathrm{rpm}$ and lift [sic] off the ground about $150 \mathrm{mph!"} \mathrm{This} \mathrm{expression} \mathrm{of} \mathrm{amazement}$ also demonstrates the role that visible displays of power play in warbirding.

Despite this visible power and danger, the operation of the aircraft can also be seen as dated and quaint. This comment from a warbird mechanic and pilot is typical, "The people seem to really like the old planes. They love to see them start with the oil and smoke belching out and everything and the coughing and the banging and stuff." The warbirds with radial engines often spew oil out the exhaust pipes when they start, and the accumulated oil in the cylinders comes out as clouds from all engines. They do "cough" and "bang" as well, suggesting that they somehow don't work as well as they should. In fact, these features are perfectly normal for the engines, and they stand out so for crowds simply because aircraft, or automobiles, for that matter, no longer do these things. ${ }^{81}$ Turbine engines don't do these things, marking again the distinction between old and new, with the old airplanes' sputtering to life leading to the attribution of more personality than the new airplanes. New airplanes "wind up" or "spin up" (the jet engine gradually spinning faster and faster to reach operating speed) instead of "coughing" to life.

\footnotetext{
${ }^{81}$ I should note that despite my conflation of the engines' operation with that of the airplanes, the interest really lies with the engines' operation on the planes. People can run engines on test stands, free of any airplane, but such operation interests warbirders much less. They might prefer to see a cutaway of an engine-a museum display where parts of the engine have been cut in half, to see how the different pieces move-over an engine working alone. The real interest in the engines lies in their ability to work on an airplane.
} 
Despite my point that the workings are visible, the complexity of the machines exists where the eye cannot see it, inside the cylinders, the crank case, the carburetor, and the propeller casing, among other places. Indeed, the supercharger used on the B-17 was the top secret technology of its day, a "black box" that few understood beyond the expert engineers. Even these hidden aspects, however, are comprehensible through diagrams and drawings as well as general experience with engines. Most warbirders have at least some experience with engines, probably from doing work on their cars or on farm equipment, and the workings of a carburetor-and a supercharger, despite its more exotic nature-is no mystery to them. The parts can be disassembled and inspected, so that one can see how they move and then imagine that movement when they are re-assembled. Returning to our crankshaft example, they loved to imagine it spinning around inside the engine. A training session I attended included a computer model visualization of the crankshaft's movements, with all the cams, the connecting rods and the pistons. For these pilots, and for me, the graphic was mesmerizing because we saw all the pieces operating together. The animation was slowed so that we could perceive the movement, which only amplified our awe as we imagined its complex rotation happening 45 times a second. Thus, even when the important parts were not visible, their movement could be imagined, and had to be, if the mechanic or pilot was to have the kind of understanding of the engine that warbirders deemed necessary. A jet engine, by contrast, is less engaging because mostly it involves a long cylinder of fan blades simply spinning, very fast. By further contrast, computers and electronics have barely any moving parts.

The hidden-but-easily-imagined workings of these machines suggest that what appeals to warbirders about the planes' visuality is their comprehensibility. One warbird mechanic who also was a current airline mechanic said that what he liked about the airplanes was that you could look at them and understand them. Whether one examines the wiring or how the control surfaces (ailerons, rudder) operate, warbirds are visually comprehensible. 
Comprehensibility relates to simplicity, which was important for warbirders' experience of agency, mentioned above, but it also is an aesthetic distinction. It suggests functional streamlining, a lack of unnecessary flourish, like the beige box PC.

\section{Sound, Tactility \& Smell}

While much warbirder appreciation of planes is visual, other senses are essential. The sound, feel and smell of warbirds distinguish them from today's aircraft, and they come up frequently in warbird discourse. The sound and feel of warbirds relate to the engines, mostly, while their smell comes from the materials used in their construction and the fluids consumed in their operation.

The sound of warbirds is perhaps the most romanticized dimension of the machines' operation. Aside from wanting to "see" a warbird fly, a fan will most want to "hear" it. The distinctive sound of big piston engines-I struggle to find a textual imitation-draws airplane afficionados. When I was working at a museum hangar, for example, a person walked up to watch a late war/postwar airliner practice landings. He had come to the museum because he had "heard round engines" in the air (round engines being a familiar term for radial engines, because the cylinders are arranged in a circle). Similarly, warbirders often buy compact discs with the recorded sound of various airplanes' operation. One retired airline mechanic, who began his career working on piston engines, said he loves to listen to the disc while driving his car, just to enjoy the sound.

The sounds become extensions of the airplane types for warbirders. The North American P-51 and the Supermarine Spitfire are popular, in part, because of the smooth sound of their shared engine, the Rolls Royce/Packard Merlin. The postwar T-28 trainer aircraft also makes a distinctive sound that owners argue is like the Harley Davidson of warbirds. A mechanic and dealer specializing in the plane says his sales slogan for the plane is "Make Noise, Burn Gas, Go fast." Finally, warbirders say that they can recognize the type of warbird simply by its sound. 
Jet airplanes, they say, all sound alike, with only a few exceptions. Their sound also is not guttural or throaty or any of the other personifying terms that warbirders use to describe their aircraft. They are, rather, piercing or shrieking, to the point of being painful and damaging. When a jet aircraft lights its afterburner, the sound drowns out everything else for miles. The volume, tone, and feel of these jet sounds, then, do not lend themselves, in warbirders' eyes, to the kind of personal connection that warbirds' engines do, which is not to say that everyone dislikes them or finds them to be undifferentiated, painful noise. People also buy CD's of jet sounds, apparently finding some way to distinguish the sound of different aircraft, and bumper stickers saying "Jet Noise: The Sound of Freedom" are common at airshows.

Like the airplanes' sound, their feel derives largely from their engines. From personal experience, I can speak to the feel of watching and riding in the aircraft, and the feel is of tremendous vibrational power. As one mechanic said, at airshows he likes to see the "Big horsepower engine out there pounding away." These "piston pounders" have a kinetic feel; you can feel the propeller moving in front.

The smell of warbirds speaks of the past in that they are musty, usually including some old canvas or material whose age is apparent through the odor. Warbirders also note the absence of such smells as plastic or vinyl—the "new car" smell—so common in today's machines. Further, the smell of the oil burning in the engines' exhaust, "never gets out of your blood," as one warbirder put it. This smell contrasts with the strong odor of jet fuel, which is basically kerosene. One mechanic told me that it's difficult to remove the smell of kerosene from one's body and clothing, saying that he could always tell the jet mechanics when they came around, their jet work marking them as a garbage truck driver is marked by his trade. These smells, then, work mainly in contrast to the present. 


\section{The Longing for Quantity}

In chapter one I described the overwhelming scale of production of World War II, and that quantity evokes a profound longing in warbirders. They long for the experience of that quantity, and its absence fosters a nostalgia in them. They frequently celebrate the massive quantities of materiel produced for World War II and lament its loss, as in this pilot's comments:

I just can't imagine how it was during World War II. [O]n Tinian and places like that, when they would fire up 120 B-29's. I just can't imagine how that was. The sound and the smell and the smoke and all that, Jeez, just unbelievable! But they did that routinely, same way in England when the B-17's and 24's started up. Even at fighter bases, when they'd fire up a hundred, hundred and fifty P-51's to go for escort. That's, that'd be a thrill just to be a part of that.

The "thrill" he longs for is simply to be overwhelmed by the quantity. He doesn't mean just any quantity, of course. The thrill is involved with these specific airplane types, with their variety of associations, but the thrill is specifically for them in quantity. This desire also shows up in efforts to assemble large flyovers of aircraft at airshows, just like during the war. Many airshows market themselves on the high number of some distinct type of warbird they expect to attend, and a recent popular type of show has been a large "gathering" of a specific type, such as the North American P-51.

Warbird discourse and literature also effuse about the quantities of aircraft produced during the war, taking that quantity alone to be a sign of the nation's greatness (an association not uncommon under capitalism). The Commemorative Air Force celebrates the war as a time of fabulous industrial production, when the "arsenal of democracy" produced hundreds of thousands of airplanes. Warbird publications abound with pictures of factories filled with partially assembled airframes and fields full of parked aircraft. They linger over 
the rows of aircraft, with the photo captions accounting for all the types shown in the picture, especially if those types are rare or no longer existent today. The scarcity of these airplanes today gets read into each of these pictures of abundance, especially those pictures taken of the postwar "boneyards," where the aircraft were gathered in great numbers before being melted into scrap metal. These pictures especially elicit warbirder longing because they represent lost opportunities. Some collectors at the time bought aircraft by the pound, "saving" them from the smelter. The cheap cost of the planes then suggest having missed out on both the chance for most anyone to buy an airplane (though they were out of most people's reach even then) and on the potential investment loss, as with the $\$ 1,000$ North American P-51 that now sells for $\$ 1.5$ million. The aircraft in these boneyard pictures sometimes sit in perfect rows, as if they were ready to fly again, while at other times they are tossed and tilted, apparently ready for the scrapper. Parallel to these aircraft waiting to be scrapped, warbirders lament the Naval aircraft that were simply pushed off carrier decks into the sea after the war, providing space for cargo to be brought back home.

This extravagant quantity of aircraft contrasts sharply with the combat planes of today. Where thousands of a single type of bomber were built during World War II, today the U.S. Air Force has a little over 200 bombers of all types. Further, that number will only decline as the cost of each airplane escalates rapidly. Perhaps the nostalgia this gap induces is what underlies the CAF's plea that the United States should be as militarily strong as it was at the end of World War II, the result of three and a half years of total war.

\section{Technological Sublime as Aesthetic}

While warbirders have an aesthetic taste for quantities of war machines, quantity can also be a form of the technological sublime, as described by David Nye (Nye 1994: xvi, Fn. 10). The technological sublime is linked to the discourse of progress in that it epitomizes American capability and usually extends into the future, rather than the past. That there

could be a romantic version of the technological sublime at first makes no sense. Yet the 
experience of being overwhelmed by machines is central to warbirding and, I would argue, other forms of industrial heritage. Old machines may be seen as quaint in that they are relatively simple and accessible, but they can also be enormous and powerful. Standing around and simply watching an aircraft engine run fits nicely under Nye's classification of the sublime as "repeated experiences of awe and wonder, often tinged with an element of terror" (xvi). People can just drink in the power of the engine's operation through the threatening, blurred propeller, the vibration of its rotation, the smell of the smoke, and its roar. Being near the airplane during a run up, and especially being inside, gives the same experience of bodily submission as watching a car race or a rocket launch. And warbirders just love this experience, as this prominent warbird pilot, who had been a mechanic in Vietnam:

I have always had an interest in horsepower. . . To someone like me who loves the challenge of turning parts to horsepower, all internal combustion engines qualify I guess. I still love to go to the drag races and see this magic of power. $5000 \mathrm{hp}$ that moves something from a dead stop to over $300 \mathrm{mph}$ in less than 5 seconds. The noise is awesome. The louder an engine is, the more power it is producing and believe me, I love to hear it.

This love of the sound, speed, power, and vibration of these engines constitutes an aesthetic. While current-day cars and airplanes may offer similarly sublime experiences_-jet fighters, for example are much louder than any warbird—other forms of "powerful" machines do not offer the same form of sublime experience. One might have some version of a sublime experience when facing a supercomputer, for example, the assemblage of 5,000 computers that Virginia Tech linked together in 2004 to create one of the most powerful computers ever, but that experience is entirely different phenomenologically.

The start up of an aircraft at an airshow provides a good overview of sublime experience. Where the warbird pilot has to carefully monitor the engine as it starts, the jet 
fighter pilot simply pushes a button and lets the engine "spin up." Once the warbird engine "coughs" to life, the firing smooths out and the engine spins regularly, the gathered crowd can hear and feel its loping rhythm. Indeed, they can hear little else because the engines are so loud. The sound is not piercing, however, like a jet engine. Rather, the sound is a deep, throaty roar. A contemporary fighter jet running at idle slices through your body, forcing you to cover your ears out of (legitimate) fear for your hearing. The warbird engine's vibration, aside from its noise, conveys a clear impression of its power. Feeling your body vibrate along with the engine, at a volume that blocks out any other sound, can displace your consciousness, taking you outside of yourself, immersing you in the feeling of the engine. The propeller provides a visual dimension to the tactile and aural sensations of the engine. power. The spinning propeller creates a feeling not just of dynamic power, but also of danger. The crowds also feel this power through the wind created by the propeller. Fans often have to scurry after their hats, blown off by the propeller's wash/blast.

Despite the display of piston power that warbirds exhibit, the performance cannot escape the larger framework within which they exist: they are obsolete. All airshow attendees have experienced the operation of military jets and know the sheer power they exhibit. Warbirds can be loud, but nothing like a jet operating at full power. Warbirds can move fast, but none are supersonic. Warbirds can even be big, but nothing like the large cargo planes of today. Warbirds can be complex, but nothing like the intricacies of today's computerized planes. The result is that this experience of sublime power is contained and limited as an experience of the past. On the other hand, this experience of power can reinforce the idea that these machines were the most powerful of their day.

\section{The Ghost Squadron}

A ghost is some entity that is present but should not be, and thereby marks a dividing point between two worlds. Therefore, we find no better indicator that warbirders see a difference between their airplanes and the current technology than the recurring reference to 
the planes as ghosts. The Confederate Air Force had, and the renamed Commemorative Air Force retains, an alternate name, "The Ghost Squadron," which also provides the title for its semi-official theme song. The CAF's member website is www.ghostsquadron.org. Popular books and calendars bearing pictures of warbirds also bear the simple title of Ghosts. The recurrence of this ghost metaphor, when the technological practice of warbirding is extensive, complex, and widespread, separates the airplanes from the current world, suggesting that they represent something lost, mere shadows of the past. Warbirders do indeed have a pervasive sense of loss in relation to the airplanes.

Three dimensions of this loss stand out. Warbirders have a sense that the airplanes themselves are merely synecdochic links to the past. Second, they feel the loss of the agency-with-machines that they believe these technologies afforded. What is absent, and what they can, in part, revive and experience again, is what working on and operating the airplanes is like. Yet even this agency can only be partially reclaimed, not only because their view of World War II is necessarily reflexive (Handler and Saxton 1988), but also because they can only partially reproduce the experience of the massive industrial production of World War II. This taste for the industrial, for machines in all their noise and mass, constitutes the warbird technoaesthetic, but this noise and mass are instantiated in machines that are marked as vanishing (Ivy 1995).

As one warbirder described to me, the appeal of World War II lies in its solidity. This characterization echoes understandings of authenticity (Trilling 1972), and I would argue that the basis of Industrial Romanticism is the search for a kind of industrial authenticity, which warbirders seek to experience through their machines. The machines are foci of an unquenchable, unrealizable desire, of a longing which cannot be fulfilled because the past it seeks occurs across an unbridgeable chasm (Stewart 1984). This chasm is not so much one of time as one of quality, a contrast between the solidity of that side and the ephemerality of this one. This better past was created by the progress of technology, yet 
in the intervening years progress somehow went astray, taking these people away from the authenticity of hard, skilled, unalienated work. 


\section{Chapter Five: Inventing Warbirder Masculinity}

Masculinity and machines have long been intimately connected in Euro-American culture. This connection has been a great source of power for men. Yet the easy equation of men and machines or "boys and their toys" provides little insight into how gender actually works in warbirding. What do warbirders imagine masculinity to be? How is masculinity performed in warbirding? How does warbirder masculinity relate to other conceptions within American society? What difference does the military background of these machines make? In this chapter I explore the invention of masculinity through warbirds and the invention of warbirds through masculinity, building on the insistence of recent STS scholarship that gender and technology are mutually constituting categories. In pursuing this investigation, I will shed light on a particular variant of post-9/11, American masculinity, a masculinity which has seen the ascendance of militarism.

\section{Gender, Technology and the Military}

Warbirders do not come to the hangar as blank slates, ready to have the categories of "masculinity" and "technology" filled in for them. They come to the hangar with specific understandings of machines and men; indeed, they come to the hangar because they have some felt connection to or interest in the machines there. In this section I will chart those understandings, drawing on my own perceptions as a native, on writings about gender and technology within Euro-American culture, and on the discourse and action of warbirders. I will focus on specific elements of the male/female binary to illuminate the play of gender categories in warbirding. After outlining those categories generally, I will relate them to technology and to militarism, showing how technology, masculinity, and militarism are intertwined categories. In the ensuing sections, I will apply these general characterizations to warbirding specifically. 


\section{Gender in the United States}

Discussion of gender within anthropology and STS in recent decades has shifted from studying women instead of just men, to studying differing ideas about women (without prejudging what counts as feminine), to studying gender (without prejudging what constitutes gender). As part of this last move, there has been increasing interest in studying masculinity, in opening up the unmarked category of maleness to examination as a way to challenge its normative position, at least in Euro-American culture. Gender varies widely cross culturally, such that no universal characteristics can be articulated. For purposes of this research, I understand gender to be a fundamental cultural construct, both embodied and symbolic, which serves to structure experience and meaning. Within Euro-American culture gender forms a hierarchical binary, with masculinity ranked higher than femininity. I draw heavily on the discussion begun by Ortner (1974) which links the male/female binary to the nature/culture binary. She hypothesized that these two binaries were connected, such that men were associated with culture - here understood as the realm of public life outside of the home - and women were associated with nature — the realm of the home and child rearing. The public life of men involved their education, development of their rationality, and competition within the professional realm, while women were sheltered at home, providing emotional enrichment for the children. Strathern (1980) later complicated this association, refuting its claim to cultural universality and showing how it could be inverted even in Euro-American culture, with men being associated with wild nature and women being the force of culture, calming or civilizing men's wildness. The cowboys and school marms of old Westerns depict this model accurately. In this second model, men exist in a Hobbesian state of nature, at war with all other men.

Building on these brief descriptions of gender binaries, we can begin to elicit the content of these categories and suggest how they come into practice. I should note, however, that the gender binaries construct masculinity and femininity, not specific men and women. 
Just because a human happens to be male does not mean that he fits into the masculine category. Even in the masculine world of warbirding we can find women playing masculine roles. Indeed, the difficulty of fitting into masculine roles for men might be seen as part of the performance of warbirding.

\section{Masculinity and Technology}

We cannot study gender in warbirding without exploring the linkages between gender and technology in Euro-American culture. Stated simply, "technology" is gendered as masculine. To be more precise, knowledge about, working on, and operating most technologies are gendered as masculine. This connection would be apparent to an outside observer, but it is also native common sense. Americans feel that men are just better with technology than women, that men "naturally" tinker with machines.

The study of gender and technology began with histories of technology which redressed the lack of focus on women and technology (Cf.Cowan 1983). This work showed that what counted as "technology" within Euro-American culture, and even within scholarly study of technology, were machines and artifacts that tended to be used by men. Machines that women typically used, on the other hand, like domestic technologies, were not included. Technologies like the vacuum and iron, the baby's bottle, and so on have played an important part in American culture. I therefore have to place the caveat that when I speak of "technology" or the machine being masculine, I refer to native conceptions of what counts as technology/machinery and their gendered associations. I want to avoid naturalizing this man-machine linkage. The masculinity-machine connection here is something to be explained, rather than assumed as an unmarked category.

After this early work, histories of technology focused on how male domination was furthered by its connection with technology (Cf.Cockburn 1981). Finally, this work has recently turned to examine how masculinity itself is constructed along with technology (Cf.Mellstrom 2002, Mellstrom 2004). Ethnographic studies of gender and technology are 
much rarer than these historical accounts, but much of the ethnographic work has focused on women and reproductive technologies (Cf.Franklin and Ragone 1998).

The cultural model which underlies the masculinity-machine association has two central dimensions. First, Euro-Americans understand men as being more rational than women. Second, men are seen as more physical (Wajcman 1991: 143-46). The Nature/Culture binary discussed above helps elucidate these qualities. Men's rationality is developed away from the home, in the professional sphere, and therefore not traditionally accessible to women, while the physical prowess to work on machines is understood to be a natural, biological inheritance of men. Emphasizing both cultivation and natural endowment might seem contradictory, but as Strathern showed, the nature/culture binary is easily inverted, allowing the alternating emphasis on men's nurtured or natural qualities. I should also note that these dimensions of gender-technology can also map onto class relations. Any man can claim these abilities as 'natural' affinities with technology, but the rational/physical split can also mark class lines: the middle class engineer/architect designs the machine (the rational work) and the working class mechanic/laborer builds and repairs it (the physical work). In either case, women have limited access to technology because they lack the rational understanding of machines and also the physical prowess to work on them.

Exactly how these general qualities of rationality and physicality come into practice, however, has changed over the years. To account for this dynamism, theorists have suggested that technology and masculinity mutually constitute each other, which fits into Wagner's understanding of culture as the constant articulation of conventional contexts into novel contexts. In other words, technologies and gender categories shift with each other, retaining the man/machine association and the cultural power that goes along with that association even when the underlying practices shift. Male power in Western culture has long been linked to the professional sphere, where the tools, and later machines or technologies of production were used. Men controlled the "engines of progress" in the form 
of factory machinery, railroads, and so on. As the means of production changed, men worked to retain this control, redefining themselves and their work as masculine even in the face of machine-induced deskilling. For example, one study of typesetters over the years showed that as the machines and work processes involved changed, typesetters redefined themselves and the nature of their skill to apply to the new situation, gradually shifting away from more physical-based explanation (strength to lift the set type) to a rational one (the ability to read set type, which is backwards), giving up previously fundamental aspects of their work as tasks were automated (Cockburn 1981).

\section{The Military and Masculinity}

Warbirds are not merely "technology," but also military technology. We therefore need to explore the connections between the military and masculinity. Although many cases of women warriors have been documented, Euro-Americans understand violence and competitiveness to be fundamental components of manhood, making them into 'natural' warriors (Wajcman 1991: 146-49, Enloe 1983). Women, on the other hand, are seen as natural peacemakers, due to their "natural" association with child-rearing. In its particular American form, this association has many variants, positive and negative. On one hand, men are felt to be more naturally violent than women, in need of women's 'civilizing' influence. On the other hand, this natural connection to war also leads men to exhibit positive traits like courage, loyalty, sacrifice, endurance, and initiative. These qualities' exhibition in warfare is lauded as high and noble, well exemplified in Teddy Roosevelt's hearty endorsement of battle as good for the soul, "A just war is in the long run far better for a man's soul than the most prosperous peace."

Euro-Americans understand war as eliciting masculine virtues to a degree impossible in any other circumstance. They have fundamentally ambivalent feelings about war in that it involves horrors, but it also pulls out these masculine qualities. For example, war is positive in that it "challenges" or "tests" men, sorting out the weak from the strong, the brave 
from the cowardly, the clever from the stupid. The "test" of war remains a powerful theme in Western culture. In this ideology war also creates unbreakable bonds between men, and the tie between warriors, or "buddies," is second only to the father-son tie in its sacredness. This view was popularized in many works that celebrate World War II, such as those by Stephen Ambrose (1992, 1997). Other literature about war lauds these bonds, but laments the conditions of their production (Gray 1959). Mosse (1990) has characterized a particular variant of this masculinity/war connection that he calls "the Myth of the War Experience." This myth underlies much of warbirders' valorization of the "Greatest Generation." As we will see, warbirds serve to provide experiential access to the myth of the war experience so that warbirders can explore, at the least, what they see as the ennobling aspects of "the Good War."

\section{Locating Myself in Gender Categories}

I introduce my own voice into the following discussion much more than I have in the previous chapters because I feel that I am personally implicated here much more than elsewhere. To the extent that I became involved in the same cultural understandings as warbirders, the elements described here — the enmeshing of one's self with the maintenance and operation of these machines, as wrapped up in gender identity — are the ones which I found compelling, at times despite my preference for critical distance. This discussion, then, reflects my own positioning within United States society. While I could resist many of the other hegemonic discourses on some level, having been trained to be critical of ideas about history, the nation, and the military, the discourses and practices connecting gender and technology were irresistible. I therefore introduce my presence in various stories and events described here, perhaps over-emphasizing the degree to which I was involved, but avoiding the implication that I was merely an outside observer. In doing this, I want to maintain the balance I have tried to strike thus far between the individual and the cultural, following Sapir in arguing that culture, while socially shared, is instantiated in the thoughts and actions of 
individual humans (Sapir 1912). Those thoughts and actions are guided by the need for and assumption of some shared coherence.

\section{Gender and Technology in Warbirding}

While all warbirders would acknowledge that interest in these planes is "a guy thing," most would also bristle at the suggestion that gender plays an important role. Such a suggestion would be objectionable to warbirders on two grounds. First, any suggestion that masculinity is something invented or something that has to be sustained through performance, might undermine (Wagner's term would be "relativize") the assumption that it is a natural quality of humans. Second, they want to see "preserving history" as the essence of what they do and would reject dwelling on gender as "political correctness" or "revisionist history" intruding to misrepresent (or deprecate) what they are doing. Despite these objections, gender is very much something they "do." Not only are the vast majority of warbirders men, so that the exception of the few women who participate proves the rule of male dominance, but the men in warbirding police their work to retain male dominance. More subtly, warbirding demonstrates the ongoing invention of the masculinity-machine linkage. Not only does warbirding articulate the conventional contexts of masculinity to the novel contexts of warbirding, but warbirders also have invented a new field for masculine performance: recovering the detritus of war and turning it into an expert practice.

In discussing this invention, I draw on the basic associations of men and machines discussed above, rationality and physicality, which are evident throughout warbirding. Warbirders celebrate the rationality of men in their reverence for the designers of the aircraft they fly. The role of these men in the "Greatest Generation" was to apply their genius to developing the tools of war. The physicality of the man-machine linkage, on the other hand, comes out in their everyday practice. A good mechanic, they say, is not afraid to get dirty and sweaty. Members say they love "turning wrenches" or "banging their knuckles" on the old machines. Hard work is greatly praised around the hangar, and everyone knows who the 
hard workers are. In addition, warbirders understand a good pilot as one who comes by his abilities naturally; his skill is embodied and physical, not taught. Even the spaces of warbirding have to be invented as domains where these masculine qualities are performed.

\section{A Masculine Domain}

The general association of masculinity and technological pursuits allows warbirders to gender their work and workspace without being conscious of that gendering. The hangars of a museum group I worked with provide a useful example of this. The group had two hangars, the northern one devoted to restoration and maintenance work on airplanes and the southern one devoted to social events, airplane parking, and museum exhibits. They could be classed roughly as the maintenance and the museum hangars. Within the hangars, there was a hierarchy of spaces, with anything airplane-related taking precedence over any other space. Maintenance and flying took precedence over restoration, and although restoration was kept separate from display and museum pieces, maintenance and aircraft display routinely intruded into the museum. This spatial hierarchy mirrored a social hierarchy, with the library and museum staff being both marginalized and feminized within the group (despite the significant monetary contribution of the museum to the Wing). The hierarchy of space also mirrored the hierarchy of objects. The airplanes were the center of all attention there, with even non-working parts taking precedence over non-aviation objects.

In terms of gender, the restoration/maintenance hangar was masculine, while the museum/display hangar was feminine. All of the tools for masculine performance were in the northern hangar: hardware, hand tools, machines, spare parts and tires, forklift, disassembled aircraft, and officers' desks and phones. The activities in the northern hangar were either explicitly or implicitly gendered. The men cleaned up and came over to the southern hangar to eat lunch, which paralleled the need for men to become "civilized" in the presence of women. The women worked to maintain the library and the exhibits in the southern hangar. The tour guides came to know the airplanes through books, rather than 
through direct maintenance work on them, paper cuts more than 'banging their knuckles.' Further, the job that the maintenance men most associated with the tour guides was taking school groups through the hangars. Although the maintainers claimed they could never do that job, dealing with children was implicitly subordinated to the important airplane work, and was thereby feminized.

We can also point out that the various jobs within the museum are gendered, even as the museum is subordinated to the maintenance and operations work. Within the museum, the work on exhibits, which requires expertise in both the military artifacts and the machines displayed, was performed mostly by men. This held true at another museum, where the founder spent his days not working on machines but performing research and tinkering with exhibits. Within the museum, he performed a masculine role, even as his role was feminized relative to the airplane operations and maintenance, which were managed by a famous pilot and restorer.

In the restoration hangar men were such an unmarked category that the presence of women in the work areas had to be policed, in a sense. Women who entered the workspace, aside from those on tour (the social role of the tour-goer being well accepted and often ignored in favor of ongoing work, unless someone asked a question), led the men to stop work and usually comment on the attractiveness of the woman or to speculate on the reason for her presence. When a female FAA official came by, many were startled to find out that she was a regulator. In another case a woman who had attended a special week-long school to learn basic warbird restoration techniques was told to try working in the library rather than on the airplanes. Her efforts to overcome this suggestion were defeated when she was not accepted into a workgroup. This was a standard social procedure in the hangar. A newcomer would attempt to choose or get assigned to work on a specific airplane, but if the group of men working on that airplane proved unwilling to include that person he (or she) would gradually fade away. 
Warbirders also thought of the restoration hangar as a retreat from feminine domestic worlds. Retirees saw the hangar as a place to escape from their home for a time, and younger men also saw the hangar as a place to get away from their wives. One young (late 30's) airline pilot said that work around the hangar provided relief from the stress of his divorce. Several retirees described their hangar time as a life-saver when they were dealing with their wives' illnesses and deaths. In part what "saved" them was the bond they created with other men, in the gendered space of the hangar. Thus, the gendered division of labor at the hangars was continually produced (Cf. Lefebvre 1991), both implicitly, through symbolization of the different artifacts and activities, and explicitly, through policing the presence of women in masculine spaces.

\section{Warbirds as an Agency of Masculinity}

The production of warbirding's space, then, involves the ongoing invention of masculinity. As with other elements of warbirding, I argue that the association of masculinity and machines must be continually reinvented to be sustained. The question then becomes how this association was and is sustained across the many new contexts of warbirding. Kenneth Burke's dramatistic pentad can help us to conceptualize two different ways in which this happens (Burke 1945). Following Burke, the motivation for any kind of social activity can be analyzed in terms of act, scene, agent, agency, and purpose. For the present discussion, two of these, agency and scene, are especially helpful. This section examines how warbirds and their related technological activities serve as an agency, or means, for the performance of masculinity. That is, warbirds, as technological activities, provide the means of building individual masculine identity and of constituting and reinforcing gender categories. I will argue in the next section that warbirds also serve as framing devices for particular kinds of masculine performance, in other words, they set the appropriate "scene," in Burke's sense, for interactions between men. 
The idea that warbirds afford the means to perform masculinity depends upon a range of notions about masculinity. At its most basic level, this performance must demonstrate competence with machines. Instead of being assumed, "machine competence" has to be performed, partly as the ongoing invention of masculinity, but also because the natives understand this competence to be in crisis. The social role of the shade-tree, amateur mechanic, commonly a feature of middle-class masculinity, has disappeared. ${ }^{82}$ With computerization, as discussed in the previous chapter, the gender-linked ability to do things with machines has disappeared, and warbirds provide a means to recover and perform it. Warbirds also provide for the development beyond mere competence to some level of expertise, which then provides the basis for status competition. This competition, in turn, is understood to be a natural quality of masculinity, along with several other attributes seen as distinctly masculine: autonomy and self-confidence. Finally, the sublime experience of warbirds' operation feeds an embodied taste for power which Americans experience as a facet of masculinity.

\section{Machine Competence}

Working on and flying airplanes are the central activities of warbirding, and within those activities we find a basic component of masculine identity in America: machine competence. Within American culture competent, skilled interaction with machines constitutes persons as masculine. The kinds of interaction one can have vary, but follow the pre-established lines of connection between technology and gender: a rational understanding of machines and a physical interaction with them.

To better understand how this competence relates to personhood, however, we have to understand the relationship between productivity and personhood in American culture.

\footnotetext{
${ }^{82}$ American men, myself included, all understand the loss of this competence as a deficiency, which is easily interpreted as a kind of feminization. Many experience it when we take our car to a mechanic and have to hope that the mechanic is telling us the truth and that the mechanic won't say anything that will expose our embarrassing lack of car expertise. Most of the men at the hangar, however, did not have this concern, at least not until their cars were computerized.
} 
American individualism equates personhood with production. Going back to Locke, the individual applies his mental and physical abilities within nature to produce something, thereby constituting himself as a person. One "makes something of oneself" by being productive, and this productivity adds to one's identity. Identity, then, is a possession of the individual, and the qualities associated with that identity can be gained or lost. The possibility of losing the productive aspect of one's identity creates a felt need to demonstrate it. The felt need to be productive appears in everything Americans do, from their vacations, where they "work" very hard to have a good time even though they are nominally not working, to school, where learning is producing an educated self, to parenting, which in its de rigeur verb form has emerged as a field of achievement for people raising children. The ability to be productive is therefore a basic component of personhood and therefore central to the invention of masculinity as well.

My own experience illustrates the connection between machine competence and masculine identity. When I went to the hangar to work, I was looking forward to experiencing a productivity radically different from that available to me in my life as an academic. I experienced it personally in many small ways, delighting in the chance to do some "real work" and to "get my hands dirty." I was pleased with myself, for instance, when I had the nasty task of removing an oil tank from an airplane wing. Working with another person, we removed the cover to the tank, but to collapse the tank for removal (it was a rubber bladder, not a metal tank), we had to take out an internal support. To get my arm far enough inside the tank to remove the support, I had to stick my head in as well. I got oil in my hair and all over my shirt, which the head mechanic thought was a little much, but my willingness to get dirty made me proud. I saw getting dirty as a form of masculine machine competence, but my feeling drew on the association of masculinity with the physicality of machines, rather than the rational analysis and understanding of machines. Hangar work for me clearly related to a model of gendered productivity, but the first big suggestion that 
something similar held for warbirders came on the day that an airplane arrived at the hangar on a truck.

\section{The MIG Arrives}

The routine of daily hangar work occasionally was broken by some large project or event that drew everyone out to watch or participate. Such an event occurred on a Saturday morning in February when a truck showed up with an airplane on back, split into pieces. The airplane was a 1950's era Mig-15, a Soviet jet plane, and it needed to be unloaded. It was not clear who exactly was in charge of the unloading process because no one had taken responsibility for the plane's arrival. Someone got the forklift, and on the rule that whoever is operating the largest piece of equipment decides what should happen, we followed that lead in unloading the wings. We unloaded them individually, followed by the tail section and the wing fuel tanks. We were then left with the fuselage. Unlike the wings, however, the fuselage was much too heavy for a single forklift. We needed some means to lift it off of the truck, if only for long enough to let the truck drive out from under it. Someone decided that a large A-frame winch stand (like a child's swing set made of thick steel pipe with a winch located where a swing would attach to the overhead bar) that was out front would be a useful tool. The stand normally held a large sign for the Wing, but it had blown over the previous night in strong winds. A group of people had gone out front to right the stand and bring it to the back to help in the unloading process. "Oliver" sent me out to help, and "Fred" came with me.

The first step was to right the stand, getting it up on its legs. We tried using the forklift to stand it up, but it could not go high enough. With that obvious solution thwarted, the various people gathered around started taking different approaches to the problem. One group worked on a way to pull the stand up with a rope, though they needed a way to keep the legs from sliding along the ground. Another group of us started trying to take the legs apart. Each leg had two parts, secured in the middle by a sleeve that was slipped over the 
pipe ends and tightened onto the pipes, and we tried to move the sleeve of one leg enough to separate the bottom half of the leg. We reasoned that the stand would then be much shorter and could easily be stood up by the forklift. Just how we were going to reattach the bottom half of the legs to stand it up again was not clear, but we had a project going and were going to finish it! We worked feverishly to move one leg's sleeve, which had partially rusted onto the pipe. We used lubricant, a pipe wrench, and hammers, succeeding in moving it a little, but not enough to free the leg. At that point, a different project was coming to fruition. Some others had decided to secure one of the legs and try driving the forklift forward while lifting up the crossbar, perhaps to give the stand enough angular momentum to rotate it all the way up. We sleeve-workers had to yield in the face of a superior piece of machinery, so we stood back to watch. The forklift driver, "Angus," was aggressive and came close to getting the stand up. Just as it neared the top, however, it started to twist, and everyone ran as the stand started to fall. Even Angus leapt out of the forklift and ran to safety. With a ringing crash, the stand hit the ground, in the process twisting off the sleeve we had been working on and elevating the taking-it-apart project to most-likely-to-succeed status. Oliver said this would allow us to carry it more easily, but I thought the whole reason was to get it righted. It seemed easier just to roll it around on its wheels, if transportation were the issue. Nevertheless, we all set to taking it apart, starting on another sleeve. The angle at which the stand had fallen unfortunately placed a fair amount of pressure on the sleeves, making their removal even more difficult. As we were absorbed in working on a sleeve, Angus decided to drive the forklift full speed into the top bar, hoping that the impact would separate another leg from its sleeve. He slammed into the bar, but this move only succeeded in scaring the shit out of us as we dove out of the way, doing nothing for the sleeves. At this point, someone came out from the hangar and said that they had found another forklift, and we didn't need to worry about the stand. I went back inside with Fred, and we both were highly amused by the whole event, noting that it was only funny because no one got hurt. 
The point I wish to draw out of this example is not that the SoCal Wing members are incompetent or dangerous, for they most certainly are not. ${ }^{83}$ Rather, what struck me most was the drive the individual men felt to exercise their handiness, their competence with mechanical things. In a novel situation with no obvious or shared schema to reach a set goal, these 8-10 individuals sought to fulfill the project any way they could. We - I was no different, except perhaps in the degree of skill — all felt the drive to do something. That drive, I argue, lies beneath much of the activity at the Wing. These (mostly) men just want to $d o$ something, to fulfill a project, almost any project that relates to machines. In most cases the organization channels this drive quite well, coupling it with the appropriate skills and enough of management to ensure that projects are completed.

\section{Remove-and-Replace versus The Satisfaction of Improvisation}

One might imagine this drive to demonstrate machine competence was simply one facet of the masculine gender role, a required performance. Yet the case of warbirders was unusual. After all, they focused on long-obsolete technologies, counter to the dominant discourse of technological progress. Here competence-seeking seemed to stem from a feeling that they lacked that kind of productivity in their daily lives. The suggestion of a felt lack came from the way some warbirders described today's technologies and from the way they described their hangar time in relation to the rest of their lives.

One of the many critiques warbirders made about American society today was that they could not work on machines anymore. Much has been written about technological change and the de-skilling of workers, and warbirders' inability to exercise their machine competence in their daily lives highlights the impact on one's personhood of these larger processes (Cf. Noble 1984). For the volunteer warbirders - those who were not

\footnotetext{
${ }^{83}$ I should note here that the Wing is one of the most successful and safe warbird organizations. Their mechanics and pilots draw on a vast store of experience with airliners and with older piston-engine aircraft. Their training pilots are some of the best from the airlines, and the many conversations I have had with the lead pilots, coupled with my observations, showed safety to be their highest priority. Indeed, I would argue that these Wing members, along with some from other Wings with which I did not interact, have helped reduce the CAF's early reputation for being cavalier with safety.
} 
professional mechanics and who may or may not have had extensive past experience working on aircraft — working on airplanes at the hangar provided the feeling of "doing something" that they had in the past. They commonly invoked their cars as the primary site for their mechanical competence, saying that with the computerization of cars, they could no longer understand or repair them. One warbirder said that what he liked about warbirds and old cars was that "a human could work on them."

Like the volunteers, the professional mechanics decried the lack of opportunity to demonstrate their machine competence. They had to go to school to understand the systems of an aircraft, but when they got a job at an airline, in the military or at a factory, they did the same task, over and over. The real "use value" in the work for them lay in having to troubleshoot a problem, having to weigh the evidence of a malfunction and come up with the solution. One restoration shop mechanic contrasted the job he was doing, slowly fashioning parts for a fighter plane on which he alone was working, with his friends doing mindless production work. This job gave him room to exercise his abilities and feel invested in the job.

These volunteer and professionals' complaints about a lack of agency in today's technology merged when they criticized the "remove-and-replace" nature of technology in aviation today. The following comment from a warbird historian and museum head nicely captures the contrast between the mechanics of old and the remove-and-replace world of today. ${ }^{84}$

I tell you one thing, though, the mechanics of World War II were a lot better than the mechanics of today. I judge that on, if you take a look at how the Air

\footnotetext{
${ }^{84}$ Even though warbirders romanticize the technological agency of World War II mechanics, as this passage shows, one World War II mechanic whom I interviewed strongly contrasted the kind of work done around the warbird hangar today with that performed by combat crews in World War II. He said that any problem that couldn't be quickly fixed by a World War II crew caused the airplane to be shifted over to depot maintenance, much as any broken VCR today would be sent to a company's regional repair facility. At the warbird hangar, however, they work on problems of all scales. From his comments, we might shift the qualitative distinction from past/present to volunteer/professional organization, where the professional organization would be the military or a business.
} 
Force and the Navy trains their mechanics today, all they want is a box to open up, and take a part off, and put the new box on. That's your mechanic of today. In World War II, they take the part off and fix it. Here are the pieces and gears and whatever, and put them all back together, check it out on the bench, put it back on the airplane, and it worked. Now that's a mechanic. They're not mechanics today.

Warbirders therefore imagine what they call "remove-and-replace" work to be something like an assembly line. They merely open up a box, "take a part off and put the new box on." Remove-and-replace therefore doubly reduces masculine competence because it prevents a mechanic from troubleshooting a problem and it requires no great skill to change a part. Remove-and-replace allows most anyone to work on a machine simply by knowing how to take a part off and bolt a new one on. While removing and replacing may require some physical exertion, as when navigating the cramped spaces of airplane compartments, turning a screwdriver with an outstretched arm and no leverage, it lacks the aura of hard, physical labor required for the old machines — the working with "pieces and gears" — and it requires no mental work. Further, this passage attributes the identity of "a mechanic" to the World War II mechanics and denies it to the remove-and-replace functionary of today. This contrast, which is clearly romanticized, attributes status based on the kind of work: removeand-replace workers are not "real" mechanics (and by implication, lacking in masculinity), while World War II mechanics (and warbird mechanics) are real mechanics.

At first glance, the contrast of new : old :: easy : hard may seem counterintuitive, since the jets produced today are by all culturally available measures much more complex. Their complexity, however, has been placed into "black boxes," the workings of which the mechanic or pilot does not need to understand. The highly complex materials, integrated circuits, design structures, and so on, of today's airplanes are therefore of no concern to the pilot or the remove-and-replace mechanic. The complexity of a warbird, on the other hand, 
is directly of concern to the pilot because he has to monitor what is happening within the various systems: the engine, the propeller, the hydraulics, and so on. As noted above, this monitoring is more than an intellectual exercise of reading gauges and making calculations. Flying warbirds requires embodied knowledge. As one warbird pilot, who had recently retired from flying military fighter jets, put it, even starting the engine is a "dance," of adjusting the mixture and listening to how the cylinders are firing.

Working on warbirds, therefore, contrasts sharply with the kind of work these men can perform away from the hangar, either at home or professionally. The professionals at restoration shops get to perform the full array of mechanical tasks instead of specializing in just one small area. They get to work on a variety of airplanes, all in different condition, and diagnose many kinds of problems. They even get to learn from their experiences when planes that they've worked on before return to the shop for further maintenance.

For the volunteers at a warbird museum hangar, having to overcome many obstacles in getting the airplanes flying provides ample opportunity to demonstrate a masculine competence with the aircraft. The incident with the winch stand showed how the quest to work on machines can fail, even with many highly-skilled individuals working at it. In a different case, that group's members showed how they could improvise in mechanical work. We were restoring a World War II trainer, something that the group had inherited from museum headquarters in hopes the group could get it back into the air. Since the plane had sat in the mud for many years, we had to strip all of the paint off of it to inspect it and clean it up. We worked on the center section of the wing, on top of which the fuselage sat. The piece was probably 10 feet wide, seven feet tall, and over a foot thick. The section was awkwardly laid down, so a couple of the others wanted to construct a jig in which to place it. One remembered a metal stand that had been behind another member's hangar for some time, so they went and claimed it. It was two strong, metal, vertical posts connected at their bases by a long pipe and resting on four wheels. It would be ideal, except it was not wide 
enough to fit the wing section. We therefore cut the pipe, fit a larger pipe over the two ends, and secured the larger pipe to the original one. We therefore could slide the original, smaller pipe out to spread the posts apart. The next step was to secure the section to the post, so we drilled some holes in the crossbars at the top of the posts and attached a couple of boards to them. These boards could then be attached to the wing section, and we suddenly had a stand for the section. This arrangement was further modified a few months later with disks fitted between the boards and the wing such that the wing section could be rotated. It was ingenious, I thought, and just the kind of satisfying improvisation that these men seek out of their days at the hangar. (I had only a small part in the whole process, trying to understand what they were doing.) In my time at the wing, I saw them perform countless projects like this wing jig, and I realized that doing such tasks was the enjoyable part of the work around the hangar.

\section{Agency or Alienation}

While warbirders revel in the chance to do enjoyable work, we might ask if gender really has a central role. After all, the issue of alienating versus person-enhancing labor is an old one. This warbirder's comments, for example, demonstrate the close connection between the enjoyment of machine agency and the felt need for productive, person-enhancing labor: In doing the work, "your spirit and your thoughts and your hands and all your resources are put at some level to complete this task. Sometimes it takes years and years and years to do it. It's a labor of love that you're rewarded by accomplishing this, and it's not just punching a clock 8 to 5 and going home." Elsewhere he explicitly acknowledges the rarity of this chance to have "a labor of love" that rewards you merely by "accomplishing this." Further, many warbirders, professional and volunteer alike, repeated his insistence that warbird work was different from just "punching a clock."

I would argue, however, that gender is central to this experience of labor, and not merely because the labor occurs in the public sphere, which conventionally has been a 
masculine sphere of activity. The following passage demonstrates why I make gender so central to this discussion.

I grew up with Erector sets. My kids probably don't know what Erector sets are, but I see them working on things or fiddling with their hands - the girls are doing makeup and whatever, the boys are you know, making new plastic toys or whatever things they assemble, so it's something that maybe extends from childhood. I grew up with an Erector set, and that was my Erector set. I relished owning that and taking care of it and putting things together and taking them apart, so this has extended itself to, essentially, my Erector set today.

This warbirder first describes the desire to work on things as something that stems from childhood, suggesting that the trait is inherent in humans. Then he connects his childhood erector set directly to the work on his warbird, a metaphorical extension which both renders the warbird work gendered (it is his erector set, not his makeup kit) and softens that association by suggesting that the work is childlike. By including "the girls," he suggests that they might have some kind of mechanical agency as well, but this agency is limited to the sphere of girl-like things: makeup. Makeup, which one could easily examine ethnographically as a technology important in Euro-American culture, is not classified as "technology" in the same way that a warplane or an erector set would be.

\section{The Challenge of Warbirds}

For most warbirders, part of the pleasure of acquiring machine competence with warbirds stems from their difficulty. The motif of "challenge" recurs throughout warbird discourse, as I noted in the previous chapter. Mechanics and pilots often insist that what they love about the old airplanes is the "challenge" of working on and flying them. The ability to meet a challenge successfully is a vital form of agency for them. As one warbirder put it, in describing why he loves to fly warbirds: "I think it's a matter of challenging yourself. I 
mean, if you don't challenge yourself intellectually, physically, in some way, you're a vegetable... I I think you've given up your right to live on the Earth.” To be a person, and not a "vegetable," one has to challenge oneself. The challenge of warbirds stems from their working complexity: warbirders need to understand the systems involved so that they can interpret the different events that occur during flight. They describe a good pilot as being "a real stick and rudder man" or simply, "a good stick." While these phrases use obvious sexual imagery, the 'challenge' of these airplanes also presents the opportunity to develop a gendered competence with machines. Meeting the challenge, in fact, is a point of pride for warbirders, as with the airline pilot I met who said only two or three of the pilots in his company could fly the warbird he had flown to an airshow. In the previous chapter, I described the qualities that warbirders say operating a warbird requires — and which they romanticize as lost to the past — and we can examine those qualities also through the filter of gender. The role of the "country boy" who was a crack shot because of his hunting experience is lost to time, but warbirders could test their expertise to interpret a distressed engine. They could hone their flying skills in case of some mechanical failure so that they would be ready for "seat of the pants flying."

This articulation of the "challenge" of warbirding employs an agonistic view which draws on the mastery discourse of masculinity. One must "rise to the challenge" and prove one's worth. In this sense, masculinity in warbirding is performative, an ongoing invention. Often this performance goes beyond the point of competence to that of expertise, as I discuss below.

\section{Expertise}

Machine competence can be developed well beyond the day to day ability to work on airplanes. For many warbirders, the old airplanes provide a field within which to become experts, both out of interest and out of a kind of status competition. Expertise, like competence, can be gendered, and it involves more than the ability to work on or operate the 
machines. Male expertise prevails in the maintenance and performance at the airshow, just as at the hangar. The mechanics and pilots are almost always men. Prominent female pilots tend to become either objects for the male gaze, distracting from their skill, I believe, or embodiments of the masculine, militarist nationalism. Further, the figure of the enthusiast, that person who does not maintain or fly an airplane, but rather obsessively tracks them by subtype and location, plays the role of the male viewer. While the enthusiast lacks the technical expertise of the pilots or mechanics, he has studied the airplanes in great detail and knows all of the variations between subtypes of warbird. He also knows the details of aircraft histories and all of the collectors - who had which plane when and where it went after that. This knowledge is explicitly gendered as something that would only interest men, as the following passage, taken from a warbird museum's Internet message board, shows.

My boys (ages 15 and 12) and I visited your museum on Sunday, April 4th and had a wonderful time! The museum was recommended by my brother-in-law. He had taken my dad (an engineer with McDonnell Douglas for 40 years) to see it and they spent all day there! To be able to actually stand next to these airplanes, touch them, see them up close, was incredible. After going inside the B-17, I told my boys we'll have to rent the movie "Memphis Belle" so they can have a better understanding of the true heroics of the crew assigned to one of those planes. And seeing the planes used for the air speed trials, "The Right Stuff" is another movie must! Although I can't identify all the aircraft by the wing structure, tail shape, nose and canopy style (I'm a female) I really gained an appreciation for everything on display and I know my boys can hardly wait to take their dad to your museum. (He'll be the one who can identify everything for them!!) Thanks again, (Ono 2004).

In this passage we see, first of all, that these warplanes are assumed to a natural interest of men. Secondly, the expert knowledge about these airplanes ("wing structure, tail shape, nose and canopy style") is equally assumed to be a natural interest of men, since the writer explains her lack of this knowledge merely by identifying her gender. Thirdly, the writer suggests that this expertise is communicated ideally from father to son, imagining the formation of homosocial bonds. 
Within the warbird world, such enthusiast expertise is not as highly valued as that of pilots or mechanics, however. (Enthusiasts might even be seen as a nuisance, as the purity they sought struck the more pragmatically oriented warbirders as misguided. I heard one collector paraphrased as saying that enthusiasts were a bother because they offered criticism without contributing even enough money to keep the lights on in his museum.) Indeed, even though enthusiasts play out a role gendered as masculine, they fit lower into the warbird hierarchy than either pilots or mechanics. Their expertise is purely rational, book knowledge, as opposed to the more physical, embodied knowledge of the pilots and mechanics. Taking the gendered relations of man-machine further, we might argue that the basis for enthusiasts' lower rank is that they lack any kind of intimate connection to airplanes. Their mastery of the airplanes is abstract and schematic, while pilots and mechanics have direct, physical contact with the machine. In the previous chapter I described the centrality of having a "relationship" with machines to the romantic view of this technological practice. Here we can see that such a "relationship" is also inflected by gendered expertise.

The lasting effect of such a relationship is a deep, embodied knowledge of the aircraft. Warbirders greatly praised the kind of expertise which developed out of what might be called "dwelling" with the aircraft — working on it and improving it over time (Ingold 2000). In this way, the aircraft can be "known" in all of its quirks and foibles, becoming in the process a person - a female, as I will describe below. This embodied knowledge best combines the rational and physical dimensions of masculine expertise, as the most skilled mechanics are those who can just "feel" and know what a machine needs. The physical dimension comes through using one's body in this relationship. A number of mechanics described the need to employ all of one's senses when inspecting an aircraft. Pilots also use their bodies, or rather, have their bodies merge with the aircraft. One pilot described his favorite aircraft - one many others hated - simply as comfortable; he always felt comfortable in it, meshing with it well. Another pilot described his love of flying the 747 
(admittedly, not a warbird, but working by the same principle), saying that he did not really land the airplane so much as land himself, with the airplane coming along with him. The rational dimension of this embodied expertise comes through studying the details of the plane's workings and through training one's body and mind to react in emergency situations. One mechanic described how carefully he had to study the manuals for an airplane so that using them felt natural and comfortable. Instructor pilots described how a good student would be able to think through a new problem. Bad pilots, on the other hand, are uncomfortable in the cockpit and cannot feel what the airplane is doing or is about to do. The intimacy of expertise which pilots and mechanics seek, then, can be seen as a kind of embodied union. I never heard a warbirder invoke sexuality to describe this union, but such a leap would not be difficult. Further, the notion of union attributes a certain personhood to the machine, and warbirders speak frequently about the "personality" of their aircraft.

\section{Gendering the Airplanes}

If the men who possess expertise about the airplanes are configured as masculine, then the airplanes themselves must be feminine, and that is how most warbirders refer to their planes. Transportation technologies of all kinds are personified and gendered in EuroAmerican culture, and they usually are gendered as female. The machines themselves get gendered by the extension of meanings from conventional gender stereotypes and by the various ways warbirders personify their airplanes, with nose art, paintings often of scantilyclad women, based on similar practices during World War II. Many warbirders also attribute gender through names or nicknames, like "the Doll" or "the Old Whore," even when they insist that they do not personify the airplane. Most warbirders describe the planes as being like women: complicated and temperamental but beautiful and desirable.

Nose art demonstrates important aspects of this gendering. Most nose art depicts women in sexually suggestive, if cartoonish, ways. These depictions range across the various forms of erotic fantasy, from country girl to mysterious Asian. The nose art which makes 
the SoCal Wing's airplane "China Doll," for example, depicts an attractive Asian woman taking off her clothes. I never heard anyone comment on the "China Doll" nose art in particular, but we could speculate that it might have been an attempt to make "dumbo" (another nickname for the type) racy. At the very least, the artist, a World War II veteran, drew on a stock of standard, sexualized images of women, using the reference to China to emphasize the "Hump mission," as I discussed in chapter two. ${ }^{85}$ Such images and names serve to naturalize the white, male gaze. The vehement reaction of warbirders to objections about the nose art further reflects the naturalization of this gaze. When military bases started banning nose art that depicted nude women, many warbirders complained about political correctness. While they bristled at this challenge to their autonomy, they invoked instead a "just the facts" version of history to justify the nose art, arguing that "the boys" of World War II painted those kinds of images because they longed for women, so the warbirds should have it, too, in order to be authentic.

In addition to these aesthetic efforts to feminize the airplanes, warbirders often used gender as a framework for experiencing the airplane and to understand their performance with the airplane. This comment from a CAF member in his 50's demonstrates the degree to which gender and technology become intermeshed in this way:

Did you see the picture? It's the greatest explanation for the difference between men and women I ever saw. I got it on the internet the other day, and it shows this box. This big control panel, divided in two. The top half was "On/Off." Men. And down below, Women, and there was every dial, knob, switch known to humans, and that was women. That's why an airplane is like a women because some of them are temperamental, and you have to

\footnotetext{
${ }^{85}$ On the other hand, the Wing has kept the nose art, even having it copied when the plane was repainted, so the name and the image indicate more than one old veteran's aesthetic.
} 
know how to treat 'em, or else they'll bite you. So that's why men call airplanes, they're all female. They're all female.

We can see in this example the play between contexts of gender and technology. The object's complexity becomes a model for imagining male-female relations, and the warbirder's mode of interaction with the airplane becomes to some degree gendered. This warbirder meant to say that men are easy to understand: all they want, as another retired airline pilot put it, is "to eat, screw, and play with their toys" (like airplanes), where women, like airplanes, are difficult to understand. Indeed, their theories about aircraft mishaps often reflect their theories about relationships with women: things go wrong for no obvious reason. The metaphorical linkage also informs their interactions with the airplanes. From this point of view, working on an airplane is not an impersonal working with metal, but a creation of a relationship with a person. One has to "respect" the airplane, or even be nice to it. In the process of this relationship, the warbirders reinvent masculinity for themselves.

Interestingly, this way of imagining the airplane provides for different kinds of relationships. On the one hand, the classic Euro-American discourse of "mastery of nature" could be put into play, as with the frequent emphasis on living up to the "challenge" of warbirds that I discussed above. Here mastery of the machine might equate to mastery of women and assuming the role of the "head of the family" so evident in the cultural politics of today. On the other hand, as the speaker of the control box example suggests, the relationship might merely be one of managing a difficult machine, of getting along despite the potential for trouble. The "management" relation, however, is no less hierarchical. It suggests, again, that men are eminently rational, and they have to deal with the obviously irrational and complex nature of women. We see here, too, the invention of different masculinities, the master and the simple, rational being. These masculinities seem contradictory, but they provide a good example of the "flexible interpretability" (Pinch and Bijker 1984), or multivocality (Miller 1987), of technological artifacts. By extension from 
well-established binaries of rational understanding and physicality, these modes of masculinity allow the actor to accommodate different circumstances and communicate different aspects of himself without undermining the conventional contexts significantly. The gendering of the airplane, then, becomes a means to articulate masculine agency, or even the lack thereof, in relating to both women and to machines.

\section{The Good Warbirder: Further Masculine Qualities}

If competence, leading to expertise, is a major preoccupation of warbirders, their discourse and practice demonstrate a range of other conventionally masculine qualities. The qualities warbirders ascribe to good mechanics and pilots parallel conventional ideals of American masculinity: autonomy, self-confidence, competitiveness, and strength. They demonstrate each of these qualities through their performance with the airplanes.

\section{Autonomy and Self-Confidence}

Autonomy as a virtue lies at the heart of American masculinity, and warbirds offer a mechanical means to demonstrate autonomy. Most warbirders highly value the autonomy the work provides them, and they also complain bitterly about any limits on their autonomy. Even mechanics, who often work with others on tasks, enjoy the autonomy of working through a task on their own, at their own pace. One professional mechanic, for example, said he loved warbird work because he was free to work on projects on his own, free of operational pressures. Pilots say flying is an experience of pure autonomy. They can move in any direction they want, in all three dimensions. Beyond this physical freedom, flying in the United States has been minimally regulated, at least when compared with other nations. To this day a pilot can take off without flying a flight plan and fly through most areas legally, which after 9/11 attests to both the importance of autonomy to flying and the political clout of pilots. Warbirders greatly distrust the Federal Aviation Administration as the agent that most threatens this autonomy. Nevertheless, warbirding remains a sphere in which men expect to be able to do what they wish. Many warbird organizations have run into difficulty 
because members resist the limits placed by the organization. The CAF, for example, has had units split away because they felt that CAF Headquarters interfered with their operations too much (Caidin 1984). Other groups have faced similar pressures.

Another masculine quality that shows up in descriptions of good warbirders is confidence in oneself. Like autonomy, this trait seemed to apply most to pilots, perhaps because the performance of this quality is more open and obvious when flying. The performance of good piloting requires, in this view, decisiveness, knowledge, and ability, all of which produces self-confidence. If someone were too tentative in his flying because he lacked self-confidence, an accident could easily ensue. For example, if one's engine is failing, one often has to act quickly to find a landing spot. Other pilots have to have faith in one's competence to fly with that person comfortably, and the only way to foster this faith before flying together is to exude confidence.

The performance of autonomy and confidence is a gendered performance. "Being a Man" requires standing alone, proudly, even though it does not preclude connections to other men. In the Hobbesian universe, a "Man" must be able to "make his own way." In warbirding, this performance is achieved through the airplanes. They become the agency of this manliness.

\section{Counter-Discourses: Safety and Ego}

Despite the centrality of masculine performance to warbirding, warbirders do employ a variety of checks on manly actions. They encourage the development of competence and expertise as much as possible, but warbird discourse employs several counter-discourses to other masculine qualities. To counter the unbridled assertion of autonomy, they use a counter-discourse of safety. To address an overly powerful assertion of self-confidence, warbirders warn about having too large an "ego." We can understand these counterdiscourses not as disrupting the gendering of warbirding, but rather as another means to sustain that gendering. For example, in the safety discourse, the natural 'wildness' of pilots 
(drawing on the nature/culture binary) requires reining in by appropriate authorities. They would prefer that other warbird pilots control themselves, but if necessary will impose restrictions on peers (as in self-regulating groups like those who certify warbird pilots for formation flying at airshows) or even request governmental regulation. Similarly, warbirders will shun a pilot with too large an ego, which they understand as self-confidence that outstrips ability. Someone with a big ego, they say, is likely to kill himself and possibly others. The very visibility of flying often leads pilots to try maneuvers that they shouldn't. Here, in fact, is one area where experienced warbirders say the FAA should intervene and bar certain maneuvers - like loops and rolls - below certain safe altitudes until a pilot has accumulated sufficient experience. Even still, "ego" can still prevail and cause a pilot to do something stupid, crashing the airplane, killing a friend, and destroying a "piece of history." These discourses of safety and ego put significant checks on autonomy.

Most justifications of safety restrictions and criticisms of ego reference two factors: the potential for government grounding all warbirds and the potential for warbird crashes. Warbirders worry constantly about the government grounding their airplanes for any variety of reasons: environmental pollution, potential for use in a terrorist attack (post 9/11), general mistrust of any war machine out of control of the military, and the potential for accidents that kill bystanders. They invoke this last reason most often to justify safety restrictions, saying that a wild or poorly trained pilot could cause a crash that would lead to the grounding of all warbirds. They see the Federal Aviation Administration as a dangerous organization in that it reacts more to sudden changes in the public will and interest than to the real issues of safety. Thus, a well-publicized crash could create enough of an outcry to ground the airplanes. Pilots whom others think are unsafe, however, can fall back on autonomy and confidence discourses to justify their actions. Warbirders respect the assertion of autonomy as a key element of masculine identity, but they also limit autonomy where they feel necessary. 
Great pilots use their machines to "push the limits," while someone with the confidence and not the ability will quickly "eat it." Staying on the right side of the line between confidence and ego, autonomy and safety was described best by Tom Wolfe as having "the Right Stuff" (Wolfe 1979). Just as in Wolfe's work, this discussion arises quickly after an airplane crash, when the pilots gather to analyze what happened. They speculate on whether the crash was caused by the lack of skill or preparation by the pilot or if it was simply an unforeseeable mechanical failure. These discussions also are mediated by the expression of emotion for lost friends and colleagues, as I will discuss below.

Pilots use the discourse of safety to evaluate each other, but mechanics also use it as a means to distance themselves from pilots. Mechanics say that pilots let "emotion" guide them into flying an airplane that they should not, because it is not safe to fly. Tensions have long existed between mechanics, whose interest is in a perfectly safe airplane, and pilots, who want to fly whenever possible. Referring back to the Nature/Culture basis of gender, we can read this 'emotion' as a lack of rationality, in need of a civilizing force. The mechanics do not wish to become feminized by assuming the role of "civilizing force," so they adopt the position of rationality, in contrast to the irrational pilots. Pilots, on the other hand, do not wish to be "controlled" by others and sacrifice autonomy, so they also draw on the discourse of safety as a rational means to limit their own autonomy. Safety serves as a mediating discourse, then, between autonomy and dependence, rational control and irrational action.

The need to rein in men's "natural wildness" that comes out in some pilots' critiques of each other finds parallels in other critiques of masculinity in warbirding. For example, a leading member of a museum group insisted that the growing number of female combat pilots in the military was a positive development and that many of the women made for better pilots because they didn't get caught up in a testosterone-induced rush and make bad decisions in tight situations. While this argument might seem to undermine the centrality of 
masculine performance to warbirding, it in fact merely displays the tension inherent in the gender binaries described above. Men can be rational, but also wild and in need of civilizing, most often by women. Since women do not succumb to "testosterone poisoning," they retain their rationality, even though they operate in a masculine domain.

\section{Power and the Technological Sublime}

Thus far I have used a phenomenological model to examine the invention of masculinity as an ongoing performance. Relying on such a model leads me to discuss a vital phenomenological component of warbirding, the technological sublime (Nye 1994). I discussed this idea extensively in chapter three, but I would like to add here the importance of the sublime experience of machines for constituting masculinity. I pointed out the importance of this experience for constituting American nationalism, but I should mention here that the thrill of the machine's power also speaks to the masculine identity of warbirders. As with "boys and their toys," the notion that men love to see and feel loud machines operate is cliched. Nevertheless, this experience does have great effect. I can speak as one who felt ambivalent about the entire enterprise of warbirding, the nationalism, militarism and techno-masculinity involved, but who found the running of the warplanes' large engines to be thrilling. This experience, of course, does not happen spontaneously, but rather is carefully framed by cultural conceptions of masculine performance, as well as by the hangar, the maintenance work required, the airshow preparations, and so on. The events are usually staged; most people in the hangar will come out to watch an aircraft start up and run just for the thrill of it. The thrill of this mechanical power translates immediately into a sensation of personal power. Warbirders, who have some form of connection to the airplane, whether they own it, fly it, work on it, or are merely a "fan" of it, incorporate the experience of that external power into themselves. Without a connection to the plane, however, the experience could be terrifying, or perhaps just annoyingly loud. With a connection to the plane, however, the experience is expansive. 


\section{Warbirds Set the Frame}

If warbirds provide the means to construct masculinity, they also frequently establish the scene or framework within which that construction occurs. I take the idea of a "scene" from Burke's dramatistic pentad and the idea of a "frame" from Goffman's symbolic interactionism (Burke 1945, Goffman 1974). Warbirds operate as key symbols to establish the frame or the scene of the airshow and hangar environments. In Goffman's terms, the frame establishes the salient categories, values and meanings that should be used to interpret actions and speech. In Burke's terms, the scene is examined as the motivation for certain discourses. The ideas are not exactly parallel, but I seek to draw on them both in my usage. I want to understand the warbirds both as setting the kinds of things that can be performed and discussed, while at the same time, I want to see the airplanes as in some sense motivating those performances.

Warbirds' presence in the hangar and at the airshow motivates a variety of gendered performances, including performances at odds with accepted masculine qualities. Within this scene warbirders express otherwise inappropriate emotions, build ties to fellow warbirders, and establish connection with the "Greatest Generation" of World War II. The most obvious and important aspect of the scene warbirds set is their invocation of World War II. Further, the airplanes establish a frame in which the relevant subjects include not just the war itself, but also war-making in general, interaction with machines, and connections between men, not to mention nationalism and industrial romanticism, which I discussed in previous chapters. Given this war-masculinity-machine frame, we must explore what discourses and activities emerged. I will argue that, despite (or perhaps because of) the agonistic basis of the frame, this frame provides for the establishment of homosocial bonds.

\section{Emotions}

The idea of warbirds-as-scene first came from the surprising amount of emotion expressed by the older men I worked with in the hangar and at airshows. My discomfort at 
the expression of this emotion, sparked by my own gendered awareness and by my sense of appropriate behavior by my elders, suggested that some feature of the interaction suspended the normal rules of conversation between men. Usually these emotions came out when discussing service in the military. Often the most emotion-producing topics touched on people who had died in the war. These felt ties between war "buddies" play an important role in the gendered fascination with war, as if war (framed here by war machines) were one of the sole means to experience masculine emotion.

Within the traditional American gender framework, emotion plays no important part in masculinity. The nature/culture dichotomy configures this understanding, with men holding the position of culture, or rationality, opposed to women's natural emotionality. Even when the roles reverse, men revert to their "natural" state, losing control of their rationality and behaving like animals, leaving women in the position of a "civilizing" or calming force. Men in a "natural" state exist in a Hobbesian war of all against all, where aggression, anger, and autonomy prevail. Within these dichotomies, there is no room for men to express emotions linked to sociality. Within the war-masculinity-machine frame, however, men are allowed to express powerful feelings of connection to other people, especially men. ${ }^{86}$

By linking the emotions of men to machines, I do not mean to suggest that men are emotional cripples who somehow must have a prop to experience authentic emotion. I don't mean to derogate these emotional experiences. I would rather like to view these tiesthrough-machines positively, eschewing any assumptions about proper forms of feeling. I do not want to fall into a notion that this emotion is inauthentic because its expression is framed by machines. There is no "right and proper" form of connection I want to put forward here. Nor do I want to present any functional explanation which depends upon a

\footnotetext{
${ }^{86} \mathrm{~A}$ similar ethos pervades some team sports, which may suggest the importance of agonistic enterprise to this expression of emotion.
} 
theory of psychic needs. I also want to avoid the functional explanation that this is a EuroAmerican means of fulfilling some cross-cultural need to create ties between men. Such an assumption would not apply in a “differentiating” culture, for example (Wagner 1981(1975)). It suffices to note that this emotion is produced as part of masculine subjectivity and, to some extent, generated by the frame.

Further, seeing men as emotionally feeble because they can only feel emotions mediated through machines (or sports, etc.) simply naturalizes the model of authentic emotion which underlies the American gender binary. By this model, women's natural emotionality makes its expression easy, while men have to resort to elaborate practices to become fully emotional. Native understanding may take exactly this position, but I do not want to naturalize it. The emotion that frequently cropped up in the hangar and at the airshow, then, was a cultural production which depended upon the framing of the aircraft. As I mentioned above, emotions often arose around the subject of soldiers fighting and dying. These emotions clearly served the interests of the state, and in that sense warbirds operated as material links to events distant in time, mediating between the personal and the national, as discussed in chapter three (Cf. White 1999). Yet these emotional expressions also constituted a distinct form of masculinity in addition to this nation-feeling. The expression, framed by the warbirds, of sadness for friends lost in the war or to flight accidents pervades warbirding. One warbird pilot and Vietnam veteran admitted that the "missing man" formation (a commemoration of pilots) always made him cry, so he preferred to be flying in the performance so that he did not have to see it. Such a confession of emotion is conventionalized, an admission of something that might be unmanly in other contexts but by the very framing of this context is not.

Perhaps the most emotional moment in a warbird context — during a safety discussion at a conference - I heard was one pilot's description of his own crash. After detailing the bad judgments and simple mishaps which led to the accident, he described 
emerging from the wreck, hidden amidst the trees, as he heard the planes that were with him flying over, searching. He said that he thought about his son flying in one of those planes, not knowing what had happened to his father. The room, mostly men, resonated with emotion at this comment. It was the evocation of a gendered, familial connection which carried such weight. ${ }^{87}$

The airshow and warbird worlds see a number of crashes each year, many fatal. One crash I witnessed illustrates how emotional, masculine ties can be used to make sense of such events. The crash involved an aircraft flown by current military pilots. It was an older aircraft, the population of which were being turned into target drones so that pilots of newer aircraft could get practice shooting down other planes. This particular plane had not yet been converted and was flown in formation with newer ones as a kind of heritage flight. The formation was over, and the planes were turning one by one to come in and land when this one lost power and crashed, killing both pilots. The warbird pilots I was with, all middleaged to retired men, had different reactions to the event, exhibiting multiple voices. One voice was a technical, analytic one, trying to figure out just what went wrong. This voice blended into the subtly competitive voice of pilots evaluating other pilots, which echoed the test pilots in The Right Stuff who debated whether the pilot who died had had "the right stuff." Another voice was emotional, but used a discourse of sacrifice as a means to evaluate the event. The "sacrifice" was that of military pilots who risk death and danger to protect their fellow citizens. While this notion of sacrifice invokes the nation as the entity unifying the citizenry, it also invokes a kind of noble masculinity. Further, this discussion of sacrifice, like the "Missing Man" formation, allows for the expression of masculine emotion. The loss of life was made sense of by reference to its occurrence in a military aircraft. Even though the show was a public relations event, the death in the machine was construed as a noble,

\footnotetext{
${ }^{87} \mathrm{I}$ am saddened to say that after I wrote the first drafts of this chapter, this same pilot was killed in a warbird crash in the fall of 2005.
} 
masculine sacrifice and was therefore open to emotional reaction. The depth of emotion came, in part, from the deaths of friends past, in the military and in warbirds.

\section{Building Ties and Expressing Connection}

The emotion expressed by warbirders, keyed by the warbirds' setting of the "scene," both expresses and constitutes ties between men. Just as warbirders would admit that their activity is a "guy thing," they would also agree that one could see warbirding as a form of "male bonding." "Male bonding," however, is an inadequate term for the breadth of ties warbirders form. They not only build friendships with fellow warbirders, but they also develop gendered connections to the war, either to kin who participated in the war or to veterans of that war. The friendships are clearly gendered (by the scene, in addition to the activities), but the connections to the war are also gendered in that they partake of the masculine authenticity of war in general and that war in particular.

The ties between warbirders often come through the tedious and difficult process of working on a warbird. As I argued above, this labor constitutes and performs a masculine, machine competence, but it also provides the opportunity for gendered exchange of stories about machines, flying, wives, sexual adventures, and so on. The war-masculinity-machine frame, then, allows for the invention of ties between men that are exclusively masculine. In a sense, these gendered ties are the social fruit of labor on the airplanes. As a restoration proceeds or as maintenance is performed over years, the men's relationships get inscribed into the airplane, making it as much a material embodiment of their bond as it is a commemoration of the past (Munn 1974).

The ties to kin and to the veterans of the war, on the other hand, often came about more indirectly, as when the members reflected on the idea that these machines were the same that were used in World War II. The major site for these ties, however, was the airshow, where warbirders encountered veterans from the war. A central motif of these encounters was the expression of emotion between men. The following comments from a 
warbird restoration shop owner with long experience in the warbird world provide a useful summary the range of emotions that stem from the warbirders' airshow encounters with veterans and others. He begins by discussing a warbirder icon of heroic masculinity, General Doolittle:

Doolittle was real pragmatic: 'I had a job to do, and I did it. I didn't have time to be scared because I was concentrating on the mission at hand. And don't ask me that question again because I'm not going to give you the pithy, emotional response.' And some of these guys did have fairly strong emotional feelings about it. And they're still able to convey it. I mean, I've been to airshows where guys have literally burst into tears and either wanted to go up and caress the airplane or sit in the navigator's seat or the pilot's seat that they used to sit in 50 years ago. Or they wouldn't go near the airplane. 'I lost too many friends. I had to do it then, I don't have to do it now. I don't want to go near the airplane.' And then you get the relatives. 'Grandpa died.' 'My uncle served.' 'My father was a navigator.' 'My mother shot rivets.' 'My grandmother built these,' or whatever. And they want, for them it's a family emotional response because they've got some close personal tie, if not to the era, at least to the specific type. And if you go to a regular airshow, that's what you'll run into.

As this passage progresses, emotional ties become more and more important. It begins with one mode of masculine performance, the heroic Doolittle taking his pain and merely doing his job, with no emotion wanted or needed, thank you very much. It immediately moves on to the contrasting case of veterans being emotional about encountering the aircraft. (Within this discourse, I should note, World War II veterans are accorded the highest status, so the attribution of effusive emotion to them could not be seen to question their masculinity. Rather, it is presented here as an alternate performance of gender.) The warbirder's account 
shows the airplane acting as a "physical framework of memory," evoking memories of the war and of friends. The plane acts here both as the key to memory and as the frame for performing the reaction to the memory. The veterans' reactions are either intimacy, "caressing" the airplane, or rejection, not wanting to "go near" it, but both reactions evoke and reproduce emotional ties to other men. The passage then discusses relatives, the other ties created through the airplanes and for which the airplanes set the scene. The speaker distributes these ties equally between male and female kin, but in my experience they were exclusively to male kin.

These encounters were always powerful for the visitors and for the warbirders. Most warbirders I met shared some story about an encounter like this, usually with a veteran. For many of the men involved, this emotional bonding seemed to be a central motivation for involvement with warbirds. They seemed to find these momentary connections deeply fulfilling. For me, however, these emotional stories were uncomfortable. I was uncomfortable because the framing of the emotional moment did not work for me. This frame depended upon an unquestioning, militaristic patriotism and belief that the sacrifice in war is inherently noble, elements I could not share unproblematically. I found the humanistic dimension of these stories deeply compelling, but the framing of war always made them suspect for me.

\section{Conclusion}

This chapter has examined a few specific ways in which the cultural association of masculinity and machines gets reinvented in warbirding. Drawing on Burke's dramatistic pentad, I have examined warbirds as both the "agency" for and a "scene" (or a "frame" in Goffman's sense) for the performance of masculinity. Warbirds offer the means to develop a masculine competence with machines, as well as perform other masculine qualities like autonomy and self-confidence. They also set the scene for the powerful, emotional 
encounters that warbirders have with veterans. The airplanes, therefore, operate as important tools for the ongoing construction of not only homosocial bonds, but also masculine identity. 


\section{Conclusion}

Since early in my anthropology career, I have been intrigued by Geertz's comment that "man [sic] is an animal suspended in webs of significance that he himself has spun" (Geertz 1973: 5). The notion that we might fabricate that which guides and sustains us makes for an illuminating paradox. The theory of cultural invention employed in this dissertation builds on that understanding by examining how warbirders employ semiotic and material resources to develop the elaborate technological practice in which they participate. These individuals "do" their culture through machines; the machines are their vehicle for creativity. At different times the machines are foregrounded for the pleasure and power they provide, while at other times they provide the grounding for imagining the nation or connecting to other humans. I would like to conclude this dissertation by reviewing both the aspects of their creativity that are most worthy of our attention and a few of the areas still left unexplored.

I begin with the central paradox of warbirding: they revive obsolete machines. The paradox derives, of course, from the discourse of technological progress, which sorts machines and artifacts into categories like high tech, merely functional, outdated, obsolete, and trash. As I show in chapter four, warbirders create a technological progress discourse which allows them to critique the machines of today as preventing human agency without significantly undercutting the hegemonic role that the progress discourse plays in the ongoing production of technologies. Warbirders' enjoyment of old machines is articulated as something more like a taste, an individual aesthetic preference, than of a critique of the larger cultural system which produces ever-newer machines for humans to master. Indeed, the "Standard View of Technology" gives warbirders no place to locate a critique of the constant demand for newer, better machines (Pfaffenberger 1992). In that view, which roughly fits with their own, the force of technological change is an external, unrelenting one over which they can have no power. They are left, then, to admire the past products of this process, and to be unhappy, if grudgingly appreciative, of the new ones. 
This grudging appreciation of newer technologies derives from their idealization of the World War II nation as the ideal to which the United States should aspire today. Since warbirders "do" their creativity through machines, their romanticization of the "Good War" as a time when the nation achieved its ideal state revolves around the machines of that time. They see the machines as not only the embodiments of technological progress during that time, but also reflections of the unity and power of that ideal nation. The machines are understood as the creations of a specifically American genius, which continues to produce "the best" aircraft for the necessary defense of the nation. While warbirders enjoy the agency provided by the old machines, then, they also apply the logic of national-strength-throughmachines to the present day. In this regard, they employ World War II as a usable past to foster a militarized nationalism, which leads them to embrace technological progress as bringing about the contemporary equivalent of their beloved airplanes. This understanding of technology's irresistible progress plays a central role in the expanding militarization of the United States, a process which finds full support in warbird circles. As weapons programs become larger and larger, consuming ever-more of the federal budget, the unrelenting "progress" of technology requires that Americans meet its demands for more resources ${ }^{88}$ For warbirders, their machine focus renders this imperative commonsensical. To them it is obvious that the United States must spend the money to "stay strong."

Their machine focus also provides for displays of their technological wonders and even exhibits like the Enola Gay at the Smithsonian, which has been polished and placed on a pedestal for admiration as a technological achievement, entirely separate from the context in which is was developed and employed. Ihave explored this foregrounding of the machine as "technological obviation," the practice of focusing on the wonders of a weapon over its various effects. Such obviation of World War II's violence through the romanticization of

\footnotetext{
${ }^{88}$ For some perspective on the amount of money spent, at the time of this writing great shock has been expressed at the potential cost of rebuilding the Gulf Coast after Hurricane Katrina. The current, estimated amount, \$200 billion, is roughly the same amount of money the United States military has budgeted to spend on its next fighter aircraft, the F-35 Joint Strike Fighter.
} 
the machines easily carries over to the present, where the dominant image of military aircraft depicts technologically sublime fighters and bombers taking-off to drop "smart bombs" "surgically" on deserving targets, with no destroyed bodies in sight.

The dropping of these "smart bombs," however, strikes many warbirders as too easy. In a careful negotiation between their romanticization of World War II and their "support for the troops" today, they laud the "sacrifice" of today's military while at the same time elevating the World War II soldiers as having had a much tougher time. They admire today's machines for their capabilities, and especially their safety, but they long for the machine competence that the World War II aircraft required. Warbirds provide an arena for the gendered performance of this competence. The men of the Commemorative Air Force and other warbird pilots and mechanics gather at hangars and airshows to perform skilled labor on and with the old airplanes, self-consciously deploying skills which have lost their relevance outside of those contexts.

The performance of gender with machines operates at several different levels, including not only competence, but also emotion, connection to others (persons and machines), and even pleasure and play. I described in chapter two the powerful, emotional encounters that warbirders have with veterans in the context of the aircraft. While even these emotions are expressed through, and often subsumed by, the aircraft, they create strong feelings of attachment to the "Greatest Generation," the current military, and the nation. Such attachment also results from the work in the hangar, as warbirders together engage in creative problem-solving in order to get the old planes up in the air. This kind of creative engagement with a task is perhaps best described as "the existential pleasure of engineering," a pleasure culturally available almost exclusively to men (Florman 1976, Faulkner 2000). The pleasure of tinkering is complemented by the pleasures of controlling a machine in flight - shown in pilots' intense evangelizing of their hobby - and the sublime experience of the machines in operation — an attraction whenever the airplanes are started up. 
The feeling that opportunities for this tinkering with machines are disappearing contributes to warbirders' view that masculinity, as well as the military and the nation, is under siege from forces of neglect and of bias. The neglect for them is best objectified by the scarcity of the machines, which have been scrapped and allowed to rot. They see this neglect as a failure to "honor" the machines and their role in history. The bias gets expressed as "political correctness" or perhaps a lack of patriotism and provides a useful foil for their unabashed expression of militaristic patriotism. Those who are less patriotic than they are fail to appreciate the sacrifices made to "defend freedom," and at times even work actively to undermine the necessary strength of the nation. Warbirders work to correct this neglect and bias by performing World War II as a "lesson" of history. This lesson presents Pearl Harbor as a necessary catastrophe which transformed the nation into its ideal form. The trauma of that attack demonstrated the need to "be strong" and "come together," a strength and unity objectified by the machines themselves. To enable these airplanes to teach this "lesson," warbirders invest their airplanes with historicity. They historicize their aircraft by developing careful genealogies, tracing objects back to the war and remaking the present aircraft "authentically" so that they map onto those wartime types. They also perform the aircraft's historicity by reenacting World War II battles and drawing careful contrasts between present-day aircraft and warbirds.

Despite the breadth of this discussion, this dissertation, like any project, leaves many aspects of its subject unexamined. Ibarely touched on the crucial issue of race in warbirding, despite its obvious invocation through the renamed "Confederate Air Force" and the neartotal absence of minority participation in warbird groups. Much more deserves to be explored in the day-to-day work on warbirds as well. Building on other cross-cultural research in the Anthropology of Technology, warbirders' work in the hangar could be seen as a kind of "dwelling," a constitution of an environment in which they relate to each other through machines (Ingold 2000). The connection between warbirding and the ongoing 
militarization of the United States is also of vital importance and an area which I hope to explore further. Few processes within American culture are as important yet as unexamined as this militarization, and the "Good War" has become a central component of the commonsense, "military definition of the situation." Finally, I would like to examine better the role of media in warbirding. From the (obsessive) photography practices of warbirders to the ubiquity of representations of the "Good War" through weapons, media have been crucial in constituting World War II (and the airplanes) as a usable past. 


\section{Works Cited}

1997. "Air Power Showdown: Part I -- the Best Fighters," produced by Aviation Week and Space Technology. McGraw-Hill Aviation Week Group, Videocassette.

n.d. "C-46 Commando." Yahoo Groups Web Page. Accessed July 24, 2005 <http://groups.yahoo.com/group/C46/>.

Ackroyd, J. A. D., and P. J. Lamont. 2000. "A Comparison of Turning Radii for Four Battle of Britain Fighter Aircraft." The Aeronautical Journal 104(February):53-8.

Adams, Michael C. C. 1994. The Best War Ever: America and World War II. Baltimore: Johns Hopkins University Press.

Adas, Michael. 1989. Machines as the Measure of Men: Science, Technology, and Ideologies of Western Dominance. Ithaca: Cornell University Press.

Ambrose, Stephen E. 1992. Band of Brothers: E Company, 506th Regiment, 101st Airborne : From Normandy to Hitler's Eagle's Nest. New York: Simon \& Schuster.

- 1997. Citizen Soldiers: The U.S. Army from the Normandy Beaches to the Bulge to the Surrender of Germany, June 7, 1944-May 7, 1945. New York: Simon \& Schuster. Anderson, Benedict. 1991 (1983). Imagined Communities: Reflections on the Origin and Spread of Nationalism, Revised edition. London: Verso.

Anonymous. 1975. The Ghost Squadron of the Confederate Air Force: A Pictorial History of the Preservation of the World's Greatest Combat Aircraft of World War II. Dallas, TX: Taylor Publishing Co.

—. 2003. "The Soccer War: The Mustang's Last Stand over Honduras." Warbirds 26(3):2831.

—. 2005a. "Awards from the 41st Annual Watsonville Fly-in and Airshow." Watsonville Fly-In \& Air Show Inc. Web Page. Accessed Apr 4, 2006 <http://www.watsonvilleflyin.org/judging.html>. 
—. 2005b. "CAF FG-1D Corsair Demonstration Narration." Web Page. Accessed January 23, 2005 <http://www.freewebs.com/cafcorsair/Narration.html>.

—. n.d.-a. "B-1B Lancer." Global Security.org Web Site. Accessed Feb 28, 2006 <http://www.globalsecurity.org/wmd/systems/b-1b.htm>.

—. n.d.-b. "B-2 Production." Global Security.org Web Site. Accessed Feb 28, 2006 <http://www.globalsecurity.org/wmd/systems/b-2-production.htm>.

—. n.d.-c. "B-29 Superfortress." Global Security.org Web Site. Accessed Feb 28, 2006 <http://www.globalsecurity.org/wmd/systems/b-29.htm>.

—. n.d.-d. "Boeing B-17G 'Flying Fortress'." United States Air Force Museum Web Site. Accessed Feb 28, 2006 <http://www.wpafb.af.mil/museum/air_power/ap16.htm>.

Appadurai, Arjun. 1996. Modernity at Large: Cultural Dimension of Globalization. Minneapolis: Minnesota University Press.

Bacevich, A. J. 2005. The New American Militarism : How Americans Are Seduced by War. New York: Oxford University Press.

Bakhtin, Mikhail M. 1981. The Dialogic Imagination: Four Essays. Caryl Emerson and Michael Holquist, trans. Austin: University of Texas Press.

Baldwin, Bill, Pat Webster, John Alger, et al. 1987. Ghost Squadron of the Confederate Air Force: Wings of Freedom. Harlingen, TX: Confederate Air Force.

Basso, Keith H. 1988. "'Speaking with Names:' Language and Landscape among the Western Apache." Cultural Anthropology 3(2):99-10.

Bennett, Tony. 1995. The Birth of the Museum: History, Theory, Politics. London: Routledge.

Bradley, James, and Ron Powers. 2000. Flags of Our Fathers. New York: Bantam Books. Brightman, Robert. 1995. "Forget Culture: Replacement, Transcendence, Relexification." Cultural Anthropology 10(4):509-546.

Brokaw, Tom. 1998. The Greatest Generation. New York: Random House. 
Burke, Kenneth. 1945. A Grammar of Motives. New York: Prentice-Hall, Inc.

Caidin, Martin. 1984. Ragwings and Heavy Iron: The Agony and Ecstasy of Flying History's Greatest Warbirds. Boston: Houghton Mifflin Company.

—. 1990 (1968). Flying Forts: The B-17 in World War II. New York: Bantam.

Cockburn, Cynthia. 1981. "The Material of Male Power." Feminist Review 9:41-58.

Cohn, Carol. 1987. "Sex and Death in the Rational World of Defense Intellectuals." Signs 12(4):687-718.

Coombes, Bill. 1998. "A 'Bar Sinister' Hellcat: The Interesting History of the Caf's Grumman F6F Hellcat." The Dispatch 23(3).

Cowan, Ruth Schwartz. 1983. More Work for Mother: The Ironies of Household Technology from the Open Hearth to the Microwave. New York: Basic Books.

Crapanzano, Vincent. 2000. Serving the Word: Literalism in America from the Pulpit to the Bench. New York: New Press.

Cullen, Jim. 1995. The Civil War in Popular Culture: A Reusable Past. Washington, DC: Smithsonian Institution Press.

Curtis, Lettice. 1999. "All in a Day's Work." FlyPast 214(May):74-6.

Deakin, John. 1998. "Pelican's Perch \#12: Warbird Crews Wanted!" Online Column. Accessed September 23, 2003 <http://www.avweb.com/news/columns/1820781.html>.

—. 2002. "Pelican's Perch \#55: Lead in the Hogwash." Online Column. Accessed October 15, 2003 <http://www.avweb.com/news/columns/182149-1.html>.

—. 2004. Full Throttle. Ada, OK: Fly-Bye-Knight Press.

Dikkers, Scott, Robert Siegel, John Krewson, et al. 1999. "Dastardly Japs Attack ColoniallyOccupied U.S. Non-State: Congress Declares War after Sneak Attack on U.S. Imperial Holding," in Our Dumb Century. Edited by Scott Dikkers, pp. 60. New York: Three Rivers Press. 
Dower, John W. 1986. War without Mercy: Race and Power in the Pacific War. New York: Pantheon Books.

Dumont, Louis. 1970. "Religion, Politics, and Society in the Individualistic Universe." Proceedings of the Royal Anthropological Institute of Great Britain and Ireland:3141.

Durkheim, Emile. 1995 (1912). The Elementary Forms of Religious Life. Karen E. Fields, trans. New York: Free Press.

Edwards, Norman, and Albert Wittredge. 2000. "Clobbering Fast Ladies." FlyPast 227:3941.

Enloe, Cynthia H. 1983. Does Khaki Become You?: The Militarisation of Women's Lives. London: Pluto Press.

Farnham, Alan. 2005. "Blame Snoopy." Forbes.com Online Magazine. Accessed Dec 26, $2005<$ http://www.fantasyofflight.com/article_blamesnoopy.htm>.

Faulkner, Wendy. 2000. "The Power and the Pleasure?: A Research Agenda for "Making Gender Stick" to Engineers." Science, Technology, and Human Values 25(1):87-119.

Fleishman, Ron. n.d. "Curtiss C-46: A Four-Engined Airplane with Two Engines." Southern California Wing, Commemorative Air Force Web Page. Accessed March 12, 2005, <http://www.orgsites.com/ca/caf-socal/C46History.htm〉.

Florman, Samuel C. 1976. The Existential Pleasures of Engineering. New York: St. Martin's Press.

Ford, James A., and Julian H. Steward. 1954. "On the Concept of Types." American Anthropologist 56(1):42-57.

Franklin, Sarah, and Helena Ragone. Editors. 1998. Reproducing Reproduction: Kinship, Power, and Technological Innovation. Philadelphia: University of Pennsylvania Press. 
Gable, Eric, and Richard Handler. 1994. "The Authority of Documents at Some American History Museums." The Journal of American History 81(1):119-136.

—. 1996. "After Authenticity at an American Heritage Site." American Anthropologist 98(3):568-578.

Geertz, Clifford. 1973. The Interpretation of Cultures. New York: Basic Books.

Goffman, Erving. 1974. Frame Analysis : An Essay on the Organization of Experience. Cambridge, Mass.: Harvard University Press.

Gray, J. Glenn. 1959. The Warriors: Reflections on Men in Battle. New York: Harper \& Row.

Gusterson, Hugh. 1991. "Nuclear War, the Gulf War, and the Disappearing Body." Journal of Urban and Cultural Studies 2(1):45-55.

Halbwachs, Maurice. 1992 (1925). "The Social Frameworks of Memory," in On Collective Memory. Edited by Lewis A. Coser, pp. 35-189. Chicago: University of Chicago Press.

Handler, Richard. 1988. Nationalism and the Politics of Culture in Quebec. Madison: University of Wisconsin Press.

—. 2002. "Cultural Theory in History Today." American Historical Review 107(5):15121520.

Handler, Richard, and Eric Gable. 1997. The New History in an Old Museum: Creating the Past at Colonial Williamsburg. Durham: Duke University Press.

Handler, Richard, and William Saxton. 1988. "Dyssimulation: Reflexivity, Narrative, and the Quest for Authenticity in "Living History"." Cultural Anthropology 3(3):242-260.

Hawkinson, Kandace. n.d. "A Brief History of the Pebble Beach Concours D'elegance." Pebble Beach Company Web Page. Accessed Mar 13, 2006 <http://www.pebblebeachconcours.net/Chronicle.htm>.

Heller, Joseph. 1961. Catch-22. New York: Simon and Schuster. 
Hughes, Thomas P. 1983. Networks of Power: Electrification in Western Society, 18801930. Baltimore: Johns Hopkins.

—. 1987. "The Evolution of Large Technological Systems," in The Social Construction of Technological Systems: New Directions in the Sociology and History of Technology. Edited by Wiebe E. Bijker, Thomas P. Hughes, and Trevor F. Pinch, pp. 51-82. Cambridge: MIT Press.

—. 1989. American Genesis: A Century of Invention and Technological Enthusiasm 18701970. New York: Viking.

Ingold, Tim. 2000. The Perception of the Environment: Essays in Livelihood, Dwelling and Skill. London: Routledge.

Ivy, Marilyn. 1995. Discourses of the Vanishing: Modernity, Phantasm, Japan. Chicago: University of Chicago Press.

Jackson, Robert E. "That Other V Grand!" Air Classics:50-3.

Johnson, Chalmers. 2005. "Militarism in America." Anthropology News 46(1):10, 13.

Kammen, Michael. 1991. Mystic Chords of Memory: The Transformation of Tradition in American Culture. New York: Knopf.

Kaplan, Stephen S. 1975. "U.S. Arms Transfers to Latin America, 1945-1974: Rational Strategy, Bureaucratic Politics, and Executive Parameters." International Studies Quarterly 19(4):399-431.

Kate, Nancy Ten. 1993. "Take Me out to an Air Show." American Demographics 15(9):2-3.

Kopytoff, Igor. 1986. "The Cultural Biography of Things: Commoditization as Process," in The Social Life of Things: Commodities in Cultural Perspective. Edited by Arjun Appadurai, pp. 64-91. Cambridge: Cambridge University Press.

Latour, Bruno. 1987. Science in Action: How to Follow Scientists and Engineers through Society. Cambridge: Harvard University Press. 
-. 1993. We Have Never Been Modern. Catherine Porter, trans. Cambridge, Massachusetts: Harvard University Press.

—. 1999. Pandora's Hope : Essays on the Reality of Science Studies. Cambridge, Mass.: Harvard University Press.

Law, John. 1987. "Technology and Heterogeneous Engineering: The Case of Portugese Expansion," in The Social Construction of Technological Systems: New Directions in the Sociology and History of Technology. Edited by Wiebe E. Bijker, Thomas P. Hughes, and Trevor F. Pinch, pp. 111-134. Cambridge: MIT Press.

Lefebvre, Henri. 1991. The Production of Space. Donald Nicholson-Smith, trans. Oxford: Basil Blackwell.

Lemonnier, Pierre. 1989. "Bark Capes, Arrowheads, and Concorde: On Social Representations of Technology," in The Meaning of Things: Material Culture and Symbolic Expression. Edited by Ian Hodder, pp. 156-171. London: Edwin Hyman.

-. 1992. Elements for an Anthropology of Technology. Ann Arbor: Museum of Anthropology, University of Michigan.

—. 1993. "Introduction," in Technological Choices: Transformation in Material Cultures since the Neolithic. Edited by Pierre Lemonnier, pp. 1-35. London: Routledge.

Lens, Sidney. 1987. Permanent War : The Militarization of America. New York: Schocken Books.

Lévi-Strauss, Claude. 1966. The Savage Mind. Chicago: The University of Chicago Press. Lutz, Catherine. 1997. "Epistemology of the Bunker: The Brainwashed and Other New Subjects of Permanent War," in Inventing the Psychological: Toward a Cultural History of Emotional Life in America. Edited by Joel Pfister and Nancy Schnog, pp. 245-267. New Haven: Yale University Press.

-. 2001. Homefront: A Military City and the American 20th Century. Boston: Beacon Press. 
—. 2002. "Making War at Home in the United States: Militarization and the Current Crisis." American Anthropologist 104(3):723-735.

MacPherson, C.B. 1962. The Political Theory of Possessive Individualism: Hobbes to Locke. Oxford: Oxford University Press.

March, Peter R. 1997. Confederate Air Force: Celebrating Forty Years. Midland, TX: Confederate Air Force.

Marcus, George E. 1995. "Ethnography in/of the World System: The Emergence of MultiSited Ethnography." Annual Review of Anthropology 24:95-117.

Martin, Emily. 1998. "Anthropology and the Cultural Study of Science." Science, Technology and Human Values 23(1):24-44.

Marx, Karl. 1976. Capital: A Critique of Political Economy. Vol. 1. Ben Fowkes, trans. London: Penguin Books.

Marx, Leo. 1964. The Machine in the Garden: Technology and the Pastoral Ideal in America. New York: Oxford University Press.

Masco, Joseph. 2004. "Nuclear Technoaesthetics: Sensory Politics from Trinity to the Virtual Bomb." American Ethnologist 31(3):349-378.

McGregor, Carter, Marty Shannon, Lloyd Nolen, et al. 1981. "Fifi:" Boeing B-29 Superfortress. Harlingen, TX: Confederate Air Force.

Mellstrom, Ulf. 2002. "Patriarchal Machines and Masculine Embodiment." Science Technology \& Human Values 27(4):460-478.

—. 2004. "Machines and Masculine Subjectivity: Technology as an Integral Part of Men's Life Experience." Men and Masculinities 6(4):368-382.

Miller, Daniel. 1987. Material Culture and Mass Consumption. Cambridge: Blackwell. Moll, Nigel. 1987. Past Perfect: Ready for Action! Osceola, WI: Motorbooks International. Mosse, George L. 1990. Fallen Soldiers: Reshaping the Memory of the World Wars. Oxford: Oxford. 
Munn, Nancy. 1974. "The Spatiotemporal Transformations of Gawa Canoes." Journal de la Societe Des Oceanistes 33:39-52.

Noble, David F. 1984. Forces of Production: A Social History of Industrial Automation. New York: Knopf.

Nora, Pierre. 1989. "Between Memory and History: Les Lieux De Memoire." Representations 26(Spring):7-24.

Nye, David E. 1994. American Technological Sublime. Cambridge, Mass.: MIT Press.

O'Leary, Michael. 2005. "Hell Hawks!" Air Classics 41(2):30-41.

Ono, Ingrid, Harrison and Garrett.April 7, 2004. "First Time to Museum." The Air Museum Message Board Forum. Accessed Jul. 26, 2005. <http://www.planesoffame.org/_disc11/00000066.htm>.

Ortner, Sherry. 1974. "Is Female to Male as Nature Is to Culture?," in Woman, Culture, and Society. Edited by Michelle Rosaldo and Louise Lamphere, pp. 67-88. Stanford: Stanford.

Paine, Chris. 1974. "The Political Economy of Arms Transfers to the Middle East." MERIP Reports 30:3-26.

Pence, Jason. 2001. "Tinker Belle: The Move to Camarillo." National Capital Squadron of the Commemorative Air Force Newsletter. Accessed March 27, 2005 <http://nationalcapitolsquadron.com/2001/nov/tinker.html>.

Pfaffenberger, Bryan. 1992. "Social Anthropology of Technology." Annual Review of Anthropology 21:491-516.

—. 1999. "Worlds in the Making: Technological Activities and the Construction of Intersubjective Meaning," in The Social Dynamics of Technology. Edited by MarciaAnne Dobres and Christopher R. Hoffman, pp. 147-166. Washington: Smithonian Institution Press. 
- 2001. "Symbols Do Not Create Meanings--Activities Do (or, Why Symbolic Anthrpology Needs the Anthropology of Technology)," in Anthropological Perspectives on Technology. Edited by Michael B. Schiffer, pp. 77-86. Albuquerque: University of New Mexico Press.

Pinch, Trevor F., and Wiebe E. Bijker. 1984. "The Social Construction of Facts and Artifacts: Or How the Sociology of Science and the Sociology of Technology Might Benefit Each Other." Social Studies of Science 14(3):399-441.

Pool, Steve, and Rich Crew. 1987. "Military Aircraft, Vol. 1, No. 1," produced by Pool \& Crew Communications, Inc., Videorecording.

Presley, Randy. 1999. "The North American T-6/Snj/Havard." North American Trainer Association Web Page. Accessed Apr 16, 2006 <http://northamericantrainer.org/t6.htm>.

Rambow, Bill. 2006. "The Widow's Web: The Recovery." Mid-Atlantic Air Museum Web Page. Accessed Mar 25, 2006 <http://www.maam.org/p61/p61_begin.htm>.

Sahlins, Marshall. 1976. Culture and Practical Reason. Chicago: University of Chicago Press.

Salmon, Tony, Ian Wooldridge, and Gene Carr. 1981. "Colonel Culpeper's Flying Circus," produced by. BBC Television, Videotape.

Sapir, Edward. 1912. "Language and Environment." American Anthropologist 14(2):226242.

—. 1938. "Why Cultural Anthropology Needs the Psychiatrist." Psychiatry 1:7-12.

Sapir, J. David. 1977. "The Anatomy of Metaphor," in The Social Use of Metaphor: Essays on the Anthropology of Rhetoric. Edited by J. David Sapir and J. Christopher Crocker, pp. 1-32. Philadelphia: University of Pennsylvania Press.

Schatzberg, Eric. 1994. "Ideology and Technical Choice: The Decline of the Wooden Airplane in the United States, 1920-1945." Technology and Culture 35(1):34-69. 
Silverstein, Michael. 2005. "Axes of Evals: Token Versus Type Interdiscursivity." Journal of Linguistic Anthropology 15(1):6-22.

Sohn, Randy. n.d. "Fifi's Early Stories: Recovery from China Lake." CAF B-29/B-24 Squadron Web Page. Accessed Mar 12, 2006 <http://www.cafb29b24.org/fifirecovery1.shtml>.

Stewart, Susan. 1984. On Longing: Narratives of the Miniature, the Gigantic, the Souvenir, the Collection. Baltimore: Johns Hopkins.

Strathern, Marilyn. 1980. "No Nature, No Culture: The Hagen Case," in Nature, Culture and Gender. Edited by Carol MacCormack and Marilyn Strathern, pp. 174-222. Cambridge: Cambridge.

Sturken, Marita. 1997. Tangled Memories : The Vietnam War, the Aids Epidemic, and the Politics of Remembering. Berkeley: University of California Press.

Terkel, Studs. 1984. The Good War: An Oral History of World War Two. New York: Pantheon Books.

Tichi, Cecilia. 1987. Shifting Gears: Technology, Literature, Culture in Modernist America. Chapel Hill: University of North Carolina Press.

Trescott, Jacqueline. 2003. "Enola Gay, Waiting in the Wings No More." Washington Post, August 19, p.C1.

Trilling, Lionel. 1972. Sincerity and Authenticity. Cambridge: Harvard University Press.

Turner, Victor. 1967. The Forest of Symbols: Aspects of Ndembu Ritual. Ithaca: Cornell University Press.

Veronico, Nicholas A., A. Kevin Grantham, and Scott Thompson. 2000. Military Aircraft Boneyards. Osceola, WI: Motorbooks International.

Vonnegut, Kurt. 1969. Slaughterhouse-Five; or, the Children's Crusade, a Duty-Dance with Death. New York: Delacorte Press. 
Wagner, Roy. 1978. Lethal Speech: Daribi Myth as Symbolic Obviation. Ithaca, N.Y.: Cornell University Press.

-. 1981 (1975). The Invention of Culture, Revised and Expanded edition. Chicago: University of Chicago Press.

Wajcman, Judy. 1991. Feminism Confronts Technology. Cambridge: Polity.

White, Geoffrey M. 1999. "Emotional Remembering: The Pragmatics of National Memory." Ethos 27(4):505-529.

—. 2004. "National Subjects: September 11 and Pearl Harbor." American Ethnologist 31(3):293-310.

Whorf, Benjamin Lee. 1956 (1939). "The Relation of Habitual Thought and Behavior to Language," in Language, Thought and Reality, pp. 134-159. Cambridge: MIT Press.

Winner, Langdon. 1977. Autonomous Technology: Technics-out-of-Control as a Theme in Political Thought. Cambridge, MA: MIT Press.

Wolfe, Tom. 1979. The Right Stuff. New York: Farrar Straus and Giroux. 